\title{
Bioquímica y fisiología de lipoproteínas en arácnidos
}

\section{Tesis Doctoral \\ Lic. Laino Aldana}

Directora: Dra. Mónica Cunningham

Co-Director: Dr. Fernando Garcia

Facultad de Ciencias Naturales y Museo

Universidad Nacional de La Plata

2011

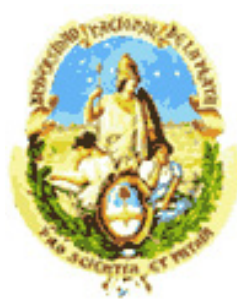


El presente trabajo de tesis para optar al grado de Doctora en Ciencias Naturales, fue realizado en el Instituto de Investigaciones Bioquímicas de La Plata (INIBIOLP), Facultad de Ciencias Médicas, UNLP, bajo la dirección de la Dra. Mónica Cunningham y el Dr. Fernando Garcia. 


\section{Mi agradecimiento}

Al Profesor Doctor Ricardo Pollero, por contagiarme el entusiasmo por la ciencia: por confiar en mi y abrirme las puertas del INIBIOLP; por sus atinados consejos que sigo teniendo presentes; porque haber sido una "Pollero" es un gusto que voy a recordar siempre; y por confirmarme que un docente de su talla puede marcar el camino de sus alumnos, doy fe.

A mis directores, Dra. Mónica Cunningham y Dr. Fernando Garcia, por ser absolutamente cuidadosos de mi formación, respetuosos de mi tiempo, y generosos con el suyo; por enseñarme todo todo lo que se sobre el trabajo de laboratorio; por su paciencia en esos tiempos de "resultados inexplicables" y su comprensión y contención en aquellos momentos en que la vida no fue tan simple, e ir al laboratorio y encontrarme con ustedes fue un refugio. De ustedes aprendí que charlando es más fácil, y en armonía, mejor; que hay pocas cosas que no puedan solucionarse; que andar modestamente, no significa avanzar poco si se es constante, y sobre todo que sin mate, no se puede trabajar. Moni, Fer, este trabajo es de ustedes.

Al Doctor Horacio Heras por sus ideas y por recordarme que también se puede hacer biología desde un tubo de ensayo.

A todo el laboratorio 8 bis, por tantas horas, tantas charlas y mates que hicieron más amenos estos años.

A Viky por soportar mi mal humor y mi llanto algunos días, compartir el buen humor otros, y por todas las horas que compartimos entre geles, buffers y mates dentro y fuera del laboratorio.

A Eva y Cristina por darme ánimo, besos y abrazos en cada pasillo que pudieron, y algún pedacito de torta, o chocolate también.

A Facu y sus colmenas, por ser incansables proveedores de arañas.

Al laboratorio 12 por compartir conmigo su insectario.

Al laboratorio 7 por ser fuente de respuestas a dudas experimentales, de drogas, reactivos, solventes y yerba que suelen acabarse en el momento menos indicado.

A todo el INIBIOLP, por ser mi segunda casa. 
Al Sr. Guillermo Gonzalez, por revisar minuciosamente el manuscrito y ayudarme con los gráficos y las fotos.

A mis amigas Marilina Romero y la Diseñadora Gráfica Romina Romero por su inmejorable colaboración con la estética y el diseño de este trabajo.

A la Biología que hace años elegí y me apasiona.

\section{Dedicado ...}

A mis padres, Ana María y Alberto, por enseñarme a ser libre para elegir qué, y quien quiero ser. Que mas podrían haberme enseñado? Gracias.....

A mi hermana Silvina, por su absoluta incondicionalidad (te adoro peque).

A mis abuelos por tantos, tantos, tantos mimos.

A Guille por su incansable paciencia, por ser mi cómplice en la vida y por quererme bien.

En memoria del Sr. Ricardo Manuel Juiz, mi abuelo, la persona más humilde y noble que conocí. Por todos las charlas que tuvimos y por las que esta vida ya no nos deja tener; por cuanto me hiciste reirr; por mi niñez entre los tomates y las habas de tu quinta, y tus bicicletas; por todas las veces que me dijiste: "estudiá viejita querida, que eso te va a dar libertad"; por el empeño que pusiste en cuidarme, y porque te quiero y te extraño irremediablemente, te dedico cada uno de mis dias y este trabajo...

A todos ustedes, espero les guste... 
Los resultados presentados en este trabajo de tesis, han sido parcialmente publicados en:

- Aldana Laino, Fernando Garcia, Mónica Cunningham, Horacio Heras. First insight into the lipid uptake, storage and movilization in arachnids. Role of midgut diverticula and lipoproteins. Journal of Insect Physiology. 2009; 55 (12): $1118-24$.

- Aldana Laino, Mónica Cunningham, Horacio Heras, Fernando Garcia. Isolation and characterization of two vitellins from eggs of the spider Polybetes pythagoricus (Araneae: Sparassidae). Comparative Biochemestry and Phisiology B. 2011 ; 158: | 42-| 48.

- Aldana Laino, Mónica Cunningham, Horacio Heras, Fernando Garcia. In vitro lipid transfer between lipoproteins and midgut-diverticula in the spider Polybetes pythagoricus (Araneae: Sparassidae). Comparative Biochemistry and Physiology B. 2011 ; 160: 181-186.

- Aldana Laino, Fernando Garcia, Mónica Cunningham. Structural characterization of a very high density lipoprotein from the spider Polybetes phytagoricus. Comparative Biochemistry and Physiology B. En preparación. 
"Los avances reales en el conocimiento, se dan en personas que hacen lo que les gusta hacern.

Albert Einstein 


\section{Indice}

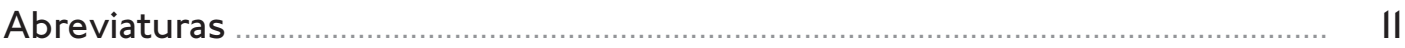

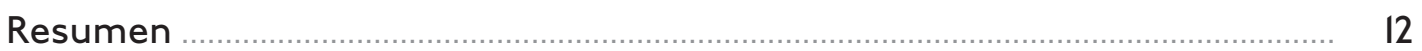

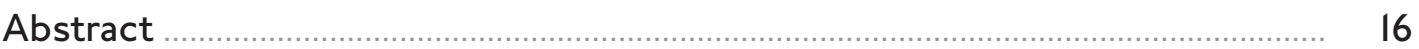

CAPITULO I: Introducción ……....................................................................... 20

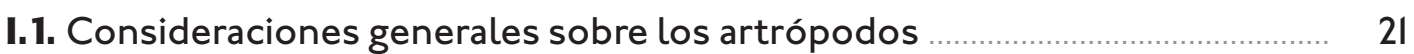

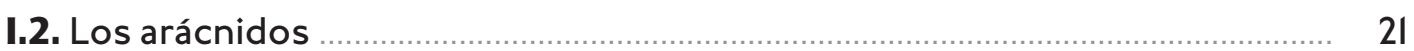

I.3. Las arañas .

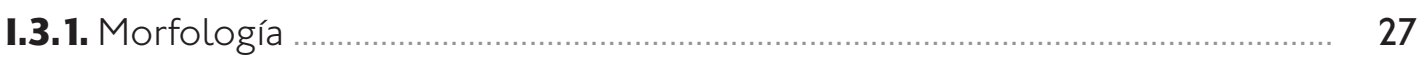

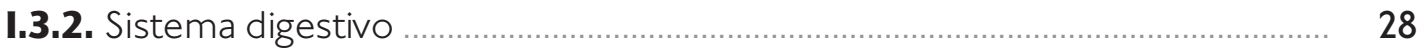

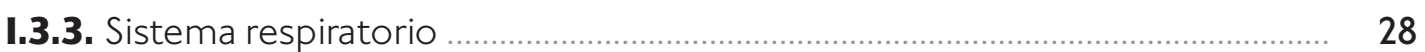

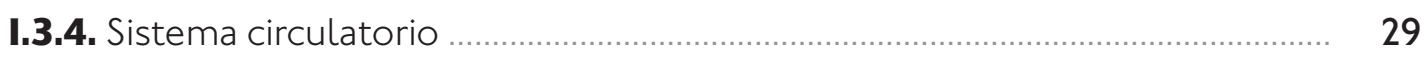

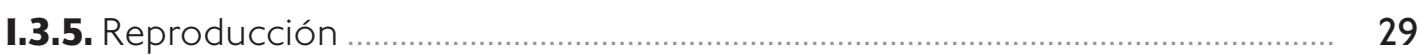

I.4. Polybetes pythagoricus .................................................................................. 31

1.5. Generalidades sobre la composición química de la hemolinfa de arañas.. 33

I.6. Mecanismos de circulación de lípidos …….......................................... 33

I.7. Lipoproteínas en invertebrados ...................................................... 34

I.7.1. Lipoproteínas circulantes no ligadas al sexo ……............................................ 35

I.7.2. Lipoproteínas circulantes ligadas al sexo (vitelogeninas) y lipovitelinas ...... 37

I.8. Sistema de transporte de lípidos en la araña Polybetes pythagoricus ......... $\quad 40$

1.9. Rol de las lipoproteínas y divertículos intestinales en la dinámica de

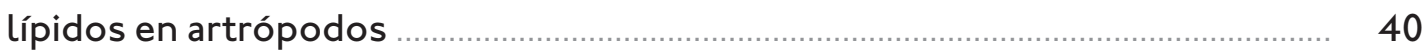

I.10. Hemocianina ….......................................................................................... 4

I. 10. 1. Estructura de la hemocianina en moluscos ................................................. 43

I.10.2. Estructura de la hemocianina en artrópodos .............................................. 43

I. 10.3. Hemocianina en Polybetes pythagoricus .................................................... 44

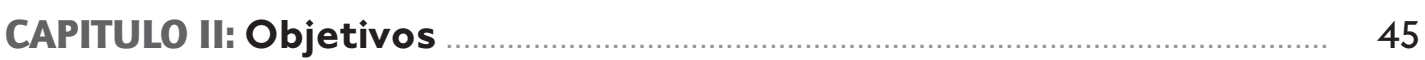

CAPITULO III: Materiales y Métodos ………….......................................... 47

III. 1. Reactivos, drogas y solventes ......................................................... 48

III.2. Muestreo, mantenimiento y disecciones de Polybetes pythagoricus ........ 48

III.2. 1. Ubicación y descripción de la zona de muestreo .......................................... 48

III.2.2. Extracción de hemolinfa y disección de órganos ....................................... 49

III.2.3. Colección de huevos y obtención de citosol ............................................ 50

III.3. Detección y aislamiento de lipoproteínas ............................................ 50

III.3. 1. Ultracentrifugación en gradiente de densidad y fraccionamiento .............. 50

III.3.2. Medidas efectuadas en las fracciones obtenidas de la 


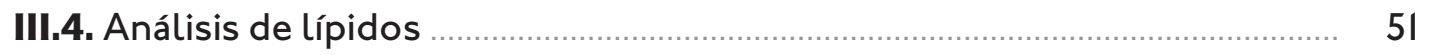

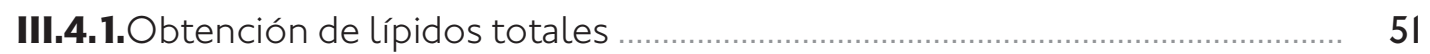

III.4.2. Cuantificación de lípidos totales por gravimetría ..................................... 52

III.4.3. Análisis de lípidos por cromatografía en capa fina (TLC) ......................... 52

III.4.4. Microdeterminación de lípidos ................................................................ 52

III.4.5. Análisis de ácidos grasos por cromatografía gas-líquido ........................... 54

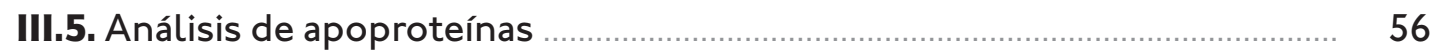

III.5. 1. Diálisis de las muestras ........................................................................... 56

III.5.2. Cuantificación de proteínas totales.......................................................... 56

III.5.3. Separación electroforética de las muestras en geles de poliacrilamida

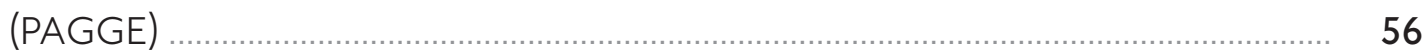

III.5.4. Revelado de las proteínas y determinación de sus pesos moleculares .... 58

III.5.5. Electroelución .................................................................................... 60

III.6. Determinación de la presencia de hemocianina en las lipovitelinas ........ 60

III.7. Determinación de carbohidratos ....................................................... 60

III.8. Preparación de anticuerpos policlonales anti HDL I y VHDL ..................... 61

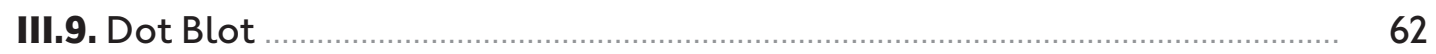

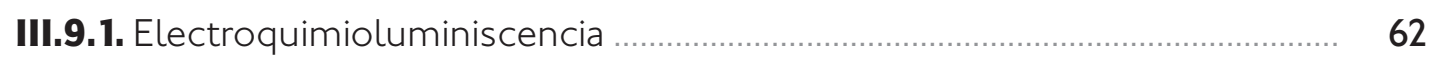

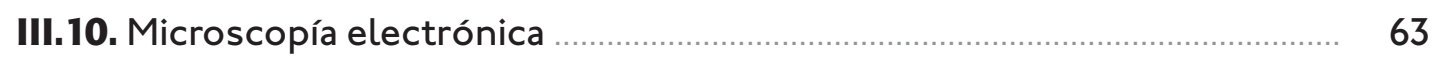

III. 11. Otas medidas efectuadas sobre la partícula lipoproteica VHDL ............ 64

III. 11. 1. Tratamiento con tripsina y PAGGE-SDS ............................................... 64

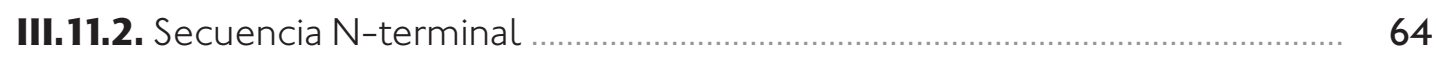

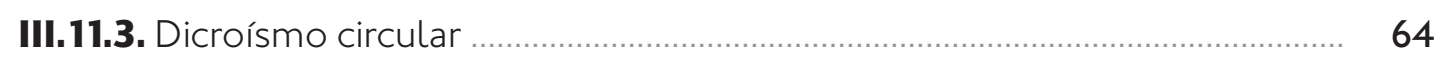

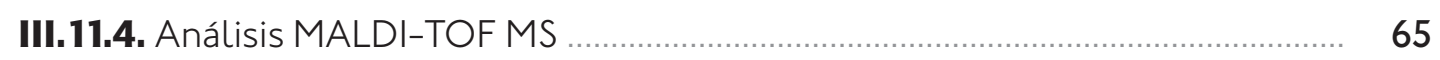

III. 11.5. Emisión de fluorescencia ......................................................................... 66

III. 12. Preparación de la sal de amonio .............................................................. 67

III. 13. Medidas de radioactividad por contador de centelleo líquido ................ 67

III. 14. Diseño experimental para el estudio de la transferencia de lípidos in vivo, entre divertículos intestinales y hemolinfa .............................................. 67

III. 14. 1. Marcación in vivo con precursor radioactivo ......................................... 67

III. 14.1.1. Experimentos de alimentación .......................................................... 67

III.14.1.2.a. Experimentos de inyección .............................................................. 68

III. 14. 1.2.b. Experimentos de inyección a distintos tiempos .................................... 68

III. 14.2. Captación de lípidos por hemocitos .................................................... 69

III. 15. Diseño experimental para el estudio de la transferencia de lípidos in vitro, entre divertículos intestinales y hemolinfa .......................................... 69

III. 15.1. Marcación in vivo con precursor radioactivo ........................................... 69

III. 15.2. Ensayos de captación de lípidos por lipoproteínas hemolinfáticas ......... 69

III. 15.3. Ensayos de liberación de lípidos de lipoproteínas hemolinfáticas ......... $\quad 70$

III. 15.4. Transferencia de lípidos entre lipoproteínas .......................................... $\quad 70$

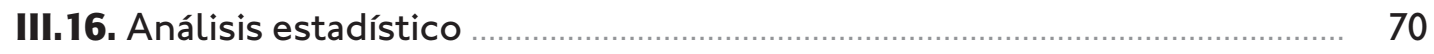


CAPITULO IV: Caracterización estructural de una lipoproteína de muy alta densidad de Polybetes pythagoricus ................................................

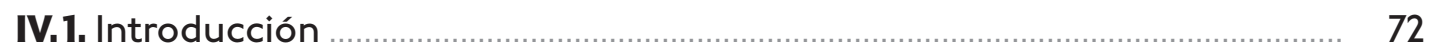

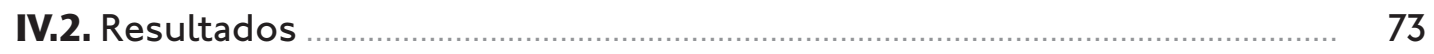

IV.2.1. Análisis de las apoproteínas en condiciones nativas. Determinación de la presencia de cobre y lípidos ..................................................................................... 73

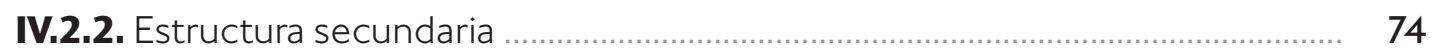

IV.2.3. Determinación de la presencia de puentes disulfuro ............................... 75

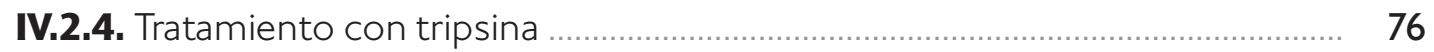

IV.2.5. Análisis de homologías de secuencias peptídicas ..................................... 77

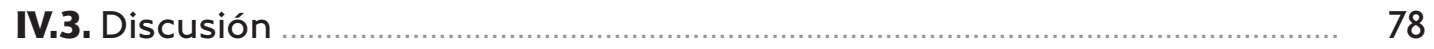

CAPITULO V: Absorción, almacenamiento y movilización de lípidos en arácnidos: El rol de los divertículos intestinales y las lipoproteínas 83

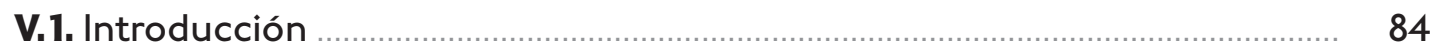

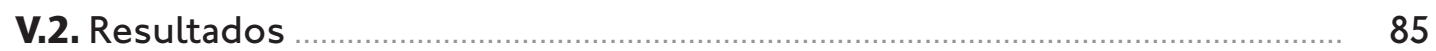

V.2.1. Composición lipídica y de ácidos grasos de los divertículos intestinales .... 85

V.2.2. Incorporación de ácidos grasos en divertículos intestinales y otros tejidos 86

V.2.3. Transporte de lípidos en hemolinfa e incorporación en los tejidos ............. 87

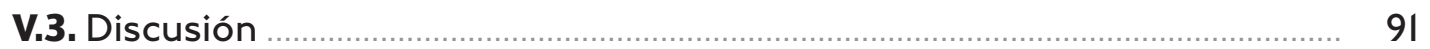

CAPITULO VI: Transferencia de lípidos in vitro entre lipoproteínas y divertículos intestinales de la araña Polybetes pythagoricus ............... 96

VI.1. Introducción ............................................................................................. 97

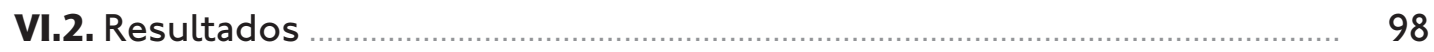

VI.2.1. Captación de lípidos por las lipoproteínas desde los divertículos

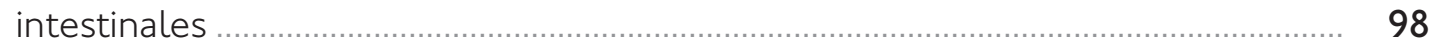

VI.2.2. Liberación de lípidos desde las lipoproteínas a los divertículos

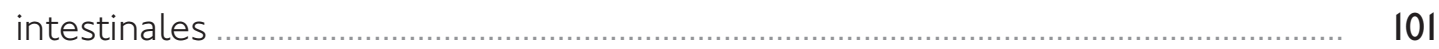

VI.2.3. Transferencia de lípidos entre lipoproteínas ......................................... 103

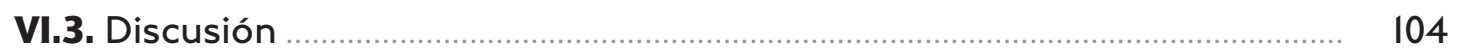

CAPITULO VII: Aislamiento y caracterización de dos lipovitelinas de la araña Polybetes pythagoricus $\ldots$

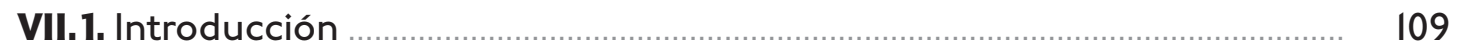

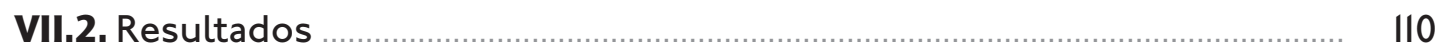

VII.2. 1. Aislamiento y caracterización proteica de lipoproteínas de huevo

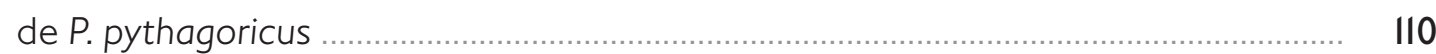

VII.2.2. Caracterización lipídica y de hidratos de carbono .................................. II3

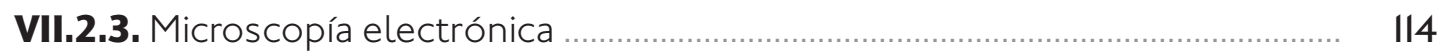

VII.2.4. Determinación de hemocianina ............................................................. $\quad 115$ 
VII.2.5. Identidad inmunológica

VII.3. Discusión

CAPITULO VIII: Conclusiones

Bibliografía 


\section{Abreviaturas}

Å: ångström

AGL: ácidos grasos libres

Ci: curie $\left(2,22 \times 10^{12}\right.$ desintegraciones por minuto)

Col: colesterol

cpm: cuentas por minuto

DAG: diacilglicerol

DC: dicroísmo circular

DI: divertículos intestinales

DMSO: dimetilsulfóxido

EMAG: ésteres metílicos de ácidos grasos

GLC: cromatografía gas-líquido

HDL: lipoproteína de alta densidad

HL: hemolinfa

HPLC: cromatografía líquida de alta presión

HPTLC: cromatografía en capa fina de alta performance

kDa: kilodalton

LDL: Lipoproteína de baja densidad

LV: Lipovitelina

MAG: monoacilglicerol

MALDI-TOF: Matrix-Assisted Laser Desorption-Ionization- Time-Of-Flight

PM: peso molecular

PAGGE: electroforesis en gel en gradiente de poliacrilamida

PC: fosfatidilcolina

PE: fosfatidiletanolamina

PL: fosfolípidos

Rf: distancia de la sustancia/frente de la fase móvil

SDS: dodecilsulfato de sodio

TAG: triacilglicerol

TEMED: tetrametilendiamina

TLC: cromatografía en capa fina

TLC-FID: cromatografía en capa fina acoplada a un detector de ionización de llama

Tris: Tris-(hidroximetil)-aminometano

Vg: vitelogenina

VHDL: Lipoproteína de muy alta densidad

Vt: vitelina

$\boldsymbol{\delta}$ : densidad 
RESUMEN 


\section{Resumen}

La especie Polybetes pythagoricus es representante de un género de arañas exclusivamente sudamericano, perteneciente al Suborden Araneomorpha, Familia Sparassidae, abundante en regiones tropicales y subtropicales. Por tratarse de una especie de fácil obtención, manipulación y mantenimiento, fue elegida como modelo de estudio para este trabajo de tesis.

En el presente estudio, se buscó ampliar el conocimiento a nivel estructural de la lipoproteína hemolinfática de muy alta densidad (VHDL) de dicha araña, se analizaron aspectos bioquímicos y fisiológicos estudiando el rol de las lipoproteínas de esta especie en la dinámica de la circulación de lípidos, y el transporte de éstos lípidos, desde y hacia los tejidos; y por último se estudió la presencia y estructura de dos lipovitelinas de huevos.

Los estudios realizados hasta la actualidad sobre lipoproteínas de invertebrados son abundantes en algunos grupos taxonómicos y escasos en otros. Los grupos más estudiados de artrópodos son los insectos y los crustáceos, pero dentro de los arácnidos la información disponible es escasa, a excepción de los ácaros, dada su importancia sanitaria y económica. La VHDL hemolinfática de $P$. pythagoricus, ya ha sido caracterizada a nivel de su composición lipídica y apoproteica, determinándose que contiene el pigmento respiratorio hemocianina como apolipoproteína, y que se encuentra asociada a la mayor parte de los lípidos circulantes. Dado que, participaría de una manera importante en el transporte y la dinámica de estos lípidos, proponemos el estudio de las características estructurales de dicha lipoproteína de muy alta densidad. Se realizaron análisis electroforéticos que nos permitieron determinar que su conformación nativa está constituida por heptámeros, hexámeros y monómeros de hemocianina, además de dímeros de dos proteínas no respiratorias, las cuales según el patrón de tripsinólisis estarían más expuestas al medio acuoso. En cuanto a su estructura secundaria, el análisis por dicroísmo circular determinó que predomina la lámina $\beta$ sobre la hélice $\alpha$, y que se encuentra además, un importante porcentaje de giros y estructura desordenada. La estructura de la partícula, estaría estabilizada por uniones no covalentes dada la ausencia de puentes disulfuro. Por otro lado se confirmó que las proteínas "no respiratorias" no contienen hemocianina, ya que no presentan cobre en su estructura, ni tampoco sus secuencias de aminoácidos resultan homólogas con hemocianinas de otras especies. Para saber cuál de las subunidades es la encargada del transporte de lípidos, realizamos una tinción con un colorante específico para lípidos que determinó que se unirían al hexámero de hemocianina y a una de las proteínas no respiratorias. Por último, obtuvimos información acerca de la homología entre la estructura primaria de las subunidades de VHDL y otras proteínas ya secuenciadas, que permitirá a futuro una caracterización más profunda sobre su estructura primaria. 
Dentro de la Clase Arachnida, las arañas, opiliones y escorpiones, tienen un sistema intestinal con ramificaciones extensamente desarrolladas llamadas divertículos intestinales, que en base a observaciones histológicas y ultraestructurales, han sido considerados como el sitio de almacenamiento de lípidos y glucógeno. En cuanto al mecanismo de circulación de lípidos en artrópodos, es bien conocido en algunos grupos como crustáceos e insectos, pero en relación a los arácnidos, la información es escasa. Considerando entonces, que el intercambio de lípidos entre lipoproteínas hemolinfáticas y tejidos, es desconocido en el subfilum Chelicerata, y que los divertículos intestinales, serían potencialmente el principal órgano involucrado en la biosíntesis de lípidos en arácnidos, nos focalizamos en la primer caracterización lipídica y de composición de ácidos grasos de este órgano, y en el metabolismo e intercambio in vivo e in vitro, de lípidos entre divertículos intestinales y lipoproteínas hemoLinfáticas. En cuanto a la composición lipídica de los divertículos intestinales, observamos una importante predominancia de triacilglicéridos, mientras que el análisis de ácidos grasos de los lípidos totales, mostró un patrón dominado por ácidos grasos insaturados. Para los estudios de transferencia in vivo, administramos ácido palmítico radiomarcado, tanto por la dieta, como directamente en la hemolinfa. Se observó que el ácido palmítico obtenido a partir de la dieta, se incorpora principalmente a los divertículos intestinales como triacilglicéridos, y en menor medida a la hemolinfa como ácidos grasos libres, mientras que el ácido palmítico circulante en hemolinfa, se incorpora en músculo manteniéndose como ácidos grasos libres, y en divertículos intestinales, donde se sintetizan triacilglicéridos y fosfolípidos. Luego de éste análisis pudimos confirmar que los divertículos intestinales serían el órgano más activo en cuanto al metabolismo de lípidos y que las lipoproteínas hemolinfáticas, HDL I y VHDL se encuentran involucradas in vivo en el transporte de lípidos desde y hacia los tejidos.

Para los estudios in vitro, se realizaron incubaciones entre divertículos intestinales marcados y hemolinfa o lipoproteínas no marcadas, y viceversa, pudiendo observar que: HDL I y VHDL son capaces in vitro de captar y liberar lípidos desde los divertículos intestinales, sin embargo HDL I tiene más capacidad de captar lípidos, mientras que VHDL se presenta más activa en la liberación. Además se observó que las lipoproteínas muestran una tendencia a captar en mayor medida ácidos grasos libres y fosfolípidos, mientras que los tricilglicéridos serían retenidos en los divertículos intestinales. También se realizaron ensayos de transferencia entre lipoproteínas, de los cuales se desprende que HDL I es capaz de transferir más lípidos a VHDL que ésta, a HDLI.

En aquellas especies en las que en su reproducción se involucra la puesta de huevos, es indispensable que éstos sean provistos de los nutrientes necesarios para el desarrollo embrionario. Estos nutrientes, representados por lípidos, proteínas e hidratos de carbono, se asocian dando lugar a la formación de lipovitelinas, que por su rol primordial en la reproducción, han sido detalladamente 
estudiadas en los principales grupos de artrópodos como insectos y crustáceos. Por este motivo, y como último objetivo de este trabajo nos propusimos identificar, aislar y caracterizar las posibles lipoproteínas presentes en el vitelo de las arañas, utilizando como modelo a P. pythagoricus. Por ultracentrifugación en gradiente de densidad del citosol, determinamos que los huevos de esta especie presentan dos lipovitelinas, una HDL que llamamos LVI y una VHDL que llamamos LV2, ambas mostraron morfología esferoidal cuando se analizaron por microscopía electrónica. LVI presenta dos subunidades de 64 y 25 kDa, y LV2 tres subunidades principales de 18I, 67 y $60 \mathrm{kDa}$, y una menor de 18 kDa. En cuanto al análisis de lípidos, tanto en LVI como en LV2 predominaron los fosfolípidos, y entre los lípidos neutros, los más abundantes fueron los ésteres de colesterol. En la composición de ácidos grasos, predominan los insaturados, principalmente el 18: I, y entre los saturados el más abundante es el 16:0. Esta composición coincidió con la de los divertículos intestinales de P. pythagoricus. Cuando se estudió la posible relación entre estas lipovitelinas y las lipoproteínas hemolinfáticas de P. pythagoricus, se observó que no presentan hemocianina en su estructura, ni muestran relación inmunológica con las lipoproteínas hemolinfáticas.

En síntesis, en este trabajo se avanzó en la caracterización estructural de una lipoproteína hemolinfática con alto contenido de hemocianina, y se confirmó su importante participación en la dinámica de los lípidos circulantes; se obtuvieron resultados que nos permiten suponer un modelo de circulación y almacenamiento de lípidos en la araña P. pythagoricus, en el que se propone que los ácidos grasos libres de la dieta o los circulantes, serían tomados por los divertículos intestinales, donde se procesan y se utilizan para la síntesis de lípidos complejos, principalmente triacilglicéridos y fosfolípidos. Luego estos lípidos podrían ser almacenados en divertículos intestinales ó, transferidos a la hemoLinfa donde serían captados por las lipoproteínas, principalmente por HDL I, que en circulación podría transferirlos a la VHDL para ser liberados a los tejidos donde serían utilizados. Por último, se aislaron y caracterizaron dos lipovitelinas de huevo, por primera vez en el Orden Araneae. 
ABSTRACT 


\section{Abstract}

Polybetes pythagoricus is a species from an exclusively South American spider genus, belonging to the Suborder Araneomorpha, member of the Fam. Sparassidae, which is abundant in tropical and sub-tropical regions. Being a specimen easy to obtain, manipulate, and mantain, it was chosen as a study model for this thesis work.

The aim of the present study was to extend the structural knowledge of the hemolymphatic very high density lipoprotein (VHDL) from Polybetes pythagoricus. We analyzed several biochemical and physiological aspects, in relation with the role of lipoproteins from this species on the lipid circulation dynamics, along with lipid transport features among different tissues. Furthermore, presence and structure of two egg lipovitellins were also investigated.

Studies carried over up to date on invertebrate lipoproteins are abundant only for some taxonomical groups. Insect and crustacean have been very well described, but information is very limited for other arthropods such as arachnids, with the exception of mite, in view of its medical and economic importance. Lipid and protein composition from hemolymphatic VHDL of P. pythagoricus has been characterized as containing the respiratory pigment hemocyanin in the form of an apolipoprotein associated to nearly all circulatory lipids. Since it would play an important role in lipid transport and dynamics, we propose to investigate the structural aspects of this very high density lipoprotein.

Electrophoretic analysis allowed us to determine its native conformation composed of hemocyanin heptamers, hexamers and monomers, along with dimmers of two other non-respiratory proteins which, according to its trypsinolysis pattern are more exposed to aqueous environment. Regarding its secondary structure, circular dichroism data showed more $\beta$ sheet compared with $\alpha$ helix presence, with an important contribution of turns as well as random structure. Since disulfide bonds are not present, the particle structure would be stabilized non-covalently. On the other hand, the absence of cupper atoms in the "nonrespiratory" proteins and its amino acid sequence difference to hemocyanins from other species, leaded to the conclusion that they do not contain hemocyanin. A specific lipid staining showed that lipids would bind to the hemocyanin hexamer and one of the non-respiratory proteins. Finally, information obtained from homology studies between the primary structure from VHDL subunits and from other already sequenced proteins will lead to a deeper understanding of our model.

Spiders, harvestmen and scorpions, all members of the Class Arachnida, present an intestinal system with extensively developed branches known as midgut diverticula which act as storage site for lipids and glycogen, based on histological and ultrastructural observations. Regarding lipid circulation mecha- 
nism in arthropods, again, it is well known in some groups such as crustacean and insects, but knowledge is very poor for arachnids. Taking into account that lipid exchange between hemolymphatic lipoproteins and tissues is not described in the Subfilum Chelicerata, and that midgut diverticula are probably the main organs for arachnid lipid biosynthesis, we focused our work on the lipid and fatty acid characterization of this organ, and also on the metabolism and lipid exchange (in vivo and in vitro) between midgut diverticula and hemolymphatic lipoproteins.

While triacylglycerides were the main lipid present in midgut diverticula, the total fatty acid composition showed a predominantly saturated fatty acid profile. For in vivo transfer studies radioactive palmitic acid was delivered either as a diet component or directly into hemolymph. In the first case, the radioactive fatty acid incorporates mainly into midgut diverticula and to a lesser extent in hemolymph as free fatty acid. On the other hand, while hemolymph circulating palmitic acid is incorporated into muscle in the form of free fatty acids, it enters midgut diverticula to become part of triacylglicerides and phospholipids. Based on these data, we could confirm that midgut diverticula are the most active compartment for lipid metabolism, whereas hemolymphatic lipoproteins HDL I and VHDL are actively involved in the lipid in vivo transport between different tissues.

For in vitro studies we incubated labeled or unlabeled midgut diverticula with unlabeled or labeled hemolymph or lipoproteins, respectively. Results show that while both HDLI and VHDL are able to in vitro uptake and release lipids from midgut diverticula, HDL I is more active for the first of the processes, and VHDL for the second. Further, lipoproteins show a higher affinity for free fatty acids and phospholipids, whereas triacylglycerides are more likely to be kept in diverticula. From transfer studies between lipoproteins, we can conclude that there is a higher flux in the direction from HDL I to VHDL.

In those species whose reproduction involves eggs, it is crucial that these receive nutrients needed for embryo development. This nutrient supply composed of lipids, proteins, and carbohydrates allow formation of lipovitellins. Given its critical role in reproduction, lipovitellins have been very well studied in the main arthropod groups such as insects and crustacean. So, as another objective of this investigation, we identified, isolated, and characterized those lipovitellins present in the vitellus using P. pythagoricus as a model. Citosol density gradient centrifugation studies showed that eggs from $P$. pythagoricus exhibit two lipovitellins, one HDL (LVI) and one VHDL (LV2), with spheroidal morphology when analyzed by electron microscopy. LVI is composed of two subunits of 64 and 25 $\mathrm{kDa}$, whereas LV2 presents three main subunits of 181,67 and $60 \mathrm{kDa}$, and a smaller one of $18 \mathrm{kDa}$. Both LVI and LV2 contain mainly phospholipids, and among neutral lipids cholesterol esters are the most abundant. Unsaturated fatty acid 18:I and saturated fatty acid 16:0 are present at the highest level, in coincidence 
with results from midgut diverticula from the same species. Regarding the possible relationship among these lipovitellins and hemolymphatic lipoproteins from $P$. pythagoricus, we observed that the first ones don't contain hemocyanin. Further, lipovitellins and hemolymphatic lipoproteins don't show any immunologic similarity to each other.

To summarize, here we provide novel information about structural features of a hemolymphatic lipoprotein with high hemocyanin content, and confirmed its critical role in the circulating lipid dynamics. We also obtained evidence to propose a lipid circulation and storage model for the spider P. pythagoricus. Dietary or circulating free fatty acids would be recruited by midgut diverticula where they are processed and used for complex lipid biosynthesis, mainly tiacylglycerides and phospholipids. Then, these newly synthesized lipids may be stored in midgut diverticula, or they can be transfered to hemolymph, where they are collected by HDLI. Also, this lipoprotein is able to transfer them, in circulation, to VHDL from where they may be delivered to several tissues for their final utilization. In addition, for the first time two novel egg lipovitellins were isolated and characterized for a specimen belonging to the Order Araneae. 
CAPITULO I

Introducción 


\section{Introducción}

\section{1. Consideraciones generales sobre los artrópodos}

Los artrópodos constituyen el filum más numeroso y diverso dentro del reino animal. Se han descripto casi I.200.000 especies, que corresponden a más de tres veces el número del resto de las especies animales, debido principalmente a que presentan una enorme diversidad adaptativa que les ha permitido sobrevivir en todos los hábitats (Rupert \& Barnes, 1996).

Los artrópodos actuales se subdividen en:

\section{Subfilum Quelicerados}

Clase Arachnida

Clase Xiphosura

Clase Picnogonida

\section{Subfilum Crustacea}

Clase Branquiopoda

Clase Remipedia

Clase Cephalocarida

Clase Maxillopoda

Clase Ostracoda

Clase Malacostraca

\section{Subfilum Unirramia}

Clase Insecta

Clase Chilopoda

Clase Diplopoda

Clase Symphyla

Clase Pauropoda

\section{I.2. Los arácnidos}

De aquí en adelante, se hará referencia con este nombre, a los representantes de la Clase Arachnida.

Los arácnidos han aparecido en el período Silúrico hace 360 millones de años y llegan a la actualidad con una gran representatividad.

De acuerdo con el registro fósil, hay dos períodos ricos en formas fósiles de arácnidos: el Carbonífero de la era Paleozoica y el Oligoceno de la era Cenozoica. En el primero, se encuentran representados casi todos los órdenes conocidos de la Clase Arachnida, tanto actuales como extintos, además de una variada fauna correspondiente a diversos grupos animales, lo que permite suponer que en este período deben haber sido muy favorables las condiciones para la vida. El Oligoceno por su parte, fue un período propicio para la conservación, debido principalmente a la presencia de coníferas productoras de una resina conocida como ámbar, que sirvió de trampa a los insectos y arácnidos de entonces (Hoffmann, 2003) (Fig. I.I). 


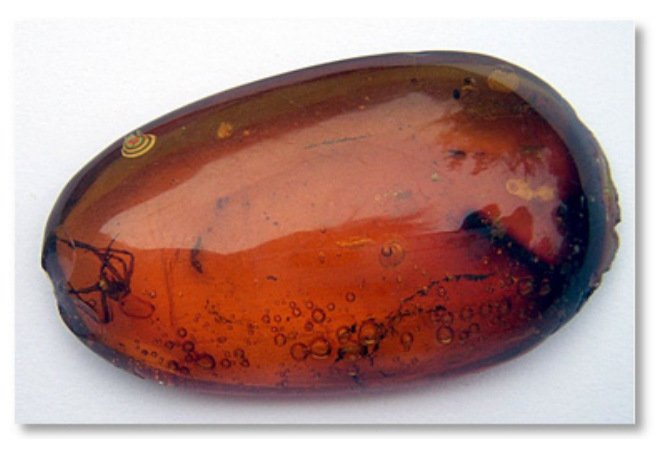

Figura I.1: Fósil de araña en ámbar. Foto de Mila Zinkova, publicada bajo los términos de la licencia de documentación libre GNU.

Es un hecho que los quelicerados constituyen un capítulo importante en la historia de la vida en nuestro planeta, ya que fueron los primeros animales que dejaron el mar y se adaptaron a vivir en tierra firme. Aunque existen diferentes opiniones sobre cuál fue el grupo de quelicerados que pasó del medio acuático al terrestre, entre los que se tienen en cuenta a los escorpiones o grupos de pequeño tamaño como los ácaros y los palpígrados, se piensa que los euriptéridos, fueron quienes se alejaron del mar. Probablemente porque las condiciones de la vida marina ya no les satisficieron, al no encontrar suficiente alimento o sitios para la reproducción, o por haber exceso de población, de contaminación o de enemigos naturales.

Los arácnidos siempre han ocupado un sitio desfavorable en los gustos y decisiones del hombre. Como dentro de este grupo, existe una minoría de especies venenosas, capaces de originar desde molestias leves, hasta en algunos casos la muerte, la aversión hacia estos animales se acrecienta aún más. Sin embargo, los arácnidos forman un eslabón importante en la cadena alimenticia, ya que además de servir de alimento a otros animales, son activos participantes en el control natural de muchas poblaciones, sobre todo de insectos, lo cual contribuye con el equilibrio biológico de diversas biocenosis y ecosistemas (Hoffmann, 2003).

En cuanto a la anatomía externa, el cuerpo de los arácnidos se divide en un prosoma anterior y un opistosoma posterior. Los apéndices se originan en el prosoma, y consisten en I par de quelíceros con funciones en la alimentación, I par de pedipalpos, con diversas funciones y modificaciones según los grupos, en muchos casos asociados a la reproducción, y 4 pares de patas caminadoras.

La mayor parte de los arácnidos son carnívoros y la digestión se produce parcialmente fuera del cuerpo. Como órganos de excreción, poseen glándulas coxales y/o túbulos de Malpighi, y grandes células fagocitarias, Llamadas nefrocitos, ubicadas tanto en el prosoma como en el opistosoma. El sistema nervioso está formado por una masa ganglionar ubicada por encima del esófago, dividida en protocerebro y tritocerebro, de la cual parten nervios y un haz nervioso posterior único, que se extiende hacia atrás en el opistosoma. El sistema respiratorio consta de pulmones en libro, tráqueas o ambos. El sistema circulatorio es abierto, con un corazón dorsal ubicado casi siempre en la parte anterior del 
opistosoma. Presentan una aorta grande anterior que riega el prosoma, una pequeña aorta posterior que lleva la sangre a la mitad posterior del opistosoma y que desde cada segmento cardíaco origina un par de pequeñas arterias abdominales. Éstas últimas vacían finalmente el fluido circulatorio en los espacios tisulares, y en un gran seno ventral que baña los pulmones en libro. Uno o más, pares de conductos venosos llevan la hemolinfa $(\mathrm{HL})$ desde el seno ventral o los pulmones en libro, en dirección a la cámara pericárdica. En cuanto al sistema reproductor, el orificio genital de ambos sexos se encuentra ventralmente en el opistosoma. En este grupo de animales las gónadas pueden ser únicas o pares, y es característica la transmisión indirecta del esperma con un espermatóforo (Rupert \& Barnes, 1996).

La Clase Arachnida, como ya se ha comentado, muestra una gran diversidad representada por los siguientes órdenes:

Orden Scorpiones

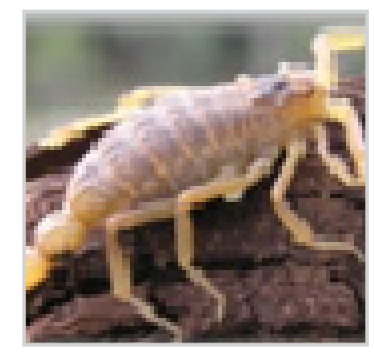

Orden Pseudoscorpionida

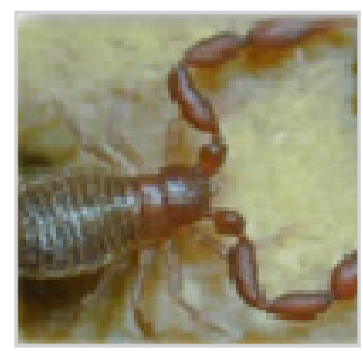

Orden Solifugae

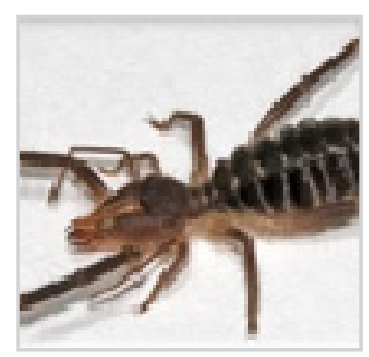

Orden Palpigradi

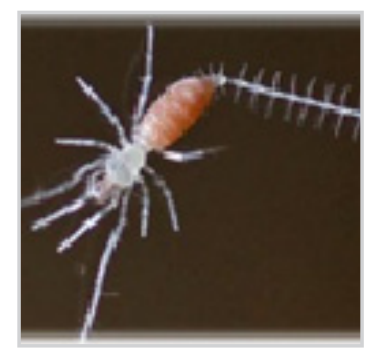




\section{Orden Uropygi}

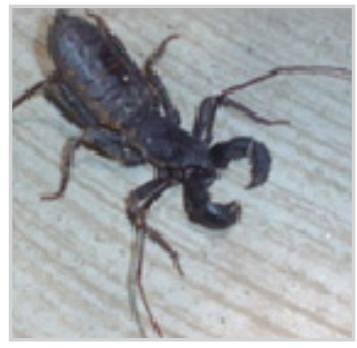

Orden Schizomida

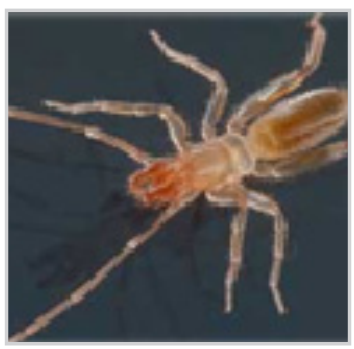

Orden Amblypygi

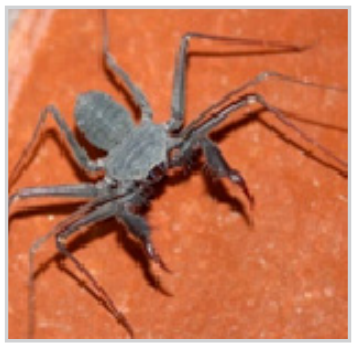

Orden Araneae

Infraorden Mygalomorphae

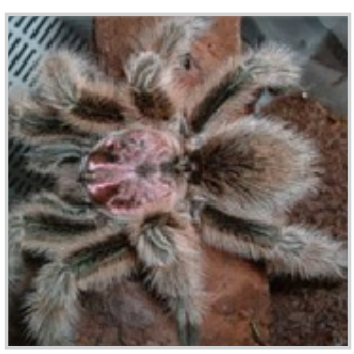

Infraorden Araneomorphae

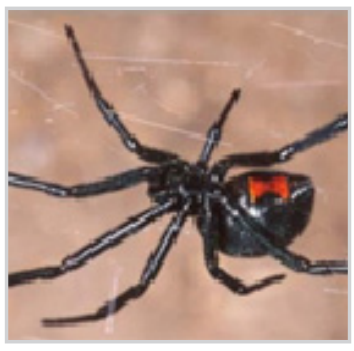

Orden Ricinulei

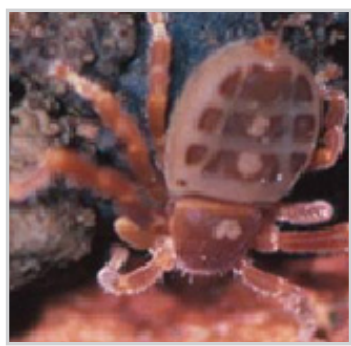




\section{Orden Opiliones

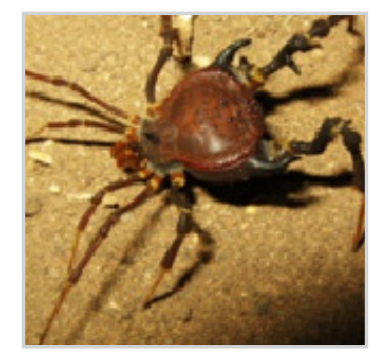

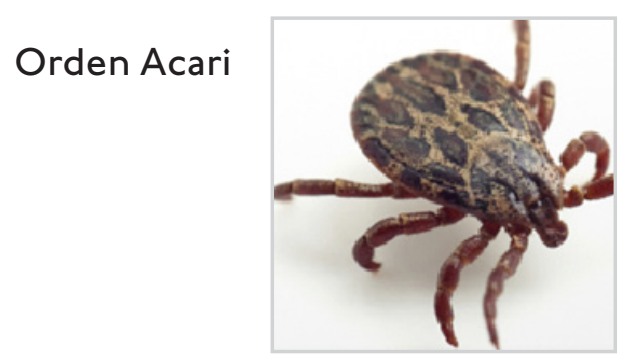

\section{I.3. Las arañas}

"Hay que echar mano de la fantasía para introducirse en el cuerpo de un ser que recibe a través del sentido del tacto casi toda la información sobre las cosas que tienen significación para su vida".

Karl von Frisch, biólogo austríaco, Premio Nobel de Fisiología en 1973.

Las arañas constituyen el orden más importante y numeroso en especies actuales de la Clase Arachnida. Se conocen alrededor de 42.000 especies, pertenecientes a 3.849 géneros aproximadamente, y más de 100 familias distribuidas en todo el mundo (Platnick, 2011). Este grupo es además, el que ha alcanzado mayor diversidad adaptativa dentro de los arácnidos, se encuentran distribuidos en todos los hábitats accesibles a la vida (con excepción del aire y el mar abierto), desde el nivel del mar, hasta cerca de 7.000 msnm en el Monte Everest. Algunas pocas especies han logrado adaptarse a la vida semiacuática, y solo una encontró la forma de vivir permanentemente bajo el agua a pesar de su respiración aérea. Existen de todos los tamaños, desde aquellas con cuerpos pequeños (2 a $10 \mathrm{~mm}$ de largo) hasta las denominadas tarántulas que pueden tener un cuerpo de hasta 80-90 mm de largo. La mayor parte de las arañas viven alejadas del hombre, solo algunas se acercan o entran a las casas para buscar alimento como moscas o cucarachas (entre otros insectos), frecuentes en los ámbitos domésticos.

Una característica llamativa de las arañas es su capacidad de secretar hilos de seda. Si bien algunos insectos también pueden producir seda, lo hacen únicamente en alguna etapa de su ciclo de vida, como por ejemplo para construir el 
cocón antes de empupar. En cambio, todas las arañas poseen glándulas hilanderas y utilizan la seda, no solo para formar cocones o sacos para huevos, sino que también pueden manipularla para tejer complicadas redes.

La relación entre el hombre y las redes de las arañas es conocida desde hace mucho tiempo, se hace referencia a este tema, ya en escritos tan antiguos como la Biblia y el Corán, y además en notas de Aristóteles y Plinio se hace mención sobre su biología y comportamiento. Existen también creencias y supersticiones en torno a las arañas, que han sido plasmadas en leyendas de varios pueblos del mundo. La más antigua, se encuentra en el poema Metamorfosis, donde se narra la fábula de la gran tejedora Aracne, que da origen al nombre de la Clase Arachnida, escrito por el poeta romano Ovidio; también en China, África, México y pueblos precolombinos, por nombrar algunos (Hoffmann, 2003).

Actualmente, el interés del hombre por estos animales ha cambiado el rumbo. En los últimos años se han realizado numerosas investigaciones donde se caracterizaron a nivel estructural, genético y bioquímico, diversos aspectos de las arañas, como sedas, venenos, relaciones con el ambiente y otros, que han dado lugar a novedosos estudios aplicados, que las ubican en un lugar de organismos beneficiosos para el hombre. Por ejemplo, existe un importante interés en la utilización de la seda como biomaterial (Schacht \& Scheibel, 2011), aplicable en el campo de la biomedicina como material quirúrgico (Aparicio et al., 2010), o como imitación de bioadhesivos (Sahni et al., 2010), también se estudian proteínas recombinantes de seda como posibles plataformas de administración de genes no virales a células tumorales (Numata et al., 2011). Además se estudió a las arañas en agricultura, como controladoras de insectos plaga en cultivos (Cheli et al., 2011; Armendano \& González, 2010; González et al., 2009; Beltramo et al., 2006; Molinari \& Minervino, 2006). En la figura 1.2 se muestran títulos de artículos de divulgación o notas periodísticas donde se hace referencia a éstas nuevas aplicaciones del estudio de arañas. 


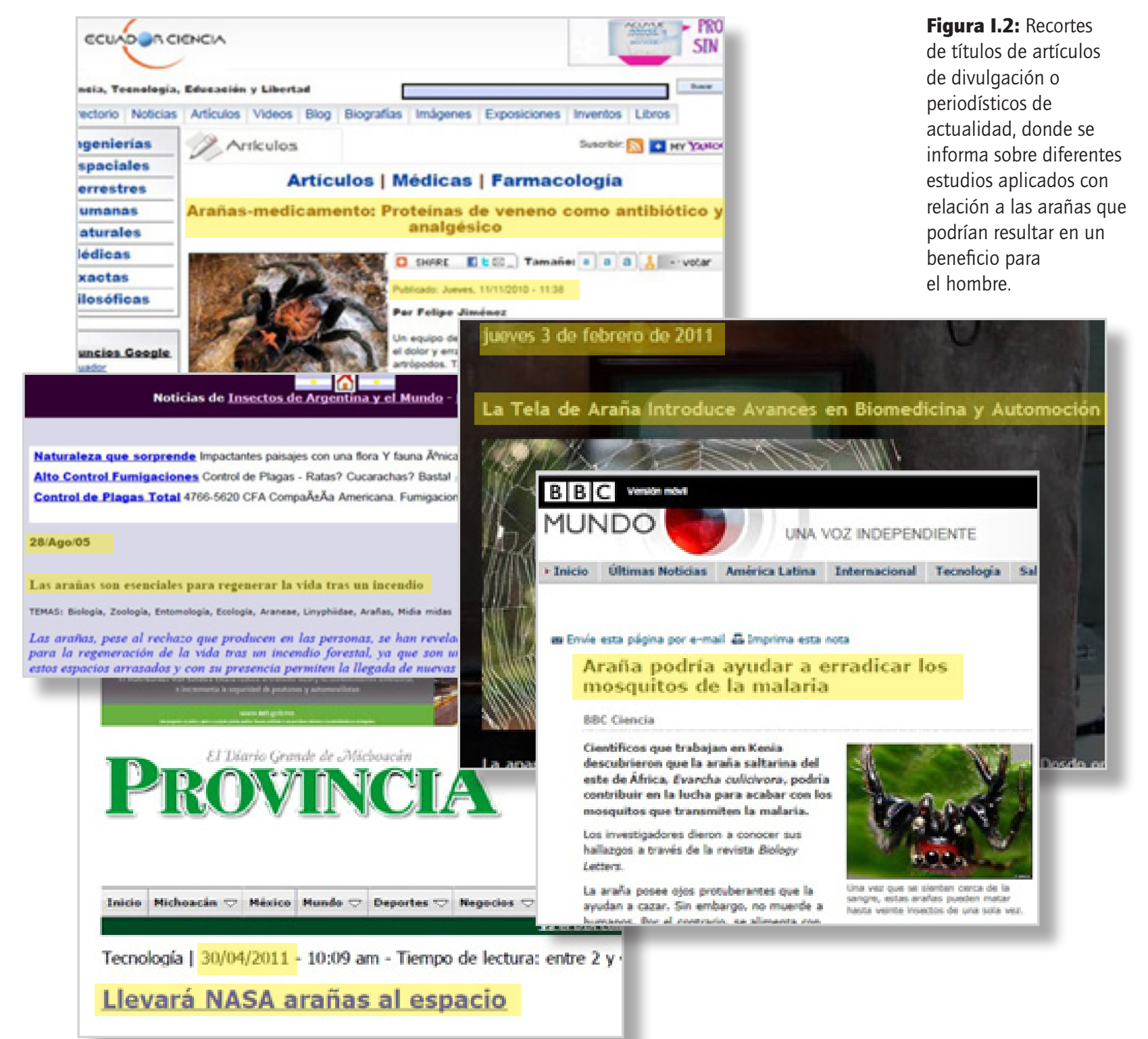

\subsubsection{Morfología}

En cuanto a su morfología presentan en el prosoma, un par de quelíceros de tamaño variable, según la especie, que llevan una uña en la que desemboca el conducto de las glándulas de veneno, localizadas en la base de éstos apéndices. Los pedipalpos femeninos son parecidos a las patas, pero en el macho se modifican como órganos copuladores. Las patas caminadoras son de longitud variable, constan de 7 artejos: una coxa y un trocánter cortos, un femur mas largo, una patela, una tibia y un metatarso delgados, y un tarso que termina en 2 o 3 uñas según el grupo. El prosoma y el opistosoma se unen por un pedicelo. En la parte ventral y anterior del opistosoma hay un surco epigástrico donde se locaLizan las aberturas reproductoras, y a los lados, los espiráculos de los pulmones en libro. En el extremo posterior del cuerpo presentan apéndices modificados llamados espineretas o hileras que son órganos tejedores donde desembocan las glándulas de la seda. 


\section{I.3.2. Sistema digestivo}

La digestión se inicia fuera del cuerpo. Mientras sostienen la presa, por los quelíceros se vierten enzimas digestivas secretadas por el intestino medio. Aquellas arañas que tienen quelíceros con dientes mastican su presa, y las que no, introducen el veneno por una picadura y succionan los tejidos digeridos. El estómago presenta un gran diámetro, a diferencia del esófago que es más angosto. En sección transversal tiene una pared cuticular flexible y varias bandas de fuertes músculos, cuando éstos se contraen incrementan el tamaño del lumen, y el estómago funciona como una bomba suctora, mientras que músculos anulares, con acción antagónica a los anteriores, disminuyen el tamaño del lumen (Foelix, 2011 ). El intestino se origina directamente por detrás del estómago, presenta una parte proximal que se ubica en el prosoma, mientras que la parte media y posterior se encuentran en el opistosoma. Consta de un tubo central con ramificaciones laterales, Llamadas divertículos intestinales (DI) que suelen estar muy desarrollados, de manera que llenan la mayor parte del opistosoma, rodeando la mayoría de los órganos. El epitelio está compuesto por al menos dos tipos celulares, entre los que se encuentran las células secretorias, que producen enzimas destinadas a completar la digestión, y células absortivas que procesan los nutrientes y los vierten a la $\mathrm{HL}$ o tejido intersticial fundamental. Los productos de excreción son frecuentemente concentrados apicalmente en las células de absorción, o pueden ser depositados como cristales en el tejido intersticial fundamental. El epitelio intestinal contiene además otro tipo de células, las células basales, que reemplazarán a las viejas células secretorias y de absorción, y los guanocitos donde se depositan cristales de guanina. La parte posterior del intestino se ensancha para formar un saco estercoral o una cámara cloacal (donde desembocan los túbulos de Malpighi), terminando en el ano (Foelix 2011).

\section{I.3.3. Sistema respiratorio}

La mayoría de las arañas poseen dos tipos de sistemas respiratorios: un par de pulmones en libro y un par de tráqueas tubulares.

Los pulmones en libro se ubican ventralmente en la parte anterior del opistosoma, cada uno consiste en un saco esclerotizado, cuya pared se pliega formando laminillas con aspecto de hoja. La difusión de los gases tiene lugar entre la HL que circula por el interior de las laminillas y el aire de los espacios interlaminares. El lado del saco que no está plegado da lugar a una cámara de aire (atrio) que continúa con los espacios interlaminares. Externamente se observan las aberturas como pequeños surcos en la cutícula que abren al atrio.

El sistema traqueal está constituido por túbulos limitados por quitina a través de los que se difunden los gases, que abren al exterior en pequeños estigmas o espiráculos apenas visibles. A diferencia de las tráqueas de los insectos, en las arañas siempre terminan en una abertura y sin contacto con las células, de 
manera que el oxígeno no es entregado directamente al tejido, sino que la HL es la encargada del transporte. El sistema de tráqueas tubulares muestra distinto grado de desarrollo según las familias de arañas, desde algunas con tubos cortos y poco desarrollados hasta otras con tubos muy ramificados que llegan al prosoma y las extremidades (Foelix, 2011).

\section{I.3.4. Sistema circulatorio}

Consiste en un sistema circulatorio abierto, de manera que los tejidos son bañados directamente por la HL. Presenta arterias que se originan en el corazón y se ramifican en el cuerpo, extendiéndose inclusive, hasta los segmentos más distales de las patas. La HL colectada en las lagunas de la parte ventral del cuerpo, pasa por los órganos respiratorios y retorna por las venas al corazón. Las arañas tienen entonces, un sistema arterial "cerrado", sin capilares y un sistema venoso abierto donde se produce el intercambio gaseoso.

La HL cumple la función de transportar nutrientes entre los órganos, y desde el tracto digestivo. También transporta de forma soluble el pigmento respiratorio hemocianina, que presenta una alta afinidad por el oxígeno y le aporta color azul debido a la presencia de cobre en su estructura. La hemocianina sería sintetizada en células llamadas cianocitos (Foelix, 2011), y representa el I,4\% del peso del cuerpo (un porcentaje relativamente alto si tenemos en cuenta que en humanos la hemoglobina representa el 1,2\% del peso).

La HL presenta una gran variedad de células llamadas hemocitos, con diversas funciones. Cumplen un rol importante en la coagulación y protección contra infecciones (Baumann et al., 2010; Pereira et al., 2007; Lorenzini et al., 2006; Silva et al., 2000); otros poseen péptidos antimicrobiales con actividad inhibitoria contra serin proteasas, como es el caso del arácnido B. microplus (Fogaca et al., 2006), o péptidos con actividad antifúngica (Barbosa et al., 2007). Estructuralmente se diferencian cuatro tipos de hemocitos (Foelix, 2011): Los más comunes son los granulares con gránulos densos concentrados en el citoplasma, otros son células de almacenamiento, fagocitos y los llamados laberidocitos que presentan una vacuola secretora. Durante la muda, según los requerimientos fisiológicos del animal, el porcentaje de hemocitos varía, al igual que en otros procesos.

\section{I.3.5. Reproducción}

Las hembras tienen un par de ovarios grandes, situados ventralmente en el opistosoma. El epitelio germinal da origen a los oocitos, los cuales, durante el proceso de desarrollo y agrandamiento, hacen prominencia hacia afuera a partir de la luz del ovario, que adopta un aspecto de racimo de uvas. Una vez maduros, los huevos pasan a un oviducto que parte de cada ovario y se dirige hacia abajo uniéndose en un tubo que termina en una vagina quitinosa, la cual desemboca en el pliegue epigástrico. Asociados a la vagina existen dos o más receptáculos 
y glándulas seminales que desembocan delante del surco epigástrico sobre una placa especial llamada epigino. Estas aberturas están destinadas a la recepción del órgano copulatorio del macho durante el apareamiento. Los espermatozoides se almacenan en los receptáculos seminales o espermatecas (Foelix, 2011).

Los machos, tienen un par de testículos con espermiductos enrollados que se unen antes de desembocar en el gonoporo en la parte media del surco epigástrico y están provistos de zonas para el almacenamiento de esperma. Los órganos copulatorios del macho no se conectan a las aberturas del conducto espermático, sino que están situados en los extremos de los pedipalpos. El segmento tarsal de éstos apéndices forma una estructura destinada exclusivamente a la transmisión de espermatozoides. Cuando el macho está sexualmente preparado, carga el pedipalpo de esperma segregado sobre una fina tela espermática. Una vez realizado el cortejo, el macho llena la hematodoca (una almohadilla elástica que tapiza el lugar donde se aloja el órgano copulador-tarso del pedipalpo del macho) con HL, erigiendo el órgano copulador dispuesto para el apareamiento, luego los introduce en las aberturas copuladoras y llena los receptáculos seminales con esperma. La hembra no pone los huevos hasta que estén maduros, recién en ese momento, los deposita en grupos sobre una película de seda, vierte sobre ellos el esperma de los receptáculos seminales y añade una lámina de seda para cubrirlos. Por lo tanto la fecundación coincide con la puesta de huevos, algún tiempo después del apareamiento (Foelix, 2011).

La figura I.3 muestra un esquema de la anatomía interna de una araña.

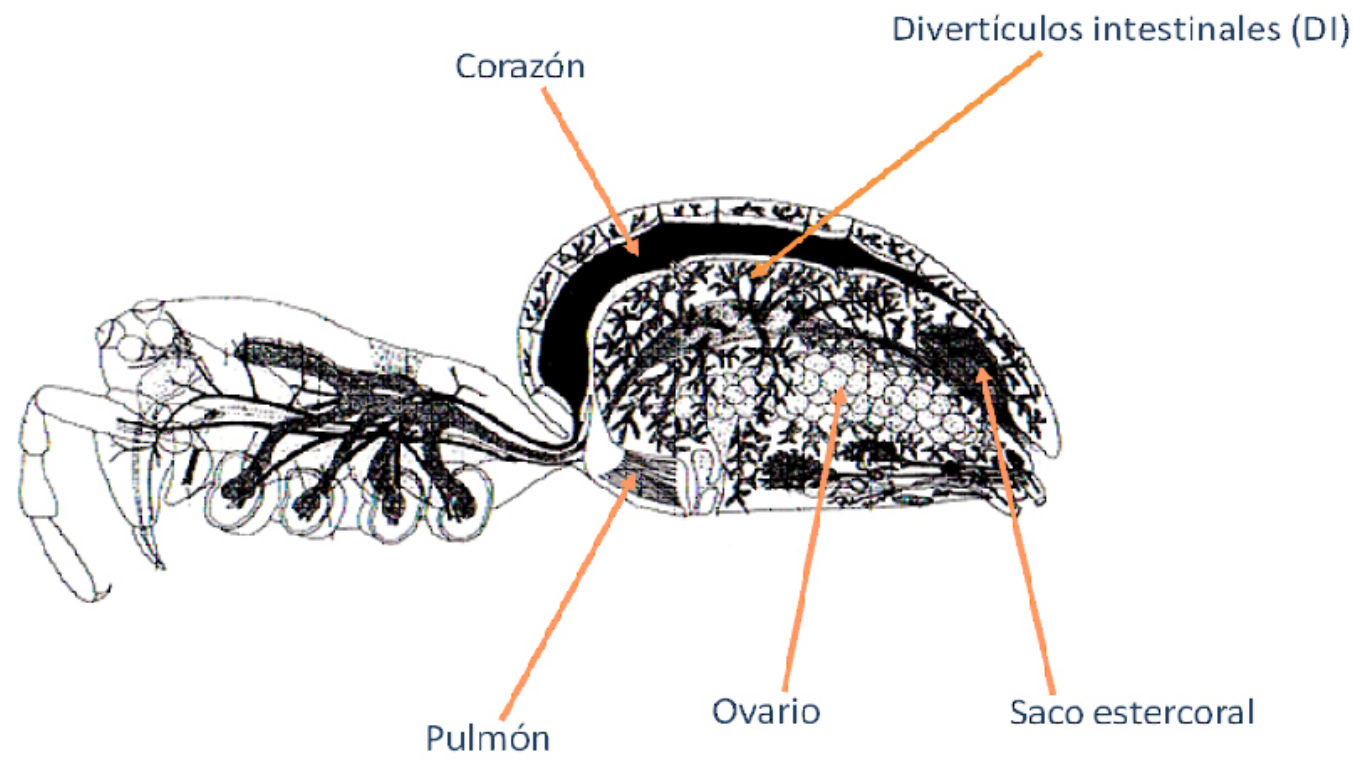

Figura l.3: Anatomía interna de una araña (Foelix 2011). 


\section{I.4. Polybetes pythagoricus (Holmberg, 1875)}

Se eligió esta especie como modelo de estudio por ser abundante y de fácil captura, manipulación y mantenimiento.

Es un género perteneciente al Suborden Opistothelae, Infraorden Araneomorphae, Familia Sparassidae, exclusivamente sudamericano, abundante en regiones tropicales y subtropicales. Se halla distribuido en Chile, Bolivia, Brasil, Paraguay, Uruguay y Argentina hasta la provincia de Río Negro, (GBIF: Global Biodiversity Information Facility) (Fig. I.4).

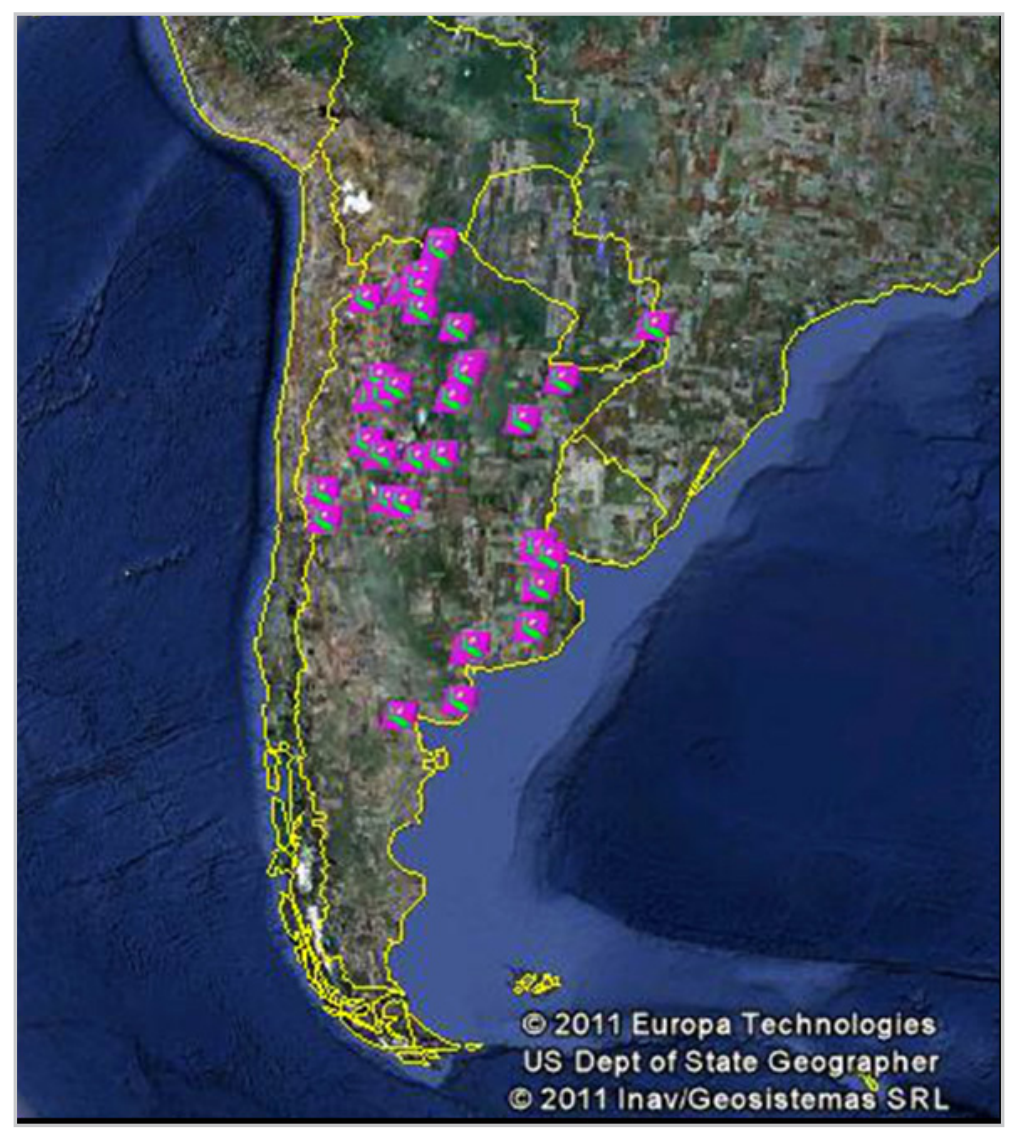

En la Argentina posee una gran popularidad que se manifiesta con su presencia en una estampilla nacional (Fig. I.5).

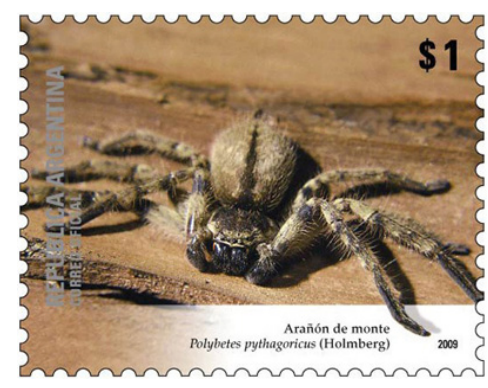

Figura I.4: Distribución geográfica de Polybetes pythagoricus (GBIF: Global Biodiversity Information Facility).
Figura 1.5: Estampilla nacional ilustrada con la imagen de $P$. pythagoricus emitida por el correo central de la República Argentina. Tirada de 80.000 ejemplares del 25 de julio de 2009. Foto: S. Enrietti, texto: C. Scioscia. 
Es una araña de hábitos nocturnos, durante el día se la suele encontrar debajo de la corteza de los árboles, principalmente eucaliptos, y en aleros de las casas. Presenta glándulas de veneno voluminosas, con un veneno de poca toxicidad que produce en el hombre molestias pasajeras con una doble acción local y neurotóxica, ambas débiles. Es una especie agresiva que muerde con facilidad si es molestada. Su enemigo natural es una avispa, conocida como avispa colorada, que deposita sus huevos en el opistosoma de la araña que sirve de alimento a las larvas.

Polybetes pythagoricus presenta como rasgo distintivo una gran mancha negra, en sentido longitudinal, en la zona ventral del opistosoma que se extiende hasta la región epigástrica (Gersschman \& Schiapelli, 1965) (Fig. I.6).

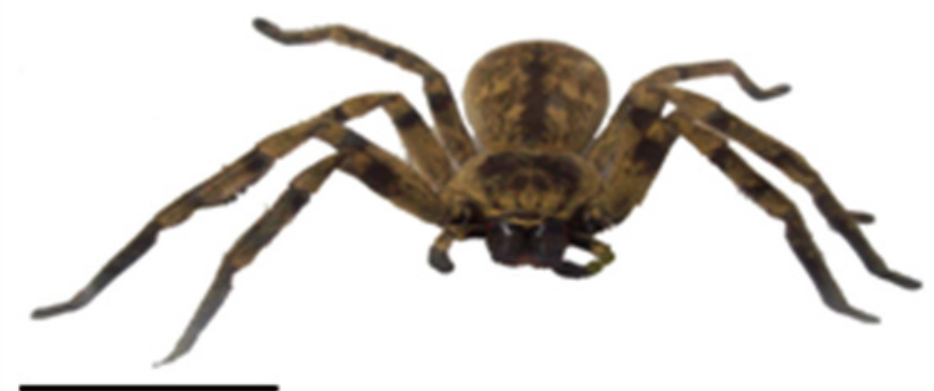

Figura I.6: Ejemplar de Polybetes pythagoricus. Vista dorsal y ventral.

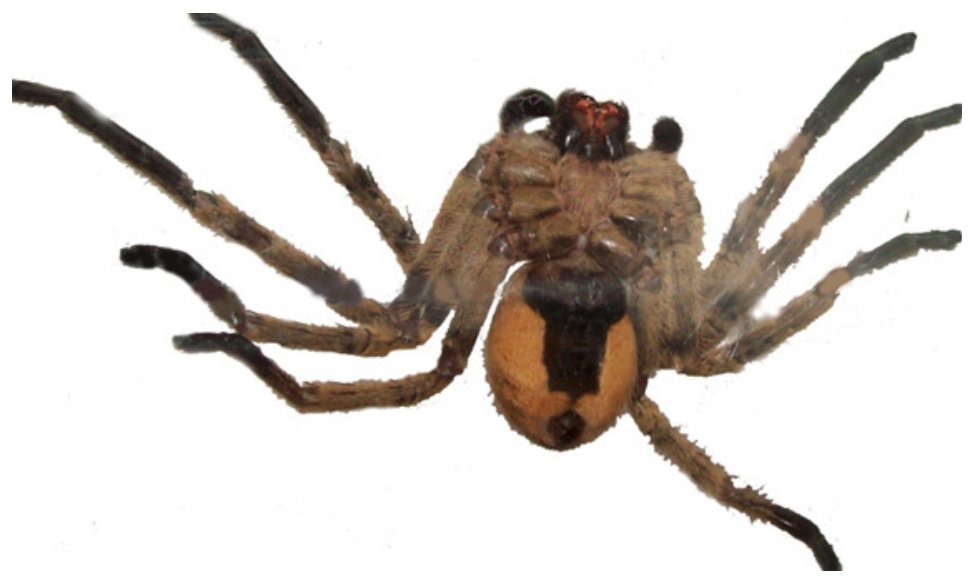

P. pythagoricus no construye nido. La ooteca de color blanco níveo, mide de 2 I a $30 \mathrm{~mm}$ de diámetro y tiene la forma de un disco plano-convexo. El piso es convexo, formado por varias capas de hilos, de las cuales las más externas constituyen una cubierta algodonosa. El techo es plano, integrado también por varias capas, y se muestra liso y ligeramente brillante. El piso y el techo se unen en la circunferencia del disco, por simple yuxtaposición y luego se prolongan hacia afuera, en un reborde a partir del cual numerosos hilos fijan la ooteca a la pared. Estos hilos, fuertes y no adherentes, se entrecruzan en una malla abierta 
y a través de sus orificios la araña pasa las patas rodeando a la ooteca por la cara inferior, de modo que, aunque la ooteca se encuentra en una posición fija, está suspendida en el aire. La araña defiende fieramente su puesta, balanceándose de uno a otro lado en forma intimidatoria y atacando si el enemigo está próximo. Si alguna presa pasa lo suficientemente cerca, la captura y la come, pero sin alejarse de la ooteca (Galiano, I97 I) (Fig. I.7).

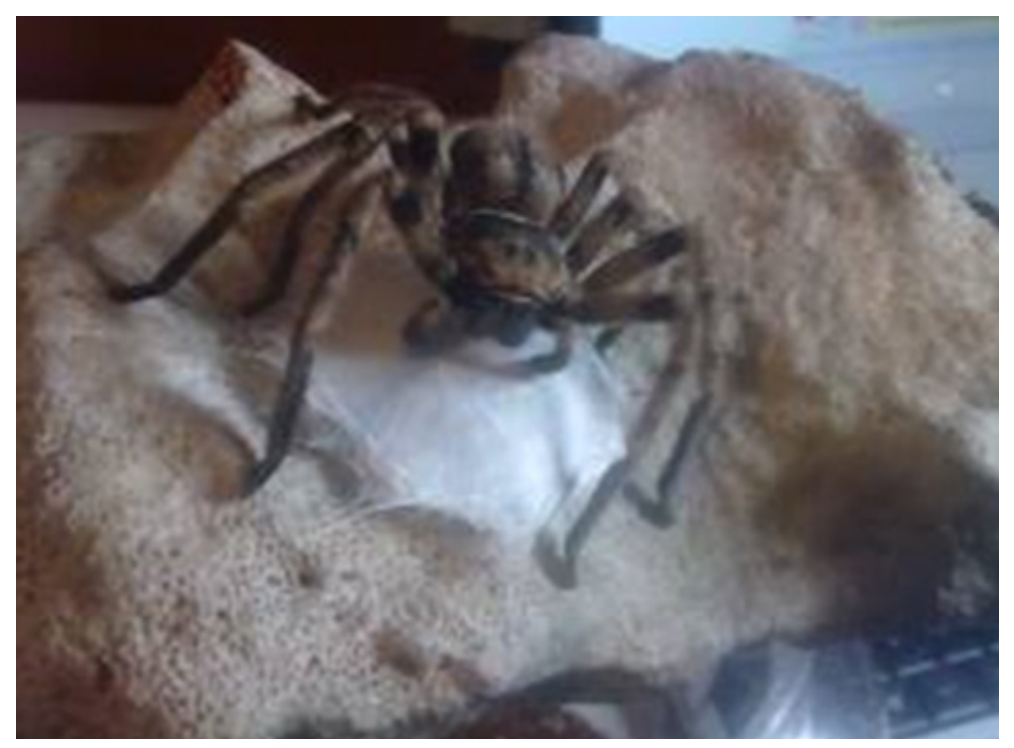

\section{I.5. Generalidades sobre la composición química de la hemolinfa de arañas}

Solo se ha descripto la composición química de la HL en pocas familias de arañas, entre ellas Sparassidae, Pisauridae, Amaurobiidae, Theraphosidae, Ctenizidae, Lycosidae, Araneidae y Agelenidae.

Entre los iones inorgánicos, el sodio y los cloruros son los componentes osmóticamente activos más abundantes, y en menores concentraciones, potasio, calcio, magnesio y fosfatos. La concentración de proteínas totales en la HL varía según la especie entre 8 y $66 \mathrm{mg} / \mathrm{ml}$, encontrándose como proteína plasmática más abundante a la hemocianina. Entre los aminoácidos, la prolina, aminoácido para el cual se ha sugerido un rol bioenergético, representa el 35\% del total (Punzo, 1983). La concentración total de ácidos grasos libres (AGL) en La HL varía entre 51 y $580 \mu \mathrm{g} / \mathrm{ml}$ (Punzo, 1983). La glucosa fue encontrada como el principal carbohidrato circulante (Schartau \& Leidescher, 1983). El pH de la HL varía desde 7,25 en Dugesiella sp. a 7,8 en Eurypelma californicum.

\section{I.6. Mecanismos de circulación de lípidos}

Debido a su carácter hidrofóbico, los lípidos no pueden circular libremente en un medio acuoso. De manera que para poder ser transportados desde
Figura I.7: Ejemplar hembra de $P$. pythagoricus con su ooteca. 
el tejido de origen hasta el de utilización o almacenamiento, se asocian con proteínas (Llamadas apolipoproteínas) formando agregados moleculares llamados Lipoproteínas.

Existe gran cantidad de información disponible con respecto a las lipoproteínas de vertebrados. En general, son agregados esféricos con un núcleo central donde se encuentran los lípidos hidrofóbicos, como triacilglicéridos (TAG) y esteroles esterificados, además de los aminoácidos hidrofóbicos de las apoproteínas, mientras que en la superficie se ubican los lípidos más polares, como los fosfolípidos (PL) y colesterol, y cadenas laterales hidrofílicas de aminoácidos de las apoproteínas (Fig. I.8). Los componentes proteicos de estos agregados moleculares cumplen dos funciones generales: solubilizar lípidos hidrofóbicos y contener señales para las células diana.

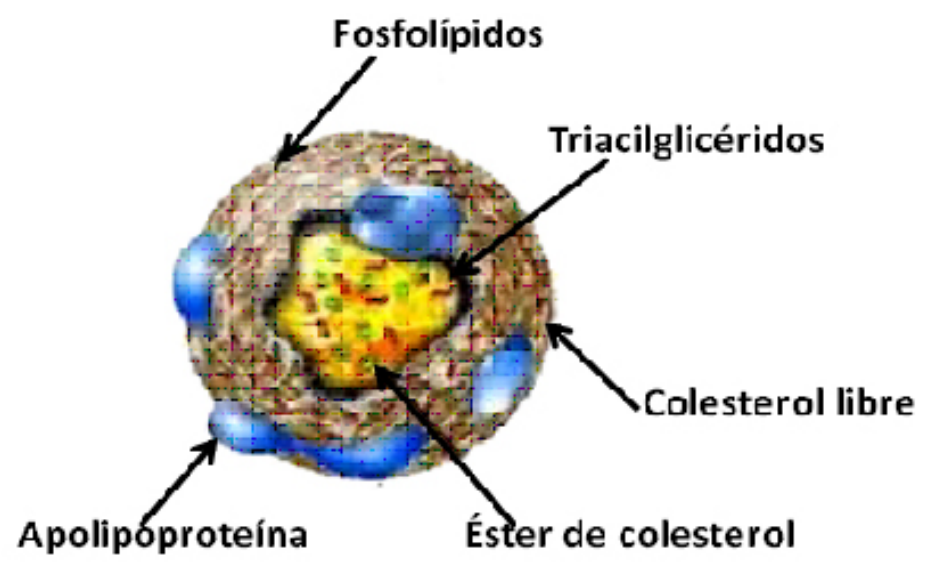

Distintas combinaciones de lípidos y proteínas originan partículas lipoproteicas de diferentes densidades de hidratación, que pueden ser separadas por ultracentrifugación. Esas diferentes combinaciones dan lugar a los quilomicrones, partículas de gran volumen con densidad inferior a $0,95 \mathrm{~g} / \mathrm{ml}$, a lipoproteínas con densidades entre 0,95 y l,006 g/ml llamadas de muy baja densidad (VLDL), otras con densidades entre 1,006 y $1,06 \mathrm{~g} / \mathrm{ml}$ de baja densidad (LDL), y aquellas con densidades entre 1,06 y l,2 $1 \mathrm{~g} / \mathrm{ml}$ son las de alta densidad (HDL). A medida que aumenta la densidad, aumenta la relación proteína/Lípido. Las lipoproteínas aseguran el transporte de lípidos tales como AGL, monoacilglicéridos (MAG), diacilglicéridos (DAG), TAG, varias especies moleculares de PL, esteroles libres y esterificados, hidrocarburos, glicolípidos y diferentes pigmentos como por ejemplo, carotenoides.

\section{I.7. Lipoproteínas en invertebrados}

Las lipoproteínas han sido detectadas en $\mathrm{HL}$, Líquido celómico, o vitelo de los siguientes filum de invertebrados: Arthropoda, Echinodermata, Annelida, Mollusca y Sipunculida. Los grupos de invertebrados más estudiados con res-
Figura I.8: Estructura general de una lipoproteína. 
pecto a las lipoproteínas plasmáticas son los insectos y crustáceos, mientras que en los quelicerados, la cantidad de información disponible es escasa.

\section{I.7. 1. Lipoproteínas circulantes no ligadas al sexo}

La HL libre de células y el fluido celómico de los invertebrados posee, con pocas excepciones, muy bajas concentraciones de lípidos, que al igual que en los vertebrados son transportados por lipoproteínas hidrosolubles, que se pueden separar por ultracentrifugación siguiendo la nomenclatura antes mencionada. El término lipoproteínas no ligadas al sexo, hace referencia a las lipoproteínas presentes en machos y hembras a lo largo de toda su vida, y a las cuales se les atribuye la circulación de lípidos a todos los tejidos, de manera independiente de las alteraciones fisiológicas generadas en las hembras en estado reproductivo.

Las primeras pruebas concluyentes sobre la existencia de un sistema de transporte de lípidos hemolinfáticos en el filum Mollusca, las constituyen los trabajos realizados en el bivalvo Diplodon delodontus (Pollero \& Heras, 1989; Pollero, 1987), donde se detectaron y caracterizaron tres lipoproteínas, de muy alta, alta y baja densidad. También en este bivalvo se comprobó la importancia de los hemocitos en el transporte de TAG, y en menor medida, colesterol y PL (Pollero et al., 1985).

En cefalópodos se realizaron estudios detallados de la composición y transporte de lípidos solo en la especie Octopus tehuelchus (Heras \& Pollero, 1992; Heras \& Pollero, 1990), donde se caracterizaron tres lipoproteínas plasmáticas, LPI (LDL), LPII (HDL) y LPIII (VHDL). LPIII transporta mas de la mitad de los lípidos circulantes, y su única apolipoproteína es el monómero del pigmento respiratorio hemocianina, mientras que LPI y LPII presentan además otros polipéptidos en su composición apolipoproteica. Los principales lípidos transportados son colesterol libre y PL. Resultó novedoso en este organismo el hecho de que el pigmento respiratorio hemocianina intervenga en el transporte de lípidos.

En el gasterópodo Pomacea canaliculata se pudieron detectar dos fracciones lipoproteicas plasmáticas, para las cuales se descartó la presencia de hemocianina (Garín \& Pollero, 1995).

En el caso de los crustáceos, se ha reportado la presencia de lipoproteínas hemolinfáticas en numerosas especies pertenecientes a diferentes órdenes. Presentan una lipoproteína con características de HDL, común a ambos sexos, con fosfatidilcolina (PC) como lípido predominante, junto a cantidades menores de colesterol y TAG, que además, generalmente contiene carotenoides. Estudios de microscopía electrónica, revelaron que en Palinurus interruptus la forma de estas partículas sería discoidal, con diámetros de 122 a $170 \AA$ (Lee \& Puppione, 1978). En los crustáceos marinos Charybdis feriata y P. japonicus, Las Lipoproteínas poseen densidades de 1,16 y $1,18 \mathrm{~g} / \mathrm{ml}$ respectivamente. Densidades 
del mismo orden fueron encontradas en el decápodo Machobrachium rosenbergii $(1,13 \mathrm{~g} / \mathrm{ml})$, en el cangrejo Eriocher japonica, $(1,16 \mathrm{~g} / \mathrm{ml}$ ) y en Pacifastacus leniuscus ( $1,145 \mathrm{~g} / \mathrm{ml}$ ) (Hall et al., 1995). En todos estos casos los lípidos predominantes fueron los PL (Komatsu et al., 1993). En el camarón Macrobrachium borellii se describió una HDL de $1,13 \mathrm{~g} / \mathrm{ml}$ de densidad, con un $36 \%$ de lípidos siendo los PL los predominantes (Garcia et al., 2002a).

En la mayoría de las especies de insectos examinados, se ha identificado una lipoproteína que no está ligada al sexo, específicamente involucrada en el transporte de DAG (Lípido cuantitativamente más importante en la HL de insectos) desde el cuerpo graso a los sitios de utilización. Chino y colaboradores ( 1981 ) denominaron a esta Lipoproteína "Lipoforina”. Una de las características de las lipoforinas que las distingue de las lipoproteínas de mamíferos, es el tiempo durante el cual permanecen en circulación. Mientras que las lipoproteínas de mamíferos se catabolizan en el transcurso de unas pocas horas, las lipoforinas, según se demostró a través del estudio de sus apoproteínas, poseen vidas medias del orden de los 3 o 4 días. En este tiempo recambian varias veces el contenido de alguno de sus componentes, como por ejemplo el de DAG, que son utilizados directamente para la producción de energía.

Las lipoforinas son macromoléculas de alto peso molecular, entre 500 y 800 kDa, de estructura globular con un diámetro de 12-17 nm (Shapiro et al., 1988). Se asume que tienen un core hidrofóbico compuesto principalmente por hidrocarburos y DAG, y una superficie compuesta de apoproteínas, PL y pequeñas cantidades de esteroles y DAG (Soulages \& Brenner, 1991). Dada la densidad de hidratación relativa de las lipoforinas, con un rango entre 1,09 y 1,17 g/ml, se las ubica en la clasificación como HDL. La proporción de lípidos varía según las especies entre 34,2 y $51,4 \%$ de la masa total de la lipoforina. Comparadas con Lipoproteínas de vertebrados, las lipoforinas muestran una virtual ausencia de TAG y colesterol esterificado, así como también un bajo contenido de esteroles libres. Los PL más comunes son PC y PE, siendo este último el mayoritario, aunque también pueden aparecer ciertas cantidades de esfingomienlina y en muy pocos casos se ha encontrado fosfatidilinositol (Soulages \& Wells, 1994b). Las lipoforinas contienen dos apoproteínas, apoLP-I con un peso molecular de aproximadamente 230-250 kDa, asociada a carbohidratos, y una apoLP-II de 70-85 kDa de peso molecular.

Haunerland y Bowers ( 1987 ), reportaron por primera vez en quelicerados la presencia de dos Lipoproteínas hemolinfáticas en la araña Eurypelma californicum. Una de ellas, es una HDL con las mismas características lipídicas y apoproteicas que las lipoforinas de insectos, que fue llamada con el mismo nombre. Esta lipoproteína tiene una densidad de $1,12 \mathrm{~g} / \mathrm{ml}$, con 44\% de lípidos y $56 \%$ de proteínas. Posee un peso molecular de 450-500 kDa, con dos apoproteínas, la apoLP-I (250 kDa) y la apoLP-II (80 kDa), ambas glicosiladas. Transportan principalmente DAG y PL. La otra Lipoproteína es una VHDL, con una densidad de I,28 
$\mathrm{g} / \mathrm{ml}$. En su estructura presenta un 8\% de lípidos, principalmente PL y TAG, con cantidades menores de AGL, MAG y DAG. Tiene un peso molecular de 220 kDa, compuesta por dos subunidades de 120 y 105 kDa respectivamente. Un estudio posterior fue realizado por los mismos autores (Haunerland \& Bowers, 1989) en otros grupos de quelicerados como escorpiones, solpúgidos, y ácaros, que en todos los casos presentaron una lipoforina similar a la de E. californicum. En el año 2000 Cunningham y colaboradores reportaron la presencia de dos lipoproteínas hemolinfáticas en la araña Latrodectus mirabilis, una HDL I que transporta el 80,4\% de los Lípidos hemolinfáticos, y una HDL2 con hemocianian como apoLipoproteína (Cunningham et al., 2000).

En la especie Polybetes pythagoricus, modelo de estudio de este trabajo de tesis, se han aislado y caracterizado 3 lipoproteínas hemolinfáticas, las cuáles serán tratadas en detalle más adelante.

\section{I.7.2. Lipoproteínas circulantes ligadas al sexo (vitelogeninas) y lipovi- telinas}

En las especies ovíparas, aquellas en las cuales las hembras ponen huevos, de manera que el embrión se desarrolla fuera del cuerpo de la madre, es necesario que el vitelo esté provisto de proteínas, lípidos y carbohidratos que actúen como recursos energéticos y de materiales para el embrión en desarrollo. En aquellos animales con huevo esencialmente cleidoico (provistos de una cubierta o cáscara que los aísla del exterior excepto por el intercambio gaseoso) este vitelo, es el único recurso de nutrientes durante la embriogénesis (Kunkel \& Nordin, 1985).

En invertebrados, la mayoría de las proteínas hidrosolubles de huevos se denominan vitelinas $(V t)$, éstas, se asocian con lípidos y carbohidratos, dando lugar a la formación de lipoproteínas que también cumplen con las necesidades metabólicas de la larva hasta que pueda alimentarse de recursos externos. Las Lipoproteínas de alta densidad encontradas en huevos de invertebrados fueron Llamadas lipovitelinas (LV) (Wallace et al., 1967), en relación a las lipoproteínas de huevo de vertebrados que llevan el mismo nombre. También se denominan LV, las lipoproteínas presentes en los ovarios de los mismos organismos. Por otro lado, las hembras en estado vitelogénico, suelen presentar en HL, Lipoproteínas específicas, cuya estructura puede ser similar o idéntica a la de sus LV. Estas Lipoproteínas específicas de sexo se denominan vitelogeninas (Vg).

La formación de vitelo, un proceso que se conoce con el nombre de vitelogénesis, involucra en muchos invertebrados la síntesis masiva de Vg, que pueden ser una o más de una proteína, que luego de modificaciones postraduccionales, da lugar a Vt o LV que se depositan en los oocitos (Lee, 1991).

Según su sitio de síntesis las $V g$ pueden tener un origen autosintético: cuando se sintetizan en ovario y oocitos, ó, heterosintético: cuando se producen en tejidos extraováricos, tales como hígado en vertebrados (Byrne et al., 1989), 
intestino en nematodes (Sharrock, 1983) y cuerpo graso en insectos (Sappington \& Raikhel, 1998).

La importancia del estudio de las LV se ha ido incrementando estos últimos años por su relación con otras lipoproteínas y por tener un rol clave en las estrategias reproductivas de invertebrados. En este sentido Baker ( 1988 ) determinó que las Vg de invertebrados (nematodes e insectos) contienen dominios homólogos con proteínas humanas como la apoB-100 de la LDL y la lipasa. Más tarde, Babin y col. ( 1999), agruparon a Vt y $\vee g$ en una superfamilia de proteínas transferidoras de lípidos (LLTP), la cual contiene proteínas de vertebrados e invertebrados involucradas en el transporte extra e intracelular de lípidos y sustancias liposolubles. Existen variaciones entre los distintos grupos de animales en cuanto al origen y a las características bioquímicas de estas lipoproteínas.

En anélidos se han realizado trabajos en hirudineos y poliquetos. Con respecto a los primeros, Baert y colaboradores ( 1991 ), describieron para Theromyzon tessulatum una lipoglicoproteína aislada de oocitos, de 490 kDa con 1,9\% de carbohidratos y $24 \%$ de lípidos que definieron como vitelina; y una lipoglicoproteína aislada de fluido celómico, definida como Vg, de 520 kDa con 2,4\% de carbohidratos y $31,8 \%$ de lípidos. En cuanto a los poliquetos, se ha descripto la presencia de Lipoproteínas de huevos en Perinereis cultrifera. Los huevos de esta especie contienen una LV con 16\% de lípidos y cinco péptidos (Lee, 1991). Tanto en esta especie como en Nereis virens se sugirió que la Vg sería sintetizada en células celómicas especializadas (García-Alonso et al., 2006; Bonnier et al., 1991; Baert \& Slomianny, 1987), mientras que la Vg de Phragmatopoma lapidosa tendría un origen tanto autosintético como heterosintético (Eckelbarger, 1979).

Los huevos de erizos de mar poseen principalmente lipoproteínas de baja densidad. En Hemicentrorus pulcherrimus, se reportaron LV de I,03 a I,06 g/ml, en los gránulos de vitelo dentro del oocito (Lee, 1991).

En moluscos se han aislado LV (generalmente HDL) en el bivalvo Pecten maximus, con un 15\% de lípidos y en el cefalópodo Sepia oficialis, con un 19\% de Lípidos, en su mayoría PL (Zagalsky et al., 1967; Fuji, 1960).

Lubzens y colaboradores (Lubzens et al., 1997) determinaron en el crustáceo P. semisulcatus (empleando anticuerpos anti-LV), que tanto la Vg como la lipovitelina están compuestas por tres apolipoproteínas de 20, 120 y 80 kDa. También determinaron que la síntesis de $\mathrm{Vg}-\mathrm{LV}$ aparentemente ocurre en el ovario y en menor medida en el hepatopáncreas. Los crustáceos decápodos presentan en sus huevos LV de alta o muy alta densidad (HDL o VHDL, respectivamente), formadas por 27 a 32\% de lípidos. El anostraco Artemia salina, tiene un contenido lipídico relativamente bajo (9\%) en sus LV, Las que aparecen en forma de gránulos de vitelo dentro del oocito. La clase lipídica predominante es la de los PL, y dentro de éstos PC. También contiene cantidades menores de TAG y colesterol. Los ésteres de colesterol generalmente están ausentes o se presentan en trazas. Además de lípidos y proteínas, suele encontrarse un 3 a $4 \%$ 
de carbohidratos (de Chaffoy de Courcelles \& Kondo, 1980). En el camarón de agua dulce Macrobrachium borellii, se aisló una LV de citosol de huevos de 440 kDa con un 23\% de lípidos, principalmente PL (Garcia et al., 2004). Se estudió además que contiene un $35,7 \%$ de $\alpha$-hélice, un $16,6 \%$ de lámina $\beta$, un $20,7 \%$ de giros y $26,9 \%$ de estructura desordenada (Garcia et al., 2006).

Las $\mathrm{Vg}$ de insectos generalmente se secretan a la $\mathrm{HL}$ como dímeros de 400-600 kDa (Tufail \& Takeda, 2008), todas se encuentran glicosiladas y en su mayoría altamente fosforiladas (Tufail et al., 2005; Giorgi et al., 1998; Takahashi, 1987). En este grupo, las Vg son sintetizadas en los ribosomas asociados al retículo endoplasmático, transferidas al aparato de Golgi y eventualmente empaquetadas en gránulos secretorios que emergen de la red trans-Golgi (Giorgi et al., 1998; Snigirevskaya et al., 1997; Mazzini et al., 1989; Giorgi et al., 1989). A Lo largo de la ruta secretoria, la Vg es modificada postraduccionalmente por glicosilación (Giorgi et al., 1998; Osir et al., 1986; Kunkel et al., 1980), fosforilación (della Cioppa \& Engelmann, 1987; Takahashi, 1987; Brennan \& Mahowald, 1982) y sulfatación (Dhadialla \& Raikhel, 1990; Bauerle \& Huttner, 1985). Luego de ser clivada y modificada de manera que facilite el transporte de hidratos de carbono, lípidos y otros nutrientes a los ovarios (Tufail et al., 2005; Sappington et al., 2002; Giorgi et al., 1999; Hagedorn et al., 1998; Raikhel \& Dhadialla, 1992), es secretada a la HL y captada por los oocitos por endocitosis mediada por receptor (Snigirevskaya \& Raikhel, 2005; Sappington \& Raikhel, 1998; Raikhel \& Dhadialla, 1992). Además de las Vg, un número de proteínas hemolinfáticas son endocitadas por el oocito durante la vitelogénesis. Estas incluyen, lipoforinas (Machado et al., 1996), arylforinas (Telfer et al., 1983), microvitelogeninas (Kawooya et al., 1986), y varias otras proteínas específicas de folículo (Sato \& Yamashita, 1991).

En ácaros, la Vg es sintetizada extraováricamente, dependiendo de la familia, puede ser sintetizada en cuerpo graso, intestino y/u ovario (Chinzei \& Yano, 1985; Coons et al., 1982; Araman, 1979), para luego ser liberada a la HL y transportada al ovario donde es selectivamente captada por los oocitos y almacenada como vitelina (Coons et al., 1982; Diehl et al., 1982). En la garrapata Ornithodoros moubata, las células del cuerpo graso asociadas al sistema traqueal sintetizan el $46 \%$ del total de Vg (Chinzei \& Yano, 1985). En este orden se han caracterizado $\mathrm{Vg}$ y $\mathrm{Vt}$, de varias especies. Se trata de complejos hemo-glicolipo-fosfo-proteínas, una estructura principalmente dada en relación con sus hábitos hematófagos. Su composición lipídica y glucosídica es bastante similar a una vitelina de insectos (Boldbaatar et al., 2010; James \& Oliver, Jr., 1997; Rosell \& Coons, 1992; Schriefer, 1991; Shanbaky et al., 1990; Dhadialla, 1986; Chinzei et al., 1983; Boctor \& Kamel, 1976; Tatchell, I97 I). Recientemente se ha caracterizado en el ácaro Tetrarrynchus urticae una vitelina que une débilmente lípidos y carbohidratos (Cabrera et al., 2009). En el Orden Araneae la información es muy escasa, solo se ha descripto una posible apovitelina presente en ovario y huevos de la araña Tegenaria atrica (Pourié \& Trabalon, 2003). 


\section{I.8. Sistema de transporte de lípidos en la araña Polybetes pythagoricus}

El sistema de transporte lipídico de la araña P. pythagoricus, ha sido estudiado, aislando y caracterizando a nivel de sus composiciones proteica y lipídica, 3 lipoproteínas: dos HDL llamadas HDL I ( $\delta=1,13 \mathrm{~g} / \mathrm{ml}$, 28\% de lípidos peso húmedo) y HDL2 ( $\delta=1,18-1,20 \mathrm{~g} / \mathrm{ml}, 3,6 \%$ de lípidos peso húmedo) y una VHDL ( $\delta=1,21-1,24 \mathrm{~g} / \mathrm{ml}, 3,55 \%$ de lípidos peso húmedo), presentando concentraciones hemolinfáticas de 2,3; 23,6 y 45,4 mg lipoproteína/ml, respectivamente. Los lípidos circulantes en P. pythagoricus $(3,41 \mathrm{mg} / \mathrm{mL} \mathrm{HL})$ son transportados entonces por HDLI (26,2\%), HDL2 (25,1\%) y VHDL (48,7\%) (Cunningham \& Pollero, 1996; Cunningham et al., 1994).

HDL I es una lipoproteína similar a la lipoforina de insectos en relación a su tamaño y composición de subunidades (ambas contienen apolipoproteínas de 250 y 80 kDa), aunque con relación a la composición lipídica, HDL I transporta principalmente TAG y PL, y en cambio la lipoforina, transporta en su mayoría DAG. En este sentido, la lipoproteína de P. pythagoricus es similar a la HDL de crustáceos (Garcia et al., 2002a; Cunningham et al., 1994). HDL2 y VHDL transportan principalmente TAG y PL y presentan una coloración gris azulada dada por su alto contenido de hemocianina asociada ( 18,9 y $36,3 \mathrm{mg} / \mathrm{ml}$ de HL respectivamente) (Cunningham \& Pollero, 1996; Cunningham et al., 1994). Ambas presentan una subunidad de 70 kDa correspondiente al monómero de hemocianina y dos bandas de 105 y 121 kDa, que según lo reportado por Cunningham y colaboradores ( 1996 ) serían proteínas "no respiratorias", siendo más abundantes en VHDL que en HDL2. Esta función del pigmento respiratorio hemocianina como transportador de lípidos (Cunningham et al., 2000; Cunningham \& Pollero, 1996), se suma a la que ha sido demostrada en cefalópodos (Heras \& Pollero, 1992; Heras \& Pollero, 1990), y a lo reportado en el crustáceo Pacifastacus leniusculus, donde se encontró que un $17 \%$ de los lípidos hemolinfáticos unidos a proteínas están asociados a hemocianina (Hall et al., 1995). La posibilidad de que los lípidos de VHDL sean solo estructurales, fue descartada en un trabajo previo donde se demostró que la partícula no pierde estabilidad, ni sufre alteraciones estructurales luego de la deslipidización (Cunningham et al., 2006).

\subsection{Rol de las lipoproteínas y divertículos intestinales (DI) en la diná- mica de lípidos en artrópodos}

En el filum Arthropoda se ha estudiado ampliamente el rol de las lipoproteínas en la dinámica de lípidos en insectos y crustáceos. En insectos se transfieren principalmente DAG desde el cuerpo graso a partículas de lipoforina preexistentes localizadas en la $\mathrm{HL}$ que luego pueden liberar los lípidos a otros tejidos (Arrese et al., 2001 a; Blacklock \& Ryan, 1994; Soulages \& Wells, 1994b). Una característica particular del transporte de lípidos en insectos, es la especificidad con la que se liberan los lípidos a los tejidos, de manera que la misma molécula de lipoforina puede entregar selectivamente DAG al cuerpo 
graso, e hidrocarburos y carotenoides a la cutícula en Manduca sexta, (Arrese et al., 2001 a). Otra característica importante de la lipoforina de insectos, es que funciona como una partícula reutilizable. El recambio de DAG se produce a un ritmo mucho mayor que los componentes proteicos (Downer, 1985), además la lipoforina es capaz de entregar sus lípidos neutros sin perder su estructura proteica (Tsuchida \& Wells, 1988). En cuanto al mecanismo de transferencia entre la lipoforina y los tejidos, se propuso que involucraría la captación de la lipoforina por un receptor y que la transferencia sería, o por difusión pasiva, o por acción activa de transportadores (Arrese et al., 2001 a).

En crustáceos, en quienes los lípidos también son transportados en $\mathrm{HL}$ por HDLs (Chang \& O Connor, 1983; Lee \& Puppione, 1978), se demostró la transferencia de diferentes lípidos ( $P L, A G L$ y TAG) desde y hacia la glándula digestiva, considerada como el principal órgano involucrado en el metabolismo de lípidos (Garcia et al., 2002b).

El rol del cuerpo graso en el metabolismo de lípidos en insectos, ha sido extensamente estudiado y revisado (Arrese et al., 200l a; Gilbert \& Chino, 1974; O'Connor \& Gilbert, 1968). Este órgano, análogo al tejido adiposo e hígado de vertebrados, sería el sitio de síntesis de proteínas hemolinfáticas, y el principal órgano de reserva de nutrientes como glucógeno (Beenakkers et al., 1985), y Lípidos, ya que almacena más del 90\% de los lípidos como TAG (Canavoso et al., 1998; Arrese \& Wells, 1997; Beenakkers et al., 1985; Downer, 1985). Se estudió que es capaz de transferir DAG y PL a la lipoforina (Coelho et al., 1997; Atella et al., 1995; Atella et al., 1992) y que tiene alta capacidad para incorporar AGL hemolinfáticos desde la lipoforina (Atella et al., 2000), de manera que, acorde a la situación metabólica puede incorporar o donar Lípidos. También se ha descripto la síntesis de ácidos grasos en el cuerpo graso de Aedes aegypti (Ziegler, 1997).

De manera similar la glándula digestiva de crustáceos está involucrada activamente en el metabolismo de lípidos, combinando las funciones de hígado, intestino, páncreas y tejido adiposo de mamíferos. Se propuso para este órgano que sería el sitio de síntesis de TAG (Lavarías et al., 2007; Lavarías et al., 2006; Garcia et al., 2002b; González Baró \& Pollero, 1993; González Baró et al., 1990; González Baró \& Pollero, 1988; Al-Mohanna \& Nott, 1986; Al-Mohanna et al., 1985).

\section{I.10. Hemocianina}

De los cuatro pigmentos respiratorios que existen en la naturaleza, hemoglobina, hemeritrina, clorocruorina y hemocianina, los arácnidos poseen solo hemocianina. Esta proteína plasmática transportadora de oxigeno se encuentra además de en algunos Artrópodos, en algunos Moluscos. A diferencia de las hemoglobinas, que pueden ser extra o intracelulares, las hemocianinas solo se encuentran en solución en la HL, con una concentración que varía considerablemente según la especie entre 0,3 y $120 \mathrm{mg} / \mathrm{ml}$. 
Son cuproproteínas de pesos moleculares muy elevados, con estructuras complejas y variadas, con los átomos de cobre ubicados de a pares, cada uno unido directamente a la proteína a través de las cadenas laterales de histidinas. La forma desoxigenada es incolora porque contiene $\mathrm{Cu}^{+1}$, y la oxigenada que contiene $\mathrm{Cu}^{+2}$, es de color azulada. $\mathrm{El}_{2}$ (que se encuentra como $\mathrm{O}_{2}{ }^{-2}$, pues hay transferencia completa de dos electrones del metal al $\mathrm{O}_{2}$ luego de su fijación), forma un puente entre los dos átomos de cobre.

El espectro de absorción de la hemocianina oxigenada muestra tres máximos: en 278 nm (aminoácidos aromáticos de la proteína), en 346 nm (banda del cobre) y en la región visible a $580 \mathrm{~nm}$. Las dos últimas bandas desaparecen al desoxigenarse (Nickerson \& Van Holde, 1971).

En artrópodos, la hemocianina se encuentra en crustáceos, arácnidos, merostomados, quilópodos y diplópodos, y está ausente en insectos. En moluscos está presente en las clases gasterópoda, poliplacófora, cefalópoda y solo en dos géneros de bivalvos (Van Bruggen, 1980).

También puede existir yuxtaposición de pigmentos respiratorios, como es el caso de gasterópodos y poliplacóforos que poseen hemocianina y hemoglobina en la rádula y otros órganos. Las hemocianinas de moluscos y artrópodos parecen haber evolucionado independientemente desde el período Cámbrico a partir de un antecesor común que sería una cuproproteína con un solo átomo de cobre. Comparten, además de la función de transportar oxigeno, la secuencia de aminoácidos del sitio activo. Esta secuencia es también coincidente con las de los centros activos de las enzimas tirosinasa, ascorbato oxidasa y ceruloplasmina (Drexel et al., 1987). Por lo tanto si bien no se excluye formalmente una antigua relación entre estas dos familias de proteínas, existe un gran número de sustituciones de aminoácidos y una posible divergencia al comienzo de la evolución de los metazoos (Burmester, 2001).

Esta proteína presenta in vitro una disociación característica hacia menores estados de agregación, en función de las variaciones de $\mathrm{pH}$, concentración de cationes, concentración proteica y fuerza iónica del medio. Por eso, en general, la presencia de $\mathrm{Ca}^{+2}$ y $\mathrm{Mg}^{+2}$, estabiliza la conformación nativa de la proteína. En el caso del decápodo Carcinus maenas se ha encontrado una pequeña cantidad de PL asociados a la hemocianina que estabilizan la estructura proteica (Zatta, 1981), así como también una posible unión entre la hemocianina y el zinc, podría estabilizar la estructura cuaternaria de la proteína en el isópodo Oniscus asellus (Rappa et al., 1992). Esta cuproproteína posee también hidratos de carbono unidos covalentemente al polipéptido, en una concentración que puede Llegar al $4 \%$ del peso de la molécula proteica.

Poco se sabe respecto al sitio y regulación de biosíntesis de la hemocianina. En cefalópodos, la síntesis se realiza durante toda la vida (Heras \& Pollero, 1990), en glándulas branquiales, que se encuentran suspendidas en la pared del manto. En el crustáceo Callinectes sapidus el sitio de síntesis es el hepatopán- 
creas (Rainer \& Brouwer, 1993). En arácnidos, y tal vez en el merostomado Limulus polyphemus, el lugar de síntesis de la hemocianina es en células especiales Llamadas cianocitos (Kempter, 1983).

\section{I.10.1. Estructura de la hemocianina en moluscos}

La hemocianina representa la principal proteína circulante, aproximadamente entre 90 y $98 \%$ en la HL de diferentes moluscos.

El peso molecular de las hemocianinas nativas varía entre $4,5 \times 10^{5}$ y $1,3 \times$ $10^{7}$ Daltons. Son cilíndricas huecas con un diámetro constante de $30 \mathrm{~nm}$ y con una longitud variable de 17,5 a $200 \mathrm{~nm}$, dependiendo de las especies (Fernández-Morán et al., 1966).

Las hemocianinas de cefalópodos y poliplacóforos tienen estructuras simples de 10 subunidades. Las subunidades o monómeros, que tienen pesos moleculares de 300 a $460 \mathrm{kDa}$, se agregan en estructuras de orden superior formando decámeros (Herkovits \& Hamilton, I 991). En todos los moluscos, los monómeros de hemocianina tienen múltiples dominios, ocho en gasterópodos y poliplacóforos y siete en cefalópodos. Cada dominio tiene un sitio de unión para el oxígeno y un peso molecular de 50-55 kDa (Linzen et al., 1985).

\section{I.10.2. Estructura de la hemocianina en artrópodos}

La hemocianina de artrópodos comparada con la de moluscos tiene una arquitectura molecular muy diferente. El peso molecular de la proteína nativa es de 500 a 3500 kDa según la especie. Están formadas por cadenas polipeptídicas pequeñas de 67 a $90 \mathrm{kDa}$, cada una de las cuales puede unir una molécula de oxígeno, mientras que una cadena polipeptídica de moluscos puede unir hasta 8 moléculas de oxígeno (Waxman, 1975). Estas subunidades polipéptidicas (monómeros) se ordenan en hexámeros $(1 \times 6)$ cúbicos, o múltiplos de hexámeros (dihexámeros: $2 \times 6$, tetrahexámeros: $4 \times 6$, hexahexámeros: $6 \times 6$, octahexámeros: $8 \times 6$ ). El nivel de agregación en la estructura cuaternaria es específico para cada especie, se han hallado otras combinaciones por disociación parcial o como productos de reensamblamiento como partículas de 19 y 7 subunidades (Markl, 1986).

Las subunidades de hemocianina de todos los artrópodos son heterogéneas con diferencias en la composición de aminoácidos y en el peso molecular. El número de subunidades diferentes aumenta con el tamaño de la molécula nativa. En artrópodos hay de dos a doce monómeros diferentes por molécula de hemocianina que se ensamblan manteniendo ciertas proporciones relativas. La mayoría de las subunidades son monoméricas pero también hay dímeros.

La hemocianina más pequeña aparece en el crustáceo Panulirus interruptus. Es un hexámero de 450 kDa, con 6 subunidades en la disposición antiprismática triangular. Todas las demás hemocianinas de artrópodos aparecen como moléculas multihexaméricas. En miriápodos se encuentran estructuras de hemocianinas de 6 hexameros (Jaenicke et al., 1999a). Estructuras de 2 hexámeros están pre- 
sentes en cangrejos, opiliones y en algunas arañas, de 4 hexámeros en otras arañas, escorpiones, uropígidos y amblipigidos. El merostomado Limulus polyphemus contiene 8 hexámeros. En la clase pignogónida, en ácaros y en solífugos no se ha encontrado hemocianina. Estos últimos poseen un buen desarrollo del sistema traqueal y probablemente no tengan necesidad de un pigmento respiratorio (Markl, 1986).

Con respecto a las arañas se ha estudiado con cierto detalle la estructura de la hemocianina en Eurypelma californicum y en Cupiennius salei. En la primera, la hemocianina representa el $80-82 \%$ de las proteínas hemolinfáticas y en la segunda el 75\%. Al disociar la hemocianina de tarántula aparece una mezcla de 6 monómeros de 67 a 76 kDa, y un dímero (la heterogeneidad se debe a diferencias tanto en la longitud de cadena como en la secuencia de aminoácidos). En C. salei el monómero es de 72 kDa (Markl, 1986).

\section{I.10.3. Hemocianina en Polybetes pythagoricus}

Como se mencionó anteriormente el sistema de transporte de lípidos de P. pythagoricus, está compuesto por tres lipoproteínas, dos de las cuales, HDL2 y VHDL, presentan hemocianina como principal apolipoproteína.

La cantidad y variedad de lípidos que presenta asociados la VHDL, la transformó en un interesante modelo para estudiar las interacciones entre lípidos y hemocianina. Cunningham y colaboradores (1999) han estudiado in vitro la capacidad de la hemocianina de pegar distintos lípidos, determinando que es capaz de unir una cantidad de lípidos significativamente superior a la observada in vivo, sugiriendo que sería una posible adaptación al transporte de distintas cantidades de lípidos hemolinfáticos, en respuesta a variaciones fisiológicas o ambientales. Además demostraron generando partículas lipoproteicas artificiales, que la hemocianina (apolipoproteína) muestra in vitro, diferentes afinidades por los distintos lípidos, que serían según orden creciente de afinidad: PC>colesterol>ácido graso.

- Teniendo en consideración los aspectos antes detallados, se plantea como hipótesis de trabajo para esta tesis los siguientes puntos:

- La partícula lipoproteica VHDL presenta una estructura compuesta por hemocianina y proteínas no respiratorias que le permite participar activamente en la dinámica de los lípidos circulantes.

- Las lipoproteínas hemolinfáticas son las encargadas del transporte de Lípidos, y de la captación y liberación, desde y hacia los divertículos intestinales. Estos últimos, son el principal órgano involucrado en el metabolismo lipídico, actuando como sitio de síntesis y almacenamiento de los mismos.

- Los huevos de Polybetes pythagoricus presentan en el vitelo, lipoproteínas encargadas de proveer al embrión de nutrientes, como lípidos, proteínas e hidratos de carbono, necesarios para el desarrollo. 
CAPITULO ||

Objetivos 


\section{Objetivos}

Como se ha comentado en la Introducción, en los últimos años han cobrado importancia, ciertas posibles aplicaciones del estudio de las arañas, que resultarían en un beneficio para el hombre.

Teniendo en cuenta la importancia que para tales aplicaciones, supone el conocimiento básico, a nivel estructural y funcional, se pretende avanzar en el estudio de aspectos bioquímicos y fisiológicos de una especie endémica de América del Sur, como la araña P. pythagoricus. Sobre esta especie ya se han realizado trabajos orientados a caracterizar sus lipoproteínas hemolinfáticas, que han permitido suponer ciertas funciones en el transporte de lípidos para las mismas.

En este sentido, los objetivos generales de este trabajo de tesis son: conocer en mayor profundidad la estructura de la partícula lipoproteica de muy alta densidad (VHDL), determinar el rol de los divertículos intestinales en el metabolismo y transporte de lípidos, y conocer la dinámica de este transporte en el sistema hemolinfático. Finalmente se pretende realizar una primera identificación y caracterización de lipoproteínas de huevo en arácnidos.

En particular se busca:

- Estudiar la conformación en estado nativo de VHDL.

- Estudiar su estructura secundaria.

- Evaluar la presencia/ausencia de puentes disulfuro, cobre y lípidos en su estructura.

- Buscar posibles homologías entre la estructura primaria de esta lipoproteína y las de otras especies, ya secuenciadas.

- Estudiar la composición lipídica de los DI.

- Evaluar la participación de los DI en el metabolismo lipídico, valorando la incorporación de precursores radioactivos administrados por distintas vías, en este órgano y otros tejidos.

- Estudiar la importancia de las lipoproteínas hemolinfáticas en el transporte de lípidos desde y hacia los DI.

- Estudiar diferencias y similitudes de las lipoproteínas, en la dinámica de los lípidos circulantes, a nivel cuali y cuantitativo.

- Evaluar el posible intercambio de lípidos entre lipoproteínas.

- Aislar lipoproteínas de huevo.

- Estudiar su forma y tamaño.

- Caracterizar estas lipovitelinas en cuanto a su composición proteica, lipídica y de hidratos de carbono.

- Determinar su posible relación con las lipoproteínas hemolinfáticas. 


\section{Materiales y Métodos}




\section{Materiales y Métodos}

\section{1. Reactivos, drogas y solventes}

El precursor radiactivo, ácido palmítico ${ }^{1}-{ }^{14} \mathrm{C}(57,0 \mathrm{mCi} / \mathrm{mmol}$, pureza 99\%), fue provisto por Amersham.

Los solventes utilizados fueron Merck (calidad pro-análisis), Darmstadt, Alemania, y Carlo Erba (grado RPE), Milán, Italia.

Los estándares de lípidos fueron provistos por Sigma Chemical Co.

Todos los lípidos utilizados y demás drogas detalladas posteriormente, fueron de grado analítico.

\section{III.2. Muestreo, mantenimiento y disecciones de Polybetes pythagoricus}

III.2.1. Ubicación y descripción de la zona de muestreo

Los ejemplares de Polybetes pythagoricus fueron colectados en montes de eucaliptos (Eucalyptus sp.), principalmente del parque Martín Rodríguez

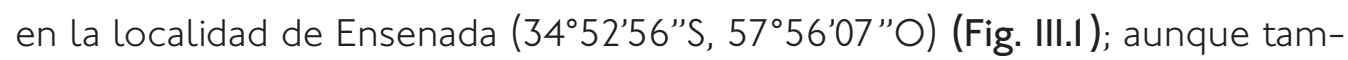
bién se realizaron muestreos en el parque Pereyra Iraola, (Berazategui-La Plata)

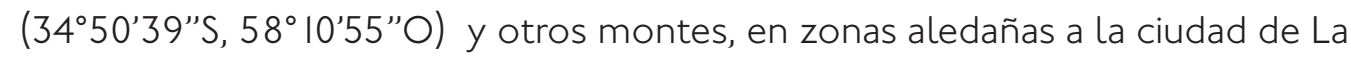
Plata. Se utilizaron aproximadamente 150 arañas colectadas en todas las épocas de año entre 2006 y 2011 .

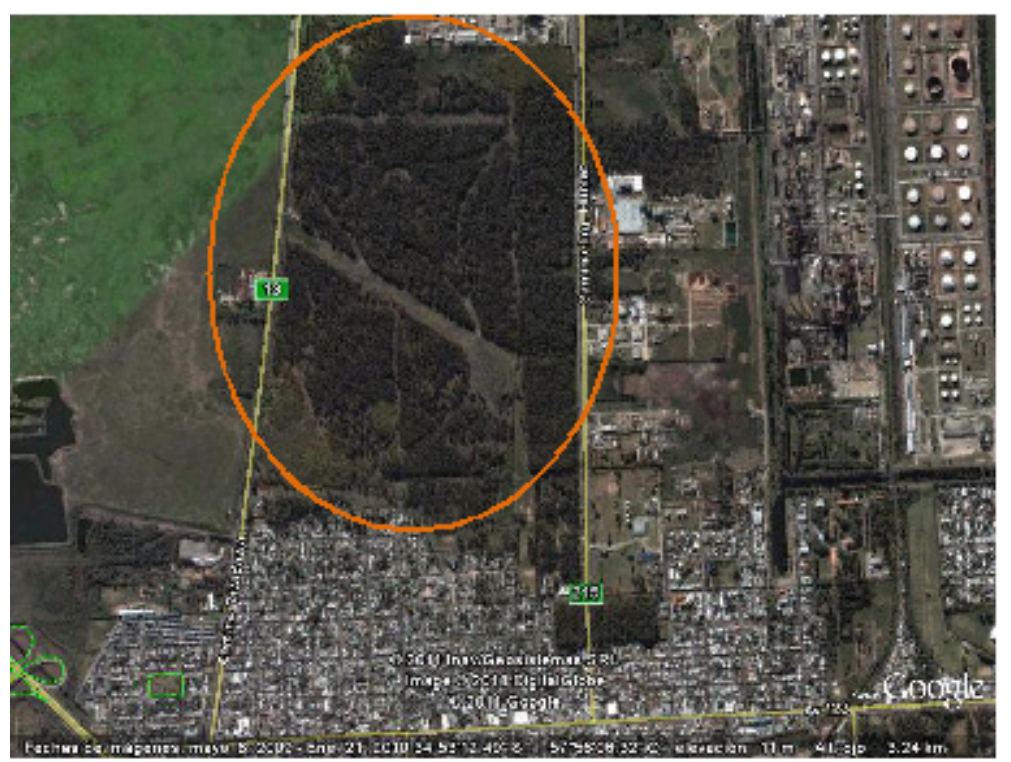

Se colectaron ejemplares adultos, machos y hembras de 2,3 $\pm 0,3 \mathrm{~g}$ de peso. Para la captura se utilizaron frascos de plástico o vidrio, que se colocaron sobre el tronco del árbol cubriendo el animal de manera que pudiese entrar al mismo, sin provocarle daños. Las arañas fueron trasladadas al laboratorio y mantenidas en los frascos de captura ( I animal por frasco), a $25^{\circ} \mathrm{C}$, hasta el mo- 
mento de su utilización (Fig. III.2). En los casos en los que los animales fueron mantenidos con vida por tiempos prolongados, fueron alimentados una vez por semana, con grillos (Acheta domestica) vivos adquiridos comercialmente.
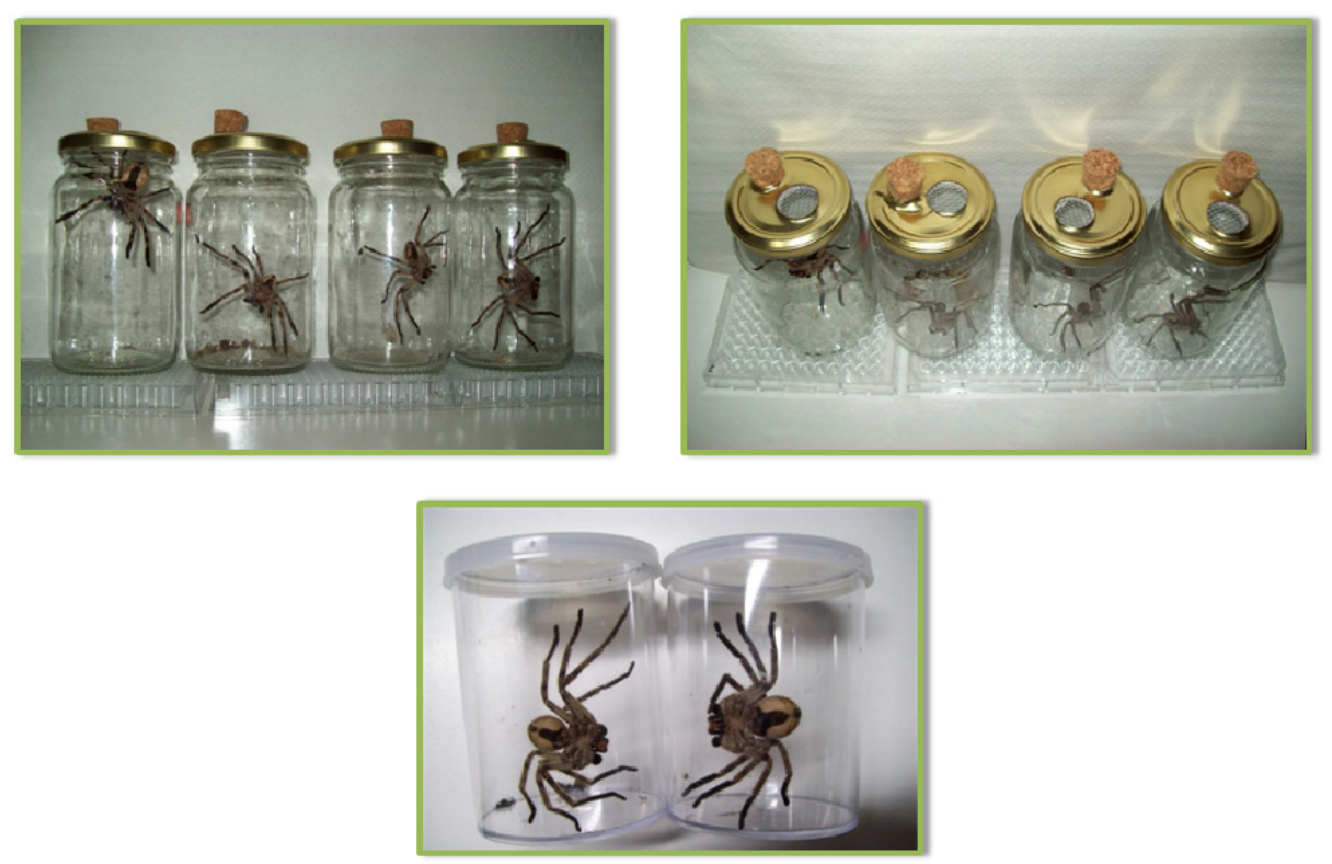

\section{III.2.2. Extracción de hemolinfa y disección de órganos}

Las arañas fueron anestesiadas con frío. Para esto, se colocaron en los mismos frascos en las que fueron colectadas y mantenidas, en un congelador a $-4^{\circ}$ C durante 10 a 15 minutos (el tiempo fue variable según el tamaño del individuo). De esta manera, se logró aletargarlas y facilitar su manipulación. Para la extracción de HL, se cortaron las patas a nivel de la articulación entre el fémur y la patela ó, entre la patela y la tibia; se colocó el cuerpo de la araña en un embudo de vidrio que desembocaba en un tubo eppendorf, y todo esto dentro de un tubo de centrífuga. Se realizó una centrifugación a baja velocidad (27 I g) durante 15 minutos en una centrífuga International Model UV, de manera que la HL fluyó libremente acumulándose en los tubos. De cada araña se obtuvieron aproximadamente $100 \mu \mathrm{L}$ de $\mathrm{HL}$ que fue conservada a $-70^{\circ} \mathrm{C}$ hasta el momento de ser utilizada.

Luego de la extracción de HL se disecaron los órganos. En primer lugar, se seccionó el cuerpo de los animales en dos, cortando a nivel del pedicelo que separa la parte anterior del cuerpo (prosoma) de la posterior (opistosoma). Luego, se realizó un corte longitudinal en el tegumento del opistosoma a través de la línea media. Levantando el tegumento se pudo ver el corazón tubular, ubicado dorsalmente, y una gran masa de tejido correspondiente a los DI. Éstos fueron tomados con una pinza de punta fina, y colocados en un tubo eppendorf
Figura III.2: Frascos de plástico y de vidrio donde las arañas fueron mantenidas en el laboratorio. 
$(0,26 \pm 0,15 \mathrm{~g} / \mathrm{DI})$. Posteriormente y por último, se retiraron los pulmones en libro, ubicados ventralmente, en la parte anterior del opistosoma $(0,004 \pm 0,002$ g/par de pulmones). Todos los órganos disecados, y el resto del cuerpo de la araña (al que consideramos, y de aquí en adelante llamaremos "músculo" por ser el tejido mayoritario), incluido el prosoma, las patas y el tegumento, fueron congelados $\mathrm{a}-70^{\circ} \mathrm{C}$ hasta el momento de ser utilizados.

\section{III.2.3. Colección de huevos y obtención de citosol}

Se colectaron en el campo hembras grávidas, fácilmente distinguibles por el gran aumento de tamaño del opistosoma, que se mantuvieron en el laboratorio a $25^{\circ} \mathrm{C}$ y en frascos individuales hasta el momento de la puesta. Fueron alimentadas una vez por semana con grillos vivos obtenidos comercialmente. Tres días después de la ovoposición, se colectaron los huevos de 4 ootecas ( 0,5 $\pm 0,2 \mathrm{~g}$ (ooteca). Éstos fueron homogeneizados en $3 \mathrm{ml}$ de buffer fosfato potasio (50 mM, pH 7,4), con la adición de un coctel inhibidor de proteasas I: $1000 \mathrm{v} / \mathrm{v}$ (Sigma Chemicals, St. Louis, MO, Usa). Los restos celulares, fracciones nucleares y mitocondrias fueron separados por centrifugación del homogenato a 10.500 g durante 20 minutos en una centrífuga Sorvall RC-2 a $4^{\circ} \mathrm{C}$. El sobrenadante se utilizó para la obtención de la fracción citosólica por sedimentación de los microsomas a $110.000 \mathrm{~g}$, por 60 minutos, en una ultracentrífuga Beckman L8M, con rotor de ángulo fijo 70.1 Ti. Esta fracción fue utilizada posteriormente para el aislamiento de lipoproteínas.

\section{III.3. Detección y aislamiento de lipoproteínas}

\section{III.3.1. Ultracentrifugación en gradiente de densidad y fraccionamiento}

Para el aislamiento de las lipoproteínas hemolinfáticas y de citosol de huevo se utilizó ultracentrifugación en gradiente de densidad, una técnica que permite separar partículas que sean similares en tamaño pero de distinta densidad.

Las muestras se colocaron en tubos de centrífuga sobre un colchón de $\mathrm{NaBr}$ de $1,26 \mathrm{~g} / \mathrm{ml}$ para la $\mathrm{HL}$, y $1,28 \mathrm{~g} / \mathrm{ml}$ para el citosol, con un volumen total de 4,3 ml. Las centrifugaciones se llevaron a cabo en una ultracentrífuga Beckman L8M, con un rotor de ángulo móvil SW60 Ti, a $272.400 \mathrm{~g}$, a $10{ }^{\circ} \mathrm{C}$ durante 24 hs. (Fig.III.3). Paralelamente se centrifugó una solución salina de $\mathrm{NaCl}$ de una densidad similar a la asumida para las muestras, l,006 g/ml para la HL y l,016 g/ $\mathrm{ml}$ para el citosol de huevos. Estos tubos fueron utilizados como blanco para determinar las densidades relativas, y corroborar la correcta formación del gradiente. El contenido, tanto de los tubos muestra como el de los tubos blanco, fue fraccionado desde el tope hasta el fondo, en alícuotas de $200 \mu \mathrm{l}$. 


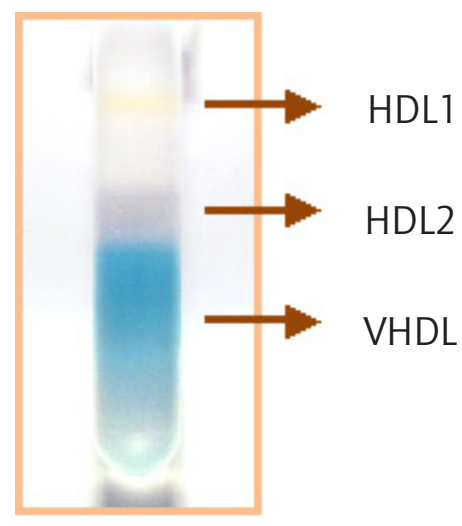

Figura III.3: Gradiente de densidad obtenido luego de ultracentrifugar la $\mathrm{HL}$ de $P$. pythagoricus a $272.400 \mathrm{~g}$ durante 24 hs.

\section{III.3.2. Medidas efectuadas en las fracciones obtenidas de la ultracentri- fugación}

- Medida de densidad de las fracciones:

Se midieron los índices de refracción (IR) de las fracciones correspondientes a los tubos blanco, con un refractómetro Abbey (Bausch \& Lomb), a $26^{\circ} \mathrm{C}$. A partir de los IR se calcularon las densidades de cada fracción interpolando los datos obtenidos con los tabulados por Lindgren ( I 975).

\section{- Monitoreo de proteínas totales:}

Para determinar las proteínas totales presentes en cada fracción del gradiente, se midió en cada alícuota, la absorción de luz UV a 280 nm, en un espectrofotómetro Agilent 8453 UV-visible. Con los valores obtenidos se construyeron perfiles (concentración relativa de proteínas vs. fracción separada del gradiente), donde se pudieron ubicar los máximos correspondientes a las lipoproteínas. Las fracciones coincidentes con estos máximos fueron reunidas y conservadas a $-70^{\circ} \mathrm{C}$ hasta el momento de su utilización.

\section{III.4. Análisis de lípidos}

\section{III.4.1. Obtención de lípidos totales}

Para la obtención de lípidos totales de tejidos, HL y lipoproteínas, se utilizó el método de Folch et al. (1957). Este método utiliza como mezcla de solventes de extracción, cloroformo:metanol (2:I v/v), en una relación de 20:1 $\checkmark / v$ respecto a la muestra. Siguiendo este método, se agitó vigorosamente la muestra con el solvente de extracción y se mantuvo a $4^{\circ} \mathrm{C}$ por un intervalo de tiempo mínimo de I hora. Luego se filtró con papel de filtro, al que se lavó posteriormente con solvente de extracción, para evitar pérdidas del extracto lipídico. Al filtrado se le agregó un $20 \%$ de su volumen de una solución $\mathrm{NaCl} 18$ $\mathrm{g} / \mathrm{l}$, se agitó y se dejó decantar a $4^{\circ} \mathrm{C}$ durante toda la noche, para permitir la separación de las fases: una superior metanol-acuosa y una inferior clorofórmica, que contiene el extracto lipídico. La fase superior se descartó, y la inferior fue lavada dos veces más con $\mathrm{NaCl} 18$ g/L. La fase clorofórmica se evaporó a seco 
con corriente de $\mathrm{N}_{2}$. El extracto lipídico fue resuspendido en un pequeño volumen de cloroformo:metanol 2: I, y se guardó a $-20^{\circ} \mathrm{C}$ en atmósfera de $\mathrm{N}_{2}$ para su posterior análisis.

\section{III.4.2. Cuantificación de lípidos totales por gravimetría}

Este análisis se utiliza para determinar la cantidad de lípidos totales presentes en una muestra. Para esto, se tomó una fracción de volumen (400 $\mu \mathrm{l})$ de la muestra total en una pequeña cápsula de vidrio, se evaporó el solvente a seco con corriente de $\mathrm{N}_{2}$, y luego se pesó en una balanza microanalítica Mettler. Este procedimiento se realizó hasta pesada constante. El peso fue referido al volumen de muestra total.

\section{III.4.3. Análisis de lípidos por cromatografía en capa fina (TLC)}

La composición de lípidos se determinó por cromatografía en capa fina utilizando placas preformadas de $20 \times 20 \mathrm{~cm}$., de alta performance (HPTLC), con base de vidrio y sílica gel como soporte, (Merck). Los lípidos fueron separados por doble desarrollo. En primer lugar, se desarrollaron los lípidos polares utilizando como fase móvil la siguiente mezcla de solventes: cloroformo:metanol:ácido acético:agua (65:25:4:4 v/v). Se desarrolló la corrida hasta la mitad de la placa y se dejó secar. Luego se desarrollaron los lípidos neutros con la mezcla: éter de petróleo:éter etílico:ácido acético (80:20:I v/v), hasta que el frente de solvente alcanzó el borde de la placa.

En ambos casos, las cubas de desarrollo conteniendo las mezclas de solventes se saturaron previamente con los vapores de éstos. Para la identificación de los distintos lípidos se corrieron simultáneamente estándares de lípidos conocidos. El revelado se realizó con vapores de iodo.

En los casos en lo que las siembras se realizaron con lípidos marcados radioactivamente, la visualización y cuantificación de los mismos se realizó utilizando un escáner óptico, Storm (Amersham), que genera imágenes digitales de muestras radiactivas, permitiendo el análisis de varias muestras simultáneamente. Las placas de TLC fueron expuestas durante toda la noche dentro de un cassette de exposición a un Storage phosphor screen, que colecta las imágenes de las muestras radiactivas, luego fue escaneado y la imagen digital analizada con el software ImageQuant TL.

\section{III.4.4. Microdeterminación de lípidos}

La cuantificación de lípidos fue realizada mediante cromatografía en capa fina acoplada a un detector de ionización de llama (TLC-FID). El equipo utilizado fue un aparato latroscan THIO (latroscan Laboratories, Tokio), autoanalizador que combina la capacidad resolutiva de la cromatografía en capa fina (TLC) con la sensibilidad de un detector de ionización de llama (FID).

La separación de los componentes se realizó sobre varillas Chromarod- 
SIII. Consisten en columnas compactas de cuarzo, de $158 \mathrm{~mm}$ de largo y I mm de diámetro, revestidas de una capa adsorbente de $75 \mu \mathrm{m}$ de espesor, compuesta de partículas de sílica gel de $5 \mu$ m de diámetro. Las muestras se sembraron en un volumen de I $\mu \mathrm{l}$, conteniendo de I a $10 \mu \mathrm{g}$ de lípidos totales. La siembra se realizó en un extremo de las varillas, y se desarrollaron como una TLC clásica. Una vez separados los componentes individuales, la detección y cuantificación se realizó pasando, mediante un dispositivo mecánico, las varillas a través del FID. Luego de ser quemadas, las varillas pueden ser reutilizadas hasta 200 veces, sin perder la capacidad resolutiva. Presenta además la ventaja de permitir sucesivos desarrollos en mezclas específicas de solventes y quemados posteriores, de tal modo de poder obtener la separación de gran parte de las clases de lípidos existentes en una muestra, a partir de una sola siembra.

El registro, se realizó dirigiendo la salida analógica a un integrador HewletPackard 3396A, con memoria de 64 Kbytes que permitió almacenar y reanalizar los datos obtenidos en cada corrida. Para el análisis cuantitativo, se realizó una curva de calibración de cada juego de varillas a utilizar, para cada clase de lípido detectado previamente mediante el análisis cualitativo.

\section{- Confección de las curvas de calibración:}

Las curvas de calibración se construyeron utilizando MAG como estándar interno, ya que no se encuentra naturalmente en la muestra a analizar (Ackman et al., 1990). Se sembraron cantidades constantes de este estándar en cada varilla, y cantidades crecientes de un estándar de una clase en particular de lípido. Luego de desarrollar y quemar las varillas, se obtuvo el cociente entre el área del estándar a analizar, y el área del estándar interno. Se realizaron varias repeticiones para cada clase de lípido, y se procedió a graficar el cociente, área del Lípido/área del estándar interno, versus la masa $(\mu \mathrm{g})$ de cada lípido sembrado. Los puntos obtenidos permitieron el ajuste de regresión lineal a la ecuación $Y=$ $a x+b$, obteniéndose así sus parámetros.

\section{- Desarrollo de la cromatografía:}

Antes de comenzar, las varillas deben ser quemadas en su totalidad para asegurar que no haya impurezas que puedan interferir con los datos obtenidos posteriormente.

Luego son activadas en una estufa a $100^{\circ} \mathrm{C}$ y sembradas con un volumen total de I $\mu$ l de estándares o de muestra incluyendo el estándar interno.

Se preparan 3 sistemas de solventes:

1) hexano:benceno (70:30 v/v): permite el desarrollo de lípidos de muy baja polaridad como hidrocarburos y esteroles esterificados.

2) benceno:cloroformo:ácido fórmico (70:25:0.8 v/v): desarrolla lípidos neutros: TAG, AGL y esteroles. 
3) cloroformo:metanol:agua (70:25:3 v/v): desarrolla lípidos polares: PE, PC y esfingomielina.

Las varillas sembradas se colocan en una cuba con solución de $\mathrm{NaCl}$ durante 5 minutos para estandarizar el contenido de humedad de las mismas, de manera que el solvente avance de forma pareja en todas las varillas.

Luego se realizó el siguiente protocolo:

1) Primer sistema de solventes: se satura la cuba de desarrollo con este sistema durante 15 minutos, y luego se permite el desarrollo completo de las varillas. El tiempo de desarrollo es de alrededor de 20 minutos (varía con las condiciones ambientales). Se retiran las varillas de la cuba, se secan en estufa y se queman en el FID desde el tope hacia abajo, hasta los 4 ó $5 \mathrm{~cm}$ del punto de siembra. Esta distancia, se determina en cada ocasión, por quemado total de la/s primera/s varillas en las que se sembraron estándares individuales para determinar los Rf de esos lípidos.

2) Las varillas se colocan en la cuba, previamente saturada con el segundo sistema de solventes. Se dejan desarrollar hasta el final (cerca de 30 minutos), se secan y se queman hasta aproximadamente $2 \mathrm{~cm}$ del punto de siembra.

3) Se colocan las varillas en la cuba saturada del tercer sistema de solventes y se desarrollan hasta al final de la varilla (aproximadamente 45 minutos). Se secan y se queman, en este caso, hasta el punto de siembra.

\section{- Cuantificación:}

En el registrador HP 3396A se integraron las áreas de los lípidos. Se obtuvieron los cocientes entre el área de cada clase lipídica, y el área del estándar interno en cada varilla. Utilizando los parámetros de la curva de calibración correspondiente, se obtuvo la masa de cada clase lipídica presente en cada varilla.

El equipo operó a una presión de $\mathrm{H} 2$ de $0,5 \mathrm{Kg} / \mathrm{cm}^{2}$, un flujo de aire de $1.200 \mathrm{ml} /$ minuto y una velocidad de barrido de 32 segundos/varilla.

Se realizaron dos curvas de calibración de las varillas, la primera para la cuantificación de lípidos de los DI y la segunda para las lipoproteínas de huevo. En ambos casos se obtuvieron coeficientes de correlación superiores a 0,9.

\section{III.4.5. Análisis de ácidos grasos por cromatografía gas-líquido}

La cromatografía gas-Líquido (GLC) es uno de los métodos generales más ampliamente usados en la separación, identificación y cuantificación de ácidos grasos y sustancias relacionadas, cuando éstas poseen una tensión de vapor apreciable, a cualquier temperatura por debajo de la temperatura de descomposición.

Los ácidos grasos de cadena corta, a las temperaturas comúnmente empleadas en las columnas de separación, se encuentran en forma gaseosa; esto es necesario para que la muestra se pueda analizar por GLC. En cambio, las muestras biológicas poseen en general ácidos grasos de mayor longitud de cadena y 
además con distinto grado de insaturación, no encontrándose en la forma necesaria para su análisis a las temperaturas utilizadas. Por esta razón, los ácidos grasos deben ser derivatizados en sus ésteres metílicos para ser analizados por GLC (Burchfield \& Storrs, 1970), ya que estos son más volátiles que sus respectivos ácidos grasos, debido a una reducción en la polaridad al formarse el éster, y además son relativamente más estables que los ácidos libres.

Los compuestos volatilizados se distribuyen entre la fase móvil gaseosa (gas portador), y la fase estacionaria líquida contenida en la columna cromatográfica, sostenida por un material poroso inerte (soporte). Una corriente de gas portador pasa continuamente a través de la columna y la mezcla de compuestos a analizar se distribuye entre ambas fases. La diferencia entre las constantes de reparto de los distintos componentes de la muestra, hace que se muevan a velocidades diferentes a través de la columna. Detectores apropiados miden las concentraciones de los componentes, que emergen de la columna junto al gas portador.

\section{- Saponificación de los lípidos:}

En el proceso de saponificación, se expone a los lípidos a una hidrólisis alcalina que rompe la unión éster entre los ácidos grasos y el resto de la molécula lipídica. De esta manera se obtienen las sales de ácidos grasos que forman parte de ésteres de colesterol, acilglicéridos y fosfoglicéridos, que son solubles en agua.

\section{- Derivatización de ácidos grasos:}

De las sales de ácidos grasos obtenidos por saponificación, se prepararon los ésteres metílicos de ácidos grasos (EMAG) de acuerdo a la metodología de Morrison y Smith ( 1992 ), desarrollada con $\mathrm{BF}_{3} /$ metanol.

\section{- Identificación de ácidos grasos:}

Los EMAG fueron analizados en un cromatógrafo gas-líquido sobre una columna capilar DB-23 (J y W Scientific) de 30 m de largo, en un cromatógrafo de gases Hewlett Packard modelo 6890 con detector de ionización de llama. Las condiciones de uso fueron las siguientes:

Fase fija Megawax 250 (Supelco)

Gas portador: $\mathrm{He}$

Flujo de gas: 0,7 ml/min.

Temperatura de la cabeza de inyección: $260^{\circ} \mathrm{C}$

Temperatura inicial del horno: $(\mathrm{tl}) 175^{\circ} \mathrm{C}$

Tiempo inicial a t l : 3 min.

Temperatura final del horno (t2): $230^{\circ} \mathrm{C}$

Tiempo final de $\mathrm{t} 2: 19 \mathrm{~min}$.

Incremento de temperatura: $3^{\circ} \mathrm{C} / \mathrm{min}$. 
El método de identificación de los EMAG se basó en el tiempo de retención relativo característico de cada ácido graso, dependiente de la columna usada, de la fase móvil y la temperatura, e independiente de otras condiciones experimentales (Ackman, 1963). Los picos fueron identificados comparando sus tiempos de retención con los de una mezcla estándar de ésteres metílicos de ácidos grasos conocidos.

\section{III.5. Análisis de apoproteínas}

\section{III.5.1. Diálisis de las muestras}

Dado que luego de la ultracentrifugación en gradiente de densidad, las Lipoproteínas se encuentran en un medio salino de $\mathrm{NaBr}$, se realizó una diálisis con el objetivo de cambiar la composición iónica del medio, adecuándola a los diferentes requerimientos. Se las colocó en un saco de diálisis (Sigma, tamaño de poro 12.000 Dalton), de acetato de celulosa, semipermeable, que permite el paso de pequeñas moléculas de sales inorgánicas, pero no de grandes moléculas como las proteínas. Las moléculas pequeñas difunden del interior del saco al buffer de diálisis hasta que la concentración salina dentro y fuera del saco se iguala. Se sumergió el saco de diálisis en un erlenmeyer con buffer fosfato potasio $50 \mathrm{mM} \mathrm{pH} \mathrm{7,4} \mathrm{en} \mathrm{una} \mathrm{relación} \mathrm{buffer} \mathrm{muestra} \mathrm{1000:I} \mathrm{v/v.} \mathrm{Se} \mathrm{sometió} \mathrm{a}$ agitación durante 12 horas a $4^{\circ} \mathrm{C}$.

\section{III.5.2. Cuantificación de proteínas totales}

La cuantificación de proteínas en las fracciones se realizó mediante el método de Lowry et al., ( 1951 ). El primer paso implica la formación de un complejo cobre-proteína en una solución alcalina. Este complejo reduce posteriormente a un reactivo fosfomolíbdico-fosfowolfrámico que da un color azul intenso. La reacción colorimétrica se midió a $750 \mathrm{~nm}$ en un espectrofotómetro Agilent 8453, utilizando albúmina sérica bovina ( $\mathrm{mg} / \mathrm{ml}$ ) como estándar.

\section{III.5.3. Separación electroforética de las muestras en geles de poliacrila- mida (PAGGE)}

Esta técnica permite la separación de proteínas según su relación carga/ masa cuando se mueven a través de un gel poroso por la aplicación de un campo eléctrico. El gel utilizado fue hecho de poliacrilamida, una matriz polimerizada de acrilamida y N,N'-metilen-(bis-acrilamida), en una relación final de 30\% $\mathrm{p} / \mathrm{v}$ de acrilamida y $0,8 \% \mathrm{p} / \mathrm{v}$ de bis-acrilamida. Se utilizó el método desarrollado por Laemmli, ( 1970 ) que consiste en dos geles contiguos pero distintos: el superior es un gel concentrador de poliacrilamida al $4 \% \mathrm{p} / \mathrm{v}$, seguido por un gel separador con un gradiente lineal de tamaño de poro, elegido según los pesos moleculares de las proteínas a separar, que fue generalmente entre 4 y $23 \% \mathrm{p} / \mathrm{v}$ de bisacrilamida. 


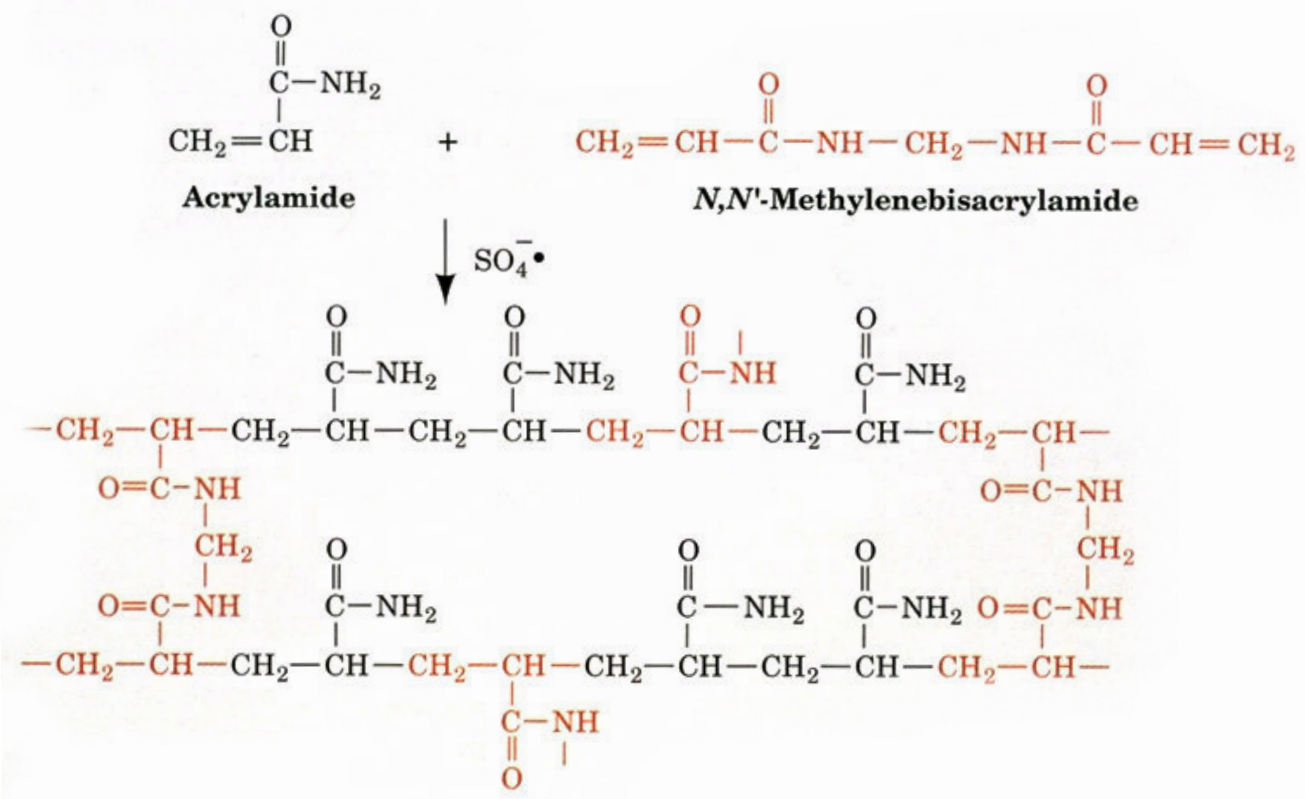

\section{- PAGGE-Nativo}

En este tipo de electroforesis, la movilidad de las moléculas depende de su relación carga/masa, por lo que no es adecuado para la determinación de sus pesos moleculares. Sin embargo, el uso de geles en gradiente y tiempos extensos de corrida permite a cada molécula alcanzar su poro límite (aquel que, dado el tamaño de la proteína, ésta no puede seguir avanzando), permitiendo una estimación del peso molecular a partir de la comparación con la movilidad de las proteínas estándar.

\section{- PAGGE-SDS}

En el gel en condiciones disociantes se agrega dodecil sulfato de sodio (SDS) I \% p/v, a los geles y buffers de los reservorios electródicos. EL SDS es un detergente aniónico que se une a las regiones hidrofóbicas de las proteínas y separa la mayoría de ellas en sus subunidades componentes. Además, se desnaturaliza a las muestras antes de la corrida calentándolas a $100^{\circ} \mathrm{C}$ durante 5 minutos. También, en este tipo de electroforesis, previo a la corrida, se pueden romper los enlaces disulfuros, reduciéndolos a grupos sulfhidrilos por el agregado de $\beta$-mercaptoetanol.

EL SDS agregado unifica la carga de todas las proteínas, por lo que la movilidad relativa de las moléculas depende solo de su masa, haciendo de la movilidad una función de sus pesos moleculares. Así, la migración de las proteínas será a velocidades inversamente proporcionales a sus pesos moleculares.

Las soluciones empleadas en la preparación y desarrollo de las electroforesis fueron: 
Solución A: Acrilamida - Bis-Acrilamida 30: 0,8\% p/v

Solución B: Buffer del gel concentrador (de siembra): Tris- $\mathrm{HCl}$ 0,125 M; $\mathrm{pH}$ 6,8

Solución C: Buffer del gel de resolución o separador: Tris- $\mathrm{HCl}$ 0,375 M; $\mathrm{pH} \mathrm{8,8}$

Solución D: Iniciador: Persulfato de amonio

Solución E: Catalizador: tetrametilendiamina (TEMED).

Se uso un buffer de desarrollo Tris-Glicina, 0,025 M Tris-0,I 92 M Glicina; $\mathrm{pH} 8,3$.

Se empleó una cuba electroforética Mini Protean 2, Bio Rad; con una fuente de poder Power 200-2.0, Bio Rad. Las electroforesis se realizaron a voltaje constante de $120 \mathrm{~V}$, y el tiempo de corrida fue de aproximadamente 3 horas para el PAGGE-Nativo y de 1,5 horas para el PAGGE-SDS.

\section{III.5.4. Revelado de las proteínas y determinación de sus pesos molecu- lares}

Una vez desarrolladas las electroforesis, los geles fueron fijados y teñidos. Las tinciones utilizadas fueron las siguientes:

\section{1) Tinción con Coomassie Brilliant Blue (Sigma Chemical Co):}

Los geles fueron sumergidos en una solución de Coomassie Brilliant Blue G-250 (0,04\% p/v) y ácido tricloroacético ( $10 \% \mathrm{p} / \mathrm{v})$ disueltos en una mezcla de metanol - agua $(40: 60 \mathrm{v} / \mathrm{v})$. Se colocaron en estufa a $60^{\circ} \mathrm{C}$ durante una hora (Merril, 1990) ó, se mantuvieron a temperatura ambiente toda una noche. La decoloración se realizó utilizando una solución de agua: metanol:ácido acético (50:40: $10 \mathrm{v} / \mathrm{v})$. Con esta técnica se detectaron hasta un mínimo de $10 \mu \mathrm{g}$ de proteínas por banda.

2) Tinción con reactivo de plata (Merril, 1990):

Consiste en la reacción del nitrato de plata con las proteínas en medio ácido, seguido de una reducción selectiva de los iones plata a plata metálica con formaldehido en condiciones alcalinas. Para mantener el pH alcalino durante la reacción se usan sales de carbonato e hidróxido de sodio. El ácido fórmico formado por la oxidación del formaldehido es tamponado por el carbonato de sodio.

Se siguió el siguiente protocolo: $\mathrm{v} / \mathrm{v})$.

1) Fijar el gel durante 20 minutos en metanol:ácido acético:agua (50: 10:40

2) Lavarlo durante 30 minutos en metanol:ácido acético:agua ( 10:5:85 $\mathrm{v} / \mathrm{v})$.

3) Sumergir en una solución de dicromato de potasio 3,4 mM y ácido nítrico $3,2 \mathrm{mM}$. 
4) Lavar en agua bidestilada durante 5 minutos.

5) Sumergir 20 minutos en una solución de nitrato de plata $12 \mathrm{mM}$.

6) Revelar (aproximadamente 5 minutos), realizando 2 recambios de una solución de carbonato de sodio 0,28 My formaldehído 37\% p/v

7) Parar la reacción de revelado con recambios de ácido acético $3 \%$ p/v

8) Lavar el gel en una solución de etanol 10\%

9) Almacenarlo en una solución de glicerol:etanol:agua (7: 10:83 v/v).

Con esta técnica se detectaron hasta un mínimo de 50 ng de proteínas por banda.

\section{3) Tinción con biquinolina para detectar presencia de cobre (Bruynick} et al., 1978):

Para esta tinción se sumerge al gel durante 3 minutos en una solución de ácido ascórbico $16 \mathrm{mM}$, con biquinolina (Sigma), 0,28 mM, en ácido acético. Las bandas positivas al cobre se observan oscuras bajo luz UV a $254 \mathrm{~nm}$ en un fondo amarillo-verdoso fluorescente.<smiles>c1ccc2nc(-c3ccc4ccccc4n3)ccc2c1</smiles>

Biquinolina

\section{4) Tinción con Sudan Black para detectar presencia de lípidos (Terpstra} et al., 1981):

El Sudan Black B es un colorante liposoluble utilizado para la tinción de TAG y lípidos neutros. Tiñe a las lipoproteínas de un color negro-azulado. Las muestras destinadas a la tinción con Sudan Black B, fueron incubadas con este colorante en una relación de 1:2 ○ 1:4, muestra - colorante, durante toda la noche a $4^{\circ} \mathrm{C}$ y luego fueron sembradas en un gel para realizar la electroforesis.

Los pesos moleculares de las bandas proteicas de interés, se determinaron utilizando mezclas de estándares de proteínas de alto y bajo peso molecular (Amersham Biosciences). Graficando los logaritmos decimales del peso molecular de las proteínas, en función de sus valores de migración relativos al colorante trazador (Rf) se obtuvo una recta de calibración que fue ajustada mediante análisis de regresión lineal. En base a la curva ajustada, se calculó el peso molecular de las muestras. Tanto en las curvas de los geles en condiciones nativas como disociante se observaron coeficientes de correlación superiores a 0,95. 


\section{III.5.5. Electroelución}

Para analizar las bandas obtenidas en condiciones nativas en una de las lipovitelinas, se las aisló de los geles de poliacrilamida por electroelución. Se utilizó un electroelutor modelo 422 de BioRad. En primer lugar se cortaron del gel las bandas con las proteínas a electroeluir y cada banda se trituró. El gel triturado se colocó en los tubos ya ubicados en el sistema de electroelución y en el fondo de los mismos se colocó un adaptador de silicona con una Membrana Cap de 12.000 a 15.000 Da de corte. Este módulo se llevó a la cuba electroforética y se llenó de buffer. Se corrió durante 6 horas a $10 \mathrm{~mA} /$ tubo. Se utilizó buffer Tris-Glicina, 0,025 MpH 8,3.

\section{III.6. Determinación de la presencia de hemocianina en las lipovitelinas}

La presencia de hemocianina en las fracciones lipoproteicas fue monitoreada por análisis del espectro UV-Visible entre 200 y $700 \mathrm{~nm}$. Se utilizó un espectrofotómetro DW-200 SLM Aminco. Se buscó la presencia del pico característico de la absorbancia del cobre a los $340 \mathrm{~nm}$.

\section{III.7. Determinación de carbohidratos}

El contenido de hexosas de las lipovitelinas fue determinado por el método de antrona-sulfúrico usando D-glucosa como estándar. El ensayo está basado en el hecho de que, cuando los carbohidratos son calentados en presencia de un ácido fuerte, son convertidos en furfurales por procesos de oxidación, reducción y condensación. Estos productos pueden reaccionar con compuestos orgánicos para dar compuestos coloreados. La antrona en solución es una mezcla en equilibrio de las formas tautoméricas 9-cetoantraceno. La modificación enol-antranol es la forma activa del reactivo de antrona (Roe, 1955).<smiles>[2H]C1c2ccccc2C(=O)c2ccccc21</smiles>

Antrona

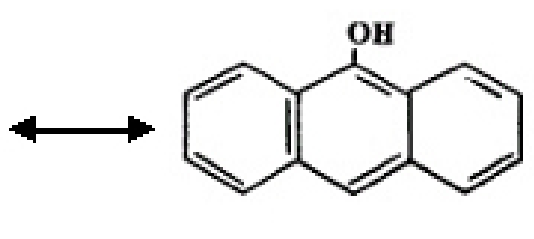

Antranol<smiles>O=Cc1ccco1</smiles>

Furfural 
Se siguió el siguiente protocolo:

1) Preparar una solución stock $66 \% \mathrm{v} / \mathrm{v}$ de $\mathrm{H}_{2} \mathrm{SO}_{4}$ agregando con agitación y enfriamiento externo, $660 \mathrm{ml}$ de $\mathrm{H}_{2} \mathrm{SO}_{4}$ sobre $340 \mathrm{ml}$ de agua destilada.

2) Disolver en I litro de esta solución, $10 \mathrm{~g}$ de tiourea y $0,5 \mathrm{~g}$ de antrona (9,10-dihidro-9-oxoantraceno), calentando la mezcla a 80-90 $\mathrm{C}$.

3) Preparar una curva estándar de glucosa en el rango de $10-80 \mathrm{ng} / \mathrm{ml}$.

4) Agregar en un tubo de vidrio con tapa, $2 \mathrm{ml}$ del reactivo de antrona, a $200 \mu$ l de la solución a ensayar o el estándar de glucosa. Agitar.

5) Poner en un baño de agua a temperatura ambiente para equilibrar la temperatura, y luego durante 15 minutos en un baño de agua a $100^{\circ} \mathrm{C}$.

6) Enfriar a temperatura ambiente y dejar en oscuridad.

7) Medir la absorbancia a $620 \mathrm{~nm}$ después de 20-30 min.

\section{III.8. Preparación de anticuerpos policlonales anti HDL I y VHDL}

Se prepararon anticuerpos policlonales contra las lipoproteínas hemolinfáticas HDL I y VHDL en ratón.

Las lipoproteínas fueron aisladas por ultracentrifugación y luego purificadas por cromatografía líquida de alta presión (HPLC), utilizando una columna de exclusión molecular Superdex 200 HR, cuyo rango es de 10.000 a 600.000 Da. El buffer de elución fue Tris-HCl 0,I M pH 8. La elución de proteínas se monitoreó con un detector UV, cuya longitud de onda se fijó en $280 \mathrm{~nm}$. Se comprobó la pureza de las fracciones por PAGGE.

Se utilizaron ratones machos de la cepa Balb-c (Harlow \& Lane, 1988) de entre 7 y 8 semanas de edad, 3 ratones para cada lipoproteína. Para lograr una respuesta inmunogénica fuerte y prolongada, cuando se trata de antígenos solubles, se utilizan estimulantes no específicos de la respuesta inmune conocidos como adyuvantes. En este caso utilizamos el adyuvante de Freund, una emulsión de agua en aceite, preparada con aceites no metabolizables, que en el caso del adyuvante completo, contiene además Mycobacterium tuberculosis muertas por calor (Harlow \& Lane, 1988). Se suministró a los animales una inyección subcutánea de $50 \mu \mathrm{g}(150 \mu \mathrm{l}$ ) de lipoproteína (previamente dializada) emulsionada en adyuvante de Freund completo (Sigma Chemical Co., St. Louis, MO). Tres semanas después se administró una segunda inyección de $50 \mu \mathrm{g}$ ( 150 $\mu \mathrm{l}$ ) de antígeno con adyuvante de Freund incompleto. Una última inyección con $50 \mu \mathrm{g}(150 \mu \mathrm{l})$ de antígeno puro, fue realizada luego de dos semanas. Seis días después de la última inyección los animales fueron sangrados. Los ratones fueron anestesiados con $180 \mu$ l de Ketamina, un anestésico general veterinario, que bloquea el sistema nervioso sin deprimir el sistema respiratorio ni circulatorio. Se realizó un corte ventral en forma de T, del tegumento y el peritoneo, hasta abrir la parrilla costal y dejar expuesto el corazón. Se pinchó la aurícula con una jeringa para extraer la sangre.

La sangre colectada fue mantenida a $37^{\circ} \mathrm{C}$ por 30 minutos para su coagu- 
lación y luego a $4^{\circ} \mathrm{C}$ durante toda la noche para lograr la retracción del coagulo. Después de una centrifugación suave ( 10.000 g durante 10 minutos), la fracción IgG fue purificada por precipitación con sulfato de amonio. El precipitado resuspendido en PBS se almacenó a $-70^{\circ} \mathrm{C}$ hasta su utilización. La especificidad del antisuero se determinó mediante inmunotransferencia empleando diferentes lipoproteínas de arácnidos y otros invertebrados.

\section{III.9. Dot Blot}

El análisis Dot Blot es una alternativa al Western Blot, que difiere en que no es necesario realizar la separación electroforética de las proteínas a analizar. Para realizarlo se colocaron gotas de $10 \mu$ l conteniendo entre 50 ng y I $\mu$ g de lipovitelinas y lipoproteínas hemolinfáticas purificadas, en tiras de membrana de nitrocelulosa (de aproximadamente $1,5 \times 5 \mathrm{~cm}$ ) (Amersham). La membrana se bloqueó durante toda la noche con una solución de leche en polvo descremada al $5 \% \mathrm{p} / \mathrm{v}$ en PBS-Tween a $37^{\circ} \mathrm{C}$. Terminado el bloqueo se incubó durante 2 horas con suero anti HDL I o anti VHDL (anticuerpos primarios) diluidos I: 1500 y 1:20.000 respectivamente en PBS-Tween conteniendo 1\% de leche descremada. Posteriormente se realizaron 6 lavados de 5 minutos cada uno con PBSTween y se incubó durante 1,5 horas con anticuerpo anti IgG de ratón generado en cabra, conjugado con peroxidasa (BioRad), diluido I: 1500 en PBS-Tween con leche descremada al $1 \%$.

Concluida esta incubación la membrana se Lavó nuevamente y se reveló por electroquimioluminiscencia.

\section{III.9.1. Electroquimioluminiscencia}

Los métodos de detección por luminiscencia presentan varias ventajas respecto a los métodos de revelado por técnicas cromogénicas. Incrementan mucho la sensibilidad del revelado, se llevan a cabo en tiempos cortos y permiten que las membranas puedan ser vueltas a emplear en distintas condiciones de revelado ya que los productos son solubles y no producen el depósito de ninguna sustancia sobre la membrana. En este tipo de reacciones, intermedios electroquímicamente generados experimentan reacciones altamente exergónicas que producen un estado electrónicamente excitado que emite luz (Forster et al., 2009).

En este sistema la peroxidasa conjugada al anticuerpo secundario produce la oxidación de su sustrato, que en nuestro caso fue el luminol (Sigma Chemical Co.), generando en la reacción emisión de luz.

Para revelar con esta técnica se prepararon dos soluciones:

\section{Solución I:}

- $100 \mu \mathrm{l}$ de una solución 0,044 g/ml de Luminol (Sigma Chemical Co.) en dimetil sulfóxido (DMSO). 
- $44 \mu \mathrm{l}$ de una solución 0,015 g/ml de ácido p-cumárico (Sigma Chemical Co.) en DMSO.

- $666 \mu$ l de buffer Tris I,5 M pH 8,5.

- 9,1 9 ml de agua bidestilada.<smiles>Nc1cccc2c1C(=O)C(=O)NC2=O</smiles>

\section{Solución 2}

- $666 \mu$ le buffer Tris I,5 MpH 8,5.

$-6,4 \mu \mathrm{L}$ de $\mathrm{H}_{2} \mathrm{O}_{2}$.

$-9,33 \mathrm{ml}$ de agua bidestilada.

Para 2 membranas se prepararon $10 \mathrm{ml}$ de cada solución. Se mezclaron los dos reactivos justo antes de usarlos en una relación l : I (v/v), al abrigo de la luz (en cuarto oscuro). La membrana que estaba en la solución del último lavado se secó entre dos papeles de filtro y se hizo reaccionar durante I minuto con el reactivo recién mezclado, (con luz roja). Se secó nuevamente entre papeles de filtro y en total oscuridad se expuso entre 10 y 30 segundos a una placa radiográfica Kodak X-Omat, XAR-5, 13 x 18 cm (Sigma Cemical Co.). Una vez terminada la exposición, se reveló la placa tratándola con una solución de revelador fotográfico comercial hasta que se comenzaran a visualizar las manchas, luego se la lavó con agua y con una solución de reactivo fijador. Se lavó finalmente con agua y se dejó secar.

\section{10. Microscopía electrónica}

Antes de realizar la microscopía electrónica, las muestras de VHDL fueron dializadas durante toda la noche con buffer Tris- $\mathrm{HCl} 20$ mM pH 8. Los preparados fueron hechos por triplicado. Se utilizaron grillas de cobre de 300 mesh con una cobertura de fomvar mas carbon, donde se depositaron $10 \mu \mathrm{L}$ de la muestra $(288 \mu \mathrm{g})$. Luego de unos minutos se retiro el sobrenadante y se tiñó negativamente con 2\% de acetato de uranilo durante 30 segundos (Forte \& Nordhausen, 1986). Se utilizó un microscopio electrónico Philips EM-30I de 60 KV y se fotografiaron con un aumento de $100.000 \mathrm{x}$.

Las muestras de lipovitelinas fueron dializadas contra buffer fosfato potasio 50 mM, pH 7,4 y teñidas negativamente con fosfotungsteno al 2\% (Forte $\&$ Nordhausen, 1986). Los preparados fueron examinados con un microscopio electrónico JEOL I00S (JEOL Co., Japan) de 100 KV y fotografiados con una am- 
plificación de 60.000 x. La amplificación final fue 120.000 x.

Para todas las Lipoproteínas examinadas, aproximadamente 100 partículas de lipoproteína libres fueron medidas en múltiples fotografías tomadas de diferentes áreas de la grilla.

\section{11. Otras medidas efectuadas sobre la partícula lipoproteica VHDL III. 11. 1. Tratamiento con tripsina y PAGGE-SDS}

Para analizar la exposición relativa de las subunidades proteicas al medio acuoso, se ensayó su susceptibilidad a la tripsina. Para esto, se incubaron $50 \mu \mathrm{g}$ de lipoproteína purificada, con tripsina (grado secuenciación, Promega, Madison, WI, USA) en $50 \mathrm{mM}$ de bicarbonato de amonio $\mathrm{pH} 8$ a $37^{\circ} \mathrm{C}$. Se ensayaron las relaciones tripsina - proteína I:20 y 1:50 durante 30 y 60 minutos. Se interrumpió la proteólisis bajando la temperatura. Luego se realizó una electroforesis en condiciones desnaturalizantes para observar la ruptura de las subunidades.

\section{11.2. Secuencia N-terminal}

La determinación de la secuencia de aminoácidos del extremo N-terminal de la proteína no respiratoria de 121 kDa que forma parte de la partícula lipoproteica VHDL, fue realizada por el Laboratorio Nacional de Investigación y Servicios en Péptidos y Proteínas (LANAIS-PRO). Se realizó un PAGGE-SDS de la lipoproteína, para obtener una buena separación entre las proteínas no respiratorias y las respiratorias, y luego se electrotransfirió a una membrana de PVDF que se envió al LANAIS-PRO para su análisis. Se utilizó el método de degradación de Edman, en un Secuenciador Modelo 477 de Applied Biosystems.

\section{11.3. Dicroísmo circular}

El dicroísmo circular (DC) es una técnica espectroscópica de absorción que permite obtener información acerca de la estructura de macromoléculas biológicas, siempre que éstas sean ópticamente activas, es decir, que roten el plano de la luz polarizada. Se utiliza como fuente luz polarizada (UV-Vis). Un rayo de luz polarizado en un plano puede considerarse formado por dos componentes polarizados circularmente, uno a la derecha y otro a la izquierda. Al pasar por un medio ópticamente activo, cada componente interactúa de manera diferente con los centros quirales de las moléculas presentes en el medio, de manera que se induce un desfasaje y un cambio de magnitud en ambos componentes polarizados circularmente, lo que provoca una rotación del plano de polarización en un ángulo $\alpha$. La distorsión de este plano genera una elipse. El DC se define mediante la relación entre el eje mayor y menor de la elipse. Esta relación es la tangente del ángulo $\theta$, conocido como elipticidad.

La rotación del plano y la diferente absorción de los componentes circularmente polarizados varían de acuerdo con la longitud de onda, pudiéndose 
obtener espectros de estos fenómenos, esto es, gráficas de la rotación o elipticidad, versus la longitud de onda, es lo que se conoce como espectros de DC.

Es posible representar el espectro de DC en el UV-lejano de cualquier proteína como una combinación lineal de contribuciones de las diferentes estructuras secundarias presentes en la misma.

Para analizar la contribución de cada estructura secundaria en la estructura de la VHDL, se realizaron espectros de DC de esta lipoproteína de muy alta densidad. Se trabajó en bicarbonato de amonio $10 \mathrm{mM}$ a $25^{\circ} \mathrm{C}$ en un espectropolarímetro Jasco 7 15, usando células de 0,I cm de paso de luz en el UVlejano ( $185-260 \mathrm{~nm}$ ). Los espectros DC fueron registrados cada $5 \mathrm{~nm}$, con un promedio de 2 espectros por segundo. La proteína se determinó por absorción a $280 \mathrm{~nm}$ utilizando un coeficiente de extinción de $1,42 \mathrm{Lg}^{-1} \mathrm{~cm}^{-1}$. Para estimar la composición de la estructura secundaria se analizaron los espectros con el programa Varselec (Toumadje et al., 1992).

\section{11.4. Análisis MALDI-TOF MS}

MALDI-TOF es una técnica de ionización utilizada en espectrometría de masas. Su nombre deriva de sus siglas en inglés: MALDI: Matrix-Assisted Laser Desorption-Ionization (desorción-ionización láser asistida por matriz) y TOF, el detector de iones acoplado: Time-Of-Flight (tiempo de vuelo). Es particularmente útil para obtener el espectro de masas de un conjunto de péptidos, también denominado "huella peptídica". En esta técnica las proteínas a analizar se colocan en una matriz absorbente de luz. La biomolécula se irradia con un pulso láser de nanosegundos. La mayor parte de la energía del láser es absorbida por la matriz, lo que evita la fragmentación no deseada de la biomolécula. Las biomoléculas ionizadas son aceleradas en un campo eléctrico, e introducidas en el tubo de vuelo. Durante este vuelo, las moléculas diferentes se separan de acuerdo a su relación masa/carga de manera que llegan al detector en diferentes momentos, y cada molécula produce una señal diferente. Las huellas peptídicas son características de cada una de las proteínas, y permiten identificarlas una a una en la base de datos, utilizando técnicas bioinformáticas.

Para el análisis MALDI-TOF de la forma monomérica de la hemocianina y de las subunidades no respiratorias, éstas fueron separadas por PAGGE-SDS en geles de poliacrilamida 4-23\% y teñidos con Coomasie Brilliant Blue. Las bandas de 67, 105 y 121 kDa fueron cortadas del gel, trituradas y desteñidas con acetonitrilo $100 \%$, seguido de cuatro Lavados con $1 \mathrm{ml}$ de agua. Luego fueron incubadas durante 20 minutos en $500 \mu \mathrm{l}$ de bicarbonato de amonio $100 \mathrm{mM}, \mathrm{y}$ otros 20 minutos con $500 \mu$ acetonitrilo al $50 \%$ en bicarbonato de amonio 50 $\mathrm{mM}$. El gel fue secado al vacío, rehidratado y digerido con $50 \mathrm{ng} / \mu \mathrm{l}$ de tripsina (grado secuenciación, Promega, Madison, WI, EE.UU.), en 25 mM de bicarbonato de amonio, a $4^{\circ} \mathrm{C}$, durante toda la noche. Los péptidos fueron extraídos y analizados por espectrometría de masas MALDI-TOF en un ABI Voyager Pro 
Maldi-Ms con ácido ciano-4-hidroxicinámico como matriz y estándares internos para la calibración. Se utilizó la base de datos Matrix Science (MSDB) para la identificación de los péptidos.

\section{III.11.5. Emisión de fluorescencia (Lakowicz, 1999)}

La fluorescencia es uno de los fenómenos de luminiscencia (es decir, emisión de luz), en el que un electrón en su estado excitado se encuentra apareado (con espín opuesto) con otro electrón en su estado basal. Cuando este electrón excitado regresa a su estado basal lo hace rápidamente, con emisión de un fotón. Cuando una molécula capaz de absorber fotones (fluoróforo) es excitada con luz, promueve a algunos de sus electrones a estados superiores de energía. La desexcitación de los mismos ocurre en dos pasos: en primer lugar el electrón regresa a un estado de energía menor, en un proceso denominado conversión interna, disipando parte de la energía en forma de calor; en segundo lugar el electrón retorna al estado basal, liberando la energía como fotones (fluorescencia). Esto hace que la energía de emisión sea generalmente menor que la de absorción, y por lo tanto la longitud de onda de la emisión, será mayor que la de la excitación. Este fenómeno, característico de la fluorescencia se denomina corrimiento de Stokes. Los datos de espectros de emisión son presentados generalmente como gráficos de intensidad de fluorescencia vs. longitud de onda (nanómetros).

Los fluoróforos son divididos en dos clases generales: extrínsecos, aquellos que son adheridos a la muestra que no presenta propiedades espectrales; e intrínsecos, aquellos que se encuentran naturalmente en la muestra. En las proteínas se encuentran fluoróforos intrínsecos, los residuos aromáticos de tres aminoácidos: tirosina, fenilalanina y triptófano, que, al encontrarse en la mayoría de las proteínas les otorgan propiedades fluorescentes a las mismas. De ellos, el que presenta más fluorescencia es el triptófano, con un máximo de absorción a $280 \mathrm{~nm}$ y un máximo de emisión a $340 \mathrm{~nm}$. Debido a que estos fluoróforos intrínsecos poseen alta sensibilidad a la polaridad del solvente en el cual se encuentren, el espectro de emisión de fluorescencia puede reflejar de alguna manera la posible conformación proteica. Es importante destacar que el análisis de su emisión da información de todos los fluoróforos excitados, la contribución de cada uno de ellos es muy difícil de estimar. La utilidad de esta emisión de fluorescencia, está dada en gran medida por la comparación que se puede generar con otros espectros de fluorescencia de lipoproteínas relacionadas estructuralmente.

EL espectro de fluorescencia fue realizado en un espectrofluorometro Perkin-Elmer LS55 (Norwalk, CT, USA) usando una lámpara de Xenón a 200 W. La lipoproteína fue resuspendida en buffer fosfato potasio $50 \mathrm{mM}(\mathrm{pH} 7,5)$. La longitud de onda de excitación fue de 280nm y la absorbancia fue inferior a 0,05. 


\section{12. Preparación de sal de amonio}

Para los experimentos de transferencia de lípidos in vivo e in vitro se utilizó como precursor radiactivo al ácido palmítico $\mathrm{I}^{-14} \mathrm{C}$. Dado que éste, como todos los lípidos, por su insolubilidad en medios acuosos, no puede ser transportado en la HL, fue necesario generar una sal que lo vehiculice fácilmente. Se preparó entonces, palmitato de amonio. Para la preparación de la sal de amonio se realizó el siguiente protocolo:

1) Colocar el ácido palmítico radiactivo en un tubo de vidrio cónico y evaporar a seco.

2) Agregar agua bidestilada según el volumen y concentración a la que se quiera la solución.

3) Agregar etanol ( $1: 75 \mu$ lácido palmítico) e hidróxido de amonio ( I:375 $\mu$ ácido palmítico)

4) Agitar

5) Eliminar el exceso de amonio, como amoníaco, calentando la solución en un baño a $50-60^{\circ} \mathrm{C}$ con corriente de aire.

\section{13. Medidas de radioactividad por contador de centelleo líquido}

La cuantificación de la radioactividad asociada a los distintos tejidos y a la $\mathrm{HL}$ en los experimentos de transferencia lipídica se realizó en un contador de centelleo Líquido LC 100 Beckman. Los recipientes de medida fueron viales plásticos descartables (Polistor) y el líquido de centelleo fue Optiphase Hisafe 2 (Perkin Elmer Life Sciences, UK). Este tipo de equipos mide la luz, producto de la colisión entre moléculas que son impactadas por las partículas $\beta$ emitidas por el compuesto radioactivo.

\section{14. Diseño experimental para el estudio de la transferencia de lípi- dos in vivo, entre divertículos intestinales y hemolinfa}

\section{14. 1. Marcación in vivo con precursor radioactivo}

\section{III.14.1.1. Experimentos de alimentación}

Si bien las arañas se caracterizan por ser animales cazadores que se alimentan de presas vivas, para el estudio de la utilización de lípidos de la dieta en adultos de $P$. pythagoricus, se eligió alimentarlas con pequeñas porciones de carne vacuna picada (existen reportes bibliográficos sobre el uso de embriones de mamíferos para la alimentación de las arañas migalomorfas). Esto, fue para evitar la posibilidad de que, al tener que administrarle a la presa un precursor radioactivo, los resultados se vieran afectados por el metabolismo lipídico de la propia presa. Sorprendentemente, esta "presa muerta" fue bien aceptada. Se administró a 3 arañas, porciones de 50 mg de carne picada, previamente marcada con $2 \mu \mathrm{Ci}$ de ácido palmítico $1^{-14} \mathrm{C}$, vehiculizado como sal de amonio. Las arañas fueron mantenidas en tarros individuales a temperatura ambiente hasta que 
terminaran de comer, esto es, hasta que ya no se podía ver restos de alimento sostenido entre los quelíceros. Este proceso tardó entre I y 3 hs. Se contaron 2 horas a partir de este momento y luego los animales fueron anestesiados para extraer HL, DI, pulmones, y el resto de los tejidos, como se describió anteriormente.

Se cuantificó la radioactividad incorporada en cada tejido y en cada clase de lípido, combinando las técnicas de cuantificación por contador de centelleo Líquido y escaneado de las placas por Storm. Las arañas fueron analizadas por separado y los datos obtenidos fueron combinados para obtener valores promedio y DS.

\section{14.1.2.a. Experimentos de inyección}

Para estudiar el destino metabólico del precursor radiactivo cuando es administrado directamente a la HL, se suministró por inyección a 5 arañas, $6 \mu \mathrm{l}$ de ácido palmítico $\mathrm{I}^{-14} \mathrm{C}$ vehiculizado como sal de amonio, en una concentración de 0,66 $\mu \mathrm{Ci}$ ( II,6 nmoles)/ $\mu$ l de solución. En primer lugar se las anestesió, dejándolas en un congelador a $-4^{\circ} \mathrm{C}$ durante 15 minutos. Luego se las colocó sobre una base de telgopor y se cubrieron con una red plástica para evitar que se muevan y caminen. Las inyecciones fueron hechas con jeringas Hamilton de punta biselada de $10 \mu \mathrm{l}$ en alguna de las articulaciones de una pata. Luego fueron mantenidas en tarros individuales a temperatura ambiente, durante 4 horas. Transcurrido este tiempo, fueron anestesiadas nuevamente, bajando la temperatura, para extraer HL, DI, pulmón y músculo, descartando la pata inyectada. Se cuantificó la radioactividad incorporada en cada tejido y en cada clase de lípido, combinando las técnicas de cuantificación por contador de centelleo líquido y escaneado de las placas por Storm.

\section{14.1.2.b. Experimentos de inyección a distintos tiempos}

Para ensayar las variaciones en función del tiempo del metabolismo del precursor radioactivo, se inyectó a 3 grupos de 5 arañas como se describió anteriormente, y se definieron 3 tiempos de incubación durante los cuales fueron mantenidas en frascos individuales a temperatura ambiente:

Grupo I: I hora.

Grupo II: 5 horas.

Grupo III: 24 horas.

Concluidas las incubaciones se las anestesió para extraer DI y HL, de la que luego se aislaron las lipoproteínas constituyentes.

Se cuantificó la radioactividad incorporada en el tejido, en HL y en las lipoproteínas hemolinfáticas, y en cada clase de lípido, combinando las técnicas de cuantificación por contador de centelleo líquido y escaneado de las placas por Storm. 


\section{14.2. Captación de lípidos por hemocitos}

Para estudiar si las células circulantes en la HL (hemocitos) son capaces de captar lípidos, se inyectaron 3 arañas con $6 \mu \mathrm{l}$ de ácido palmítico $1^{-14} \mathrm{C}$ vehiculizado como sal de amonio, en una concentración de 0,66 $\mu \mathrm{Ci}$ ( 11,6 nmoles) $/ \mu \mathrm{l}$ de solución. Después de I hora de incubación, se extrajo la HL para el aislamiento de los hemocitos. Se realizó el siguiente protocolo:

1) Colocar la HL en un tubo con $600 \mu$ l de buffer citrato previamente enfriado.

2) Agitar

3) Centrifugar a $720 \mathrm{~g}$ durante 10 minutos a $4^{\circ} \mathrm{C}$

4) Descartar el sobrenadante, y lavar el pellet de hemocitos con I ml de buffer citrato, vortexeando suavemente para disociar las celulas.

5) Centrifugar nuevamente a $720 \mathrm{~g}, 4^{\circ} \mathrm{C}$ por 10 minutos.

6) Descartar el sobrenadante y congelar los hemocitos a $-20^{\circ} \mathrm{C}$ hasta ser utilizados.

A partir de los hemocitos obtenidos, se extrajeron lípidos por la técnica Folch et al. ( 1957) y se cuantificó la radioactividad asociada por contador de centelleo líquido.

\section{15. Diseño experimental para el estudio de la transferencia de lípi- dos in vitro, entre divertículos intestinales y hemolinfa}

III. 15. 1. Marcación in vivo con precursor radioactivo

Para la marcación in vivo de los DI y la HL se administró a un grupo de 5 arañas, $6 \mu \mathrm{l}$ de ácido palmítico $1^{-14} \mathrm{C}$ vehiculizado como sal de amonio, en una concentración de 0,66 $\mu \mathrm{Ci}$ ( 11,6 nmoles)/ $\mu$ l de solución, como se describió anteriormente. Después de I hora de incubación a temperatura ambiente, se extrajo la HL y se disecaron los DI, que fueron utilizados para ensayos de transferencia entre ellos.

III. 15.2. Ensayos de captación de lípidos por lipoproteínas hemolinfáticas

Para explorar la captación de lípidos por las lipoproteínas hemolinfáticas, se incubó in vitro a los DI dadores, marcados con lípidos radioactivos ${ }^{-14} \mathrm{C}$ (45\% AGL, 39\% TAG y 15\% PL), con HL no marcada aceptora. Las incubaciones fueron hechas en buffer fosfato potasio $50 \mathrm{mM}, \mathrm{pH}$ 7,4 y 0,25 M de sacarosa, con la adición de I $\mu \mathrm{l}$ de inhibidor de proteasas (Sigma Chemicals, St. Louis, MO, Usa), en un volumen final de $1 \mathrm{ml}$. Se incubó durante 30 minutos a $25^{\circ} \mathrm{C}$, con agitación. La relación dador/aceptor fue de I DI ( $120 \pm 0,07 \mathrm{mg}$ )/ $100 \mu \mathrm{LLL}$ (cantidad de HL que posee un individuo adulto).

Por otro lado para analizar el comportamiento de cada lipoproteína por separado se hicieron incubaciones en iguales condiciones a las detalladas anteriormente, pero con las lipoproteínas aisladas:

1) DI marcado con Lípidos radioactivos ${ }^{-14} \mathrm{C}$ con HDL I sin marcar 
2) DI marcado con lípidos radioactivos ${ }^{-14} \mathrm{C}$ con VHDL sin marcar

La relación dador/aceptor fue I DI/232,4 $\mu$ g de proteína de HDL I y I DI/4542,7 $\mu \mathrm{g}$ de proteína de VHDL. Estas concentraciones de proteína son las encontradas en $100 \mu \mathrm{L}$ de $\mathrm{HL}$ (correspondiente a un individuo).

Después de las incubaciones se separaron los tejidos del medio de incubación y se extrajeron los lípidos para ser analizados.

\section{15.3. Ensayos de liberación de lípidos de lipoproteínas hemolinfáticas}

Para estudiar la liberación de lípidos de las lipoproteínas hemolinfáticas, se incubó $\mathrm{HL}$ marcada (dadora) con lípidos radioactivos ${ }^{-14} \mathrm{C}$ (56\% AGL, $16 \% \mathrm{PL}$, $28 \%$ TAG), con DI no marcados (aceptores). Las incubaciones fueron hechas en buffer fosfato potasio $50 \mathrm{mM} \mathrm{pH} \mathrm{7,4;} \mathrm{0,25} \mathrm{M} \mathrm{sacarosa,} \mathrm{con} \mathrm{la} \mathrm{adición} \mathrm{de} \mathrm{I} \mu \mathrm{l}$ de aprotinina (Sigma Chemicals, St. Louis, MO, Usa), como inhibidor de proteasas en un volumen final de I $\mathrm{ml}$. Los ensayos se realizaron a $25^{\circ} \mathrm{C}$ durante 30 minutos, con agitación. La relación dador/aceptor fue de $100 \mu \mathrm{L}$ de HL/DI ( $20 \pm$ 0,07 $\mathrm{mg}$ ), similar a lo encontrado en un individuo en condiciones fisiológicas.

Para analizar el comportamiento de cada lipoproteína por separado se realizaron incubaciones con lipoproteínas aisladas (al igual que en HL entera los Lípidos mayoritarios fueron los AGL) en las mismas condiciones que las descriptas anteriormente:

1) HDLI marcada con DI no marcado

2) VHDL marcada con DI no marcado

En ambos casos en relaciones fisiológicas. Luego de las incubaciones se separaron los tejidos y el medio de incubación, y se extrajeron los lípidos para ser analizados.

\section{15.4. Transferencia de lípidos entre lipoproteínas}

Para estudiar la transferencia de lípidos entre Lipoproteínas se realizaron incubaciones entre una cantidad constante de dador (concentración fisiológica), HDL I o VHDL marcadas, y cantidades crecientes de aceptor, HDL I o VHDL no marcadas en relaciones aceptor/dador de 0,25; 0,5 y I. Las incubaciones fueros hechas en buffer fosfato potasio $50 \mathrm{mM} \mathrm{pH} \mathrm{7,4,} \mathrm{a} 25^{\circ} \mathrm{C}$, durante 30 minutos, con agitación.

\section{16. Análisis estadístico}

Para los estudios de transferencia tanto in vivo como in vitro, los ensayos se han realizado por triplicado y se calcularon en cada caso los desvíos estándar. Los datos fueron analizados mediante el test T Student's, con el programa XLSTAT-Pro, se consideró significativo un $\mathrm{p}<0,05$. 


\section{CAPITULO IV}

Caracterización estructural de una lipoproteína de muy alta densidad de Polybetes pythagoricus 


\section{Caracterización estructural de una lipoproteína de muy alta densidad de Polybetes pythagoricus}

\section{IV.1. Introducción}

Como se mencionó en la Introducción general, dos de las tres lipoproteínas que constituyen el sistema de transporte de lípidos hemolinfáticos de la araña P. pythagoricus, las llamadas HDL2 y VHDL, presentan como principal apolipoproteína al pigmento respiratorio hemocianina.

Además de ésta difundida función como pigmento respiratorio, se han descripto para la hemocianina, otras funciones como tener actividad fenoloxidasa, antimicrobial o poder actuar como apolipoproteína asociada con la mayor parte de los lípidos circulantes (Cunningham et al., 2007; Decker \& Jaenicke, 2004; Jaenicke \& Decker, 2004; Bridges, 2001 ; Cunningham et al., 2000; Cunningham et al., 1999; Decker \& Rimke, 1998; Terwilliger, 1998; Cunningham \& Pollero, 1996). La interacción de la hemocianina con los lípidos, ha sido descripta por primera vez por Zatta ( 1981 ), quien determinó la existencia de pequeñas cantidades de PL transportados por la hemocianina del cangrejo Carcinus maeñas, y le asignó a estos lípidos un rol estabilizador de la estructura apolipoproteica. El primer reporte de un posible rol de la hemocianina como transportadora de lípidos fue hecho por Heras y Pollero (1992; 1990) en el molusco Octopus tehuelchus. En 1995, Hall y colaboradores (Hall et al., 1995) mostraron que la hemocianina del cangrejo de río Pacifastacus leniusculus, se encuentra asociada a una parte considerable del total de los lípidos hemolinfáticos. El hecho de que la cantidad de lípidos asociados a la hemocianina en la araña Polybetes pythagoricus es significativa, nos llevó a considerar a VHDL como un modelo apropiado para estudiar, no solo la fisiología del transporte de lípidos, sino también, las interacciones entre la hemocianina y los lípidos.

La VHDL, ya ha sido parcialmente caracterizada en un trabajo anterior, en el que se reporta que esta partícula lipoproteica, presenta un 3,55\% de lípidos, entre los cuales los PL son los predominantes, y además se han aislado por HPLC subfracciones de esta lipoproteína, determinándose que la subfracción I corresponde al monómero de hemocianina, la subfracción Il al hexámero de hemocianina y 2 proteínas no respiratorias, y la subfracción III al heptámero de hemocianina (Cunningham \& Pollero, 1996) (para más detalles ver Introducción).

Dado que esta lipoproteína participaría de una manera importante en el transporte y la dinámica de los Lípidos circulantes en esta especie (ver capítulos Vy VI) decidimos realizar una caracterización estructural de VHDL, estudiando, en general, su estructura primaria, secundaria, terciaria y cuaternaria. Es importante destacar que en el presente estudio, se realiza una caracterización de la partícula lipoproteica completa, considerando a la hemocianina como apolipoproteína componente de una lipoproteína, y no solo como hemocianina libre. 
Para ello utilizamos varias técnicas, tales como, dicroísmo circular, proteólisis parcial con tripsina y emisión de fluorescencia, para obtener información sobre su estructura secundaria y grado de exposición de sus subunidades. Además se utilizó MALDI-TOF para determinar las relaciones existentes entre secuencias proteicas de las apolipoproteínas presentes en la VHDL y las secuencias proteicas descriptas para otros invertebrados.

\section{IV.2. Resultados}

\section{IV.2. 1. Análisis de las apoproteínas en condiciones nativas. Determinación de la presencia de cobre y lípidos}

Se estudiaron los constituyentes apoproteicos utilizando electroforesis en gradiente en condiciones nativas. En la figura IV.I se muestra el electroferograma obtenido. Se observan cinco bandas principales de los siguientes pesos moleculares: 490 kDa correspondiente al heptámero de hemocianina, 440 kDa correspondiente al hexámero de hemocianina, 230 y 198 kDa correspondientes a las proteínas no respiratorias y una banda de alrededor de 70 kDa, que correspondería al monómero de hemocianina, estos resultados son coincidentes con los que han obtenido Cunningham y colaboradores, luego de un análisis electroforético en condiciones nativas de las subfracciones de VHDL aisladas por HPLC (Cunningham \& Pollero, 1996), pero en este caso se ha analizado la partícula en condiciones nativas en lugar de sus subfracciones.

Para determinar la presencia de cobre en la estructura nativa de la VHDL, se tiñó un gel nativo con biquinolina, un colorante específico para cuproproteínas. La falta de tinción en las proteínas no respiratorias mostró que éstas, no incluyen cobre en su estructura (Fig. IV.I A). Para detectar la presencia de Lípidos, las muestras fueron teñidas con Sudan Black, y luego se corrieron en un gel en condiciones nativas que reveló que, tanto el hexámero de hemocianina (440 $\mathrm{kDa}$ ), como las bandas de alto peso molecular de las proteínas no respiratorias (230 kDa), tienen lípidos en su estructura (Fig. IV.I B).

A

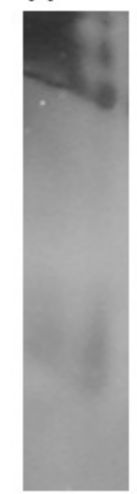

1

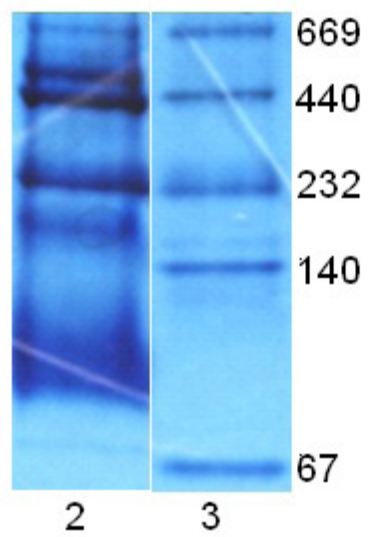

B

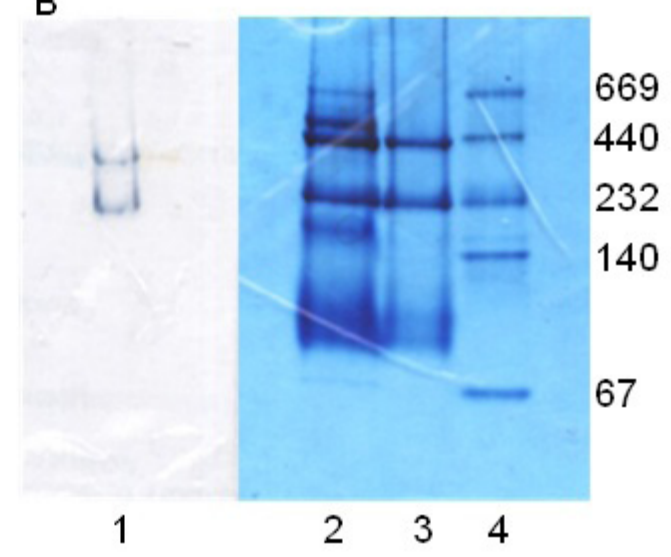

Figura IV.1:

A: PAGGE-Nativo teñido con biquinolina para detectar presencia de cobre. B: PAGGE-Nativo teñido con Sudan Black para detectar presencia de lípidos. 


\section{IV.2.2. Estructura secundaria}

Con el objetivo de obtener información sobre la estructura secundaria de la lipoproteína de muy alta densidad aislada de la HL de P. pythagoricus, se utiLizó dicroísmo circular. En la figura IV.2A se observa el espectro de DC de UV lejano de la proteína. En el perfil se pueden identificar una banda positiva, con un máximo cercano a los $190 \mathrm{~nm}$ y una banda negativa con un mínimo aproximadamente a los $205 \mathrm{~nm}$. De la deconvolución espectral realizada con el programa Varselec, se estimó que esta lipoproteína contiene un 20\% de $\alpha$-hélice, un $29 \%$ de lámina- $\beta, 22,7 \%$ de giros y $29,7 \%$ de estructura aleatoria.

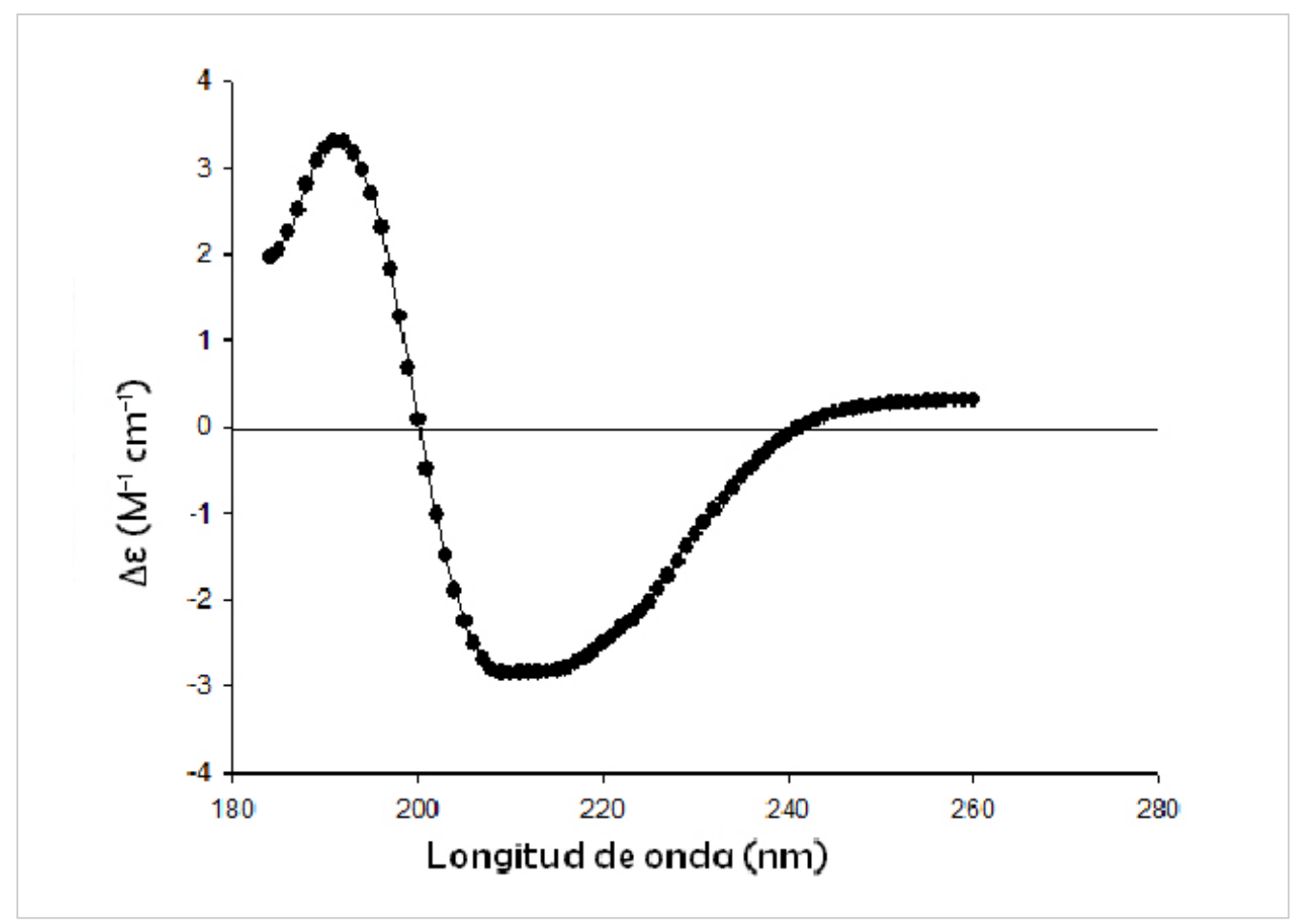

Figura IV.2A: Espectro de DC en el UV lejano de la VHDL de $P$. pythagoricus.

El espectro de emisión de fluorescencia de VHDL, obtenido con excitación a 280 nm, muestra un máximo a 336 nm (Fig. IV.2B), esto sugiere que varios residuos de triptófano estarían ubicados en un entorno hidrofóbico (Lakowicz, 1999). 


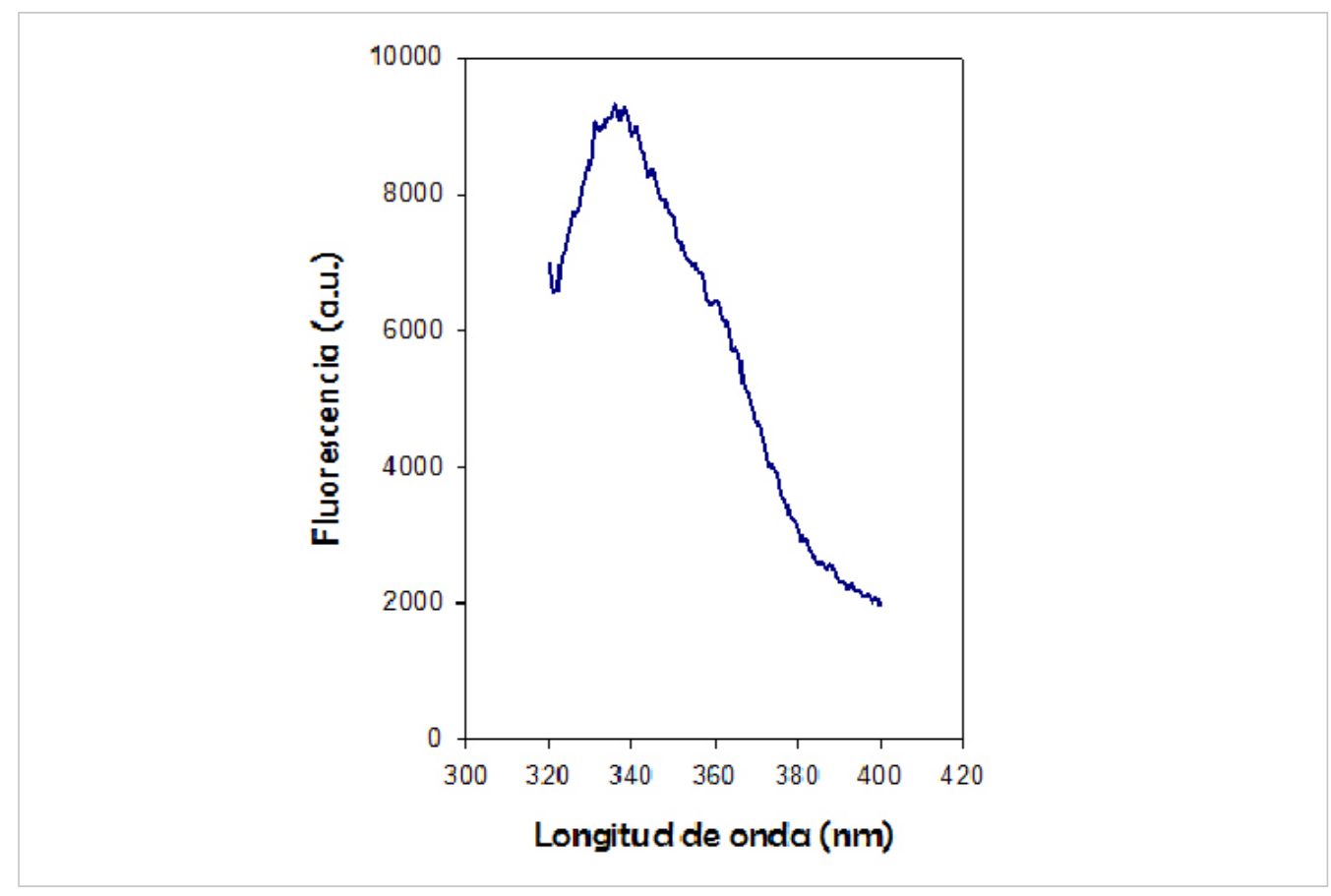

\section{IV.2.3. Determinación de la presencia de puentes disulfuro}

Conociendo por trabajos previos que esta lipoproteína está compuesta por subunidades de hemocianina y proteínas no respiratorias (Cunningham \& Pollero, 1996), se realizó un PAGGE-SDS, bajo condiciones oxidantes y reductoras, con el objetivo de conocer la naturaleza de las interacciones que mantienen unidas a éstas subunidades. En la figura IV.3 se pudo observar que tanto en Las muestras que fueron tratadas con $\beta$-mercaptoetanol, como en aquellas a las que no se trató con este agente reductor, el peso molecular del monómero y de las proteínas no respiratorias fue el mismo: 67, 105 y 12 I kDa respectivamente, indicando la ausencia de puentes disulfuro entre las subunidades.

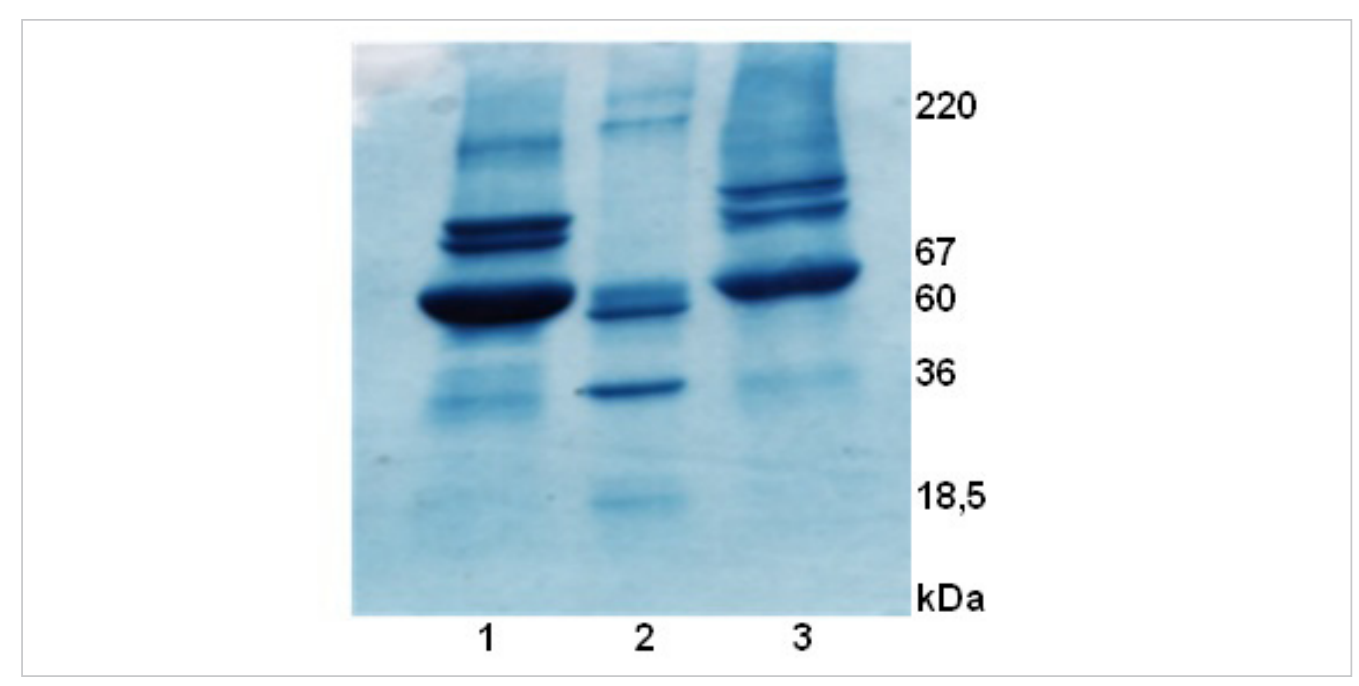

\section{Figura IV.2B:}

Espectro de emisión de fluorescencia de la VHDL de $P$. pythagoricus.
Figura IV.3: PAGGE-SDS (4-23\%). Línea 1: VHDL con b-mercaptoetanol. Línea 2: estándar de PM. Línea 3: VHDL sin b-mercaptoetanol. 


\section{IV.2.4. Tratamiento con tripsina}

Para analizar la exposición relativa de las subunidades proteicas al medio acuoso, se ensayó su susceptibilidad a la tripsina. Se realizaron incubaciones donde se ensayaron distintas relaciones tripsina:VHDL nativa, y distintos tiempos de incubación, seguidas de un análisis por electroforesis en condiciones nativas y disociantes. En el PAGGE-Nativo se observó degradación de las proteínas no respiratorias en los tres tiempos estudiados ( I, 15 y 30 minutos) (Fig. IV.4A). Un resultado similar se obtuvo del PAGGE-SDS que mostró una importante proteólisis de las subunidades de 105 y 121 kDa (Fig. IV.4B). Tanto en la determinación de tripsinólisis en condiciones nativas como disociantes, el monómero presentó algún grado de degradación, en especial cuando las incubaciones se realizaron durante tiempos más prolongados, aunque no fue tan importante como el de las subunidades de 105 y 121 kDa. Estos resultados podrían indicar que en la estructura de la VHDL en condiciones nativas, las dos proteínas no respiratorias se encontrarían más expuestas al medio acuoso, que las estructuras que poseen hemocianina como heptámeros, hexámeros y monómeros, las cuales se encontrarían menos expuestas o se plegarían de tal manera que no son susceptibles a la tripsinólisis.
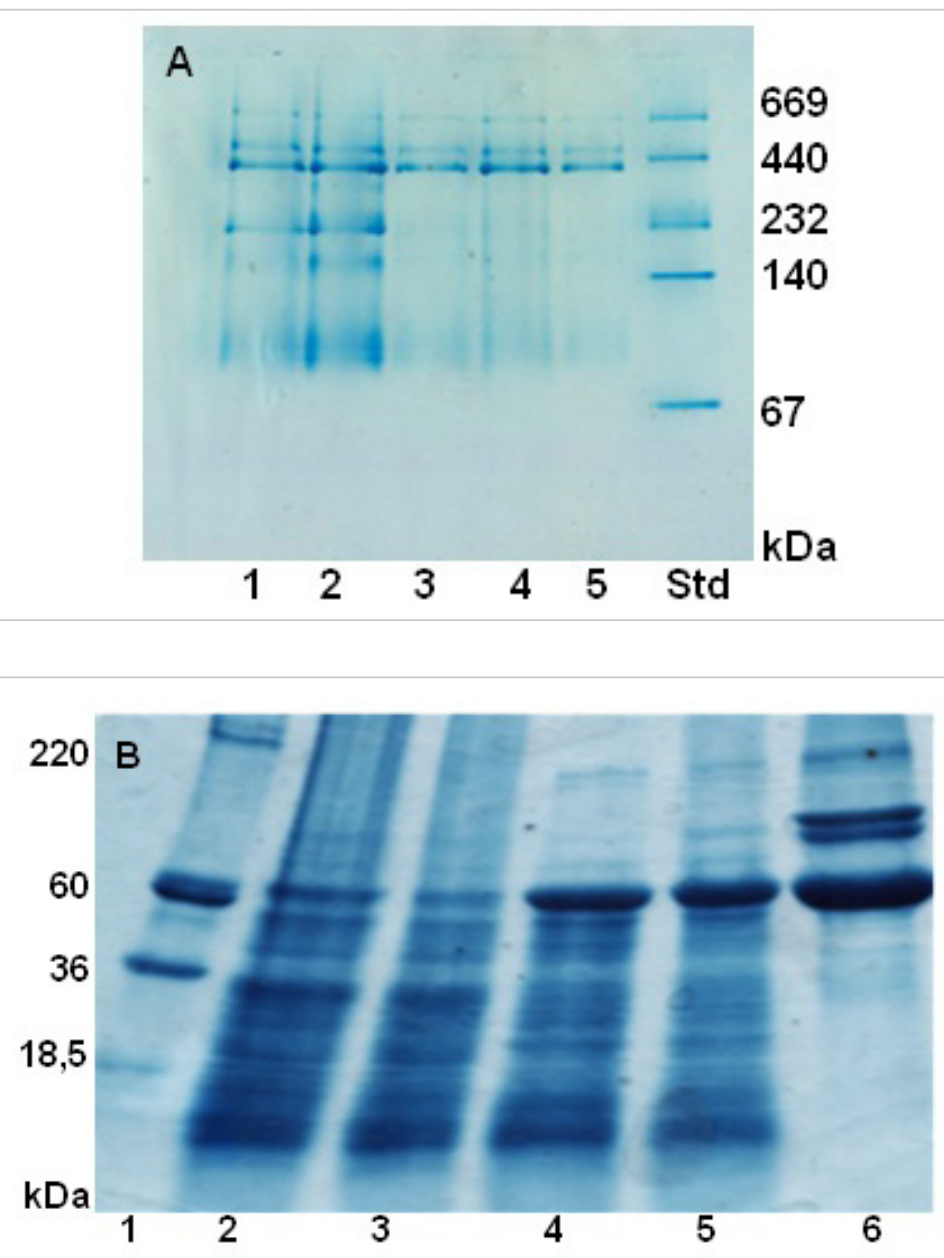

Figura IV.4B: PAGGESDS (4-23\%). Línea 1: estándar PM. Líneas 2 y 3: VHDL incubada con tripsina $(1: 20)$ durante 30 y 60 minutos respectivamente. Líneas 4 y 5: VHDL incubada con tripsina (1:50) durante 30 y 60 minutos respectivamente. Línea 6 : VHDL control. 


\section{IV.2.5. Análisis de homologías de secuencias peptídicas}

Las huellas peptídicas (fingerprinting) de la subunidad de 67 kDa (correspondiente al monómero de hemocianina), fueron obtenidas por clivaje con tripsina y análisis por MALDI-TOF. La figura IV.5 muestra el espectro de masas de los fragmentos trípticos de la proteína analizada. La búsqueda de péptidos coincidentes en las bases de datos, identificó que 10 polipéptidos presentes en el monómero fueron homólogos con la subunidad 3 de la hemocianina de la araña Cupiennius salei. En la figura IV.6 se observan las secuencias de aminoácidos de los péptidos coincidentes.

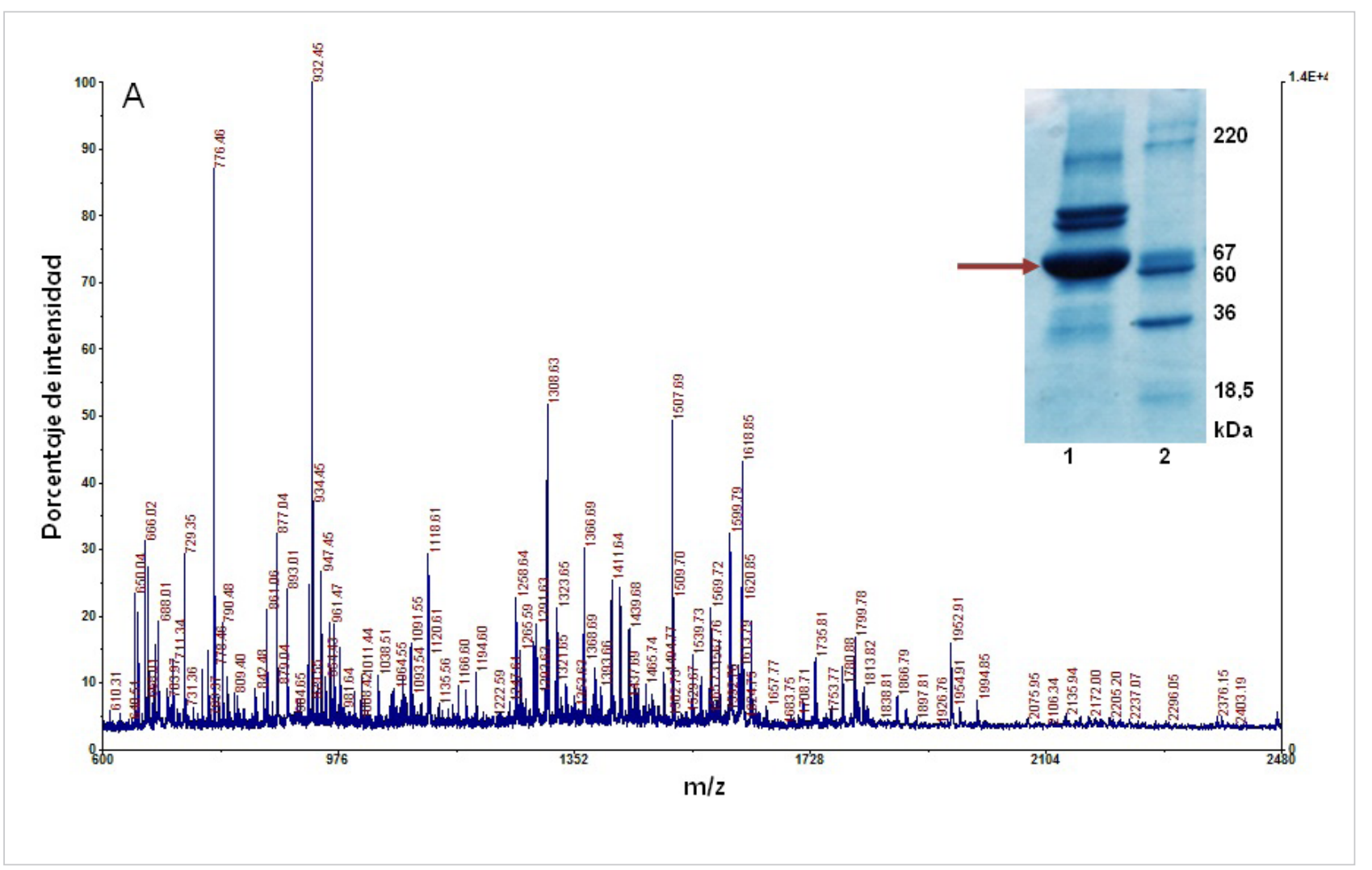

Figura IV.5: Espectro de masas de fragmentos trípticos del monómero de hemocianina. Inset: PAGGE-SDS 4-23\%. Línea 1: VHDL, línea 2: estándar PM. La flecha señala la subunidad correspondiente. 


\section{Monómero}

1 MTVKEMYDRI LPLFEKLTSL TRLQLPVEER DPRLAHVGRL PRGTLFSCFH

51 EKHLAEATEL FEILFAANDF DDFIKLATQA RNIVNEGLFV YVLSVAVVHR

101 DDCRGITLPP IQEVFPDRFV PAETINLAIK ESKNHPDIDI EVEIQQTGNI

151 MEPEYKLAYF REDIATNAHH WYWHVVYPAN WDEGLTGKVK DRKGELFYYM

201 HQQMCARYDC ERLSNGLNRM IPFHNFEEKL EGYAPHLTSL VSGLHYASRP

251 TGFSLRDLPD VDVQDMERWR ERILEAIDLQ HVHAADGSEL ALDEANGANI

301 LGTLIEASSS SPNKAFYGSL HNWGHVMMAR MHDPDGRFQE NPGVMSDTST

351 SLRDPIFYRW HRFVDNIFQQ YKATLHQYTK EQLSFAGIKI LSTQVNAKQA

401 NVVTTYLKED RLDLSHGINF GTGHKVYVKY HHLEHEPFSL IINVENNTGA

451 AKHATLRVFL GPKYDELGNR LAPDEQRRLM IELDKFHKEL APGKNVINRN

501 AAESNVTLSH TYTFDELRSG EGGPADANEY CSCGWPEHML LPKGTHKGME

551 YELFVMATDY TQDNPDGANV KTTCADAVSY CGAKDQKYPD LKPMGFPFDR

601 PVSARTAEEL LTENMSLTDV LIKYVG
Figura IV.6: Secuencias de aminoácidos luego del análisis por MALDITOF. Los péptidos que resultaron homólogos se muestran en rojo. P $<0,05$.

\section{IV.3. Discusión}

La lipoproteína que llamamos VHDL, es una de las tres que conforman el sistema de transporte de lípidos hemolinfáticos de la araña P. pythagoricus. Es una lipoproteína de muy alta densidad, con una alta concentración en HL, que presenta la particularidad de tener hemocianina como apolipoproteína, una función que resulta novedosa para este pigmento, dentro de los arácnidos. Solo en dos especies de arañas, P. pythagoricus y L. mirabilis, se ha encontrado hemocianina asociada a lípidos, de manera que constituya lipoproteínas, de alta densidad en L. mirabilis, y de alta y muy alta densidad en P. pythagoricus, mientras que en otras especies de arácnidos, no existen hasta el momento, datos sobre la existencia de lipoproteínas cuyo componente proteico este constituido por hemocianina (Cunningham et al., 2007), aunque sí, se ha descripto en la tarántula Eurypelma californicum que su hemocianina es capaz de ligar otros compuestos hidrofóbicos como ecdisona (Jaenicke et al., 1999b). En otros artrópodos, existen reportes sobre asociaciones hemocianina-lípidos, como en el crustáceo Pacifastacus leniusculus, donde ha sido descripto que la densidad de la hemocianina es de $1,31 \mathrm{~g} / \mathrm{ml}$ y que contiene aproximadamente $0,2 \% \mathrm{p} / \mathrm{p}$ de lípidos. En este cangrejo, aunque la cantidad de lípidos por molécula de hemocianina es baja, una considerable parte de los lípidos circulantes ( $17 \%$ ) se encuentran relacionados a esta proteína, con lo cual jugaría un rol importante en el transporte de lípidos hemolinfáticos (Hall et al., 1995). En P. pythagoricus existe además de VHDL, una lipoproteína hemolinfática de alta densidad, llamada HDL2, que también contiene hemocianina como apolipoproteína. En este trabajo solo se ha utilizado VHDL, por un lado porque su concentración hemolinfática es dos veces más abundante que la de HDL2 (Cunningham \& Pollero, 1996), y por otro, porque esta partícula polifuncional posee un rol destacado en la dinámica de lípidos en ensayos realizados in vivo e in vitro (ver capítulo $\vee$ y IV). 
En el análisis electroforético en condiciones nativas de la VHDL, se pudo observar para esta lipoproteína, la presencia de cinco bandas principales, que corresponderían al heptámero (490 kDa), hexámero (440 kDa), proteínas no respiratorias (230 y 198 kDa) y monómero (70 kDa). En trabajos previos realizados por Cunningham y colaboradores sobre esta lipoproteína, los autores reportan que en condiciones nativas se observa una banda de 70 kDa, cuando se analiza por electroforesis la subfracción III de la VHDL aislada por HPLC utilizando columnas de exclusión molecular. Cuando esta subfracción es analizada en condiciones disociantes, presenta el mismo comportamiento electroforético, lo cual haría suponer que se trata del monómero de hemocianina (Cunningham \& Pollero, 1996).

La presencia de heptámeros en la estructura cuaternaria de la hemocianina, ya ha sido reportada en el quelicerado Cupiennius salei (Ballweber et al., 2002; Markl, 1980). Los autores encontraron en la HL de esta especie, bandas proteicas que representan $2 \times 6$ y $1 \times 6$ meros de hemocianinas, además de una proteína no respiratoria, y una significativa cantidad de heptámeros, formados por una disociación parcial de la estructura $2 \times 6$.

Es conocido que a $\mathrm{pH}$ alcalino y en ausencia de cationes divalentes, la molécula de hemocianina nativa se disocia en distintos polipéptidos (Ali et al., 1995; Lamy et al., 1981; Lamy et al., 1980). Si bien en nuestro estudio utilizamos un $\mathrm{pH}$ adecuado, y se incluyeron cloruro de calcio y de magnesio en el buffer de aislamiento de la lipoproteína, dado que se trata de una partícula muy compleja, pudo haber ocurrido cierta disociación de hexámeros o posibles dihexámeros que hayan dado lugar a la aparición de heptámeros. Maaroufi y Lamy ( 1993 ) demostraron que hay un equilibrio entre heterodímeros y monómeros y, entre monómeros y homodímeros, en la hemocianina de los escorpiones Scorpio maurus y Androctonus australis. En nuestro caso se observó un equilibrio entre el heptámero, hexámero y monómero, cuando la VHDL de P. pythagoricus fue purificada por HPLC usando columnas de exclusión molecular (datos no mostrados), que estaría dado por un equilibrio dinámico, que daría lugar a la transición monómero-hexámero, y que sería altamente dependiente del pH y la presencia de cationes divalentes (Brenowitz et al., 1984; Brenowitz et al., 1983; Van Holde \& Miller, 1982; Lamy et al., 1977).

Las características de la estructura secundaria de la VHDL de P. pythagoricus fueron estudiadas utilizando DC. La información disponible al respecto sobre arañas y grupos relacionados es muy escasa. En la lipoproteína de P. pythagoricus se observó que el contenido de lámina $\beta$, fue mayor que el de hélice $\alpha$, con un 29 y $21,6 \%$ respectivamente, además de un $22,7 \%$ de giros. Estos resultados en general fueron similares a los observados por Dolaska-Angelova (2005) en Carcinus aestuarii, donde la hemocianina presenta: $16 \%$ hélice $\alpha, 30,1 \%$ de lámina $\beta, 20 \%$ de giros y $34 \%$ de estructura desordenada. Con respecto a otras arañas, solo se ha caracterizado la estructura secundaria en la araña Eurypelma 
californicum. A diferencia de lo encontrado en P. pythagoricus, presenta un 25,2\% de hélice $\alpha, 21,6 \%$ de lámina $\beta, 22,4 \%$ de giros y $28,5 \%$ de estructura desordenada. En la hemocianina del escorpión Padinus imperator, se repite el hecho de que el porcentaje de hélice $\alpha$ es ligeramente superior al de lámina $\beta$, reportándose un 26,5 y 20,6\% respectivamente (Baird et al., 2007). En estudios previos, Lee y colaboradores (2003), han descripto que la hemocianina de crustáceos puede ser procesada por una proteinasa tipo cisteína, para generar un péptido antimicrobiano llamado astacidina I. Este péptido presenta una estructura de lámina $\beta$ (aproximadamente 50\%) basada en su espectro de DC, que es probable que sea importante para su actividad antibacteriana. Probablemente, el hecho de que en la VHDL de $P$. pythagoricus exista un porcentaje algo más elevado de lámina $b$ que de hélice a, podría estar indicando una actividad de ese tipo. De todos modos son necesarios más experimentos para poder asegurar esta hipótesis.

El máximo de emisión de fluorescencia para la VHDL de la especie en estudio fue de $336 \mathrm{~nm}$, un valor intermedio entre los reportados para las hemocianinas de Euripelma califórnicum, de $338 \mathrm{~nm}$, y del crustáceo Panulirus interruptus, de $328 \mathrm{~nm}$ (Erker et al., 2008), e igual al reportado para el crustáceo P. monodon (Yeh et al., 1999). Estos resultados sugieren similitudes en el entorno de los residuos triptófano entre los distintos grupos. Las propiedades de fluorescencia podrían ser explotadas en estudios próximos, para estudiar el pegado de distintos lípidos, por ejemplo evaluando su unión a alguna de las subunidades que conforman la lipoproteína, o a todas ellas.

Para analizar la presencia o ausencia de puentes disulfuros en la VHDL, esta fue sujeta a PAGGE-SDS bajo condiciones oxidantes y reductoras. Este anáLisis mostró que no hay diferencias cuando se comparan los perfiles electroforéticos en presencia o ausencia de $\beta$-mercaptoetanol, indicando la ausencia de puentes disulfuro entre las subunidades de la partícula (Fig. IV.3). Los pesos moleculares tanto del monómero, como de las proteínas no respiratorias, fueron iguales en ambas condiciones: 67, 105 y 121 kDa respectivamente. Cada una de las proteínas no respiratorias, podría ser un dímero, como indican sus pesos moleculares en condiciones nativas. El análisis electroforético en condiciones disociantes de la araña Cupiennius salei, tanto con el agregado de un agente reductor, como sin él, revelan una única banda de hemocianina, en el rango de 70 kDa. La proteína no respiratoria forma una banda simple de alrededor de 110 kDa en condiciones no reductoras, y una doble banda de 100 y $121 \mathrm{kDa}$, al agregar $\beta$-mercaptoetanol. Una banda adicional de $140 \mathrm{kDa}$ aparece solo bajo condiciones no reductoras (Ballweber et al., 2002), que podría interpretarse como un dímero de hemocianina unido por puentes disulfuro (Markl, 1980). En el escorpión Scorpio maurus, cuando se analizó su hemocianina por cromatografía de exclusión molecular, se definieron 3 zonas cromatográficas: I, II y III. Las zonas I y || probablemente corresponden a dímeros y monómero de hemocianina respectivamente. Analizada por PAGGE-SDS, la zona I produce bandas de 238 
y $105 \mathrm{kDa}$ en ausencia de grupos tiol, y bandas de 126 y $106 \mathrm{kDa}$ en presencia de $\beta$-mercaptoetanol (Maaroufi \& Lamy, 1993). El peso molecular del monómero fue determinado por electroforesis en gel en condiciones disociantes, en ausencia y presencia de $\beta$-mercaptoetanol, la presencia de grupos tiol no modificó la movilidad electroforética. En estudios previos Markl y colaboradores ( 1976 ), mostraron que la proteína no respiratoria de la araña Dugesiella helluo, es un tetrámero consistente de subunidades de 95 y 110 kDa con una estructura $\alpha_{2} \boldsymbol{\beta}_{2}$, y un coeficiente de sedimentación de $16 \mathrm{~S}$. Como podemos ver, la información respecto a la presencia o ausencia de puentes disulfuro en las proteínas no respiratorias es incompleta y dispersa, de manera que no es posible llegar a una generalización sobre este punto.

Las proteínas no respiratorias mostraron una alta susceptibilidad a la tripsinólisis, lo cual podría sugerir que estas subunidades, que forman parte de la estructura hexamérica, (Cunningham \& Pollero, 1996), estarían más expuestas al medio acuoso. Posiblemente, este patrón de tripsinólisis sugiera un rol en el transporte de lípidos para dichas subunidades, principalmente para la banda de 121 kDa, que en condiciones nativas mostró poseer lípidos.

Para determinar la presencia de lípidos en la estructura nativa de VHDL, las proteínas fueron teñidas con Sudan Black y analizadas por PAGGE-Nativo. Esta tinción, mostró que el hexámero de hemocianina y una de las proteínas no respiratorias, la correspondiente a la banda de 230 kDa, presentan lípidos en su estructura. Como se ha mencionado anteriormente, Cunningham y colaboradores ( 1996), pudieron observar que las proteínas no respiratorias formarían parte de la estructura hexamérica de la VHDL, dado que cuando se aíslan subfracciones de esta lipoproteína por HPLC en columnas de exclusión molecular, y luego estas subfracciones son analizadas por electroforesis en condiciones disociantes, se observa que la subfracción Il contiene el monómero de hemocianina y las dos proteínas no respiratorias. Es posible entonces, que el hexámero contenga a la proteína no respiratoria, y que sea ésta la que une lípidos, o que en particular la hemocianina con esta estructura, sea capaz de unir Lípidos. Son necesarios estudios estructurales más profundos para determinar cuál de las dos posibilidades es la que está ocurriendo en este caso. Sin embargo, la función del pigmento respiratorio como transportador de lípidos, ya ha sido reportada en otros organismos como el cefalópodo Octopus tehuelchus (Heras \& Pollero, 1992; Heras \& Pollero, 1990), con lo cual nuestro resultado podría sumar evidencias al hecho de que la hemocianina de P. pythagoricus funcionaría como una apolipoproteína. Se ha encontrado una significativa cantidad de lípidos asociados a las lipoproteínas con hemocianina tanto de P. pythagoricus, como de L. mirabilis. Aunque VHDL tiene una baja relación lípido/proteína, es remarcable su importancia cuantitativa en la HL de P. pythagoricus, ya que transporta la mayor parte de los Lípidos hemolinfáticos (Cunningham \& Pollero, 1996). Lo mismo ocurre, aunque en menor proporción, en la HDL2 de L. mirabilis (Cunningham et al., 2000). 
Para comparar los fragmentos trípticos obtenidos por tripsinólisis, y analizados por MALDI-TOF de la VHDL, se utilizó el programa informático BLAST, con el objetivo de encontrar homologías con secuencias conocidas. Los péptidos obtenidos de los monómeros de hemocianina de la VHDL, presentan una homología significativa con la subunidad 3 de la hemocianina de la araña Cupiennius salei, es importante destacar que también existió homología en menor grado, con los monómeros 6, 2, 5, 4 y I de la misma especie (Ballweber et al., 2002). Además, el análisis de algoritmos BLAST (Altschul et al., 1997), mostró que la secuencia deducida, es también similar a la de otras hemocianinas de arácnidos, tales como las subunidades G, E, F, D, A y B de la araña Nephila anaurata madagascariensis (Averdam et al., 2003), las subunidades 4, 6, 5a, 2 , 3b, 3a, 3c, 5b, de la hemocianina del escorpión Pandinus imperator (Roeding et al., 2009), y las subunidades de hemocianina de la araña Eurypelma californicum (Voit et al., 2000), demostrando que los monómeros de hemocianinas se encuentran altamente conservados por lo menos dentro de los arácnidos. Estos resultados nos permitirán a futuro avanzar, empleando técnicas de biología molecular, en una caracterización más profunda, que involucre la secuenciación de las subunidades de VHDL.

La tinción realizada sobre el PAGGE-Nativo para detectar cuproproteínas mostró que las bandas de 105 y 121 kDa no presentan cobre en su estructura. Esto, sumado al hecho de que luego del análisis por MALDI-TOF, no resultaron homólogas a hemocianinas de otras especies (resultados no mostrados), confirmaría que se trata de subunidades diferentes a la hemocianina que forman parte de la estructura de la partícula lipoproteica.

Este estudio es un comienzo. La determinación de la estructura cuaternaria de una lipoproteína tan compleja como la VHDL de P. pythagoricus, requiere la realización de otros estudios orientados a resolver cuestiones tales como: ¿Cuántas subunidades diferentes componen una partícula entera?, ¿Qué número de cada una de ellas hay en cada molécula?, ¿Se trata de una población homogénea de moléculas? Estas preguntas nos permiten plantear a futuro, nuevos objetivos de trabajo, que probablemente nos den las respuestas a dichas preguntas. 
Absorción, almacenamiento y movilización de lípidos en arácnidos: El rol de los divertículos intestinales y las lipoproteínas 


\section{- Absorción, almacenamiento y movilización de lípidos en arácnidos: El rol de los divertículos intestinales y las lipoproteínas}

\section{1. Introducción}

El cuerpo graso de insectos y la glándula digestiva de crustáceos (a veces llamada hepatopáncreas), son órganos involucrados en el metabolismo lipídico que han sido extensamente estudiados en artrópodos (Arrese et al., 200I b; Gilbert \& Chino, 1974; O 'Connor \& Gilert, 1968). La glándula digestiva de crustáceos, participa activamente en el metabolismo lipídico, ya que combina las funciones de hígado, intestino, páncreas y tejido adiposo de mamíferos (Lavarías et al., 2007; Lavarías et al., 2006; Garcia et al., 2002b; González Baró \& Pollero, 1998 ; González Baró \& Pollero, 1993; González Baró et al., 1990; Al-Mohanna \& Nott, 1986; Al-Mohanna et al., 1985), mientras que en los insectos, el cuerpo graso almacena y metaboliza grandes cantidades de lípidos que soportan las necesidades metabólicas del vuelo, metamorfosis y reproducción (Ziegler \& Ibrahim, 2001 ; Arrese et al., 200I b; Ryan \& Van Der Horst, 2000; Tsuchida \& Wells, 1990; Fernando-Warnakulasuria et al., 1988). Dentro de la Clase Arachnida, se conoce que las arañas, opiliones y escorpiones, tienen un sistema intestinal extensamente desarrollado que ha sido considerado como el sitio de almacenamiento de lípidos y glucógeno (Foelix, 1996), pero éstas son conclusiones basadas en observaciones histológicas y ultraestructurales (Shultz \& Pinto-da-Rocha, 2007; Foelix, 1996; McCormick \& Polis, 1990; Becker \& Peters, 1985a; Becker \& Peters, 1985b), ya que sorprendentemente, existe muy poca información a nivel bioquímico, en relación al órgano que cumple las funciones de síntesis y almacenamiento de lípidos. El intestino medio de arañas (que desde ahora llamaremos divertículos intestinales (DI)), presenta elaboradas ramificaciones que ocupan la mayor parte del opistosoma donde rodea la mayoría de los órganos, y que pueden inclusive extenderse hasta el prosoma.

En relación al mecanismo de circulación de lípidos en artrópodos, éste es bien conocido en crustáceos e insectos. En cuanto a los arácnidos, existe poca información, solo en unas pocas especies se han identificado lipoproteínas hemolinfáticas de alta (HDL) y de muy alta densidad (VHDL) (para una revisión ver (Cunningham et al., 2007)).

Considerando que el intercambio de lípidos entre lipoproteínas hemolinfáticas y tejidos es desconocido en el subfilum Chelicerata, y que los DI serían potencialmente el principal órgano involucrado en la biosíntesis de lípidos en arácnidos, el presente estudio se focaliza en la primer caracterización lipídica y de composición de ácidos grasos de los DI, y en el metabolismo e intercambio in vivo de lípidos entre DI y lipoproteínas hemolinfáticas. 


\section{V.2. Resultados}

\section{V.2.1. Composición lipídica y de ácidos grasos de los divertículos intestinales}

Con el fin de determinar el contenido y la composición lipídica de los DI de la araña $P$. pythagoricus, se extrajeron los lípidos totales y se cuantificaron por gravimetría. Las clases de lípidos se cuantificaron por TLC-FID y los ácidos grasos por GLC.

El contenido total de lípidos de los DI fue de 8,08 \pm 3,9\% (peso húmedo). En cuanto a la composición lipídica se observó una importante predominancia de los TAG, representados por un $74,2 \%$, seguidos por los $P L$ que suman un 15,9\% (Tabla V.I).

\begin{tabular}{ll} 
Clases de lípidos & $\%(\mathbf{p} / \mathbf{p})$ \\
\hline Hidrocarburos & $1,68 \pm 1,4$ \\
\hline Esteroles esterificados & $1,55 \pm 0,5$ \\
\hline Triacilglicéridos & $74,25 \pm 11,3$ \\
\hline Ácidos grasos libres & $1 \pm 0,1$ \\
\hline Colesterol & $2,73 \pm 1,1$ \\
\hline Diacilglicéridos & Trazas \\
\hline Fosfatidiletanolamina & $2,73 \pm 4,4$ \\
\hline Fosfatidilcolina & $13,23 \pm 2,6$ \\
\hline Esfingomielina & $1,9 \pm 2,3$ \\
\hline
\end{tabular}

El análisis de ácidos grasos de los lípidos totales, mostró un patrón dominado por ácidos grasos insaturados, entre los que se observó a 18:1 n-9, 18:2 n-6 y 16: I n-7 como los cuantitativamente más importantes, mientras que entre los saturados el predominante fue el 16:0 (Tabla V.2).

\begin{tabular}{ll} 
Ácidos grasos & $\%(\mathbf{p} / \mathbf{p})$ \\
$14: 0$ & $1,48 \pm 0,33$ \\
\hline $16: 0$ & $15,05 \pm 1,67$ \\
\hline $18: 0$ & $7,23 \pm 0,99$ \\
\hline $16: 1 n-7$ & $10,16 \pm 1,29$ \\
\hline $18: 1 n-9$ & $30,12 \pm 2,23$ \\
\hline $18: 1 n-7$ & $3,76 \pm 0,35$ \\
\hline $20: 1 n-9$ & $0,89 \pm 0,11$ \\
\hline $18: 2 n-6$ & $23,38 \pm 2,29$ \\
\hline $18: 3 n-3$ & $3,93 \pm 0,45$ \\
\hline $20: 4 n-6$ & $2,25 \pm 0,98$ \\
\hline $20: 5 n-3$ & $1,8 \pm 1$ \\
\hline$\Sigma$ saturados & $23,76 \pm 2,99$ \\
\hline$\Sigma$ monoenos & $44,96 \pm 3,98$ \\
\hline$\Sigma$ poliinsaturados & $31,36 \pm 4,72$ \\
\hline
\end{tabular}

Tabla V.1: Composición lipídica de los DI de $P$. pythagoricus. Los valores representan la media de 3 análisis individuales \pm DS.

Tabla V.2: Principales ácidos grasos de los lípidos totales de los DI de P. pythagoricus. Los valores representan la media de 3 análisis individuales \pm DS. 


\section{V.2.2. Incorporación de ácidos grasos en divertículos intestinales y otros tejidos}

Para estudiar la captación y liberación de lípidos in vivo, en los tejidos y $\mathrm{HL}$ de la araña $P$. pythagoricus, se administró ácido palmítico radiomarcado a ejemplares adultos de esta especie (ver Materiales y Métodos). De esta manera buscamos observar, no solo la distribución de la marca en los distintos tejidos, sino también en las distintas clases de lípidos a las que se incorpora. En algunos casos el precursor radioactivo fue administrado con el alimento, y en otros, por inyección directa en la HL.

Los experimentos de alimentación, mostraron que después de 2 horas de la ingesta de ácido palmítico $1-{ }^{14} \mathrm{C}$, cerca del $80 \%$ de la marca fue incorporada en los DI, y el resto distribuido en los otros tejidos (Tabla V.3).

Por otro lado, la distribución de la radioactividad entre las clases lipídicas, mostró diferencias según el tejido analizado. Los DI utilizaron el 78\% del precursor suministrado para la síntesis de TAG, además de sintetizar PL (6\%) y trazas de DAG, esto nos permite suponer que los DI serían un tejido con una activa participación en el metabolismo de lípidos. En HL, en cambio, la marca se encontró asociada principalmente a AGL (65\%) y PL (35\%), mientras que en el "músculo" (músculo, gónadas y tegumento) se vinculó a AGL, PL (70 y 16\% respectivamente) y en menor medida a TAG. Es interesante remarcar lo observado en los pulmones en libro, donde los AGL fueron los únicos Lípidos radiomarcados (Tabla V.3). El análisis de la distribución de la marca luego de 12 hs. de ser alimentadas, mostró un patrón de distribución muy similar, con más del 85\% de la marca encontrada en el DI, particularmente asociada a TAG (resultados no mostrados).

\begin{tabular}{lccccc}
\hline Tejido & $\begin{array}{c}\text { Divertículos } \\
\text { intestinales }\end{array}$ & Hemolinfa & Músculo & Pulmón \\
\hline \% Radioactividad & $79,3 \pm 8,42$ & $4,7 \pm 1,3$ & $14,2 \pm 5,6$ & $2,64 \pm 1,6$ \\
\hline Triacilglicérido & $78,5 \pm 10,67$ & $\operatorname{Tr}$ & $8,6 \pm 1,02$ & $\mathrm{ND}$ \\
\hline Ácido graso libre & $15,3 \pm 6,65$ & $65, \mathrm{I} \pm 12,63$ & $70,4 \pm 6,43$ & 100 \\
\hline Diacilglicérido & $\operatorname{Tr}$ & $\mathrm{ND}$ & $\mathrm{ND}$ & $\mathrm{ND}$ \\
\hline Fosfolípidos $\left(^{*}\right.$ & $6,3 \pm 2,15$ & $35,7 \pm 11,66$ & $16,3 \pm 2,66$ & $\mathrm{ND}$ \\
\hline
\end{tabular}

Tabla V.3: Incorporación de radioactividad en tejidos y clases de lípidos después de 2 horas de alimentación con ácidos grasos marcados. Los valores representan la media \pm DS de datos de 3 individuos. Tr: trazas; ND: No detectable, $\left(^{*}\right)$ Principalmente PC + PE. 


\section{V.2.3. Transporte de lípidos en hemolinfa e incorporación en los tejidos}

Para confirmar que los DI representan el principal órgano metabólico de lípidos, se estudió la distribución de la radioactividad entre las clases de lípidos de los tejidos de la araña. Se inyectó ácido palmítico I $-{ }^{14} \mathrm{C}$ en la HL y se incubó durante 4 hs., para permitir la movilización de la marca al resto de los tejidos. Luego de transcurrido este tiempo, la mayor parte de la marca fue encontrada en la fracción llamada "músculo", seguida por los DI (Tabla V.4). Es remarcable en este punto, que el análisis de la incorporación en cada clase de lípido mostró un patrón muy similar al obtenido en los experimentos de alimentación. Por lo tanto, en músculo se observó principalmente AGL radiomarcado (85\%) y pequeñas cantidades de PL y DAG, mientras que en DI la mayor parte del precursor radioactivo fue incorporado en TAG (77\%) y en menor porcentaje en PL. Este tiempo de incubación fue suficiente para encontrar además de AGL, PL circulantes en HL (34\%), y pequeñas cantidades de TAG (Tabla V.4).

Luego de este análisis pudimos confirmar que los DI serían el órgano más activo en cuanto al metabolismo de lípidos, de manera que en la segunda parte de este estudio, nos centramos en la interacción de éste con la HL.

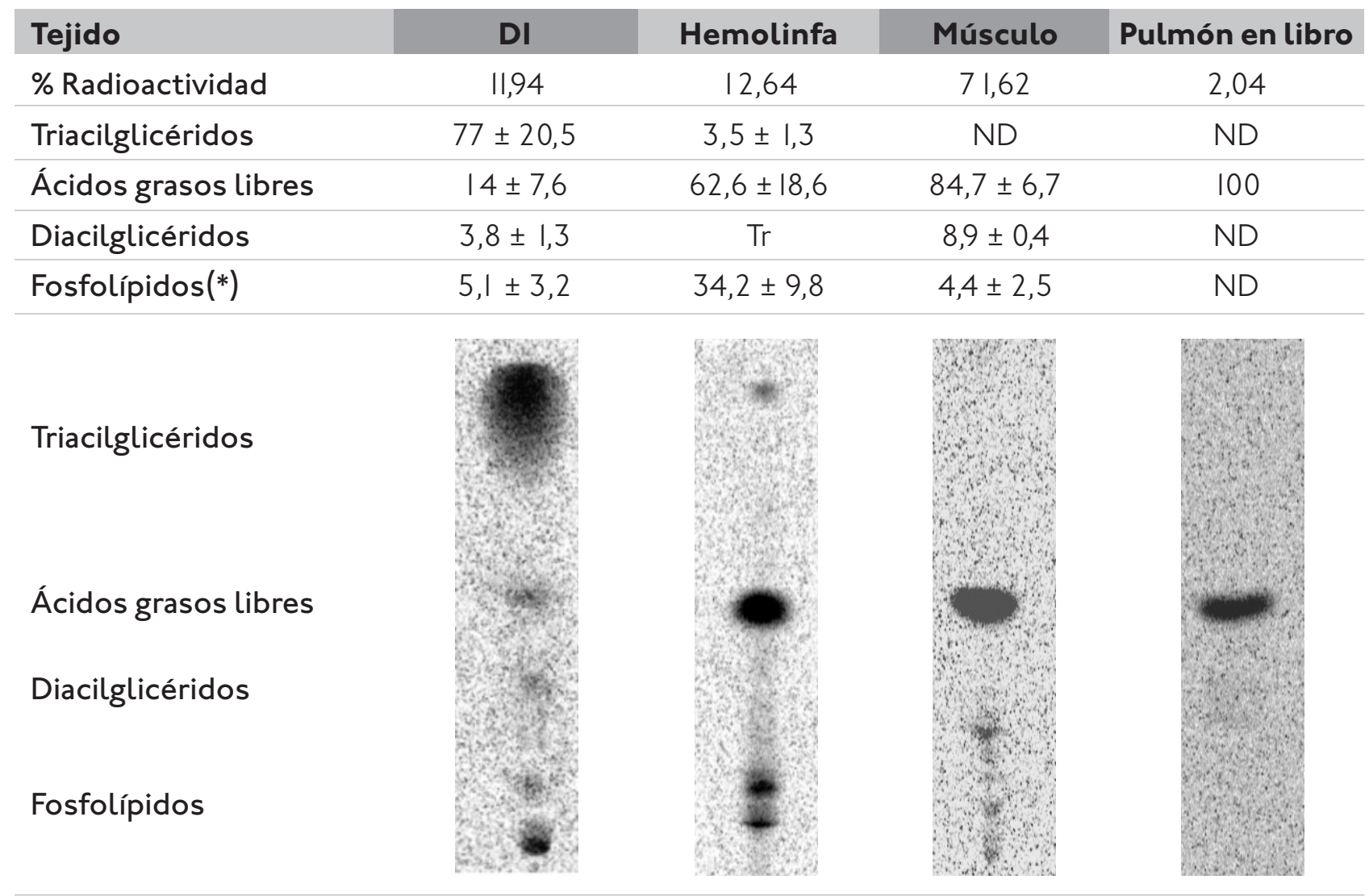

Tabla V.4: Distribución de la radioactividad en tejidos e incorporación en las clases de lípidos después de la inyección de ácido palmítico $1{ }^{14} \mathrm{C}(\%)$. Los valores representan la media \pm DS de los datos de 5 individuos analizados después de 4 horas de inyección con ácido palmítico $1-^{14} \mathrm{C}$. ND: No detectable, $\left({ }^{*}\right)$ Principalmente $\mathrm{PC}+\mathrm{PE}$. Panel inferior: radiocromatogramas típicos. 
Analizamos entonces, el intercambio de lípidos entre lipoproteínas y DI luego de la inyección de acido palmítico radiomarcado, siguiendo la marca durante 24 hs. Una hora después de la inyección, observamos que fue incorporada principalmente en $\mathrm{HL}$, mostrando un decrecimiento constante en ésta, a expensas de un incremento en DI a lo largo del tiempo de incubación. Después de 24 hs., más del 90\% de la marca se encontró asociada a los DI. (Fig. V.I).

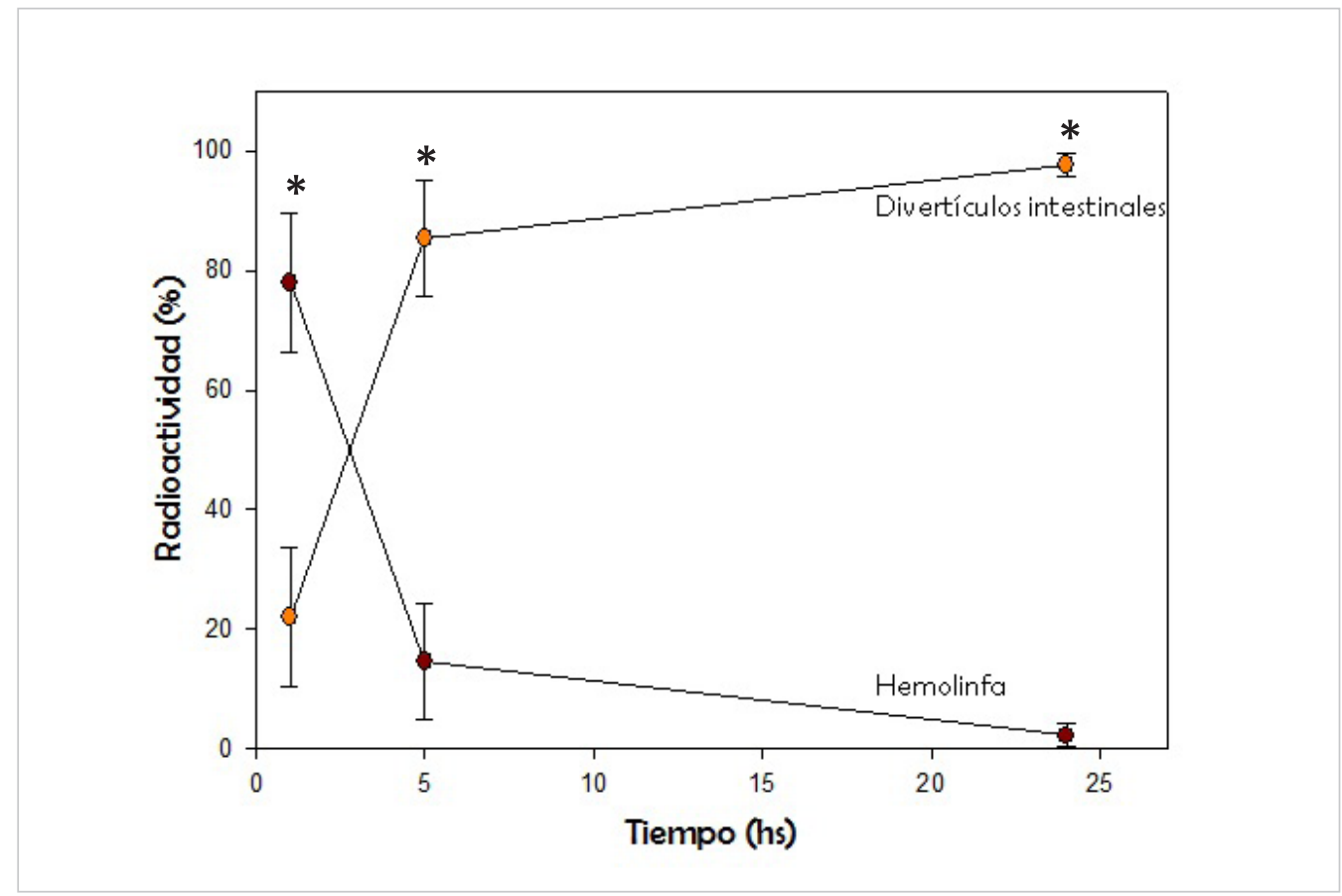

Figura V.1: Distribución de la radioactividad a lo largo del tiempo en $\mathrm{HL}$ y DI de P. pythagoricus después de la inyección de ácido palmítico $1-{ }^{14} \mathrm{C}$. Las barras de error indican DS $(n=5)$. Se utilizó el test $T$ Student`s para comparar la significancia de las diferencias entre $\mathrm{HL}$ y DI: * $\mathrm{P}<0.05$.

Para estudiar como la HL transporta los lípidos, se aislaron las lipoproteínas por ultracentrifugación en gradiente de densidad y se midió la radioactividad asociada a las mismas. La figura V.2 muestra un perfil donde se grafica, densidad de las alícuotas obtenidas luego de la ultracentrifugación vs. absorbancia a 280 $\mathrm{nm}$, que evidencia dos picos bien definidos. Uno de ellos a la densidad de 1,I3 $\mathrm{g} / \mathrm{ml}$ correspondiente con HDL I y otro, entre 1,18 y $1,24 \mathrm{~g} / \mathrm{ml}$, que coincide con las densidades de HDL2+VHDL. En esta figura también mostramos un perfil de densidad vs. radioactividad, donde se ve claramente que la marca se asoció con HDL I y VHDL pero no con HDL2. 


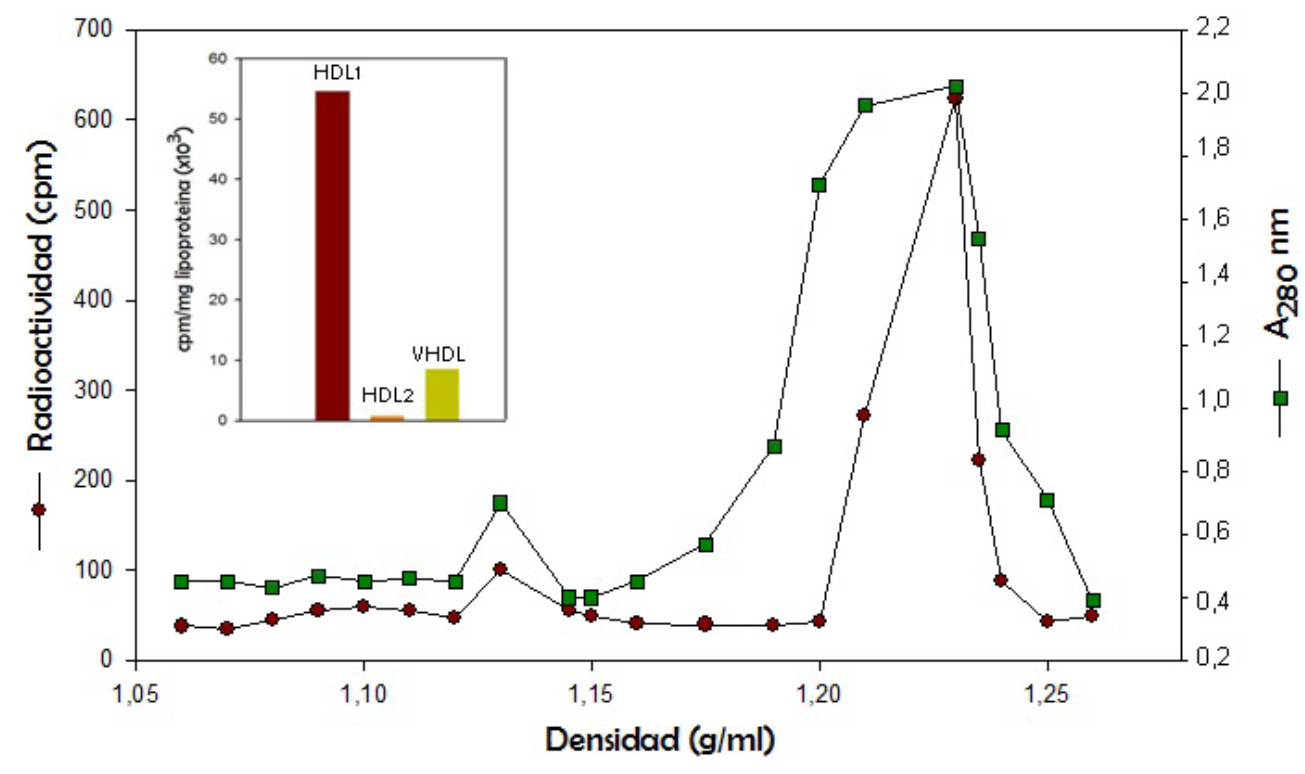

En cuanto a la distribución de marca entre las lipoproteínas a lo largo del tiempo, vemos que, a tiempos cortos de incubación la mayor parte de la radioactividad se asocia a VHDL (83 y 74\% a I y 5 hs. respectivamente), con una actividad específica 6 veces más alta que HDL I, mientras que a las 24 hs., HDL I y VHDL muestran cantidades casi iguales de marca (Fig. V.3). Vale recalcar que aunque VHDL tiene un contenido de lípidos 8 veces menor que HDL I, se encuentra 20 veces más concentrada en $\mathrm{HL}$.

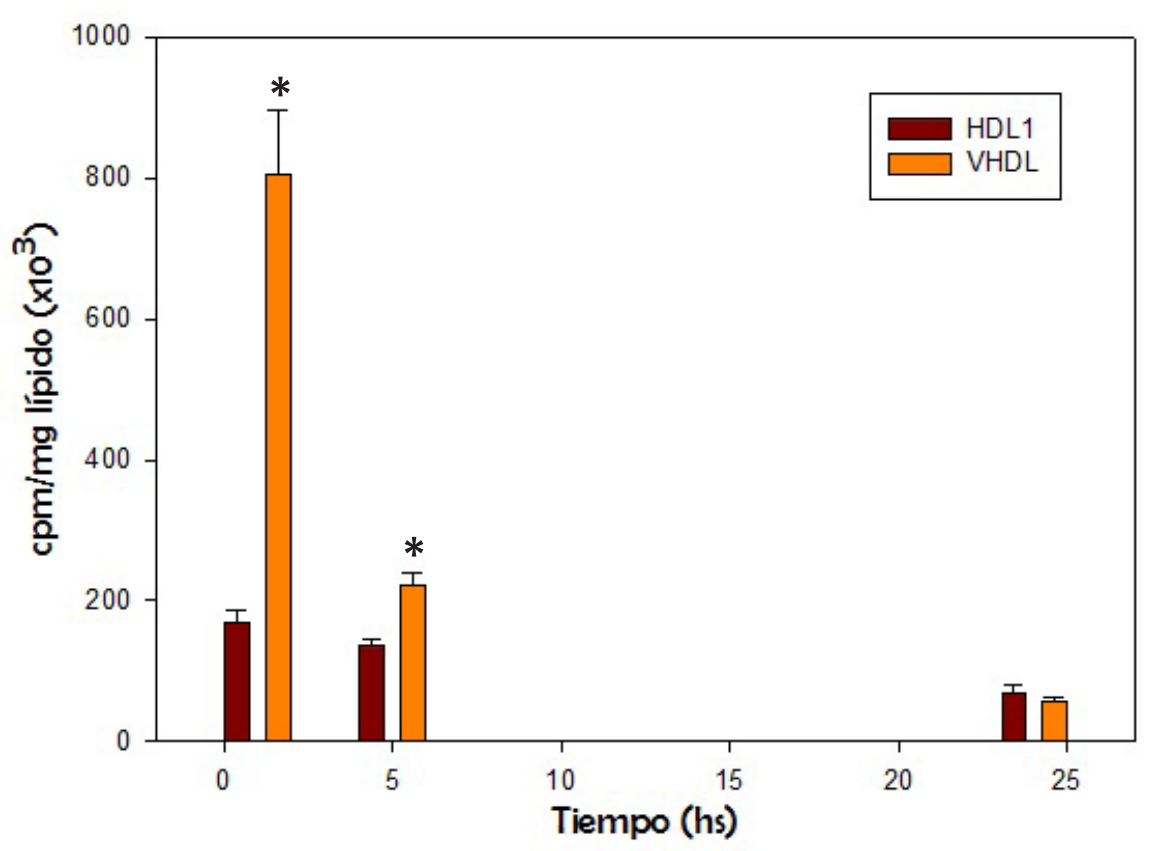

Figura V.2: Distribución de proteínas (absorbancia a $280 \mathrm{~nm}$ ) y radioactividad en las fracciones hemolinfáticas de $P$. pythagoricus obtenidas por ultracentrifugación en gradiente de densidad. Inset: actividad específica de las lipoproteínas.

Figura V.3: Distribución de la radioactividad en función del tiempo entre lipoproteínas después de la inyección de ácido palmítico ${ }^{1-C^{14}}$ en $P$. pythagoricus. Los valores representan la media \pm DS de datos de 3 individuos.

Se utilizó el test T Student`s para comparar la significancia de las diferencias entre HDL1 y VHDL: * $\mathrm{P}<0.05$. 
En la figura V.4 se muestra la distribución de la radioactividad en las clases de lípidos de los DI y lipoproteínas a diferentes tiempos de incubación. Los principales lípidos marcados en HDLI a tiempos cortos, fueron los AGL (57\%) y PL (39\%). Esta relación cambia lentamente a lo largo del tiempo hasta que después de 24 hs., la marca en PL se incrementa a más del 85\% en esta lipoproteína. Una pequeña cantidad de TAG marcados se observaron en todos los tiempos de incubación.

VHDL mostró un patrón muy similar a HDL I, aunque a 5 hs., los niveles de AGL fueron significativamente más altos (Fig. V.4). Al igual que en HDLI, después de 24 hs. la mayor parte de la marca estuvo asociada a PL (7 l\%). Nuevamente una pequeña cantidad de TAG se encontró asociado a esta lipoproteína en todos los tiempos ensayados. El análisis en función del tiempo de los lípidos hemolinfáticos marcados muestra que los AGL decrecen a lo largo del tiempo, concomitantemente con un incremento de los PL, observándose este patrón en ambas lipoproteínas.

En la parte correspondiente a los DI de la figura V.4, se observa el destino metabólico de los ácidos grasos. Después de 1 h. de inyección, el 79\% de la marca de DI estuvo asociada a AGL, pero el 5,4\% fue incorporado en TAG. A 5 hs. de incubación, cerca de la mitad de la marca fue incorporada en TAG. A las 24 hs., (tiempo en el que casi toda la marca se encuentra en relación a los lípidos de los DI) ha metabolizado la mayoría de los AGL, incorporándolos en TAG y $\mathrm{PL}$. Es de remarcar que existe una pequeña, pero significante, incorporación en DAG, un intermedio metabólico en la síntesis de acilglicéridos, con pocos cambios en la cantidad de marca asociada a este lípido a lo largo de los tiempos de incubación.

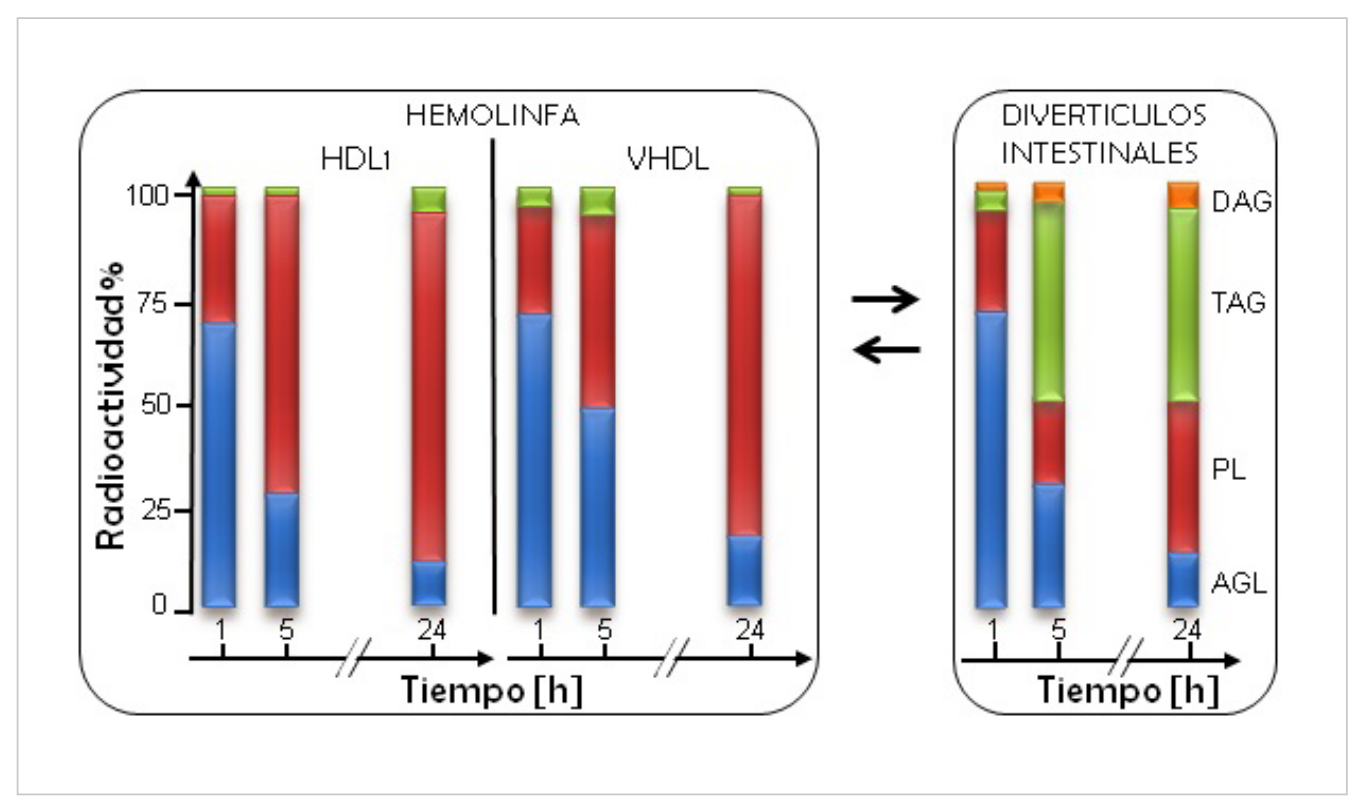

Figura V.4: Distribución de la radioactividad en función del tiempo entre las clases de lípidos de lipoproteínas y DI de $P$. pythagoricus. 


\section{V.3. Discusión}

Los individuos adultos de la araña P. pythagoricus alimentados con ácido palmítico radiomarcado, mostraron que los DI son capaces de captar e incorporar AGL del alimento y utilizarlos para sintetizar lípidos complejos, principalmente TAG y PL. Esto, es similar a lo descripto en crustáceos e insectos cuyas glándulas digestivas y cuerpo graso respectivamente, poseen características similares en cuanto su metabolismo lipídico (Atella et al., 2000; Kanazawa \& Koshio, 1994; Kallapur et al., 1984; Gilbert \& Chino, 1974). Se encontró también, una pequeña cantidad de marca asociada a DAG, indicando que éste podría ser un intermediario involucrado en la síntesis de acilglicéridos. Por lo tanto los lípidos de la dieta (o al menos los AGL productos del proceso digestivo), serían utilizados por los DI para la síntesis "de novo" de acilglicéridos, por la ruta del ácido fosfatídico o por la del monoacilglicerol (MAG), similar a lo que ocurre en insectos (Canavoso et al., 2001 ; Arrese et al., 2001 a), de cualquier modo, no es posible establecer la ruta exacta a partir de este diseño experimental. Aunque no fue analizado particularmente, y asumiendo que las arañas tendrían intermedios metabólicos similares a otros artrópodos, se puede inferir de la cantidad de marca recuperada en la fracción lipídica, que probablemente algunas moléculas de palmitato hayan sido oxidadas a acetil-CoA e incorporadas en otra molécula no-lipídica o perdida como $\mathrm{CO}_{2}$.

La distribución de la radioactividad en las clases de lípidos se aproxima a la distribución de masas de lípidos totales de los DI, lo cual, sumado a la descripción histológica que sugiere que estarían involucrados en el almacenamiento de lípidos (Foelix, 2011), soporta la hipótesis de que este órgano jugaría un rol importante en las funciones de pegado, almacenamiento y síntesis de lípidos. Una comparación de la composición lipídica entre los DI, el cuerpo graso y la glándula digestiva indica que comparten un patrón similar. En P. pythagoricus los TAG de los DI constituyen la principal forma de almacenamiento lipídico, representando cerca del 74\% del total de los lípidos, como ocurre en el cuerpo graso de insectos (70-90\%) (Cvacka et al., 2006; Sobotnik et al., 2006; Bailey, 1975) y en la glándula digestiva de crustáceos (alrededor del 68\%), (González Baró \& Pollero, 1998).

En cuanto a la composición de ácidos grasos está dominada por los de 16 y 18 carbonos, (oleico, linoleico y palmítico), los mismos reportados para el hepatopáncreas del escorpión Buthus quinquestriatus (El-Salhy et al., 1981). Este espectro se corresponde en general con un "patrón terrestre", en el cual los ácidos grasos de la familia n-6 prevalecen sobre los de la familia n-3. También se asemeja a la composición del cuerpo graso de algunos insectos, mientras que en el órgano de reserva de los crustáceos se observan diferentes proporciones de ácidos grasos insaturados, en relación al medio acuático (Cvacka et al., 2006; Sobotnik et al., 2006; Beenakkers \& Gilbert, 1968).

En arañas adultas después de la alimentación, los PL sintetizados y trazas 
de TAG son transferidos, junto a los $A G L$, desde los DI hacia la HL, a diferencia de lo que ocurre en insectos, donde su cuerpo graso transfiere principalmente PL y DAG (Coelho et al., 1997; Atella et al., 1995). Después de la alimentación con ácido palmítico $1-{ }^{14} \mathrm{C}$, observamos que, mientras que los $A G L$ representan el 17\% de la masa de lípidos de la HL (Cunningham \& Pollero, 1996), cerca del $65 \%$ de los lípidos radiomarcados están representados por AGL. Hasta el momento no hay información disponible en arácnidos sobre la síntesis de lipoproteínas para explicar estas diferencias, pero si consideramos que la radioactividad total de la $\mathrm{HL}$ es solo el $4,7 \%$ de los $35 \mathrm{nmol}$ de ácido palmítico $1-{ }^{14} \mathrm{C}$ con que fueron alimentadas, la masa de AGL radiomarcados representan una pequeña fracción de la masa total en la HL en esta especie, similar a otros vertebrados e invertebrados en los cuales la cantidad de AGL circulantes es baja. La cantidad de radioactividad asociada a los DI es de cerca del $80 \%$ del total de la radiactividad con la que fueron alimentadas, mientras que en otros tejidos, muestran el remanente de la marca (20\%), principalmente distribuidos en PL y AGL. Si consideramos que el alimento es primero tomado y procesado por los DI, La presencia de lípidos marcados en HL soportan la idea de que serían transferidos desde los DI y transportados por la HL al resto de los tejidos, como sucede en vertebrados y otros artrópodos. Además, cuando los AGL fueron inyectados directamente en la $\mathrm{HL}$, fue diferente la captación de marca por los tejidos: en lugar de ser captados por los DI, los AGL fueron incorporados al "músculo", que mostró solo una pequeña incorporación de lípidos complejos, sugiriendo que estos tejidos pueden usar la pequeña cantidad de ácidos grasos radiomarcados para otros fines. Notablemente, después de la alimentación o la inyección de palmitato radioactivo, cerca del $2 \%$ de la marca se encontró asociada a los pulmones en libro, pero solo como AGL, sin la incorporación en otros lípidos. Aunque no hay reportes sobre la composición lipídica del pulmón, podemos asumir que es dominada principalmente por lípidos estructurales. Si bien no sabemos exactamente porque solo se encontraros AGL, una explicación podría ser que el metabolismo del pulmón en libro es más bien lento, y que el tiempo después de la alimentación o de la inyección no es suficiente para la incorporación del palmitato marcado en otros lípidos complejos o, que hay una lipoproteína-lipasa en los pulmones que degrada los acilglicéridos hemolinfáticos antes de su incorporación en los pulmones y que después no hay reesterificación en lípidos complejos y son solo utilizados para $\beta$-oxidación, o una combinación de ambas hipótesis.

Hasta el presente no hay información sobre cuál es el recurso lipídico que las arañas utilizan como energía. A diferencia de otros tejidos, los DI, muestran un metabolismo muy activo. De hecho, fueron capaces de incorporar ácidos grasos de la HL e incorporarlos en TAG y PL en una relación muy similar a la de los experimentos de alimentación. La incorporación en DI es similar a lo que ocurre en cuerpo graso de insectos o en glándula digestiva de crustáceos (Garcia et al., 
2002a; Soulages et al., 1988; Gilbert \& Chino, 1974). Si tenemos en cuenta que las arañas pueden vivir durante un largo tiempo sin alimentarse (más de 200 días para el caso de la viuda negra) (Foelix, 2011), los TAG almacenados jugarían un papel importante en la distribución de energía al resto del cuerpo. Basándonos en los resultados anteriores a cortos tiempos, estudiamos la capacidad de los DI in vivo, de metabolizar y liberar AGL a las lipoproteínas a lo largo de un período de 24 hs. Cerca del 90\% de la marca inyectada, fue captada por los DI luego de 5 hs. de incubación. Estos AGL fueron rápidamente incorporados en PL y TAG, similar a lo observado en los experimentos de alimentación, aunque con menos marca asociada a lípidos neutros (Tabla V.I y Fig. V.4). La presencia de DAG marcados sostiene la idea de que la síntesis de acilglicéridos en arácnidos seguiría el patrón convencional de insectos.

En conjunto, estos experimentos demuestran que los DI son capaces de captar lípidos circulantes desde la HL o de la dieta, metabolizar los AGL, y liberar los diferentes lípidos hacia la lipoproteínas hemolinfáticas para la distribución hacia los distintos órganos.

El rol de las lipoproteínas en el intercambio de lípidos entre los DI y la HL, fue estudiado siguiendo los cambios en la composición lipídica a lo largo de 24 hs., después de la inyección de ácido palmítico $1-{ }^{14} \mathrm{C}$ como precursor. Como ya se mencionó, los ácidos grasos de HL fueron captados por DI e incorporados en TAG y PL. Luego, estos acilglicéridos fueron liberados a las lipoproteínas hemolinfáticas. Independientemente de los tiempos de incubación, HDL I y VHDL siempre estuvieron involucradas en la captación/liberación de lípidos desde o hacia los DI. Fue sorprendente el hecho de que HDL2 solo haya captado una pequeña cantidad de lípidos marcados, ya que esta lipoproteína es similar a VHDL en cuanto a que ambas presentan hemocianina como apolipoproteína, y subunidades de 105 y 121 kDa como proteínas no respiratorias. Sin embargo, estas dos lipoproteínas son diferentes en la relación entre sus subunidades apolipoproteicas de 105 y 121 kDa, así como en sus densidades de hidratación y composición lipídica (Cunningham \& Pollero, 1996), lo cual podría explicar las diferencias encontradas en la captación de lípidos radiactivos. Por otro lado, se podría especular con que los lípidos de HDL2 solo tengan una función estructural, similar a lo que ocurre en el cangrejo Carcinus maeñas en el cual los PL asociados a la hemocianina estabilizan la estructura de la proteína (Zatta, I 981), aunque cabe remarcar sobre este punto, que la posibilidad de que los lípidos de VHDL sean solo estructurales, fue descartada en un trabajo previo, donde se demostró que la partícula no pierde su estabilidad ni sufre alteraciones estructurales, luego de ser deslipidizada (Cunningham et al., 2006). Si bien la presencia de lípidos asociados a la hemocianina, ya se ha reportado para otras arañas (Jaenicke et al., 1999b), es necesario más conocimiento sobre la estructura de la lipoproteína y su capacidad de carga para entender esto.

La distribución de la radioactividad en $\mathrm{HL}$ a tiempos cortos muestra que 
la VHDL transporta significativamente más cantidad de marca que la HDL I. Por otro lado observamos que la VHDL de P. pythagoricus deslipidizada in vitro, tiene una gran capacidad para pegar lípidos (principalmente AGL) y consecuentemente de transportarlos (Cunningham et al., 1999). Esta característica probablemente explica la actividad específica de VHDL a tiempos cortos después de la inyección de ácido palmítico, que excede a HDL I en un factor de 4 y está de acuerdo con el patrón de marcado de la VHDL de E. californicum que incorpora principalmente AGL y en menor cantidad PL y TAG desde un "hepatopáncreas" marcado in vitro. A diferencia de P. pythagoricus, la VHDL de E. californicum no contiene hemocianina como apolipoproteína (Stratakis et al., 1993).

A pesar de la diferente distribución de la marca entre HDL I y VHDL a I h., la composición de lípidos radiomarcados cambia a lo largo del tiempo de manera proporcional en ambas lipoproteínas, indicando que tienen un rol similar en la dinámica de lípidos de la araña. HDLI parece tener un rol semejante a la lipoforina de insectos en cuanto al sitio de absorción, distribución y almacenamiento de lípidos (Downer, 1985), además de que al igual que los insectos, los PL son el mayor componente de las lipoproteínas de arácnidos (Cunningham et al., 2000; Cunningham \& Pollero, 1996; Cunningham et al., 1994).

Después de una inyección de ácidos grasos radiomarcados directamente en la HL, se pudo observar que los PL y TAG sintetizados por los DI fueron transferidos de vuelta a la HL y, que luego de 24 hs., la distribución de lípidos radiomarcados de las lipoproteínas, se aproximó a la composición lipídica reportada, dominada por PL, AGL y TAG (Cunningham \& Pollero, 1996). Además, ambas lipoproteínas captaron marca en igual cantidad, como se refleja en sus actividades específicas comparables. Esto es similar al metabolismo de la glándula digestiva de crustáceos que capta AGL y libera PL a la HL, pudiendo decir quizás que el metabolismo de lípidos de los arácnidos se encontraría "más cerca” del de los crustáceos, que del de los insectos, un hecho destacable, considerando que las arañas se encuentran ecológicamente mas relacionadas con estos últimos.

Los resultados presentados, muestran por primera vez que los DI de arácnidos son el principal sitio de almacenamiento y el mayor centro metabólico involucrado en la captación y liberación de lípidos. Además, se demostró claramente que las dos lipoproteínas participan en el transporte desde y hacia los tejidos, permitiéndonos suponer un modelo de circulación de lípidos en la araña $P$. pythagoricus, en el cual los AGL ya sean suministrados por la dieta o directamente a la $\mathrm{HL}$, son metabolizados en los DI incorporándose principalmente en TAG y PL. Luego, los PL son transferidos a las lipoproteínas hemolinfáticas para ser transportados hacia otros órganos donde son utilizados, mientras que Los TAG son en su mayoría almacenados en DI (Fig. V.5). 


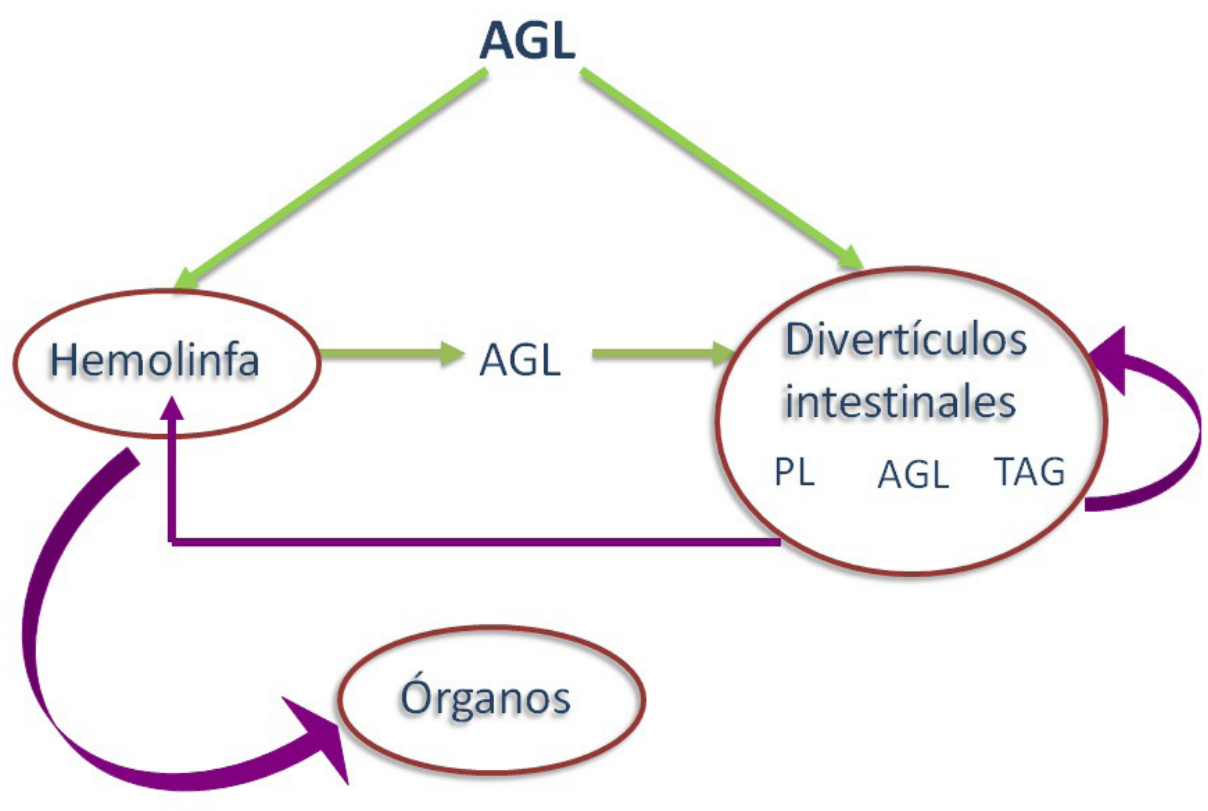

Figura V.5: Posible

modelo de circulación

de lípidos en las

arañas, utilizando como

ejemplar de estudio a $P$.

pythagoricus. 
Transferencia de lípidos in vitro entre lipoproteínas y divertículos intestinales de la araña Polybetes pythagoricus 


\section{Transferencia de lípidos in vitro entre lipoproteínas y divertículos intestinales de la araña Polybetes pythagoricus}

\section{VI.1. Introducción}

Las lipoproteínas circulantes en invertebrados han sido estudiadas principalmente en los phyla Arthropoda y Mollusca, como se ha detallado en la Introducción general. En cuanto a los artrópodos acuáticos, las lipoproteínas de crustáceos, han sido descriptas y revisadas por Lee y Puppione ( 1978), Chang y O 'Connor ( 1983) y Lee ( 1991 ). En relación a los artrópodos terrestres, el mecanismo de circulación de lípidos es bien conocido en insectos (Soulages \& Wells, 1994b; Chino, 1985), sin embargo, y como ya se ha señalado para otros aspectos de los estudios bioquímicos en arácnidos, la existencia de lipoproteínas hemoLinfáticas en esta Clase, ha sido reportada en pocas especies de los órdenes Araneida, Scorpionida, Solpugida y Acarina (Cunningham et al., 2007), y particularmente entre las arañas, se han caracterizado lipoproteínas en solo tres especies: Eurypelma californicum, Lactrodectus mirabilis y Polybetes pythagoricus.

En cuanto al rol de las lipoproteínas en la dinámica de lípidos, es conocido que en insectos se transfieren principalmente DAG desde el cuerpo graso a partículas de lipoforina preexistentes localizadas en la $\mathrm{HL}$; que luego pueden Liberar los lípidos a otros tejidos (Arrese et al., 200l a; Blacklock \& Ryan, 1994; Soulages \& Wells, 1994b). En crustáceos, se ha demostrado que los lípidos son transportados en $\mathrm{HL}$ por HDLs (Chang \& O Connor, 1983; Lee \& Puppione, 1978), y que diferentes lípidos como PL, AGL y TAG son transferidos desde y hacia la glándula digestiva (principal órgano involucrado en el metabolismo de lípidos).

En el capítulo $V$, se discuten resultados de experimentos realizados in vivo, que nos permitieron evaluar la dinámica de los lípidos, y determinar que HDL I y VHDL participan activamente en la captación y liberación de lípidos radiomarcados desde y hacia los DI, donde luego estos sintetizan principalmente TAG y $\mathrm{PL}$ en una relación similar a su composición lipídica. Este tipo de diseño experimental, en el que se trabaja, como ya se mencionó, con modelos vivos, dificulta la identificación de el/los órgano/s involucrados en el origen y destino de los lípidos.

Para lograr una mejor comprensión de los resultados obtenidos a partir de los ensayos in vivo, en este capítulo se realizaron ensayos in vitro, donde solo participaron un par dador/aceptor (Lipoproteínas/DI) en concentraciones fisiológicas, que permitieron analizar el rol de las lipoproteínas hemolinfáticas de la araña Polybetes pythagoricus, en un sistema cerrado, en relación a la captación y liberación de lípidos desde y hacia los DI, así como la transferencia de lípidos entre lipoproteínas aisladas. 


\section{VI.2. Resultados}

\section{VI.2.1. Captación de lípidos por las lipoproteínas desde los divertículos intestinales}

El primer set de experimentos, fue diseñado para determinar la captación de lípidos por las lipoproteínas cuando se encuentran formando parte de la HL entera, en este caso, y de aquí en adelante cuando se haga referencia a la HL entera, se tratará de aquella que fue utilizada tal como fue extraída de la araña. En este ensayo entonces, se incubaron DI radiomarcados con HL no marcada, en una relación igual a la que se encontraría en un individuo (ver Materiales y Métodos). Luego de 30 minutos de incubación, la HL fue sujeta a una ultracentrifugación en gradiente de densidad, y posteriormente en cada fracción se realizaron registros simultáneos de masa de proteínas y radioactividad, que permitieron observar que los máximos de radioactividad estaban asociados a las Lipoproteínas HDL I y VHDL. HDL2, al igual que se observó en el capítulo V, no mostró radioactividad asociada. El porcentaje de lípidos marcados captados por las lipoproteínas fue de $28 \pm 12 \%$ de la marca originalmente asociada a los DI (inset Fig. VI.I), de los cuales, el $67 \pm 6 \%$ fue captado por HDLI y el $33,7 \pm 7 \%$ por VHDL (Fig. VI.I).

El segundo set de experimentos fue realizado con el objetivo de estudiar la captación de lípidos, ahora por las lipoproteínas aisladas. En este ensayo, luego de incubar durante 30 minutos, DI radiomarcados con HDL I ó VHDL sin marcar, también en concentraciones fisiológicas, el $48 \pm 9 \%$ y el $29 \pm 15 \%$ de la radioactividad originalmente asociada con DI, fue transferida a HDLI y VHDL, respectivamente (Fig. VI.I).

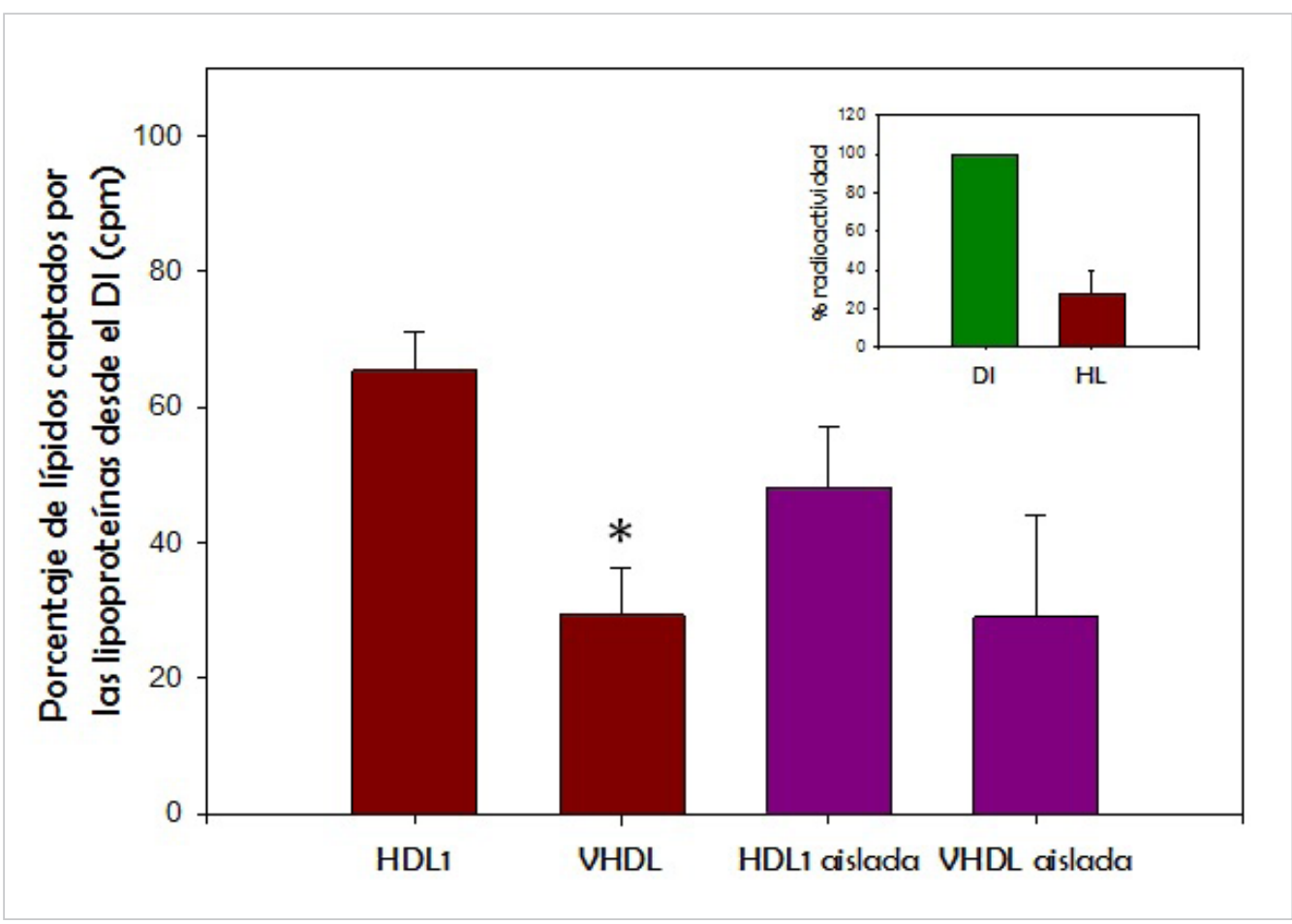

Figura VI. 1: Porcentaje de lípidos ${ }^{-14} \mathrm{C}$ (cpm) captados por la $\mathrm{HL}(\square)$ o por las lipoproteínas aisladas $(\square)$ cuando fueron incubadas con $1 \mathrm{DI}$. El inset muestra el porcentaje de marca captado por la HL. Las barras de error indican el DS de la media $(n=3)$. Se utilizó el test T Student`s para comparar la significancia de las diferencias entre HDL1 y VHDL en HL y en lipoproteínas aisladas: * $\mathrm{P}<0.05$. 
Dado que se conoce y se ha comentado en la Introducción, que en algunos grupos de invertebrados, las células hemolinfáticas llamadas hemocitos, intervienen en el transporte de lípidos, decidimos estudiar su participación en la dinámica de lípidos en el caso de P. pythagoricus. Se analizaron los lípidos${ }^{14} \mathrm{C}$ captados por los hemocitos, y se observó que solo un $3 \%$ de la marca de HL estaba asociada a dichas células. Este dato nos permitió determinar que la intervención de los hemocitos en los experimentos de transferencia es escasa.

Para realizar estos ensayos de transferencia, los DI se marcaron in vivo aprovechando el metabolismo de AGL que se ha estudiado en el capítulo V. El hecho de utilizar distintos individuos con posibles diferencias en su metabolismo y distintos tamaños de DI, dio lugar a que las marcaciones de las que partimos para realizar las transferencias in vitro, también mostraran diferencias. La figura VI.2 muestra la relación entre la cantidad inicial de lípidos- ${ }^{14} \mathrm{C}$ en DI, y la cantidad de radioactividad captada por las lipoproteínas (cpm/mg proteínas) bajo las condiciones antes descriptas. En ambas lipoproteínas se encontró una correlación lineal desde I,2 a $92 \times 10^{3}, \mathrm{r}^{2}=0,95$ para HDL I (Fig. VI.2A), y desde 5,5 a $26 \times 10^{3}, r^{2}=0,96$ para VHDL (Fig. VI.2B).
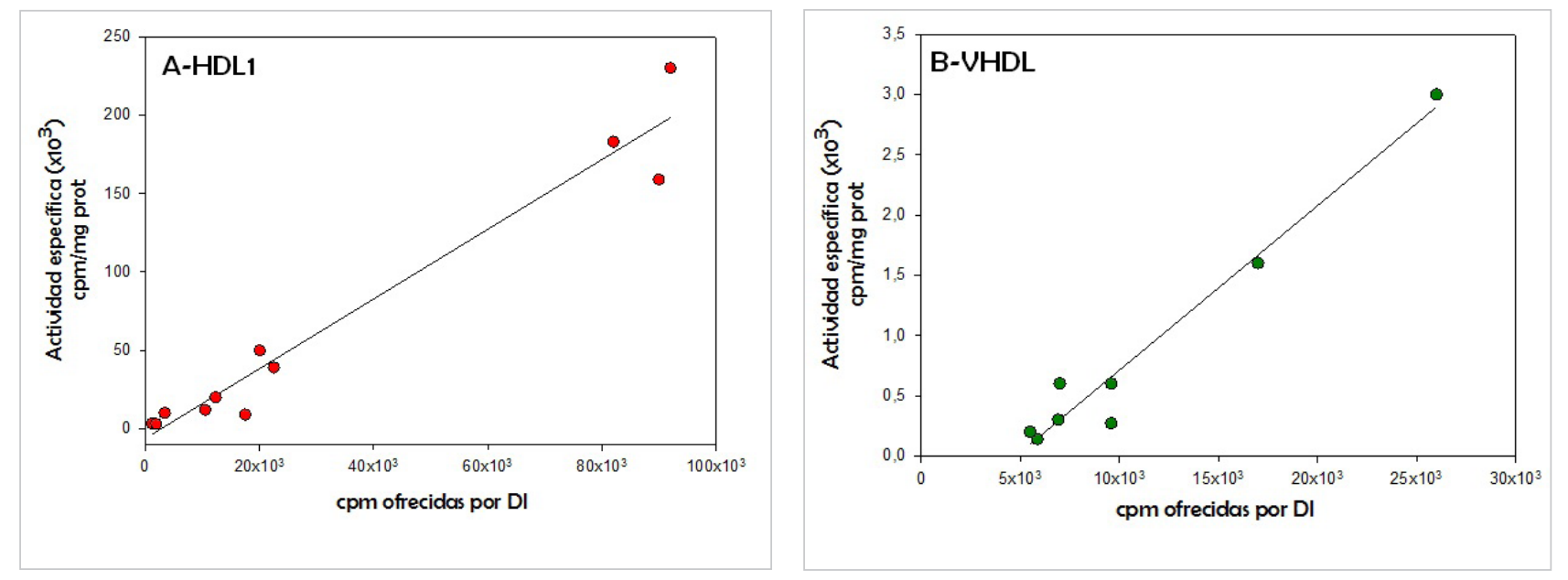

Figura VI.2: Cantidad de cpm (actividad específica) captadas por las lipoproteínas, HDL1 (A) y VHDL (B), en relación a la marca inicial ofrecida por los DI dadores $(n=8)$. Correlación lineal > a $r^{2}=0,95$ en ambos casos.

En relación a la captación de cada clase de lípido en particular por las lipoproteínas, el resultado de la distribución de las clases de lípidos marcados, en los experimentos donde se incubaron in vitro, DI marcados con HL no-marcada, evidencian que las lipoproteínas captan principalmente $P L$, seguidos por $A G L$ y TAG. PL y AGL fueron captados por ambas lipoproteínas en cantidades similares, mientras que los TAG fueron captados principalmente por VHDL (Fig. VI.3). 


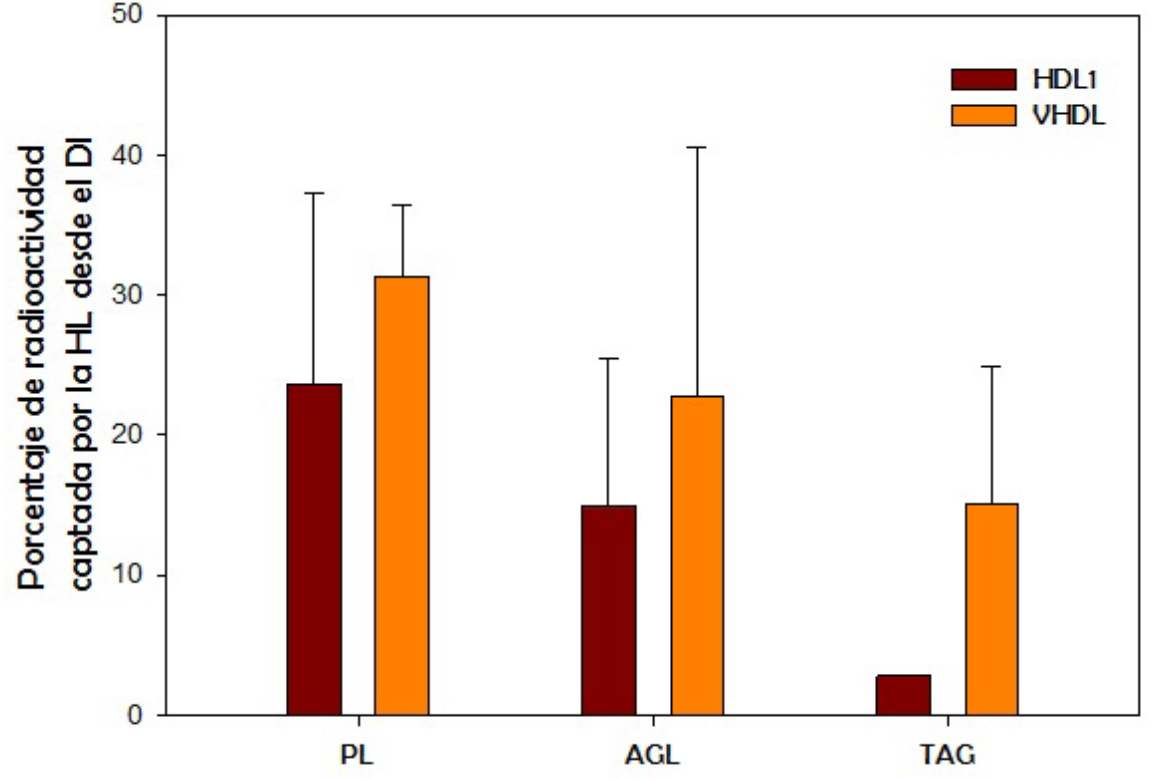

En relación a los ensayos en los cuales se evaluó la captación de lípidos marcados de los DI por las lipoproteínas aisladas, se pudo notar que ambas lipoproteínas captaron PL, AGL y TAG de manera similar (alrededor del 35-60\%) (Fig. VI.4).

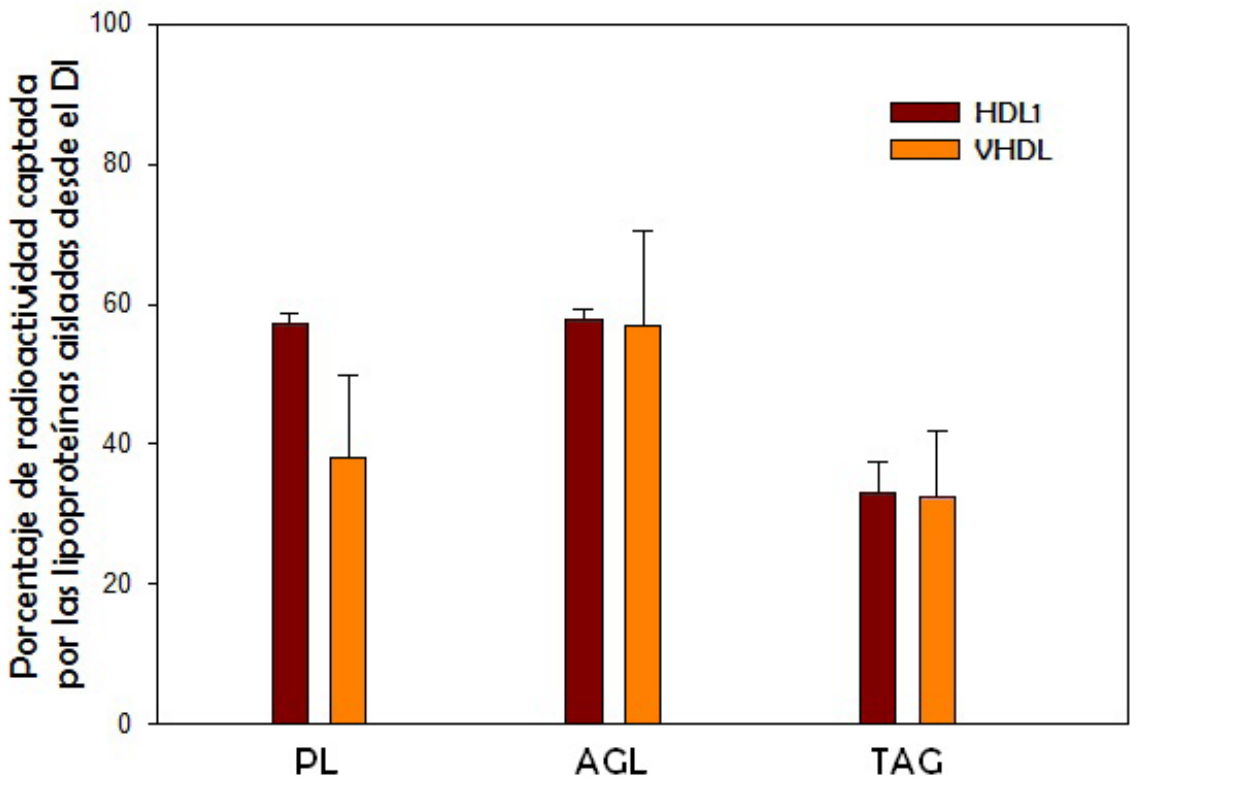

Figura VI.3: Porcentaje de los distintos lípidos captados por las lipoproteínas, desde los DI dadores. Los ensayos fueron hechos con $\mathrm{HL}$ entera y luego cada lipoproteína, analizada por separado.

Figura VI.4: Porcentaje de los distintos lípidos captados por las lipoproteínas, desde los DI dadores, en ensayos con lipoproteínas aisladas. (Los valores representan la media de tres experimentos $\pm S D$ ). 


\section{VI.2.2. Liberación de lípidos desde las lipoproteínas a los divertículos intestinales}

Para estudiar la liberación de lípidos por las lipoproteínas, se incubó a los DI no marcados con HL marcada durante 30 minutos, y se observó que alrededor del $80 \%$ de la marca fue liberada por la HL y captada por los DI. Un porcentaje similar de transferencia fue observado analizando la suma de las transferencias de las lipoproteínas aisladas como dadoras de lípidos (HDL I +VHDL, Fig. VI.5), además se observó que las lipoproteínas aisladas no tienen el mismo comportamiento en la liberación (HDL I y VHDL, Fig. VI.5), sino que VHDL tiene una capacidad más alta de liberar lípidos que HDL I.

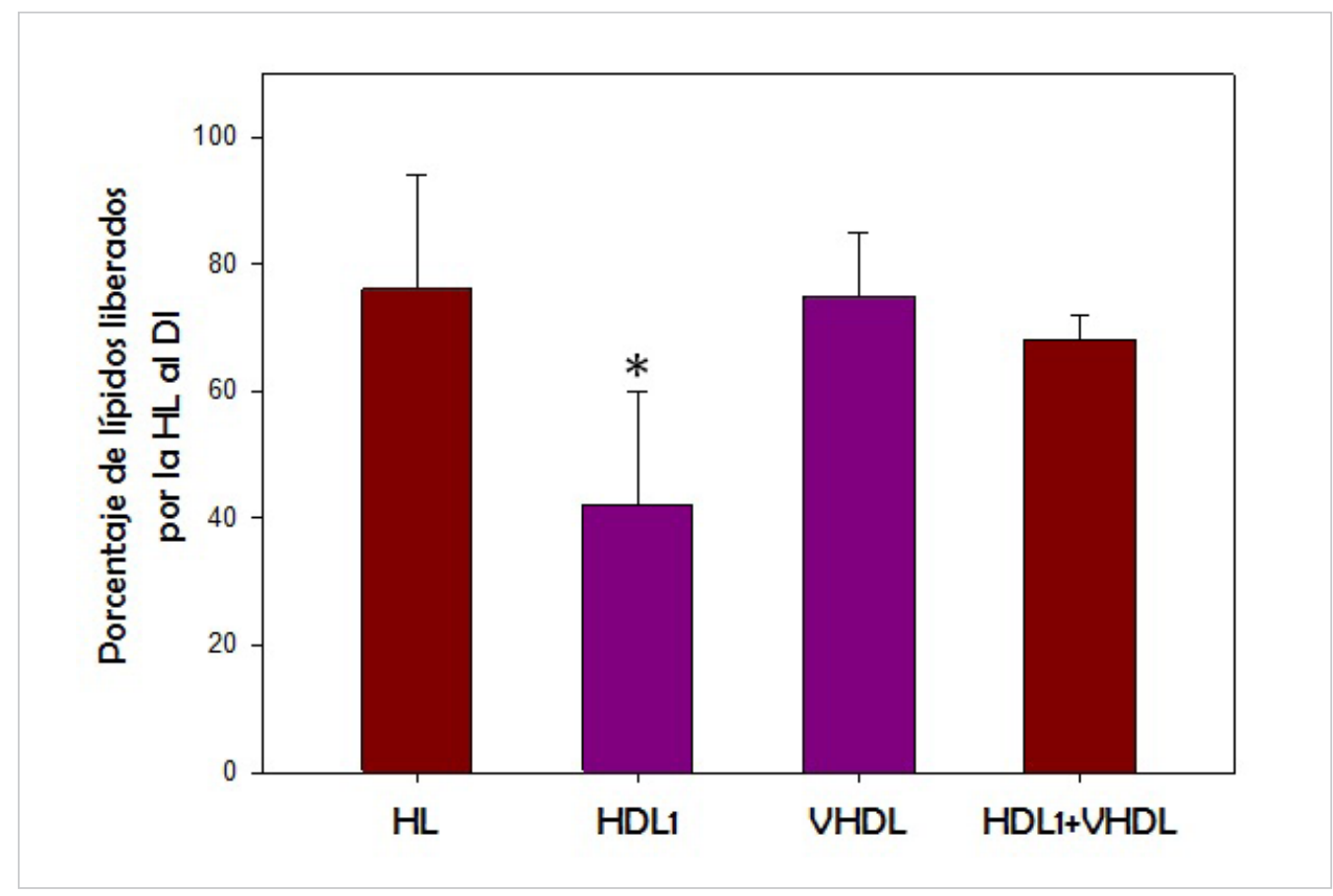

Figura VI.5: Lípidos${ }^{14} \mathrm{C}$ liberados hacia los DI por la HL (ם) y lipoproteínas aisladas (ם). Las barras de error indican el DS de las medias $(n=3)$. Se utilizó el test T Student para comparar la significancia de las diferencias entre HDL 1 y VHDL: * $\mathrm{P}<$ 0.05 .

Nuevamente el hecho de generar HL marcada utilizando individuos vivos, dio lugar a diferencias en las marcaciones iniciales de la HL y lipoproteínas utilizadas para realizar las transferencias in vitro. La relación entre la cantidad inicial de marca y su capacidad de liberar Lípidos se observa en la figura VI.6. Es evidente que existe una correlación lineal $\left(r^{2}=0,9\right)$ entre la cantidad de cpm en las diferentes lipoproteínas y la cantidad de marca que ha sido transferida a los DI. Las cantidades iniciales varían entre $1 \times 10^{3}$ a $20 \times 10^{3} \mathrm{cpm}$ en todos los ensayos. 


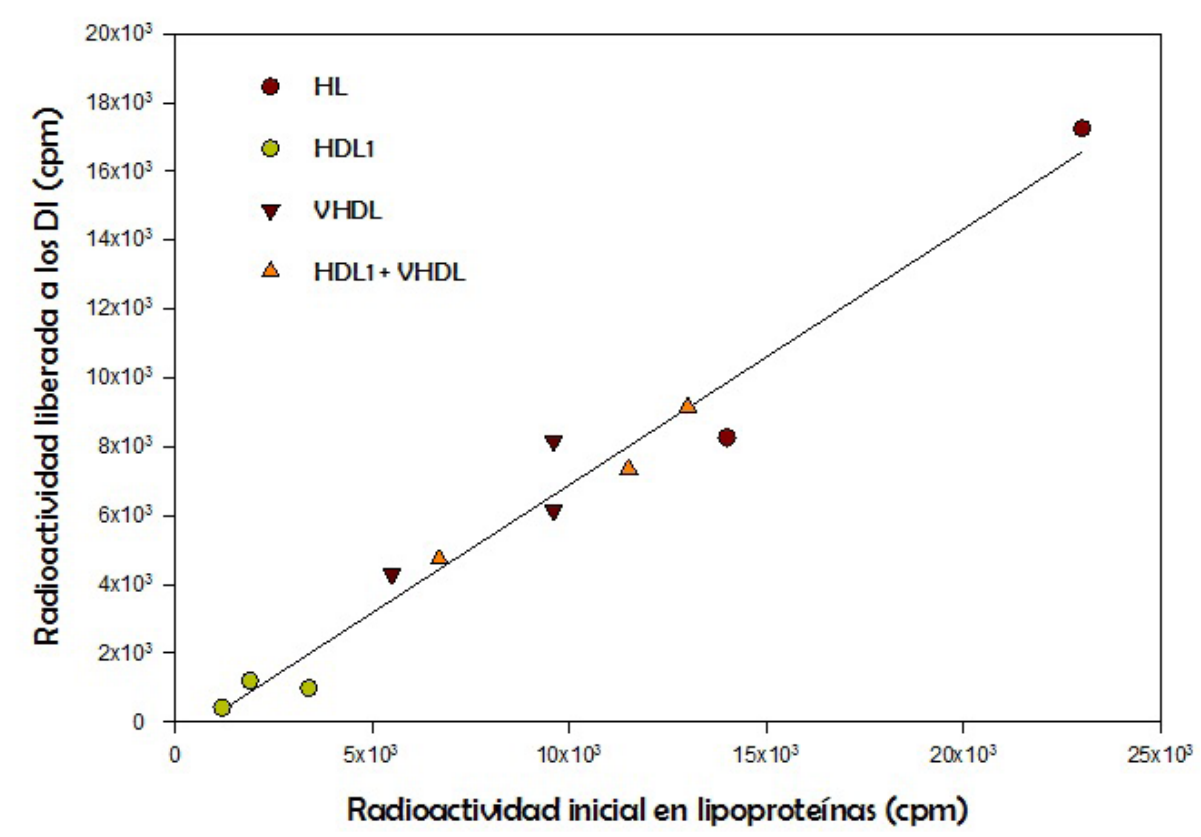

Figura VI.6: Cantidad de lípidos ${ }^{14} \mathrm{C}$ (cpm) liberados por las lipoproteínas en relación a la cantidad de cpm iniciales, $\mathrm{n}=10$. Correlación lineal superior a $\mathrm{r}^{2}=0,96$.

El porcentaje de diferentes lípidos liberados por la HL entera hacia los DI se muestra en la figura VI.7. PL, AGL y TAG fueron liberados en un 44, 75, 73\%, respectivamente. En relación a HDL I y VHDL aisladas, PL, AGL y TAG, fueron transferidos en un porcentaje similar, entre 40 y $50 \%$ para HDL I y para VHDL entre 55 y $70 \%$ (Fig. VI.8).

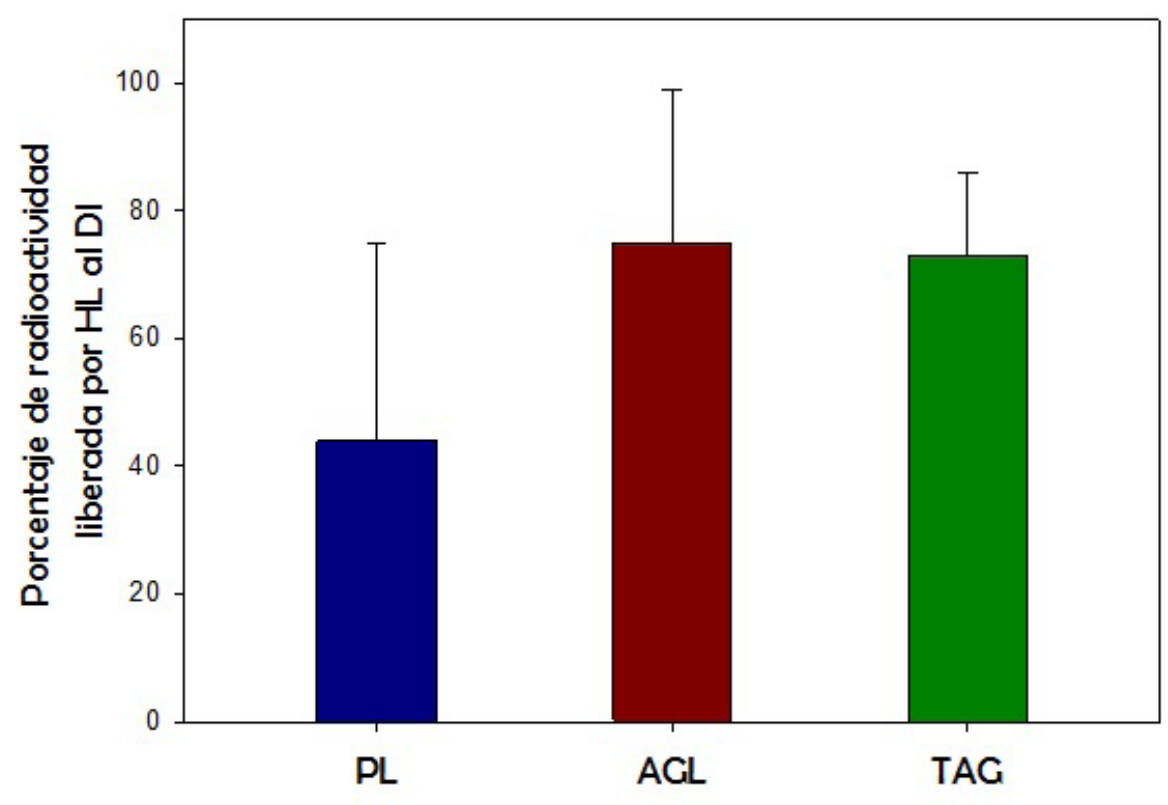

Figura VI.7: Porcentaje de diferentes lípidos${ }^{14} \mathrm{C}$ liberados por las lipoproteínas en ensayos con HL entera (LoS valores representan la media de tres experimentos $\pm S D$ ). 


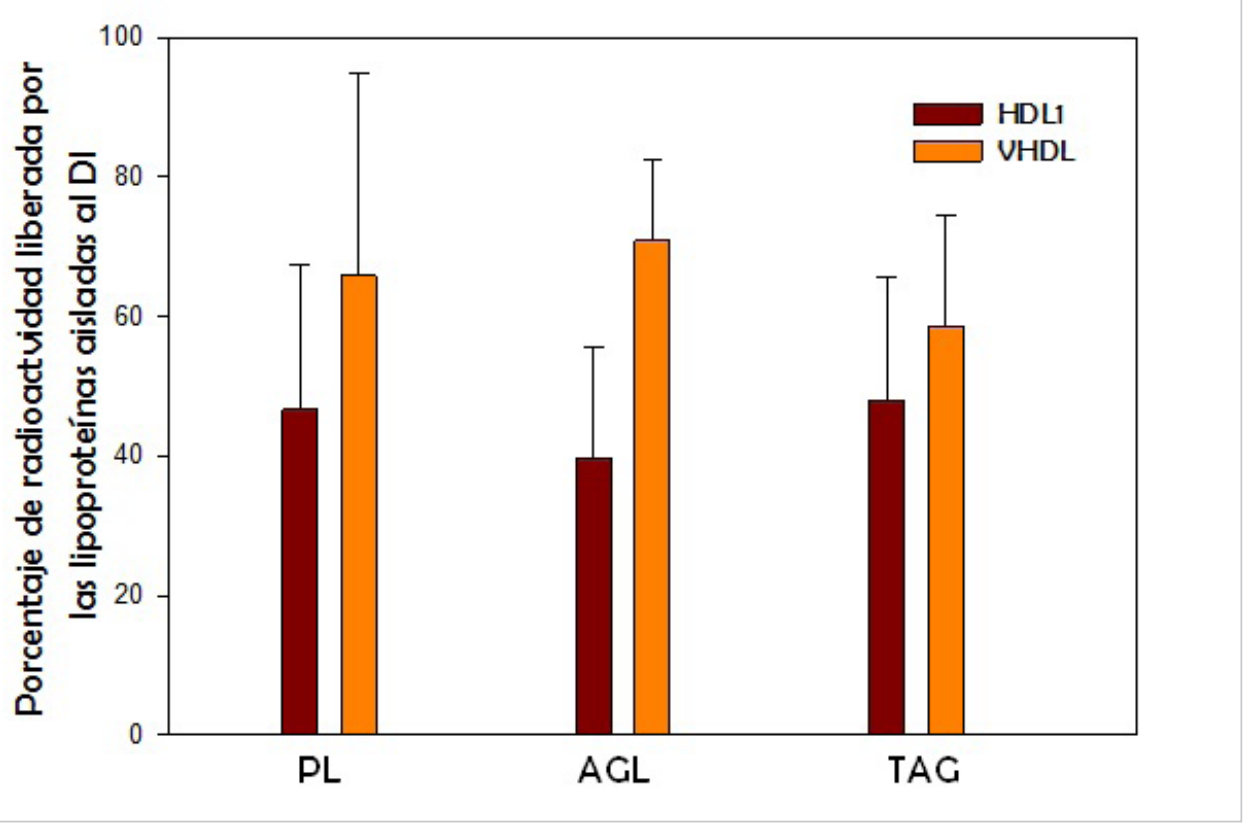

Figura VI.8: Porcentaje de los distintos lípidos liberados por las lipoproteínas, a los DI en ensayos con lipoproteínas aisladas. (Los valores representan la media de tres experimentos $\pm \mathrm{SD})$.

\section{VI.2.3. Transferencia de lípidos entre lipoproteínas}

Teniendo en cuenta las diferencias encontradas en relación a las diferentes capacidades de las lipoproteínas de captar y liberar lípidos, nos propusimos estudiar la posible transferencia entre ellas. La figura VI.9 muestra la transferencia de lípidos- ${ }^{14} \mathrm{C}$ entre VHDL y HDL I y vice-versa, en incubaciones realizadas con diferentes relaciones aceptor/dador. Este experimento fue realizado en presencia de cantidades constantes del dador de lípidos (VHDL- ${ }^{14} \mathrm{C}$ o HDL I- ${ }^{14} \mathrm{C}$ ), e incrementando los niveles de aceptor (HDL I ó VHDL no marcadas), expresando Los resultados como porcentaje de radioactividad transferida. Cuando HDL I fue usada como dador de lípidos, el 60\% de la marca transferida fue captada por la VHDL. Por otro lado, cuando VHDL fue utilizada como dador de lípidos, en presencia de niveles crecientes de HDL I, La transferencia fue de alrededor del $20 \%$. Estos resultados demuestran que HDL I es capaz de transferir más lípidos- ${ }^{14} \mathrm{C}$ a VHDL que ésta, a HDLI. 


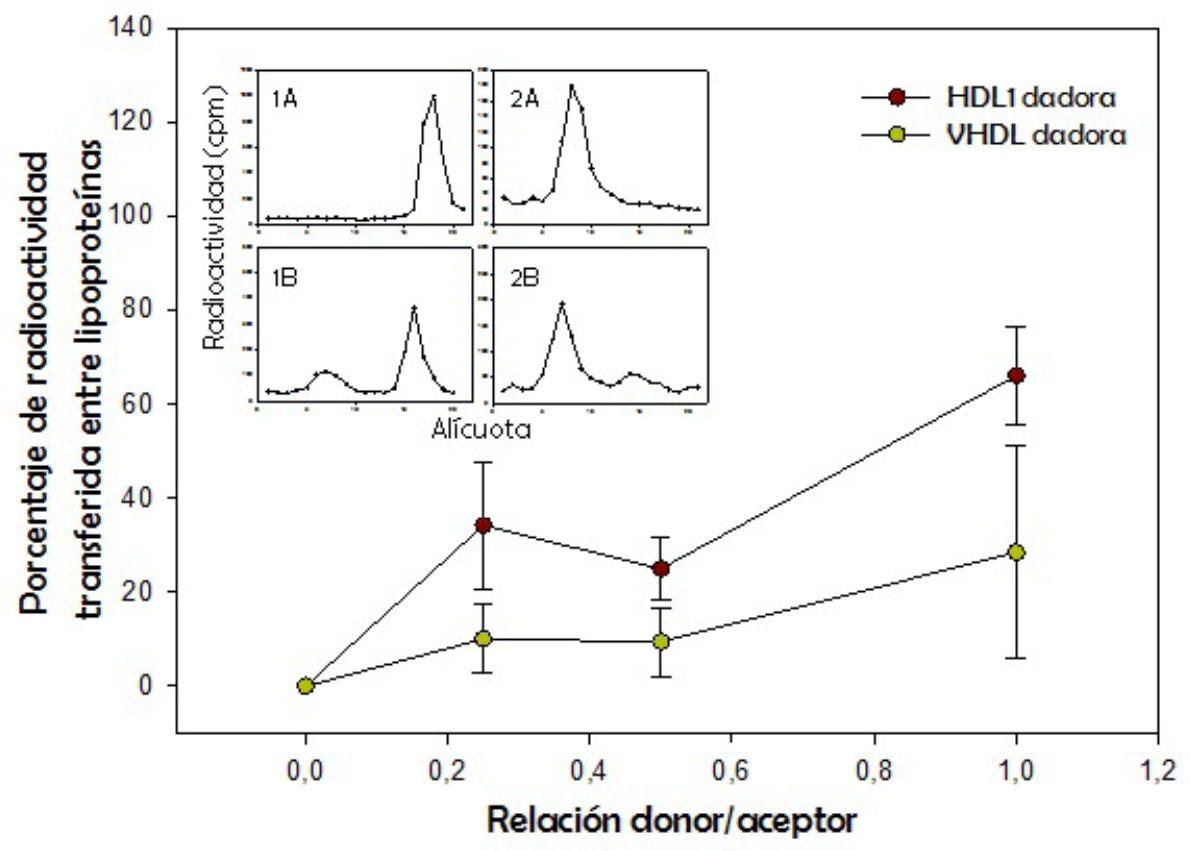

Figura VI.9: Lípidos${ }^{14} \mathrm{C}$ transferidos entre lipoproteínas con diferentes relación aceptor/dador. Inset: las lipoproteínas fueron sujetas a centrifugación en gradiente de densidad, seguido por fraccionamiento y determinación de la radioactividad en cada facción. (Panel 1A) VHDL $-{ }^{14} \mathrm{C}$ dadora, (panel 1B) $\mathrm{VHDL}-{ }^{-14} \mathrm{C}$ (dadora) con HDL1 no-marcada (aceptor) relación 1/1, (panel 2A) HDL $1{ }^{14} \mathrm{C}$ dadora, (panel 2B) HDL $1-{ }^{14} \mathrm{C}$ (dadora) con VHDL (aceptor) relación $1 / 1$.

\section{VI.3. Discusión}

En estudios anteriores se ha reportado la composición lípido-proteica, y las propiedades físico-químicas de las tres lipoproteínas circulantes (HDL I, HDL2 y VHDL) de la araña Polybetes pythagoricus (Cunningham et al., 2007; Cunningham \& Pollero, 1996; Cunningham et al., 1994), de manera que se ha podido especular sobre la funcionalidad de estas tres lipoproteínas en base a su composición proteica.

En este estudio, se utilizó el metabolismo de ácido palmítico- ${ }^{14} \mathrm{C}$, que se ha estudiado en el capítulo $V$, para generar lípidos radiomarcados ( $A G L, P L, y$ TAG), tanto en lipoproteínas hemolinfáticas como en DI, los cuales juegan un rol fundamental en la circulación, síntesis y almacenamiento de lípidos, respectivamente. El uso tanto de DI como de HL y lipoproteínas marcados y no marcados en concentraciones fisiológicas, nos permitió determinar la captación y transferencia de lípidos por las lipoproteínas en un sistema cerrado, constituido únicamente por un par dador/aceptor, en una relación similar a la encontrada en un individuo.

Como era esperable, alrededor del 20\% de la marca presente en DI fue captada por HDL I y VHDL. En los ensayos con ambas lipoproteínas, se evidenció una linealidad en relación a la cantidad inicial de lípidos contenidos en los DI (dadores), demostrando que ambas lipoproteínas tienen el mismo comportamiento en la captación de lípidos, sin alcanzar la saturación. Como se ha observado y discutido previamente, HDL2 no estuvo involucrada en la dinámica de lípidos, probablemente porque su principal función sea el transporte de $\mathrm{O}_{2}$ 
en relación a sus subunidades de hemocianina, y sus lípidos podrían tener una función estructural únicamente, o un rol estabilizador, como fue reportado para la hemocianina de crustáceos (Zatta, 1981).

En cuanto a las otras dos lipoproteínas, la mayor parte de los lípidos radiomarcados fueron captados por HDL I en comparación con VHDL. Esto es esperable ya que HDL I contiene alrededor de un $30 \%$ de lípidos, mientras que VHDL solo tiene un $3 \%$, y es además comparable con lo que ocurre en otros grupos de artrópodos, donde lipoproteínas con similares densidades de hidratación a HDLI, son las predominantes y responsables de la mayor parte del transporte de lípidos, como es el caso de los insectos (Gonzalez et al., 1995) y crustáceos (Yepiz-Plascencia et al., 2000). Aunque los datos relacionados con las lipoproteínas de arácnidos son incompletos y dispersos, existe información disponible que sugiere que HDL I cumpliría esta función. Por ejemplo, la araña Latrodectus mirabilis, conocida popularmente como "viuda negra" tiene dos lipoproteínas, una de ellas HDL I, con la misma densidad de hidratación ( I,I 3 g/ $\mathrm{ml}$ ) que la de P. pythagoricus, que transporta el $80 \%$ del total de los lípidos hemolinfáticos (Cunningham et al., 2000).

Las hemocianinas de artrópodos son partículas multifuncionales cuya principal función es el transporte de $\mathrm{O}_{2}$, pero además tienen otras, tales como ser buffer y osmolitos (Paul \& Pirow, 1998), transporte de hormonas durante la muda (Jaenicke et al., 1999b) y actividad fenoloxidasa (Decker \& Rimke, 1998) entre otras. En P. pythagoricus demostramos en experimentos in vivo detallados en el capítulo $V$, que la VHDL de ésta especie (una lipoproteína que contiene hemocianina como apolipoproteína), está involucrada en la captación desde los DI y en el transporte de lípidos. Sin embargo, el diseño de estos estudios in vivo no permite la descripción del comportamiento de las lipoproteínas en la dinámica de lípidos. Por el contrario, el presente estudio, muestra claramente la contribución de VHDL a la dinámica de lípidos de esta araña, tanto aislada, como formando parte de la HL. Los resultados indican que juega un rol importante (aunque no predominante) en la captación, y también participa, esta vez de manera preponderante, en la liberación de Lípidos hacia los DI, liberando un 30\% más de marca que HDL I. Existe una aparente controversia entre HDL I y VHDL en cuanto a su importancia relativa en la captación y liberación de lípidos, ya que HDL I capta más, pero VHDL libera mas, este hecho podría posiblemente, ser explicado por la transferencia de lípidos entre lipoproteínas, dando lugar a la siguiente hipótesis: teniendo en cuenta los ensayos realizados in vivo, la mayoría de los lípidos son captados por HDL I, luego, mientras circulan por HL, son transferidos a la VHDL (Fig. VI.9) como se reporta para el insecto Triatoma infestans (Gonzalez et al., 1995) y por último la VHDL podría liberarlos a otros tejidos tales como músculo o DI (Fig. VI.5), hecho que también es apoyado por los experimentos realizados in vivo, que demostraron que VHDL libera más lípidos que HDLI a los diferentes tejidos (Fig. VI.I0). 


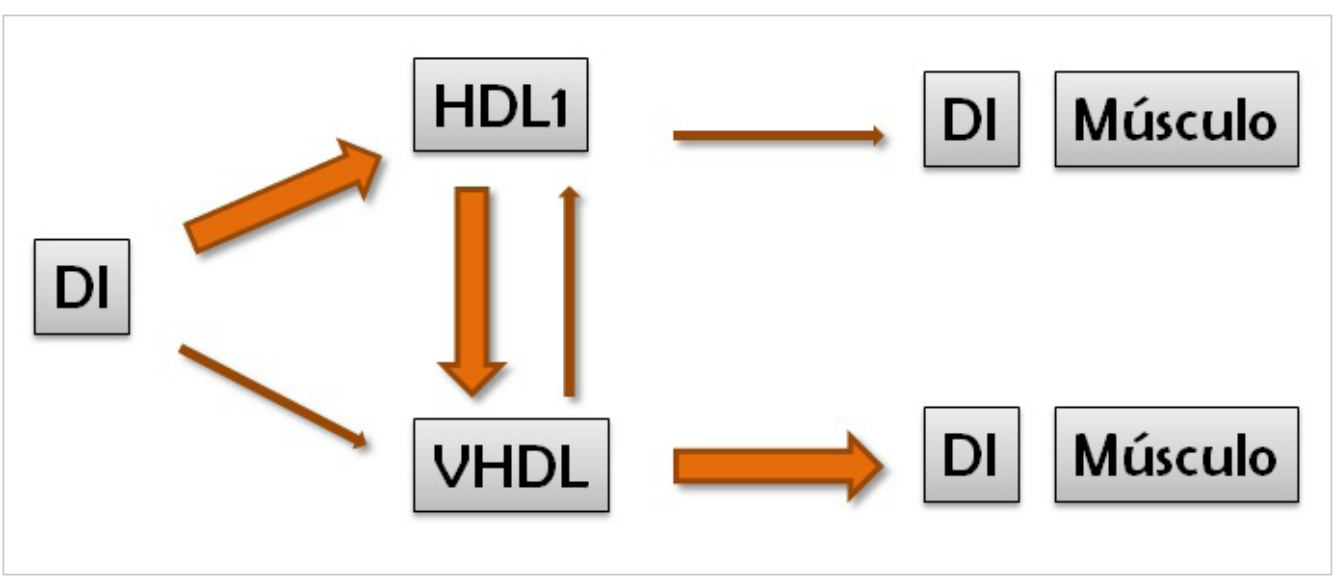

La particular función de la hemocianina como transportadora de lípidos, ha sido analizada en invertebrados, primeramente en el molusco Octopus tehuelchus (Heras \& Pollero, 1990), y sugerida en el crustáceo Pacifastacus leniusculus (Hall et al., 1995). En moluscos, la hemocianina es la apolipoproteína de una VHDL Llamada LP3, La cual transporta principalmente AGL, hidrocarburos y esteroles esterificados. Los PL se encuentran en cambio, asociados a LPI (Heras \& Pollero, 1990), para la cual posteriormente se ha demostrado que también contiene hemocianina (Heras \& Pollero, 1992). Este transporte diferencial de distintos lípidos por distintas lipoproteínas, también ha sido reportado en insectos donde la HDLp transporta principalmente DAG como lípido energético (77\%) y VHDL transporta AGL (83\%) (Gonzalez et al., 1995; Gonzalez et al., 1991; Rimoldi et al., 1989). Por el contrario, nuestros resultados muestran que en $P$. pythagoricus, el rol de ambas lipoproteínas (HDL I y VHDL) en la dinámica de AGL, PL y TAG es similar, no encontrándose diferencias significativas en la transferencia de los diferentes lípidos.

Debemos notar en este punto, que la importante variabilidad que presentan los resultados, podría deberse a que los animales fueron colectados en el campo, pudiendo presentar diferencias en cuanto a su estado de salud y situación nutricional, hecho que, podría provocar grandes desvíos; a pesar de que las condiciones de trabajo fueron estandarizadas en cuanto al tamaño, sexo, y ayuno de los animales.

Arañas y moluscos tienen diferentes formas de transporte de lípidos, aunque comparten el hecho de que AGL y PL son los principales lípidos transportados. La evolución de ambos grupos muestra que han divergido desde el Cámbrico, dando como resultado, hemocianinas con diferentes secuencias de aminoácidos y un diferente rol de los hemocitos en la captación de lípidos por la HL. Aunque es posible que los hemocitos de moluscos y de arañas no correspondan al mismo tipo celular, en cefalópodos se encontró que un $30 \%$ de los Lípidos son captados por las células circulantes, pero solo un $3 \%$ se encontró asociado con hemocitos en P. pythagoricus. Inclusive dentro de las arañas, no
Figura VI.10: Posible flujo de lípidos entre DI y lipoproteínas hemolinfáticas en la araña P. pythagoricus. 
puede ser generalizado el rol de la hemocianina en el transporte de lípidos para todas las especies, dado que no se pudo establecer su asociación con los lípidos en las tarántulas (Stratakis et al., 1993). Lo mismo ocurre en moluscos, donde la hemocianina se comporta como una apolipoproteína en $\mathrm{O}$. tehuelchus, (Heras \& Pollero, 1992) pero no en el gasterópodo Pomacea canaliculata (Garín \& Pollero, 1995). Se necesitan más estudios para dilucidar la relación estructura-función a través de la evolución de la hemocianina en diferentes grupos de invertebrados.

En relación a la circulación de lípidos, es evidente que las lipoproteínas tienden a captar principalmente PL y AGL de los DI, de acuerdo con su composición lipídica, ya que HDL I y VHDL, contienen alrededor de 60\% de PL y 15\% de AGL. Los PL, que fueron encontrados predominantes entre los lípidos circulantes de arañas (Cunningham et al., 2007) y también en crustáceos (Garcia et al., 2002b; Lee \& Puppione, 1988), serían luego distribuidos entre los diferentes tejidos. Ambas lipoproteínas hemolinfáticas, transfieren principalmente AGL que serían empleados para la síntesis de acilglicéridos, como ocurre en el insecto Rhodnius prolixus (Atella et al., 2000) o en el crustáceo Macrobrachium borellii (Garcia et al., 2002b), mientras que los TAG almacenados en los DI serían principalmente usados como recurso energético de acuerdo a lo observado en P. pythagoricus y discutido anteriormente en esta tesis, y a la baja transferencia hacia las lipoproteínas.

En conclusión, este estudio, sostiene la hipótesis de que HDL I y VHDL están involucradas en la captación y liberación de AGL, PL y TAG en la araña P. pythagoricus, y apoya un flujo direccional de lípidos de HDL I y VHDL, sugiriendo un nuevo modo de transporte de lípidos entre lipoproteínas y DI. 
Aislamiento y caracterización de dos lipovitelinas de la araña Polybetes pythagoricus 


\section{Aislamiento y caracterización de dos lipovitelinas de la araña Polybetes pythagoricus}

\section{1. Introducción}

En aquellas especies en las que en su reproducción se involucra la puesta de huevos, es indispensable que éstos sean provistos de los nutrientes necesarios para el desarrollo embrionario.

En arañas en particular, es destacable que el vitelo debe contener la totalidad de los recursos energéticos necesarios para el desarrollo, eclosión, muda y vida del juvenil, hasta que pueda cazar su propia presa (Foelix, 2011 ), tanto que, si el desarrollo del embrión ocurre en invierno, éstos pueden vivir hasta 200 días sin recursos energéticos externos, valiéndose únicamente de los nutrientes suministrados por el vitelo (Schaerefer, 1976). Del mismo modo ocurre en la garrapata Ornithodoros moubata, donde los recursos del vitelo son capaces de sostener la vida de los primeros estadíos ninfales, durante largos períodos de estivación, sin alimento, hasta que encuentre un vertebrado hospedador (Chinzei \& Yano, 1985).

Los nutrientes, representados por lípidos, proteínas e hidratos de carbono, se asocian dando lugar a la formación de lipovitelinas. Dado su rol primordial en la reproducción, estos agregados moleculares, han sido blanco de los estudios bioquímicos orientados a su caracterización, utilización durante el desarrollo y evaluación de requerimientos nutricionales, en los principales grupos de artrópodos; aunque si bien han sido detalladamente caracterizadas en crustáceos (Garcia et al., 2006; Walker et al., 2006; Chen et al., 2004; Kawazoe et al., 2000; Lubzens et al., 1997) e insectos (Tufail \& Takeda, 2008; Salerno et al., 2002; Chino, 1997; Dhadialla \& Raikhel, 1990), en relación a los arácnidos, la información de la que se dispone es escasa. La excepción la constituye el Orden Acari, que ha sido ampliamente estudiado dada su importancia económica y sanitaria como causante de enfermedades al hombre, animales domésticos y ganado (causantes de alergias, transmisores de virus, bacterias y protozoos, ectoparásitos, etc.), así como por aspectos beneficiosos, como formar parte del ciclo del suelo, ser bioindicadores y otros. Inclusive en los últimos años, el conocimiento sobre la estructura de las Vt y su procesamiento durante la embriogénesis, se aplicó al estudio de posibles vacunas contra estos parásitos (Seixas et al., 2011; Seixas et al., 2008; Tellam et al., 2002).

En este orden se han caracterizado $\mathrm{Vg}$ y $\mathrm{Vt}$ en varias especies, determinándose que se trata de complejos hemo-glico-lipo-fosfo-proteínas, una estructura principalmente relacionada con sus hábitos hematófagos (Cabrera et al., 2009a; James \& Oliver, Jr., 1997; Rosell \& Coons, 1992; Chinzei et al., 1983).

En cambio, en el orden Araneae solo se ha descripto en forma incompleta, una posible apovitelina presente en ovario y huevos de la araña doméstica de 
Europa Central, Tegenaria atrica (Pourie \& Trabalon, 2003).

El objetivo de este estudio fue identificar, aislar y caracterizar las posibles Lipoproteínas presentes en el vitelo de la araña P. pythagoricus. Para tener un mejor entendimiento de sus aspectos funcionales, esenciales para el desarrollo embrionario, reunimos información sobre sus composiciones lipídicas, de ácidos grasos y apolipoproteica. Determinamos los carbohidratos totales, la forma y tamaño de las partículas lipoproteicas, y finalmente analizamos si poseen relación inmunológica con las lipoproteínas hemolinfáticas.

\section{VII.2. Resultados}

\section{VII.2.1. Aislamiento y caracterización proteica de lipoproteínas de huevo} de P. pythagoricus

Con el fin de aislar las posibles lipoproteínas presentes en huevos de la araña P. pythagoricus, se homogeneizó el contenido de 4 ootecas como se describe en el capítulo Materiales y Métodos, se obtuvo la fracción citosólica y se la sometió a una ultracentrifugación en gradiente de densidad. Luego de 24 hs. de centrifugación a 272.400 g, se obtuvo el siguiente resultado (Fig. VII.I):

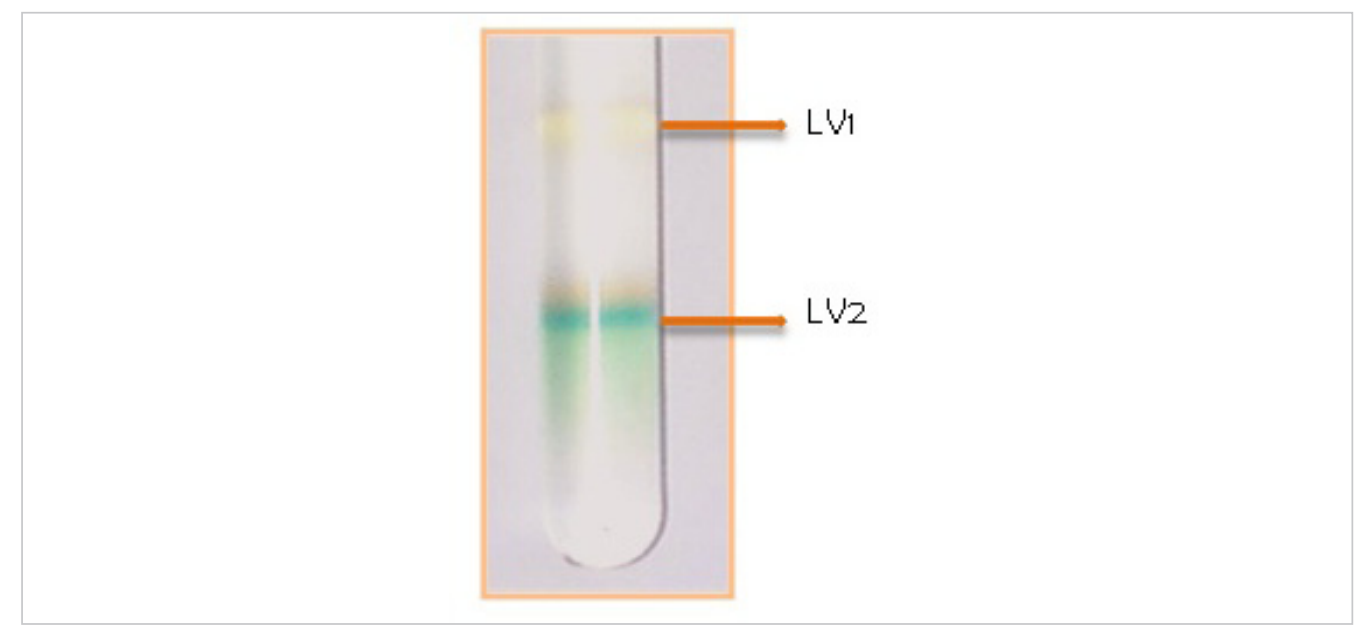

Posteriormente se fraccionó el gradiente de densidad en alícuotas de 200 $\mu \mathrm{l}$, y se realizaron medidas de absorbancia a $280 \mathrm{~nm}$ de cada una de ellas, para construir un perfil graficando, contenido relativo de proteínas vs. densidad de las alícuotas. Este perfil nos permitió observar dos picos, correspondientes a las zonas con mayor concentración proteica, que evidencian la presencia de lipoproteínas. Una de ellas, a la que llamamos Lipovitelina I (LVI), presentó una densidad de hidratación de $1,16 \mathrm{~g} / \mathrm{ml}$, de manera que se la pudo definir como una Lipoproteína de alta densidad (HDL). La segunda lipoproteína, con una densidad de hidratación de $1,24 \mathrm{~g} / \mathrm{ml}$ fue definida como una lipoproteína de muy alta densidad (VHDL), denominada Lipovitelina 2 (LV2) (Fig. VII.2).
Figura VII.1: Gradiente de densidad obtenido luego de ultracentrifugar el citosol de huevos de la araña $P$. pythagoricus. 
Las fracciones correspondientes a LVI y LV2 fueron caracterizadas por separado. El contenido total de proteínas de huevo fue de 48,67 $\mu \mathrm{g} / \mathrm{mg}$ huevo, de Los cuales LVI representa el 27,05\% ( I , I $7 \mu \mathrm{g} / \mathrm{mg}$ huevo) y LV2 el 23\% ( II, I $9 \mu \mathrm{g}$ / mg huevo), mostrando que estas dos lipovitelinas constituyen el $51,5 \%$ del total de las proteínas presentes en el huevo.

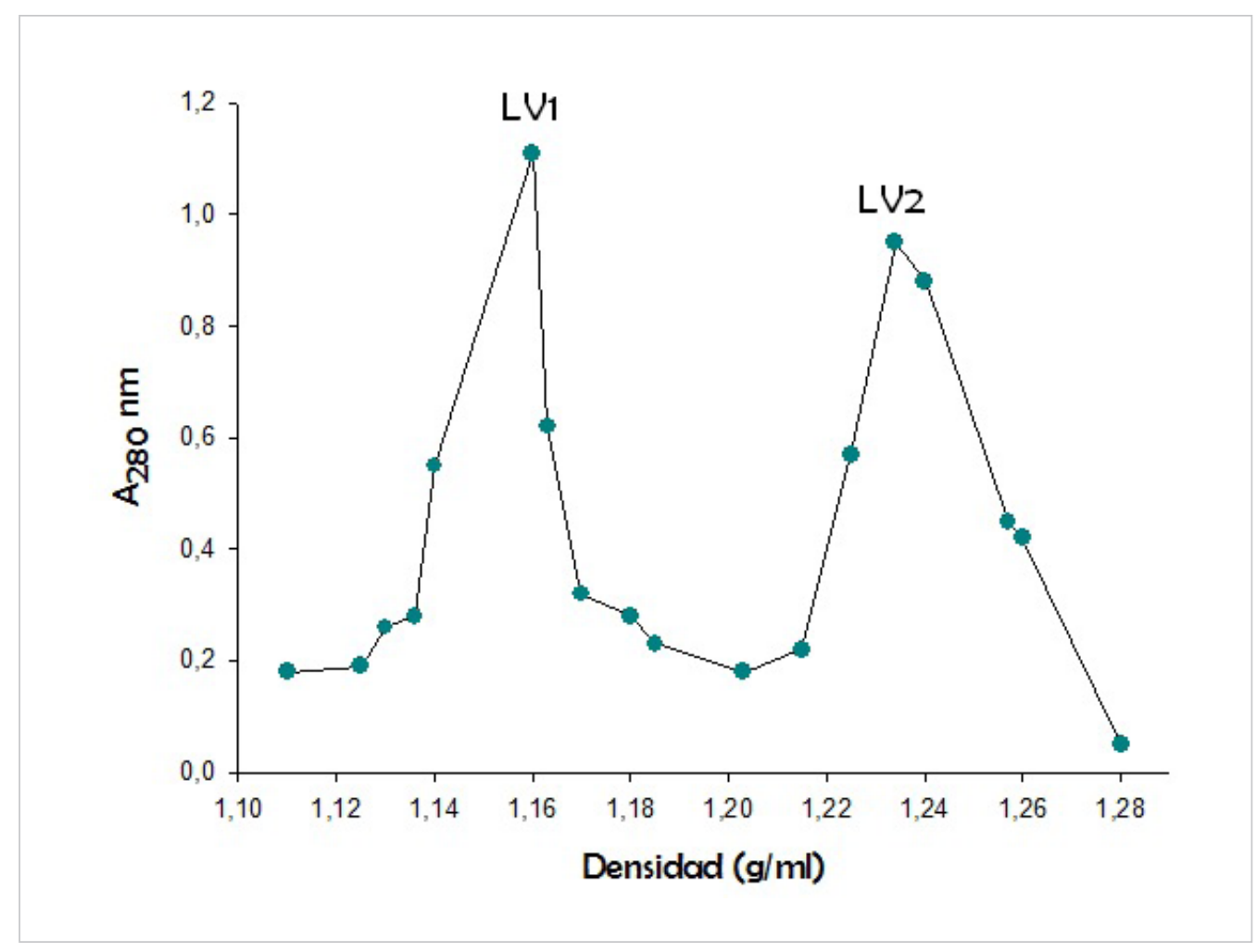

\section{Figura VII.2:}

Distribución de las proteínas (A $280 \mathrm{~nm}$ ) de citosol de huevos de $P$. pythagoricus obtenida por ultracentrifugación en gradiente de densidad en $\mathrm{NaBr} \delta=$ $1,28 \mathrm{~g} / \mathrm{ml}$.

Comenzamos la caracterización de LV I y LV2 estudiando la composición apoproteica de las mismas, para lo cual se realizó un análisis electroforético tanto en condiciones nativas como disociantes. En la figura VII.3 se muestran los resultados obtenidos del PAGGE-Nativo de LVI y LV2. En LVI se observa una única banda de 550 kDa, mientras que en LV2 fueron observadas 3 bandas, de 57 I, 400 y 257 kDa. 


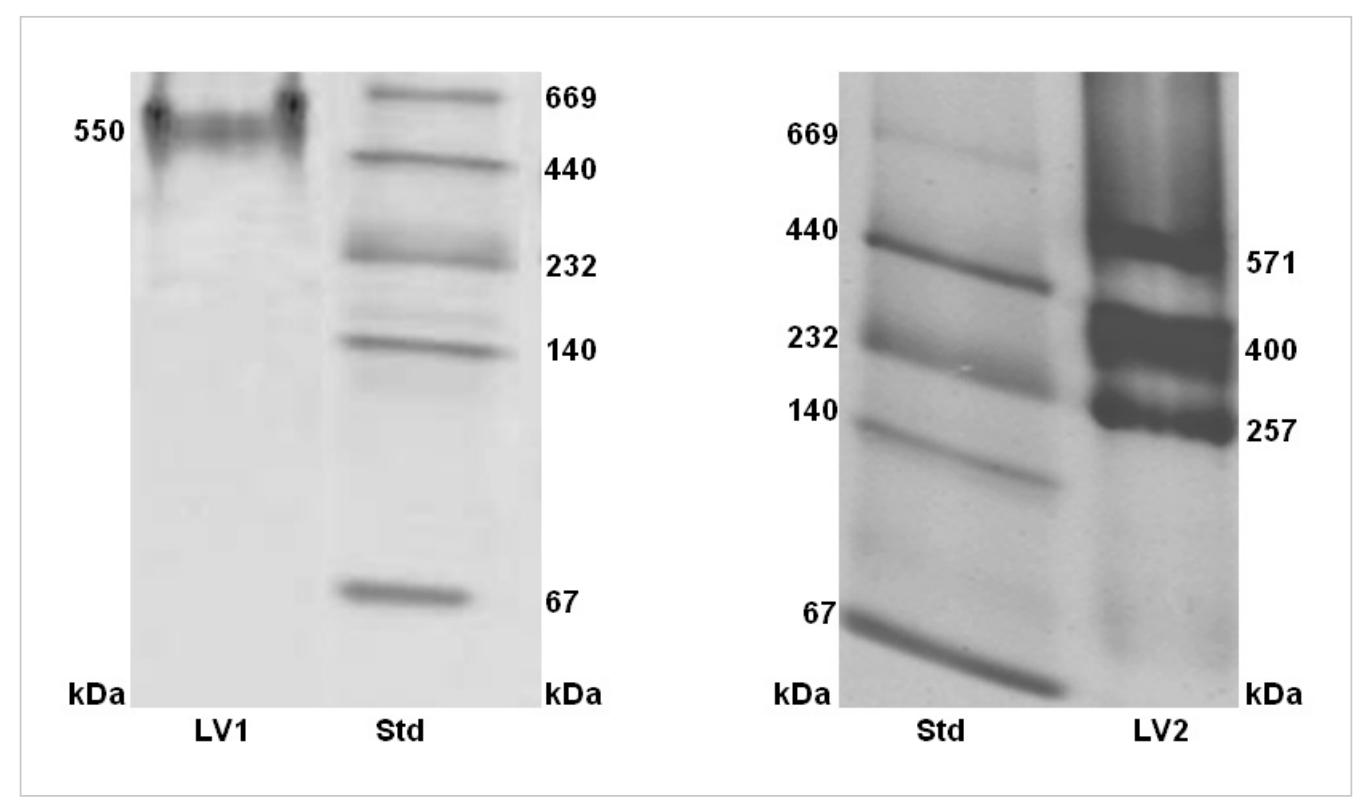

Luego del análisis electroforético en condiciones disociantes, en LVI se encontraron dos apoproteínas predominantes de 64 y 25 kDa (Fig. VII.4A). En el caso de LV2, las tres bandas encontradas en condiciones nativas, fueron aisladas del gel por electroelución, lo cual nos permitió el análisis por separado de cada una en condiciones disociantes, para de esta manera, conocer las diferencias o similitudes que podrían presentar en el patrón de bandas resultante. Así, se pudo observar que, aunque en diferentes proporciones, las tres presentaban Las mismas bandas, con pesos moleculares de 181, 67 y 60 kDa, además de una subunidad de 18 kDa (línea I, Fig. VII.4B).

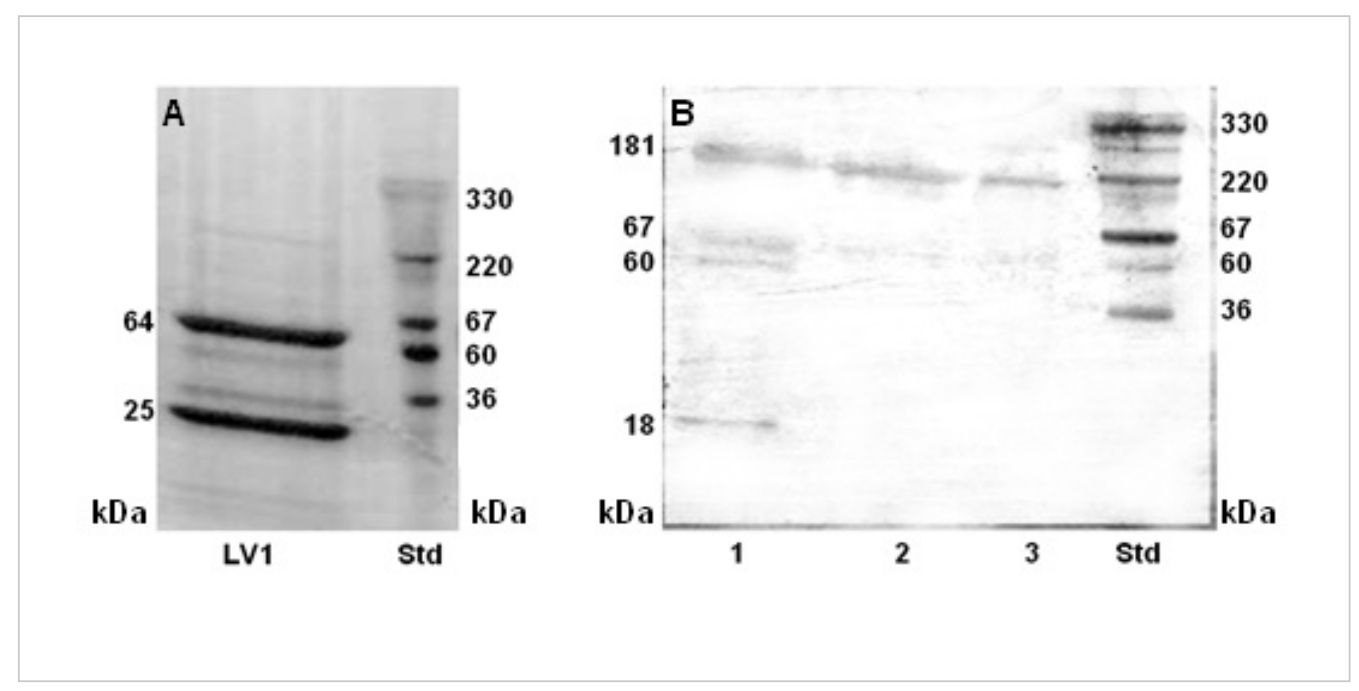

Figura VII.3: PAGGENativo de LV1 y LV2. Se utilizó un gradiente de poliacrilamida de 4-23\%. Las proteínas fueron visualizadas con Coomasie Brillant Blue.

Figura VII.4: PAGGESDS (gradiente de poliacrilamida $4-23 \%)$. (A) LV1, las proteínas fueronteñidas con Coomasie Brillant Blue. (B) Bandas electroeluídas del PAGGE-Nativo de LV2. Línea 1257 kDa, línea 2400 kDa, línea 3 $571 \mathrm{kDa}$. Las proteínas fueron visualizadas con tinción de plata. 
VII.2.2. Caracterización lipídica y de hidratos de carbono

Se realizó el análisis cuantitativo de la composición lipídica de las dos lipoproteínas aisladas del citosol de huevo de P. pythagoricus, cuyos resultados se muestran en la tabla VII.I. El contenido de lípidos totales fue de 49,3 y 9,7\% para LVI y LV2 respectivamente.

En ambas lipoproteínas los lípidos predominantes fueron los PL, (principalmente PC y PE), con un 57,1\% en LVI y un $47 \%$ en LV2. Con respecto a los lípidos neutros, los esteroles esterificados fueron cuantitativamente los más importantes con $16,6 \%$ y $24,2 \%$ en LVI y LV2 respectivamente. Se cuantificaron también hidrocarburos, TAG, Col y DAG que presentaron un porcentaje < al 10\% (Tabla VII.I).

\begin{tabular}{lcc} 
& $\mathbf{L V} \mathbf{~}$ & $\mathbf{L V} \mathbf{2}$ \\
\hline Densidad (g/ml) & $\mathbf{I , 1 6}$ & $\mathbf{1 , 2 3}$ \\
\hline $\boldsymbol{\mu g}$ proteína/mg huevo & $\mathbf{1 3 , 1 7}$ & $\mathbf{1 1 , 1 9}$ \\
\hline Proteínas de lipoproteína \% & $\mathbf{4 9 , \mathbf { I I }}$ & $\mathbf{8 9 , 5 3}$ \\
\hline Carbohidratos de lipoproteína \% & $\mathbf{1 , 4 8}$ & $\mathbf{0 , 6 9}$ \\
\hline Lípidos de lipoproteína \% & $\mathbf{4 9 , 3 9}$ & $\mathbf{9 , 7 7}$ \\
\hline Clases de lípidos de lipoproteínas \% & & \\
\hline Hidrocarburos & $7,4 \pm 0,1$ & $9,5 \pm 0,4$ \\
\hline Esteroles esterificados & $16,6 \pm \mathbf{I , 1}$ & $24,2 \pm 1,5$ \\
\hline Triacilglicéridos & $8,0 \pm 0,3$ & $9,5 \pm 0,4$ \\
\hline Colesterol & $8,0 \pm 0,3$ & $3,3 \pm 0,1$ \\
\hline Diacilglicéridos & $3,0 \pm 0,1$ & $4,3 \pm 0,3$ \\
\hline Fosfatidiletanolamina & $25,4 \pm 0,8$ & $20,1 \pm 0,5$ \\
\hline Fosfatidilcolina & $23,8 \pm 0,6$ & $17,5 \pm 0,3$ \\
\hline Otros fosfolípidos & $7,9 \pm 0,2$ & $9,4 \pm 0,2$ \\
\hline
\end{tabular}

\section{Tabla VII.1:}

Composición lipídica de LV1 y LV2 aisladas de huevos de $P$. pythagoricus. Los datos de clases de lípidos son expresados como porcentaje del peso y cuantificados por TLC-FID. Los valores corresponden a la media \pm DS de 3 análisis independientes de un pool de 4 ootecas.

En la tabla VII.2 se muestra la composición de ácidos grasos de ambas lipoproteínas. Los predominantes fueron en orden decreciente: 18: In-9, 18:2n-6, 16:0 y 18:0 en LVI, y 18:I n-9, 16:0, 18:2 n-6 y 18:0 en LV2. 


\begin{tabular}{lcc} 
Ácidos grasos de lipoproteínas \% & LV $\mathbf{~}$ & LV $\mathbf{~}$ \\
\hline $14: 0$ & $0,7 \pm 0,3$ & $1,62 \pm 0,44$ \\
\hline $16: 0$ & $18,2 \pm 1,1$ & $23,8 \pm 5,8$ \\
\hline $18: 0$ & $10,03 \pm 0,03$ & $11,2 \pm 1,1$ \\
\hline $16: 1 n-7$ & $5,6 \pm 2,9$ & $3,9 \pm 1,3$ \\
\hline $18: 1 n-9$ & $31,03 \pm 5,8$ & $31,05 \pm 7,9$ \\
\hline $20: 1 n-9$ & $0,78 \pm 0,03$ & $0,17 \pm 0,24$ \\
\hline $16: 2 n-4$ & $1,49 \pm 0,29$ & $1,09 \pm 0,19$ \\
\hline $18: 2 n-6$ & $26,2 \pm 5,44$ & $22,8 \pm 6,5$ \\
\hline $18: 3 n-1$ & $0,59 \pm 0,04$ & $0,12 \pm 0,17$ \\
\hline $18: 3 n-3$ & $2,18 \pm 0,64$ & $1,28 \pm 0,18$ \\
\hline $20: 4 n-3$ & $2,03 \pm 0,12$ & $1,05 \pm 0,03$ \\
\hline $20: 5 n-3$ & $1,3 \pm 0,25$ & $0,7 \pm 0,008$ \\
\hline$\Sigma$ saturados & $29,2 \pm 1,43$ & $35,12 \pm 7,34$ \\
\hline$\Sigma$ monoinsaturados & $37,68 \pm 8,73$ & $36,42 \pm 9,44$ \\
\hline$\Sigma$ poliinsaturados & $33,79 \pm 6,78$ & $27,04 \pm 7,07$ \\
\hline
\end{tabular}

Tabla VII.2:

Composición de ácidos grasos de LV1 y LV2 aisladas de huevos de P. pythagoricus. Los datos son expresados como porcentaje del peso y cuantificados por GLC-FID. Los valores corresponden a la media \pm DS de 3 análisis independientes de un pool de 4 ootecas.

Para determinar el contenido total de hexosas de las lipoproteínas, se utilizó el método de antrona/sulfúrico, que dio como resultado I,48 y 0,69\% p/p para LVI y LV2 respectivamente.

\section{VII.2.3. Microscopía electrónica}

Para el estudio de la morfología y tamaño de las partículas lipoproteicas, se tomaron fotos de microscopia electrónica realizada con tinción negativa de ambas lipoproteínas. Éstas, nos permitieron observar partículas de morfología casi esférica, cuyas dimensiones son de 20,0 \pm 4,I nm de diámetro en LV I y 27,3 \pm 4,7 nm en LV2 (Fig. VII.5). No se encontraron estructuras de apilamientos, típicos de lipoproteínas discoidales (Forte et al., 1974), ni estructuras morfológicas características de hemocianinas de moluscos, como la formación de agregados tipo decámeros (Herkovits \& Hamilton, 1991), o de artrópodos, las cuales poseen asociaciones de diferentes grados entre partículas que dan lugar a la formación de hexámeros o múltiplos de hexámeros (Markl, 1986; FernándezMorán et al., 1966). 


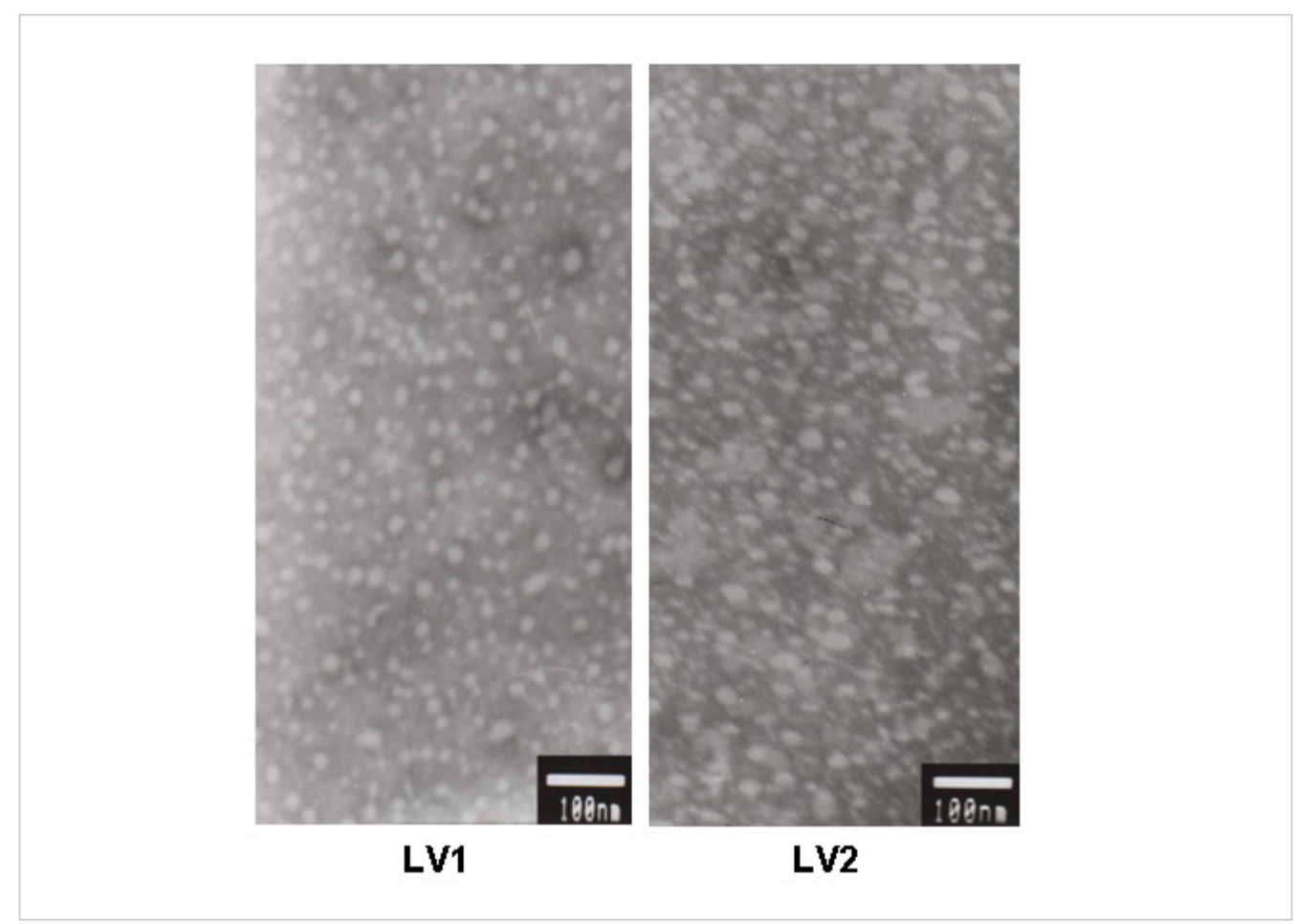

Dado que en esta especie, no se ha aislado ni descripto hasta el momento, la presencia de lipoproteínas relacionadas con la reproducción que actúen como Vg, luego de obtener información sobre la composición proteica y lipídica de LV I y LV2, decidimos realizar ensayos que nos permitieran determinar las posibles relaciones entre éstas y las lipoproteínas hemolinfáticas ya descriptas en P. pythagoricus.

En primer lugar se realizó un PAGGE-Nativo teñido con biquinolina, un colorante específico para cuproproteínas. Esta tinción resultó negativa tanto para LV I como para LV2, indicando la ausencia de cobre en sus estructuras (resultados no mostrados). Posteriormente se realizaron los siguientes ensayos:

\section{VII.2.4. Determinación de hemocianina}

Para estudiar la presencia/ausencia de hemocianina en Las LV, se realizaron espectros de absorción de las mismas entre 220 y 550 nm, buscando la absorción a $340 \mathrm{~nm}$ característica de las oxihemocianinas. Como control positivo se utilizó VHDL hemolinfática que mostró un espectro de absorción típico, con sus picos a 280 y 340 nm. En las LV no se observó absorción a 340 nm, indicando la ausencia de oxihemocianina (Fig. VII.6).

\section{Figura VII.5:}

Microscopía electrónica de lipovitelinas (LV1 y LV2) aisladas de huevos de $P$. pythagoricus, teñidas negativamente. Ampliación final $x$ 120.000 


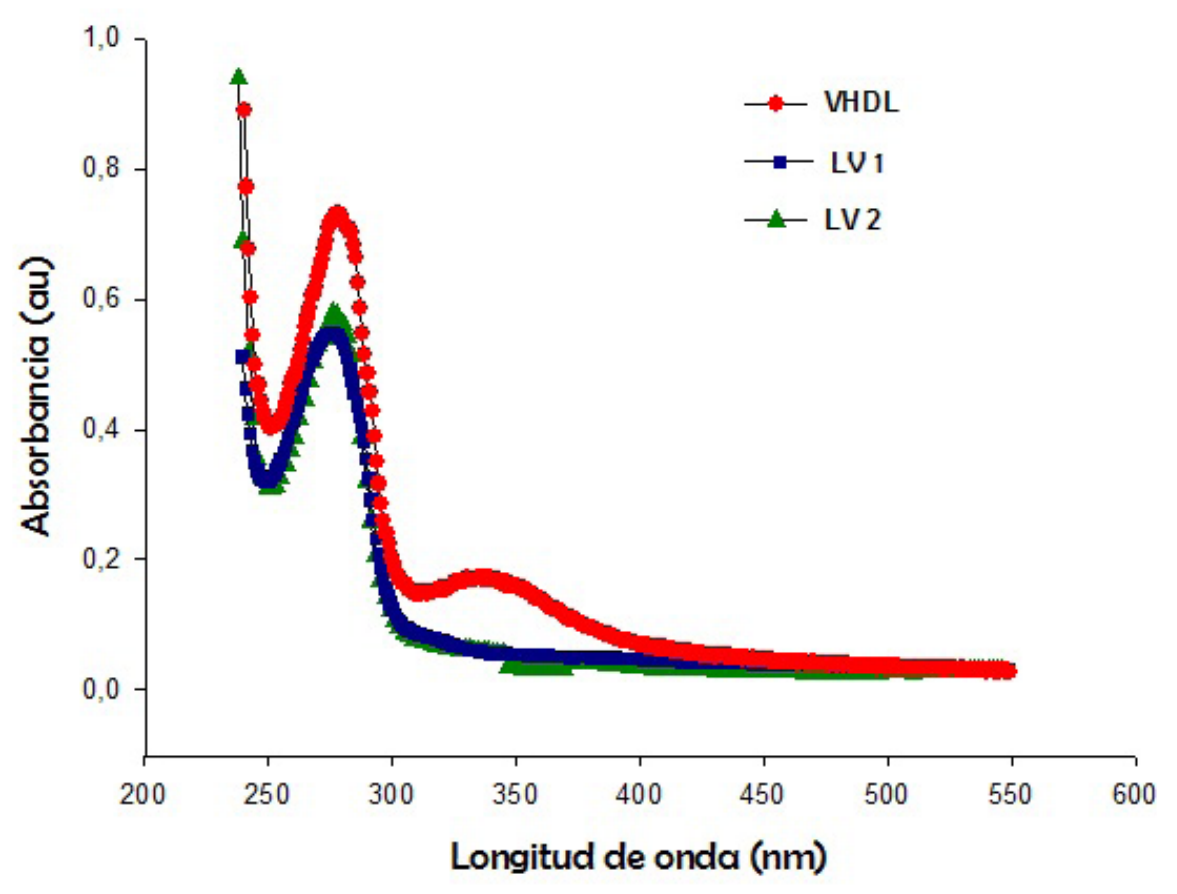

Figura VII.6: Espectro

de absorción UV-

Visible de VHDL, LV1

y LV2. La absorción de

las lipoproteínas fue

monitoreada en el rango

de $220-550 \mathrm{~nm}$

\section{VII.2.5. Identidad inmunológica}

Se analizó la posible relación inmunológica entre Las LV y las lipoproteínas hemolinfáticas, utilizando anticuerpos policlonales anti-HDL I y anti-VHDL (Fig. VII.7). La ausencia de reacción cruzada entre las lipoproteínas de huevo y las hemolinfáticas indican la ausencia de relación inmunológica entre ellas.

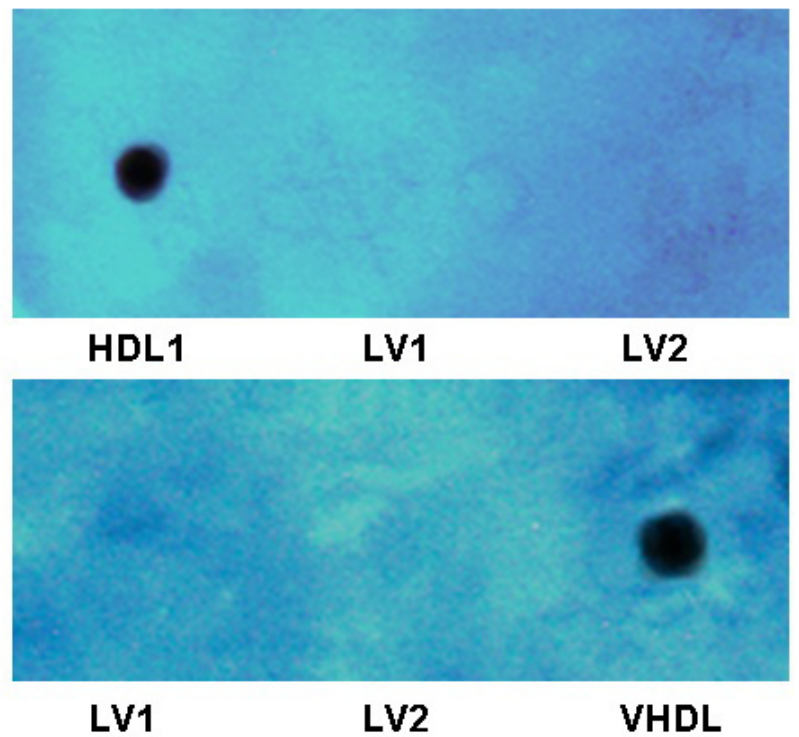

Figura VII.7: Dot blot de lipoproteínas de huevo y de HL usando anticuerpos policlonales anti-HDL1 y anti-VHDL construidos en ratón 


\section{VII.3. Discusión}

Con el objetivo de identificar las lipoproteínas presentes en huevos de la araña $P$. pythagoricus, se realizó un estudio del citosol de los mismos, en el cual se pudo determinar la presencia de dos lipovitelinas, que representan cerca de la mitad (51,5\%) de las proteínas totales del huevo. Éstas fueron aisladas, caracterizadas y denominadas LVI y LV2. Este porcentaje de proteínas se encuentra dentro de un relativamente amplio rango, respecto de las lipoproteínas de huevo de otros organismos, que incluye desde un $50 \%$ para los insectos (Harnish \& White, 1982), un 60\% para invertebrados no artrópodos como el hirudineo Theromyzon tessulatum (Baert et al., 1992), hasta un 80\% en la garrapata Ornithodoros moubata (Chinzei et al., 1983).

Teniendo en cuenta su densidad de hidratación de $1,16 \mathrm{~g} / \mathrm{ml}$ clasificamos a LV I como una lipoproteína de alta densidad (HDL), con un 49,3\% de lípidos, y 13,17 4 g proteína/mg huevo.

El alto porcentaje de lípidos de LV I es mayor al encontrado en lipovitelinas de otros grupos de quelicerados. En el Orden Acari, por ejemplo, las lipovitelinas de O. moubata, tienen un 7,6\% de lípidos (Chinzei et al., 1983), mientras que la $\mathrm{Vg}$ de Dermacentor andersoni (una garrapata muy estudiada debido a su importancia sanitaria como transmisora de la fiebre del Colorado) tiene un 5,5 a un 8,5\% de lípidos (Boctor \& Kamel, 1976). Por otro lado, en insectos, el contenido de lípidos tanto de $\mathrm{Vg}$ como de $\mathrm{Vt}$, es también menor, y se encuentra entre un 7 y un $9 \%$. Como ejemplos dentro de este grupo encontramos a Philosamia cynthia, cuyas Vg y Vt contienen 7 y $8 \%$ respectivamente (Chinzei et al., 1981), o la Vg de Locusta migratoria con 9\% y su Vt con 7\% (Chino et al., 1977), mientras que la $\mathrm{Vg}$ de Bombix mori presenta un 7\% de lípidos (Izumi \& Tomino, 1980). Es interesante notar, que si bien LV I se diferencia en este aspecto de las Vt de ácaros e insectos, es bastante similar a las de crustáceos que contienen un porcentaje lipídico mas elevado. Existen reportes de huevos de seis géneros de decápodos: Pagarus, Sasarma, Uca, Libnia, Cancer y Homarus, que contienen aproximadamente $30 \%$ de lípidos (Wallace et al., 1967), además Callinectes sapidus presenta un 48\% (Kerr, 1969), y más recientemente Garcia et al. (2004) determinó, que la lipovitelina de Macrobrachium borellii, un camarón de agua dulce distribuido en nuestro país, tiene un 30\% de lípidos. Sumado a estos grupos de artrópodos, se ha caracterizado el componente lipídico de lipovitelinas de otros invertebrados, como es el caso del hirudineo Theromyzon tessulatum donde también se encontró un alto porcentaje de lípidos, de 31,8\% en la Vg y $24 \%$ en la Vt (Baert et al., 1992). El alto porcentaje de lípidos encontrado en las Vt de crustáceos se corresponde con la gran capacidad de transporte de lípidos de sus Vg que luego de ser internalizadas por los oocitos durante la vitelogénesis, y modificadas dando lugar a las lipovitelinas, constituyen la principal fuente de lípidos para el huevo, como se describe para varias especies de decápodos (Ravid et al., 1999; Kerr, 1969). Probablemente, sea el mismo caso de LVI de la 
araña P. pythagoricus, aunque todavía no se ha aislado su Vg circulante asociada, podría existir una lipoproteína precursora sintetizada extrováricamente, que transporte lípidos a través de la HL hasta los oocitos, ya que este mecanismo de vitelogénesis heterosintética es el más difundido en vertebrados e invertebrados superiores como insectos, mientras que la vitelogénesis autosintética es generalmente atribuida a invertebrados inferiores (Boyer, 1972).

LV2, fue definida como una lipoproteína de muy alta densidad (VHDL) en relación a su densidad de hidratación de $1,24 \mathrm{~g} / \mathrm{ml}$. Aporta una cantidad de proteínas similar a LVI ( II,I 9 Mg/mg huevo), aunque a diferencia de ésta última, presenta un bajo porcentaje lipídico (9,7\%), similar a lo encontrado en garrapatas e insectos (Chinzei et al., 1983; Izumi \& Tomino, 1980; Chino et al., 1977).

En cuanto a la composición de lípidos de ambas lipovitelinas, los PL (principalmente PC y PE), a los que generalmente se les ha atribuido una función estructural, fueron cuantitativamente los más importantes, representados por un 57,I y $47 \%$ en LVI y LV2 respectivamente. Esta gran proporción de PL se corresponde con los reportes hechos en ácaros. En la Vt de O. moubata, los PL alcanzan un 77,7\% (Chinzei et al., 1983), y tanto en esta especie como en Ixodes escapularis, PC y PE fueron los únicos PL detectados (James \& Oliver, Jr., 1997). En un análisis cualitativo de las Vt de Dermacentor variabilis, Rosell y Coons ( ( 991 ), observaron solo PE como representante de los PL, mientras que en el extracto de huevo encontraron además, PC, fosfatidilinositol, esfingomielina y Lisolecitina. En las Vg/Vt de crustáceos, como en Callinectes sapidus (Kerr, 1969) e insectos, los PL también fueron los Lípidos más abundantes, con valores entre 51 y $84 \%$ en L. migratoria, P. cynthia y B. mori (Chinzei et al., 1981 ; Izumi \& Tomino, 1980; Chino et al., 1977).

Con respecto a los lípidos neutros, el colesterol esterificado fue el más abundante en ambas lipoproteínas ( $16,6 \%$ en LVI y 24,2\% en LV2). Este porcentaje sorprendentemente alto de esteroles esterificados, fue reportado también, y por primera vez para lipoproteínas de invertebrados, en las lipoproteínas hemolinfáticas del ácaro B. microplus con 34,7\% de éster de colesterol (MayaMonteiro et al., 2000). Sin embargo, la presencia de esteroles esterificados fue también descripta en las Vt de D. variabilis, aunque en menor proporción (Rosell \& Coons, 1992). Si bien no se ha estudiado el rol de los ésteres de colesterol en particular, es posible que los esteroles libres sean principalmente componentes de membrana, mientras que los esteroles esterificados, estén involucrados en el transporte y almacenamiento de colesterol, como proponen Jones y colaboradores (1985).

Entre los acilglicéridos, fueron predominantes los TAG en ambas lipoviteLinas, coincidiendo con la composición lipídica de las lipoproteínas hemolinfáticas de P. pythagoricus. Si bien representan los lípidos neutros más abundantes en circulación, a diferencia de lo que ocurre en la araña E. californicum, o en la lipoforina de insectos donde predominan los DAG (Cunningham et al., 2007), se 
encuentran presentes en poca concentración en relación a los Lípidos mayoritarios representados por los PL. En otros ácaros estudiados como O. moubata e I. escapularis, también se reportó una predominancia de TAG sobre los DAG en la composición lipídica de sus Vt (James \& Oliver, Jr., 1997; Chinzei et al., 1983) y no se han hallado DAG en las Vt de Dermacentor variabilis (Rosell \& Coons, 1991), mostrando que en estas especies, al igual que en $P$. pythagoricus, los TAG son probablemente uno de los mayores recursos energéticos del embrión.

A partir de la gran predominancia de PL encontrada en la mayoría de las Lipovitelinas estudiadas, y la abundancia de ésteres de colesterol en LVI y LV2 de $P$. pythagoricus, podríamos suponer que las Vt jugarían un rol importante en el aporte, no solo de lípidos con función energética para el embrión en desarroUlo, como los TAG, sino también de precursores estructurales para la síntesis de membrana del huevo y del embrión, como proponen entre otros Baert ( 991 ) para T. tessulatum.

La composición de ácidos grasos de las lipovitelinas, es a nuestro entender el primer reporte en la Clase Arachnida. Se encuentra dominada por los ácidos oleico, linoleico y palmítico, y coincide con la encontrada en los DI descripta anteriormente en este trabajo de tesis. La similitud entre las composiciones de ácidos grasos de DI y lipovitelinas, nos permitiría suponer que posiblemente exista una lipoproteína sintetizada en DI, que transporte ácidos grasos o acilglicéridos desde este órgano hasta los oocitos en desarrollo, actuando de esta manera como $\mathrm{Vg}$, aunque esta posible $\mathrm{Vg}$ no ha sido aislada aún.

La presencia de glicosilación en lipoproteínas relacionadas con la reproducción ha sido reportada en varias especies de Acari (Cabrera et al., 2009a; James \& Oliver, Jr., 1997; Chinzei et al., 1983) y es común en Lipoproteínas de huevo de varios invertebrados (Ituarte et al., 2010; Heras et al., 2007; Mukai et al., 2004; Dreon et al., 2002; Baert et al., 1991). En cuanto a los insectos, todas las Vg descriptas hasta el momento están glicosiladas (Tufail et al., 2005; Giorgi et al., 1998) con porcentajes de hidratos de carbono que van entre un I\% para Hyalophora cecropia (Kunkel \& Pan, 1976) hasta un II\% para Locusta migratoria (Chinzei et al., 1981). Dhadialla y Raikel ( 1990), sugieren que la glicosilación sería un paso importante para la secreción de la Vg del cuerpo graso. Además, la observación en Blattela germánica (cuya Vg tiene un 7\% de carbohidratos (Kunkel \& Pan, 1976)) de $\alpha$-manosidasa en los primeros seis días de desarrollo podría suponer que los oligosacáridos asociados a las Vt servirían como protección de la proteólisis no-específica y ayudarían a mantener la conformación tridimensional (Purcell et al., 1988). El contenido de carbohidratos en lipovitelinas de $P$. pythagoricus ( 1,48 y $0,69 \%$ en LV I y LV2 respectivamente) si bien es algo menor a lo reportado para la mayoría de los insectos, es coincidente con lo descripto en lipoproteínas hemolinfáticas y de vitelo de ácaros (4,5 y 3\%) (Maya-Monteiro et al., 2000; Boctor \& Kamel, 1976). Es posible, dada la baja proporción de hidratos de carbono en las lipovitelinas de esta araña, que su principal función 
no sea como recurso energético, sino que cumplan un rol en la señalización de proteínas como se describió para el crustáceo Emerita asiática (Tirumalai \& Subramoniam, 2001).

Los pesos moleculares de LVI y LV2 nativas están de acuerdo con el rango descripto para las Vt de ácaros e insectos (Cabrera et al., 2009b; Tufail \& Takeda, 2008b; Chinzei et al., 1983). De manera similar, en lipovitelinas de crustáceos y perivitelinas de moluscos se ha reportado el mismo rango de peso molecular de entre 300 y 600 kDa (Garcia et al., 2010; Ituarte et al., 2008; Mukai et al., 2004; Garcia-Orozco et al., 2002; Garín et al., 1996; Kisugi et al., 1987). Es generalmente aceptado en insectos, que las $V t$ son menos solubles que sus correspondientes $\mathrm{Vg}$. Esto podría facilitar el almacenamiento dentro de los oocitos, y estaría dado por la pérdida de algunos Lípidos y por la generación de agregados de proteína (Kunkel \& Nordin, 1985). En Theromyzon tessulatum existe una diferencia en cuanto al peso molecular y el contenido lipídico de la Vg y la Vt. Según los autores, una cantidad considerable de lípidos son removidos de la Vg luego de ser internalizada en los oocitos explicando las diferencias en el tamaño y en la solubilidad (Baert et al., 1992). En el poliqueto Perinereis cultrifera también se explicó la diferencia de peso molecular entre $\vee g$ y $\vee t$ por la pérdida de lípidos luego de la internalización en los oocitos (Baert, 1988). Esto puede estar ocurriendo para la LV2, ya que en condiciones nativas mostró tres lipoproteínas que estarían compuestas por las mismas subunidades en diferentes proporciones. Estas tres lipoproteínas presentan masas moleculares similares a las dos bandas encontradas en una electroforesis nativa de Vt del ácaro D. variabilis, (Cabrera et al., 2009a). También puede ocurrir agregación como en las Vg del ácaro O. moubata (Chinzei et al., 1983). Sin embargo, no podemos descartar la hipótesis de que LV2 puede presentarse en múltiples formas dadas por una utilización diferencial a lo largo de la embriogénesis, como se observa en insectos y ácaros (Boctor et al., 1986; Kunkel \& Nordin, 1985). En este sentido, Rosell y Coons (Rosell \& Coons, 1991) describieron en D. variabilis un comportamiento electroforético heterogéneo representado por tres bandas en condiciones nativas. La proteólisis limitada fue descripta también en otros invertebrados, incluyendo echinoideos. Scott y Lennarz (1989) observaron la desaparición de una glicoproteína de 160 kDa en embriones del erizo de mar Strongylocentrotus purpuratus, acompañada de la aparición de un número de glicoproteínas de bajo peso molecular, que presentaron reacción inmunológica cruzada con el péptido de 160 kDa.

En cuanto a la posibilidad de que alguna de las Lipoproteínas hemolinfáticas hace tiempo reportadas para P. pythagoricus (Cunningham \& Pollero, 1996; Cunningham et al., 1994), estuvieran actuando como Vg dando lugar a LVI, LV2 o a ambas, los presentes resultados sugieren que las lipovitelinas no están relacionadas con las lipoproteínas circulantes en $\mathrm{HL}$, en cuanto a sus pesos moleculares, ni a su identidad inmunológica. 
Con respecto a la presencia de hemocianina en huevos, Sanchez y colaboradores ( 1998 ), describieron una proteína soluble en la HL del embrión de la langosta Schistocerca americana, Llamada: "proteína hemolinfática embrionaria”, cuya secuencia es similar a la hemocianina, y particularmente presenta motivos involucrados directa o indirectamente en el transporte de oxígeno. Del mismo modo los ácaros tienen hemoglicolipoproteínas altamente conservadas y no ligadas al sexo, derivadas de un gen ancestral tipo $\mathrm{Vg}$, que no solo sirven como reserva de lípidos para el embrión, sino que también secuestran al grupo hemo para evitar la formación de especies radicales potencialmente dañinas (Donohue et al., 2008). Por otro lado, el mismo autor (Donohue et al., 2009) sugiere una relación entre hemoglicoproteínas de ácaros y lipoproteínas de arañas, comparando la HDLI de Latrodectus mirabilis con la CP (carrier protein) de ácaros. En las lipovitelinas de la araña P. pythagoricus hemos observado que no poseen hemocianina, ya que sus partículas no muestran la absorbancia característica de las oxihemocianinas (Wolfgang et al., 2004). Además, la tinción con biquinolina (datos no mostrados), la microscopía electrónica, y la ausencia de reacción cruzada con VHDL hemolinfática (que como ya mencionamos, tiene hemocianina como principal apoproteína), confirman los resultados. Este hecho también se observó en el crustáceo Penaeus vannamei, donde la Vt no cruza con la hemocianina hemolinfática (Garcia-Orozco et al., 2002).

Al microscopio electrónico y con tinción negativa, las lipovitelinas de P. pythagoricus se observan con morfología esferoidal, como también ocurre en la HDL circulante de insectos y la Vt de crustáceos (Garcia et al., 2002a; Soulages \& Wells, 1994a; Pattnaik et al., 1979; Gilbert \& Chino, 1974), e inclusive dentro de quelicerados, recientemente se ha establecido en un escorpión, que la estructura general de su $\mathrm{Vt}$, no es discoidal como se espera para una lipoproteína aparentemente ancestral (Schenk et al., 2009). Esta morfología esférica puede deberse a la presencia de lípidos capaces de formar un core hidrofóbico, como ocurre en LVI que presenta un 24\% de lípidos neutros, y con LV2 que aunque es una VHDL, y por lo tanto su contenido lipídico es menor, su porcentaje de Lípidos neutros es similar. Por otro lado, la característica estructura dimérica de Vt y $\vee g$ encontrada en $\mathrm{HL}$ y huevos del acaro $O$. moubata no se observó en las LV de la araña P. pythagoricus (Chinzei et al., 1983).

Hasta el presente, la única descripción de apovitelinas de arañas, es un reporte incompleto sobre el peso molecular de una posible $\mathrm{Vg} / \mathrm{Vt}$ encontrada en HL, ovario y huevos de Tegenaria atrica (Pourie \& Trabalon, 2003). Aunque las dos lipovitelinas de $P$. pythagoricus tienen subunidades con pesos moleculares similares a los de T. atrica (64 y 58 kDa), es poca la información como para especular respecto a la relación entre ellas, además estas $\mathrm{Vg} / \mathrm{Vt}$ podrían estar afectadas posiblemente por procesos proteolíticos.

En conclusión, en el presente trabajo se han identificado, aislado y caracterizado, en cuanto a su composición proteica y lipídica, su forma, tamaño y 
su relación con lipoproteínas hemolinfáticas, dos nuevas lipoglicoproteínas de huevo de la araña P. pythagoricus; es importante destacar que el presente estudio genera una base de información, la cual posibilita la realización de futuros estudios, para comprender el origen y función de éstas nuevas partículas en un grupo tan amplio y diversos como los arácnidos. 


\section{Conclusiones}




\section{Conclusiones}

En este capítulo se enumeran las conclusiones que se desprenden de este trabajo de tesis doctoral.

Se profundizó la caracterización estructural de la lipoproteína hemolinfática con alto contenido de hemocianina (VHDL) analizándose en general su estructura primaria, secundaria, terciaria y cuaternaria. En particular concluimos que:

Su conformación nativa está constituida por heptámeros, hexámeros y monómeros de hemocianina, junto con dímeros de dos proteínas no respiratorias. Éstas últimas se encuentran más expuestas el entorno acuoso.

$\checkmark$ Presenta una estructura secundaria donde predomina la lámina $\beta$ sobre la hélice $\alpha$.

$\checkmark$ Su estructura se encuentra estabilizada por uniones no covalentes dada la ausencia de puentes disulfuro.

$\checkmark$ Se confirmó que las proteínas llamadas "no respiratorias" no contienen hemocianina, ya que no presentan cobre en su estructura, ni sus secuencias de aminoácidos resultan homólogas con hemocianinas de otras especies.

$\checkmark$ El hexámero de hemocianina y una de las proteínas no respiratorias serian las encargadas del transporte de lípidos.

$\checkmark$ Se caracterizó la estructura primaria de 10 polipéptidos presentes en el monómero de hemocianina, y 18 polipéptidos de la subunidad de 105 kDa, que resultaron homólogos con otras proteínas secuenciadas.

Con relación a los estudios sobre rol de los DI y lipoproteínas en la dinámica de lípidos concluimos que:

$\checkmark$ La composición Lipídica de los DI se encuentra dominada por TAG, Lo cual indica un importante rol de este órgano en el almacenamiento de lípidos. Con respecto a la composición de ácidos grasos predominan los insaturados, especialmente 18: I n-9. Entre los saturados el más importante es el 16:0.

$\checkmark$ El ácido palmítico obtenido a partir de la dieta se incorpora principalmente a los DI como TAG, y en menor medida a la HL como AGL.

$\checkmark$ El ácido palmítico circulante en $\mathrm{HL}$, se incorpora en músculo manteniéndose como AGL, y en DI, donde se sintetizan TAG y PL.

$\checkmark$ Las lipoproteínas hemolinfáticas HDL I y VHDL se encuentran involucradas in vivo en el transporte de lípidos desde y hacia los tejidos.

$\checkmark$ HDL I y VHDL son capaces in vitro de captar y liberar Lípidos desde los DI.

$\checkmark$ HDL I tiene más capacidad de captar lípidos, mientras que VHDL se presenta más activa en la liberación. 
Las Lipoproteínas muestran una tendencia a captar en mayor medida PL y $A G L$, mientras que los TAG serían retenidos en DI.

$\checkmark$ HDL I es capaz de transferir más lípidos a VHDL que ésta, a HDL I.

Los hemocitos no participan significativamente en el transporte de lípidos en HL.

Como conclusión general, los resultados nos permiten suponer un modelo de circulación y almacenamiento de lípidos en la araña P. pythagoricus, en el que se propone que los AGL de la dieta o los circulantes, serían captados por los DI, donde se procesarían y se utilizarían para la síntesis de lípidos complejos, principalmente TAG y PL. Luego, estos Lípidos podrian ser almacenados en DI ó, transferidos a la HL donde serían captados por las lipoproteínas, principalmente por HDL I. En circulación, podrían ser transferidos a VHDL para ser liberados a los tejidos y posteriormente ser utilizados (Fig. VIII.I).

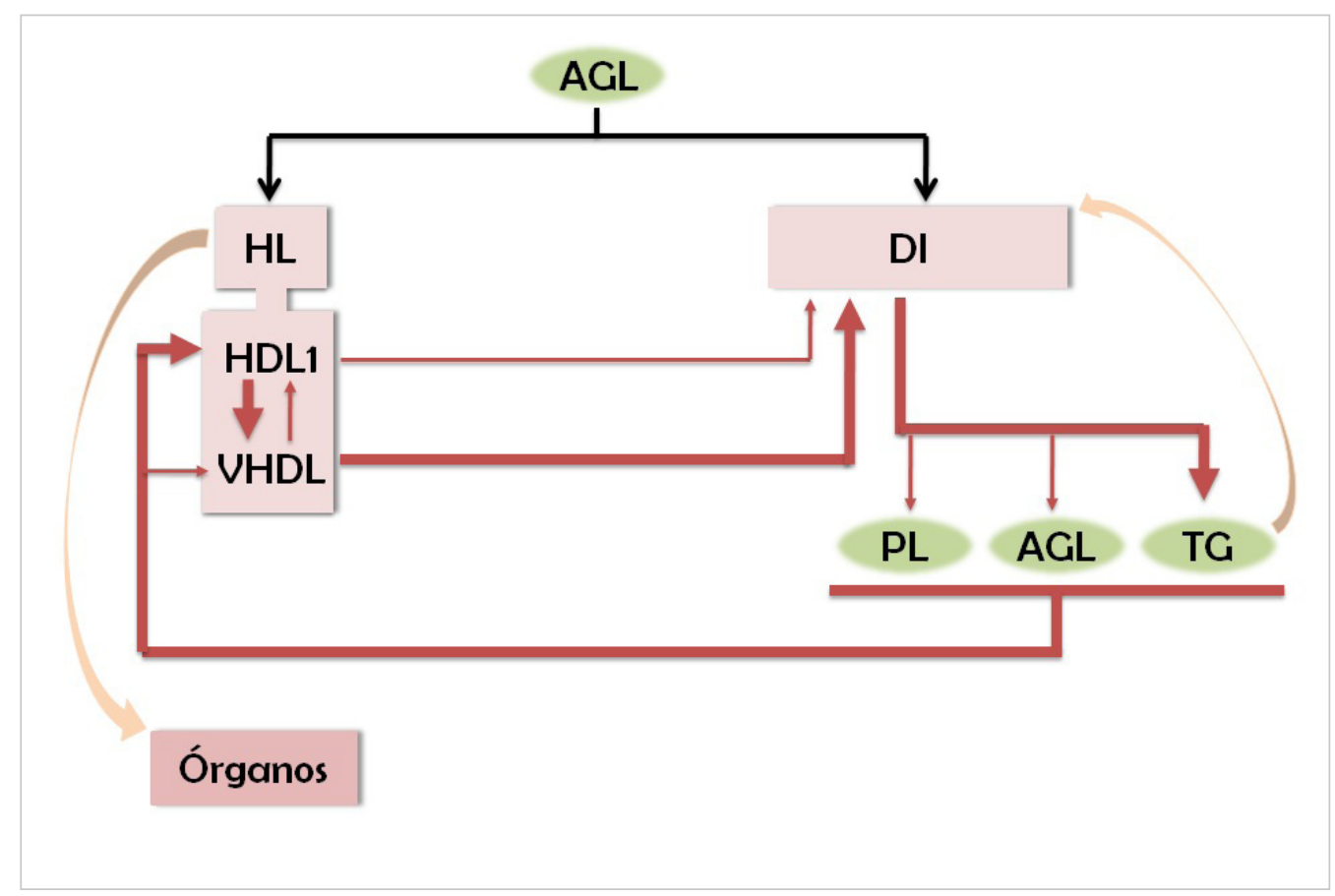

Figura VIII. 1: Posible modelo de circulación de lípidos en las arañas utilizando como modelo a P. pythagoricus. 
Finalmente se identificaron, aislaron y caracterizaron, por primera vez en arañas, dos lipovitelinas de huevo:

$\checkmark$ Los huevos de P. pythagoricus presentan dos lipovitelinas de morfología esferoidal, una HDL llamada LVI y una VHDL llamada LV2.

$\checkmark$ LVI presenta dos subunidades de 64 y $25 \mathrm{kDa}$, y LV2 tres subunidades principales de 181 , 67 y 60 kDa, y una menor de 18 kDa.

$\checkmark$ En ambas lipoproteínas predominan los PL.

$\checkmark$ Entre los lípidos neutros, los más abundantes son los ésteres de colesterol.

$\checkmark$ En la composición de ácidos grasos, predominan los insaturados, principalmente el 18: I, y entre los saturados el más abundante es el 16:0. Esta composición coincidió con la de los DI de P. pythagoricus.

$\checkmark$ No presentan hemocianina en su estructura, ni muestran relación inmunológica con las lipoproteínas hemolinfáticas. 
BIBLIOGRAFIA 


\section{Bibliografía}

Ackman, R.G. 1963. J. Am. Oil Chem. Soc. 40, 558.

Ackman, R.G., McLeod, C., Banerjee, A.K. 1990. An overview of analyses by chromarod-iatroscan TLC-FID. J. Planar Chromat. 3, 450-490.

Al-Mohanna, S.Y., Nott, J.A. 1986. B-Cells and digestion in the hepatopancreas of Penaeus semisulcatus (Crustacea: Decapoda). J. Mar. Biol. Assoc. U. K. 66, 403-414.

Al-Mohanna, S.Y., Nott, J.A., Lane, D.J.W. 1985. Mitotic E- and secretory F-cells in the hepatopancreas of the shrimp Penaeus semisulcatus (Crustacea: Decapoda). J. Mar. Biol. Assoc. U. K. 65, 901-910.

Ali, S.A., Zaidi, Z.H., Abbasi, A. 1995. Oxygen transport proteins I. Structure and organization of hemocyanin from scorpion (Buthus sindicus). Comp. Biochem. Physiol. 112 A (1), 225-232.

Altschul, S.F., Madden, T.L., Schaffer, A.A., Zhang, J., Zhang, Z., Miller, W., Lipmman, D. 1997. Gapped BLAST and PSI-BLAST: a new generation of protein database search programs. Nucleic Acids Res. 25, 33893402.

Aparicio, G.M., Bonilla-Hurtado, V.A., Vargas, R.A. 2010. Caracterización mecánica y térmica del biopolímero hilo de araña Nephila clavipes como posible material para prótesis en hernia inguinal. Rev. Col. de Física 42 (2), 176-180.

Araman, S.F. 1979. Protein digestion and synthesis in ixodid females. In: Rodriguez, J.G.R. (ed.), Recent advan. in acarology, New York. 385395.

Armendano, A., González, A. 2010. Comunidad de arañas (Arachnida, Araneae) del cultivo de alfalfa (Medicago sativa) en Buenos Aires, Argentina. Rev. Biol. Trop. 58 (2), 757-767.

Arrese, E.L., Canavoso, L.E., Jouni, Z.E., Pennington, J.E., Tsuchida, K., Wells, M.A. 2001a. Lipid storage and mobilization in insects: current status and future directions. Insect Biochem. Molec. Biol. 31, 7-17.

Arrese, E.L., Gazard, J.L., Flowers, M.T., Soulages, J.L., Wells, M.A. 2001b. Diacylglycerol transport in the insect fat body: evidence of involvement of lipid droplets and the cytosolic fraction. J. Lipid Res. $42,225-234$. 
Arrese, E.L., Wells, M.A. 1997. Adipokinetic hormone-induced lipolysis in the fat body of an insect, Manduca sexta: synthesis of sn-1,2-diacylglycerols. J. Lipid Res. 38, 68-76.

Atella, G.C., Arruda, M.A., Masuda, H., Gondim, K.C. 2000. Fatty acid incorporation by Rhodnius prolixus midgut. Arch. Insect Biochem. Physiol. 43, 99107.

Atella, G.C., Gondim, C., Masuda, H. 1995. Loading of lipophorin particles with phospholipids at the midgut of Rhodnius prolixus. Arch. Insect Biochem. Physiol. 30, 337-350.

Atella, G.C., Gondim, K.C., Masuda, H. 1992. Transfer of phospholipids from fat body to lipophorin in Rhodnius prolixus. Arch. Insect Biochem. Physiol. 19, 133-144.

Averdam, A., Markl, J., Burmester, T. 2003. Subunit sequences of the $4 \times 6$-mer hemocyanin from the golden orb-web spider, Nephila inaurata. Eur. J Biochem. 270, 3432-3439.

Babin, P.J., Bogerd, J., Kooiman, F.P., van Marrewijk, W.J., Van Der Horst, D.J. 1999. Apolipophorin II/I, apolipoprotein B, vitellogenin, and microsomal triglyceride transfer protein genes are derived from a common ancestor. J. Mol. Evol. 49, 150-160.

Baert, J. 1992. A 15 000-M, protein proteolytically derived from vitellogenin within oocyte of Perinereis cultrifera (polychaete annelid). Eur. J. Biochem. 177, 625-630.

Baert, J., Britel, M., Sautiere, P., and Malecha, J. 1992. Ovohemerythrin, a major 14-kDa yolk protein distinct from vitellogenin in leech. Eur. J. Biochem. 209, 563-569.

Baert, J., Britel, M., Slomianny, M.C., Delbart, C., Fournet, B., Sautiere, P., Malecha, J. 1991.Yolk protein in leech. Eur. J. Biochem. 201, 191198.

Baert, J., Slomianny, M.C. 1987. Heterosynthetic origin of the major yolk protein, vitellin, in a nereid, Perinereis cultrifera (polychaete annelid). Comp. Biochem. Physiol. 88 A (4), 1191-1199.

Bailey, E. 1975. Biochemistry of insect flight. Part 2. Fuel supply. In: Candy, D.J. and Kilby, B.A. (eds.), Insect Biochemistry and Function, Chapman and Hall, London. 89-176.

Baird, S., Kelly, S.M., Price, N.C., Jaenicke, E., Meesters, C., Nillius, D., Decker, H., Nairn, J. 2007. Hemocyanin conformational changes associated with SDS-induced phenol oxidase activation. Biochim. Biophys. Acta. 1774, 1380-1394. 
Baker, M.E. 1988. Is vitellogenin an ancestor of apolipoprotein B-100 of human low-density lipoprotein and human lipoprotein lipase? Biochem. J. 255, 1057-1060.

Ballweber, P., Markl, J., Burmester, T. 2002. Complete hemocyanin subunit sequences of the hunting spider Cupiennius salei: recent hemocyanin remodeling in entelegyne spiders. J. Biol. Chem. 277, 14451-14457.

Barbosa, F.M., Daffre, S., Maldonada, R.A., Miranda, A., Nimrichter, L., Rodrigues, M.L. 2007. Gomesin, a peptide produced by the spider Acanthoscurria gomesiana, is a potent anticryptococcalagent that acts in synergism with fluconazole. Research Letter DOI:10.1111/ j.1574-6968.2007.00850.x.

Bauerle, P.A., Huttner, W.B. 1985. Tyrosine sulfation of yolk proteins 1, 2 and 3 in Drosophila melanogaster. J. Biol. Chem. 260, 6434-6439.

Baumann, T., Kuhn-Nentwig, L., Largiader, C.R., Nentwig, W. 2010. Expression of defensins in non-infected araneomorph spiders. Cell.Moll.Life.Sci DOI 10.1007/s00018-010-0354-2.

Becker, A., Peters, W. 1985a. Fine structure of the midgut gland of Phalangium opilio (Chelicerata, Phalangida). Zoomorphology 105, 317-325.

Becker, A., Peters, W. 1985b. The ultrastructure of the midgut and the formation of peritrophic membranes in a harvestman, Phalangium opilio (Chelicerata, Phalangida). Zoomorphology 105, 326-332.

Beenakkers, A., Van Der Horst, D.J., Van Marrewijk, W.J.A. 1985. Insect lipids and lipoproteins, and their role in physiological processes. Prog. Lipid Res. 24, 19-67.

Beenakkers, A.M., Gilbert, L.I. 1968. The fatty acid composition of fat body and haemolymph lipids in Hyalophora cecropia and its relation to lipid release. J. Insect Physiol. 14, 481-494.

Beltramo, J., Bertolaccini, I., González, A. 2006. Spiders of soybean crops in Santa Fe province, Argentina: influence of surrounding spontaneous vegetation on lot colonization. Braz. J. Biol. 66 (3), 891-898.

Blacklock, B.J., Ryan, R.O. 1994. Hemolymph lipid transport. Insect Biochem. Molec. Biol. 24, 855-873.

Boctor, F.N., Kamel, M.Y. 1976. Purification and characterization of two lipovitellins fro eggs of the tick, Dermacentor andersoni. Insect Biochem. 6, 233-240. 
Boctor, F.N., Kamel, M.Y., Sidrak, W. 1986. Biochemical studies on tick embryogenesis: lipovitellin and protease activity in Dermacentor andersoni (Acari: Ixodidae). J. Med. Entomol. 23, 429-432.

Boldbaatar, D., Umemiya-Shirafuji, R., Liao, M., Tanaka, T., Xuan, X., Fujisaki, K. 2010. Multiple vitellogenins from the Haemaphysalis longicornis tick are crucial for ovarian development. J. Insect. Physiol. 56 (11), 1587-1598.

Bonnier, P., Porchet-Hennere, E., Baert, J. 1991. Identification of the eleocytes as the vitellogenin producing cells in nereids. Biol.Cell 73 (2-3), 179181.

Boyer, B.C. 1972. Ultrastructural studies of differentiation in the oocyte of the polyclad turbellarian, Prostheceraeus floridanus. J. Morphol. 136 (3), 273-295.

Brennan, M.D., Mahowald, A.P. 1982. Phosphorylation of the vitellogenin polypeptides of Drosophila melanogaster. Insect Biochem. 12, 669673.

Brenowitz, M., Bonaventura, C., Bonaventura, J. 1983. Assembly and calciuminduced cooperativity of Limulus IV hemocyanin: A model system for analysis of structure-function relationships in the absence of subunit heterogeneity. Biochemestry 22, 4707-4713.

Brenowitz, M., Bonaventura, C., Bonaventura, J. 1984. Self-association and oxygen-binding characteristics of the isolated sububits of Limulus polyphemus hemocyanin. Arch.Biochem.Biophys. 230, 238-249.

Bridges, C.R. 2001. Modulation of haemocyanin oxygen affinity: properties and physiological implications in a changing world. J. Exp. Biol. 204, 1021-1032.

Bruynick, W.J., Gutteride, S., Mason, H.S. 1978. Detection of copper on polyacrylamide gels. Anal. Biochem. 89, 174-177.

Burchfield, H.P. and Storrs, E.E. 1970. Biochem. Appl. Gas Chromat, Academic Press, London. 527.

Burmester, T. 2001. Molecular evolution of the arthropod hemocyanin superfamily. Mol. Biol. Evol. 18 (2), 184-195.

Byrne, B.M., Gruber, M., Ab G. 1989. The evolution of egg yolk proteins. Prog. Biophys. Mol. Biol. 53, 33-69.

Cabrera, A.R., Donohue, K.V., Khalil, S.M., Sonenshine, D.E., Roe, R.M. 2009. Characterization of vitellin protein in the twospotted spider mite, Tetranychus urticae (Acari: Tetranychidae). J. Insect. Physiol. 55, 655-661. 
Canavoso, L.E., Bertello, L.E., de Lederkremer, R.M., Rubiolo, E.R. 1998. Effect of fasting on the composition of the fat body lipid of Dipetalogaster maximus, Triatoma infestans and Panstrongylus megistus (Hemiptera: Reduviidae). J. Comp. Physiol. 168 B, 549-554.

Canavoso, L.E., Jouni, Z.E., Karnas, K.J., Pennington, J.E., Wells, M.A. 2001. Fat metabolism in insects. Annu. Rev. Nutr. 21, 23-46.

Chang, E.S., O'Connor, J.M. 1983. Metabolism and transport of carbohydrates and lipid. In: Mantel, L.H. (ed.), The Biology of Crustacea, Academic Press.

Cheli, G., Armendana, A., González, A. 2006. Feeding preferences of the spider Misumenops pallidus (Araneae: Thomisidae) on potential prey insects from alfalfa crops. Rev.Bio.Trop. 54 (2), 505-513.

Chen, L., Jiang, H., Zhou, Z., Li, K., Li, K., Deng, G.Y., Liu, Z. 2004. Purification of vitellin from the ovary of Chinese mitten-handed crab (Eriocheir sinensis) and development of an antivitellin ELISA. Comp. Biochem. Physiol. 138 B, 305-311.

Chino, H., Downer, R.G., Wyatt, G., Gilbert, L.I. 1981.Lipophorins, a major class of lipoproteins of insect hemolimph. Insect Biochem. 11, 491.

Chino, H. 1985. Lipid transport: biochemistry of hemolymph lipophorin. In: Kerkut, G.A. and Gilbert, L.I. (eds.), Comprehensive insect physiology, biochemistry and pharmacology, Vol. 10. Pergamon Press, New York. 115-135.

Chino, H. 1997. Physiological significance of lipid transport by lipophorin for long-distance flight in insects. Comp. Biochem. Physiol. 117 B, 455461.

Chino, H., Downer, R.G., Takahashi, K. 1977. The role of diacylglycerol-carrying lipoprotein I in lipid transport during insect vitellogenesis. Biochim. Biophys. Acta. 487, 508-516.

Chinzei, Y., Chino, H., Takahashi, K. 1983. Purification and propieties of vitellogenin and vitellin from a tick, Ornithodoros moubata. J. Comp. Physiol. 152 B, 13-21.

Chinzei, Y., Chino, H., Wyatt, G. 1981. Purification and properties of locust vitellin and vitellogenin. Insect Biochem. 11, 1-7.

Chinzei, Y. and Yano, I. 1985. Vitellin is the nutrient reserve during starvation in the nynphal stage of a tick. Experientia 41, 948-950. 
Coelho, H.S., Atella, G.C., Moreira, M.F., Gondim, K.C., Masuda, H. 1997. Lipophorin density variation during oogenesis on Rhodnius prolixus. Arch. Insect Biochem. Physiol. 35, 301-313.

Coons, L., Tarnowski, B., Ourth, D.D. 1982. Rhipicephalus sanguinius: localization of vitellogenin synthesis by immunological methods and electron microscopy. Exp. Parasitol. 54 (3), 331-339.

Cunningham, M.L., Garcia, F., Garda, H., Pollero, R.J. 2006. Hemocyanin lipid uptake in Polybetes pythagoricus is altered by fenitrothion. Pestic. Biochem. Physiol. 85, 57-62.

Cunningham, M.L., Garcia, F., Pollero, R.J. 2007. Arachnid lipoproteins: Comparative aspects. Comp. Biochem. Physiol. 146 C, 79-87.

Cunningham, M.L., Gomez, C., Pollero, R.J. 1999. Lipid binding capacity of spider hemocyanin. J. Exp. Zool. 284, 368-373.

Cunningham, M.L., Gonzalez, A., Pollero, R.J. 2000. Characterization of lipoproteins isolated from the hemolymph of the spider Latrodectus mirabilis. J. Arachnol. 28, 49-55.

Cunningham, M.L., Pollero, R.J. 1996. Characterization of lipoprotein fractions with high content of hemocyanin in the hemolymphatic plasma of Polybetes pythagoricus. J. Exp. Zool. 274, 275-280.

Cunningham, M.L., Pollero, R.J., Gonzalez, A. 1994. Lipid circulation in spiders. Transport of phospholipids, free acids and triacylglycerols as the major lipid classes by a high-density lipoprotein fraction isolated from plasma of Polybetes pythagoricus. Comp. Biochem. Physiol. 109 B, 333-338.

Cvacka, J., Hovorka, O., Jiros, P., Kindl, J., Stransky, K., Valterova, I. 2006. Analysis of triacylglycerols in fat body of bumblebees by chromatographic methods. J. Chromatogr. 1101, 226-237.

de Chaffoy de Courcelles, D., Kondo, M. 1980. Lipovitellin from the crustacean, Artemia salina. Biochemical analysis of lipovitellin complex from the yolk granules. J. Biol. Chem. 255, 6727-6733.

Decker, H. and Jaenicke, E. 2004. Recent findings on phenoloxidase activity and antimicrobial activity of hemocyanins. Dev. Comp. Immunol. 28 (78), 673-687.

Decker, H., Rimke, T. 1998. Tarantula hemocyanin shows phenoloxidase activity. J. Biol. Chem. 273, 25889-25892. 
della Cioppa, G., Engelmann, F. 1987. The vitellogenin of Leucophae maderae. Synthesis as a large phosphorylated precursor. Insect Biochem. 17, 401-415.

Dhadialla, T.S. 1986. Purification and some biochemical propierties of vitellins from Rhipicephalus appendiculatus eggs and their use as antigens to induce type II immune resistance in rabits. J. Cell. Biochem. 10, 77.

Dhadialla, T.S., Raikhel, A.S. 1990. Biosynthesis of mosquito vitellogenin. J. Biol. Chem. 265, 9924-9933.

Diehl, P.A., Aeschlimann, A., Obenchain, F.D. 1982. Tick reproduction: oogenesis and ovoposition. In: Obenchain, F.D. and Galum, R. (eds.), Physiology of Ticks, Pargamon, New York. 377-350.

Dolaska-Angelova, P., Dolashki, A., Savvides, S.N., Hristova, R., Van Beeumen, J., Voelter, W., Devreese, B., Weser, U., Di Muro, P., Salvato, B., Stevanovic, S. 2005. Structure of hemocyanin subunit CaeSS2 of the crustacean mediterranean crab Carcinus aestuarii. J. Biochem. 138, 303-312.

Donohue, K.V., Khalil, S.M., Mitchell, R.D., Sonenshine, D.E., Roe, R.M. 2008. Molecular characterization of the major hemelipoglycoprotein in ixodid ticks. Insect Mol. Biol. 17, 197-208.

Donohue, K.V., Khalil, S.M., Sonenshine, D.E., Roe, R.M. 2009. Heme-binding storage proteins in the Chelicerata. J. Insect Physiol. 55, 287-296.

Downer, R.G.H. 1985. Lipid metabolism. In: Kerkut, G.A. and Gilbert, L.I. (eds.), Comprehensive insect physiology, biochemistry and pharmacology, Vol. 10. Pergamon Press, Oxford. 77-113.

Dreon, M.S., Lavarías, S., Garín, C.F., Heras, H., Pollero, R.J. 2002. Synthesis, distribution, and levels of an egg lipoprotein from the apple snail Pomacea canaliculata (Mollusca: Gastropoda). J. Exp. Zool. 292, 323-330.

Drexel, R., Siegmund, S., Schneider, H., Linzen, B., Gielens, C., Préaux, G., Lontie, R., Kellerman, J., Lottspeich, F. 1987. Complete amino-acid sequence of a functional unit from a molluscan hemocyanin (Helix pomatia). Biol. Chem. Hoppe-Seyler 368, 617-635.

Eckelbarger, K.J. 1979. Ultrastructural evidence for both autosynthetic and heterosynthetic yolk formation in the oocytes of an annelid (Phragmatopoma lapidosa: Polychaeta). Tissue and Cell 11 (3), 425443. 
El-Salhy, M., Gustafsson, I.B., Grimelius, L., Vessby, B. 1981. The lipid composition of the haemolymph and hepatopancreas of the scorpion (Buthus quinquestriatus). Comp. Biochem. Physiol. 69 B, 873-876.

Erker, W., Hubler, R., Decker, H. 2008.Tryptophan quenching as linear sensor for oxigen binding of artropod hemocyanins. Biochim. et Biophys. Acta. 1780, 1143-1147.

Fernández-Morán, H., Van Bruggen, E.F.J., Ohtsuki, M. 1966. Macromolecular organization of hemocyanins and apohemocyanins as revealed by electron microscopy. J. Mol. Biol. 16, 191-207.

Fernando-Warnakulasuria, G.J., Tsuchida, K., Wells, M. 1988. Effect of dietary lipid contenton lipid transport and storage during larval development of Manduca sexta. Insect Biochem. Molec. Biol. 10, 77-113.

Foelix, R.F. 2011. Biology of Spiders, Harvard University Press, London.

Fogaca, A.C., Almeida, I.C., Eberlin, M.N., Tanaka, A.S., Bulet, P., Daffre, S. 2006. Ixodidin, a novel antimicrobial peptide from the hemocytes of the cattle tick Boophilus microplus with inhibitory activity against serine proteinases. Peptides 27, 667-674.

Folch, J., Lees, M., Sloane-Stanley, G.H. 1957. A simple method for the isolation and purification of total lipids from animal tissues. J. Biol. Chem. 226, 497-509.

Forster, R.J., Bertoncello, P., Keyes, T.E. 2009. Electrogenerated Chemiluminescence. An. Rev. Anal. Chem. 2, 359-385.

Forte, T.M., Gong, E., Nichols, A.V. 1974. Interaction by sonication of C-apolipoproteins with lipid: An electron microscopic study . Biochim. Biophys. Acta 337, 169-183.

Forte, T.M., Nordhausen, R.W. 1986. Electron microscopy of negatively stained lipoproteins. Meth. Enzymol.v128, 442-457.

Fuji, T. 1960. Comparative biochemical studies on the eggs yolk proteins of various animal species. Acta Embryol. Morph. Exp. 3, 260-285.

Galiano, M.E. 1971. El desarrollo postembrionario larval en especies del género Polybetes Simon, 1897 (Araneae, Saparassidae). Acta Zool. Lilloana, XXVIII, 221-225.

Garcia, C.F., Cunningham, M.L., Soulages, J.L., Heras, H., Garda, H.A. 2010. Structure and stability of crustacean lipovitellin: Influence of lipid content and composition. Comp. Biochem. Physiol. 155 B, 126-131. 
Garcia, F., Cunningham, M.L., González Baró, M.R., Garda, H.A., Pollero, R.J. 2002a. Effect of fenitrothion on the physical properties of crustacean lipoproteins. Lipids 37, 673-679.

Garcia, F., Cunningham, M.L., Soulages, J.L., Garda, H.A., Pollero, R.J. 2006. Structural characterization of the lipovitellin from the shrimp Macrobrachium borellii. Comp. Biochem. Physiol. 145 B, 365-370.

Garcia, F., González Baró, M.R., Garda, H., Cunningham, M.L., Pollero, R.J. 2004. Fenitrothion-induced structural and functional perturbations in the yolk lipoproteins of the shrimp Macrobrachium borellii. Lipids 39, 389-396.

Garcia, F., González Baró, M.R., Pollero, R.J. 2002b. Transfer of lipids between hemolymph and hepatopancreas in the shrimp Macrobrachium borellii. Lipids 37, 581-585.

García-Alonso, J., Hoeger, U., Rebscher, N. 2006. Regulation of vitellogenesis in Nereis virens (Annelida: Polychaeta): effect of estradiol-17beta on eleocytes. Comp. Biochem. Physiol. 143 A (1), 55-61.

Garcia-Orozco, K.D., Vargas-Albores, F., Sotelo-Mundo, R.R., Yepiz-Plascencia, G. 2002. Molecular characterization of vitellin from the ovaries of the white shrimp Penaeus (Litopenaeus) vannamei. Comp. Biochem. Physiol. 133 B, 361-369.

Garín, C.F., Heras, H., Pollero, R.J. 1996. Lipoproteins of the egg perivitellin fluid of Pomacea canaliculata snails (Mollusca: Gastropoda). J. Exp. Zool. 276, 307-314.

Garín, C.F., Pollero, R.J. 1995. Isolation and characterization of a low density lipoprotein fraction from plasma of the aquatic snail Ampullaria canaliculata. Comp. Biochem. Physiol. 111 B, 147-150.

Gersschman, B.d.P., Schiapelli, R. 1965. El género Polybetes Simon, 1897, en la Argentina. (Araneae-Sparassidae). Revta. Mus. Argent. Cienc. Nat. 1, 313-319.

Gilbert, L.I., Chino, H. 1974. Transport of lipids in insects. J. Lipid Res. 15, 439456.

Giorgi, F., Bradley, J.T., Nordin, J.H. 1999. Differential vitellin polypeptide processing in insect embryos. Micron 30, 579-596.

Giorgi, F., Bradley, J.T., Vignali, R., Mazzini, M. 1989. An autoradiographic analysis of vitellogenin synthesis and secretion in the fat body of the stick insect Bacillus rossius. Tissue and Cell 21, 543-558. 
Giorgi, F., Cecchettini, A., Falleni, A., Masetti, M., Gremigni, V. 1998. Vitellogenin is glycosylated in the fat body of the stick insect Carausius morosus and not further modified upon transfer to the ovarian follicle. Micron. 29, 451-460.

González, A., Lilgesthröm, G., Minervino, E., Castro, D., González, S., Armendano, A. 2009. Predation by Misumenops pallidus (Araneae: Thomisidae) on insect pests of soybean cultures in Buenos Aires Province, Argentina. The J. of Arach. 37, 282-286.

González Baró, M.R., Irazú, C.E., Pollero, R.J. 1990. Palmitoyl-CoA ligase activity in hepatopancreas and gill microsomes of the freshwater shrimp Macrobrachium borellii. Comp. Biochem. Physiol. 97 B, 129-133.

González Baró, M.R., Pollero, R.J. 1988. Lipid characterization and distribution among tissues of the freshwater crustacean Macrobrachium borellii during an annual cycle. Comp. Biochem. Physiol. 91 B, 711-715.

González Baró, M.R., Pollero, R.J. 1993. Palmitic acid metabolism in hepatopancreas of the freshwater crustacean Macrobrachium borellii during an annual cycle. Comp. Biochem. Physiol. 106 B, 7175.

González Baró, M.R., Pollero, R.J. 1998. Fatty acid metabolism of Macrobrachium borellii: dietary origin of arachidonic and eicosapentaenoic acids. Comp. Biochem. Physiol. 119 A, 747-752.

Gonzalez, M.S., Rimoldi, O., Brenner, R. 1995. Studies on very-high-density lipoprotein of Triatoma infestans hemolymph in relation to its function as free fatty acid carrier. Comp. Biochem. Physiol. 110 B, 767-775.

Gonzalez, M.S., Soulages, J.L., Brenner, R.R. 1991. Changes in the hemolymph lipophorin and very high density lipoprotein levels during the 5th nymphal and adult stages of triatoma infestans. Insect Biochem. 21, 679-687.

Hagedorn, H.H., Maddison, D.R.,Tu, Z. 1998. The evolution of vitellogenins, cyclorrhaphan yolk proteins and related molecules. Adv. Insect Physiol. 27, 335-384.

Hall, M., van Heusden, M.C., Söderhäll, K. 1995. Identification of the major lipoproteins in crayfish hemolimph as proteins involved in immune recognition and clotting. Biochem. Bioph. Res.Co. 216, 939-946.

Harlow, E. Lane, D. 1988. Antibodies. A laboratory manual. Cold Sprin Harbor Laboratory, New York. 1-726. 
Harnish, D.G., White, B.N. 1982. An evolutionary model for the insect vitellins. J. Mol. Evol. 18 (6), 405-413.

Haunerland, N.H., Bowers, W.S. 1987. Lipoproteins in the hemolimph of the tarantula, Eurypelma californicum. Comp. Biochem. Physiol. 86 B, 571-574.

Haunerland, N.H., Bowers, W.S. 1989. Comparative studies on arthropod lipoproteins. Comp. Biochem. Physiol. 92 B, 137-141.

Heras, H., Dreon, M.S., Ituarte, S., Pollero, R.J. 2007. Egg carotenoproteins in neotropical Ampullariidae (Gastropoda: Arquitaenioglossa). Comp. Biochem. Physiol. 146 C, 158-167.

Heras, H., Pollero, R.J. 1990. Occurrence of plasma lipoproteins in octopods. Partial characterization and interorgan transport of lipids. J. Exp. Mar. Biol. Ecol. 140, 29-38.

Heras, H., Pollero, R.J. 1992. Hemocyanin as an apolipoprotein in the hemolymph of the cephalopod Octopus tehuelchus. Biochim. Biophys. Acta. $1125,245-250$.

Herkovits, T.T., Hamilton, M.G. 1991. Mini Review. Higher order assemblies of molluscan hemocyanins. Comp. Biochem. Physiol 99 B, 19-34.

Hoffmann, A. 2003. El maravilloso mundo de los arácnidos. Secretaría de Educación Pública. Fondo de Cultura Económica. Consejo Nacional de Ciencia y Tecnología. México.

Ituarte, S., Dreon, M.S., Pasquevich, M.Y., Fernandez, P.E., Heras, H. 2010. Carbohydrates and glycoforms of the major egg perivitellins from Pomacea apple snails (Architaenioglossa: Ampullariidae). Comp. Biochem. Physiol. 157 B, 66-72.

Ituarte, S., Dreon, M.S., Pollero, R.J., Heras, H. 2008. Isolation and partial characterization of a new lipo-glyco-carotenoprotein from Pomacea scalaris (Gastropoda: Ampullariidae). Mol. Reprod. Dev. 75, 14411448.

Izumi, S., Tomino, S. 1980. Purification and molecular properties of vitellin from the silkworm Bombix mori. Insect Biochem. 10, 199-208.

Jaenicke, E. and Decker, H. 2004. Functional changes in the family of type 3 copper proteins in evolution. Chem.Biol.Chem. 5, 163-176.

Jaenicke, E., Decker, H., Gebauer, W., Markl, J., Burmester, T. 1999a. Identification, structure, and properties of hemocyanins from diplopod myriapoda. J. Biol. Chem. 274 (41), 29071-29074. 
Jaenicke, E., Foll, R., Decker, H. 1999b. Spider hemocyanin binds ecdysone and 20-OH-ecdysone. J. Biol. Chem. 274, 34267-34271.

James, A.M., Oliver, J.H., Jr. 1997. Purification and partial characterization of vitellin from the black-legged tick, Ixodes scapularis. Insect Biochem. Molec. Biol. 27, 639-649.

Jones, A., Glomset, J. 1985. Biosynthesis, function and metabolism of sterol esters. In: Danielsson, H. and Sjovall, J. (eds.), Sterols and bile acids, Elsevier Science, Amsterdam 95-119.

Kallapur, V.L., Ramamohanrao, Y., Narasubhai, A.V. 1984. Triacylglycerol synthesis in the premolt field crab Paratelphusa hydrodromus (Milne-Edwards) (Crustacea). Arch. Int. Physiol. Biochim. 92, 119124.

Kanazawa, A., Koshio, S. 1994. Lipid nutrition of the spiny lobster Panulirus japonicus (Decapoda, Palinuridae): A review. Crustaceana 67, 226232.

Kawazoe, I., Jasmani, S., Shih, T., Suzuki, Y., Aida, K. 2000. Purification and characterization of vitellin from the ovary of kuruma prawn, Penaeus japonicus. Fisheries Sci. 66, 390-396.

Kawooya, J.K., Osir, E.O., Law, J.H. 1986. Physical and chemical properties of microvitellogenin. A protein from the egg of the tobacco hornworm moth, Manduca sexta. J. Biol. Chem. 261, 10844-10849.

Kempter, B. 1983. Site of hemocyanin biosynthesis in the tarantula Eurypelma californicum. Naturwissenschaften 70, 255-256.

Kerr, M.S. 1969. The hemolymph proteins of the blue crab, Callinectes sapidus. II. A lipoprotein serologically identical to oocyte lipovitellin. Dev. Biol. 20, 1-17.

Kisugi, J., Kamiya, H., Yamazaki, M. 1987. Purification and characterization of aplysianin $E$, an antitumor factor from sea hare eggs. Cancer Res. $47,5649-5653$.

Komatsu, M., Ando, S., Teshima, S.I. 1993. Comparison of hemolymph lipoproteins from 4 species of crustacea. J. Exp. Zool. 266, 257-265.

Kunkel, J. Nordin, J. 1985. Yolk proteins. Pergamon, Oxford.

Kunkel, J., Shepard, G.L., McCarthy, R.A., Ethier, D.B., Nordin, J. 1980. Concanavalin reactivity and carbohydrate structure of Blattella germanica vitellin. Insect Biochem. 10, 703-714. 
Kunkel, J.G., Pan, M.L. 1976. Selectivity of yolk protein uptake comparisonof vitellogenins of two insects. J. Insect Physiol. 22, 809-818.

Laemmli, U.K. 1970. Cleavage of structural proteins during the assembly of the head of bacteriophage T4. Nature 227, 680-685.

Lakowicz, J.R. 1999. Principles of fluorescence spectroscopy. Kluwer Academic. Plenum Publishers, New York.

Lamy, J., Bijlholy, M.M.C., Sizaret, P., Lamy, J., Van Bruggen, E.F.J. 1981. Quaternary structure of scorpion (Androctonus australis) hemocyanin. Localization of subunits with immunological methods and electron microscopy. Biochemistry 20, 1849-1856.

Lamy, J., Lamy, J., Bonaventura, J., Bonaventura, C. 1980. Structure, function, and assembly in the hemocyanin system of the scorpion Androctonus australis. Biochemistry 19, 3039-3047.

Lamy, J., Lamy, J., Weill, J. 1977. The influence of cations on the dissociation of hemocyanin of the scorpion Androctonus australis garzonii provoked by $1 \mathrm{M}$ urea. FEBS Let. 77, 197-200.

Lavarías, S., Garcia, F., Pollero, R.J., Heras, H. 2007. Effect of the watersoluble fraction of petroleum on microsomal lipid metabolism of Macrobrachium borellii (Arthropoda: Crustacea). Aquat. Toxicol. 82, 265-271.

Lavarías, S., Pollero, R.J., Heras, H. 2006. Activation of lipid catabolism by the water-soluble fraction of petroleum in the crustacean Macrobrachium borellii. Aquat. Toxicol. 77, 190-196.

Lee, R.F. 1991. Lipoproteins from the hemolymph and ovaries of marine invertebrates. In: Gilles, R. (ed.), Advances in comparative and environmental physiology, Vol. 7. Springer-Verlag, London, pp. 187208.

Lee, R.F., Puppione, D.L. 1978. Serum lipoproteins in the spiny lobster, Panulirus interruptus. Comp. Biochem. Physiol. 59 B, 239-243.

Lee, R.F., Puppione, D.L. 1988. Lipoproteins I and II from the hemolymph of the Blue Crab Callinectes sapidus: Lipoprotein II associated with vitellogenesis. J. Exp. Zool. 248, 278-289.

Lee, S.Y., Lee, B.L., Soderhall, K. 2003. Processing of an antibacterial peptide from hemocyanin of the freshwater crayfish Pacifastacus leniusculus. J Biol. Chem. 278, 7927-7933.

Lindgren, F.T. 1975. Analysis of lipids and lipoproteins. In: Perkins, E.G. (ed.), Am. Oil Chem. Soc, Champaign, Illinois. 139. 
Linzen, B., Soeter, N.M., Riggs, A.F., Schnider, H.J., Schartau, W., Moore, M.D., Yokota, E., Behrens, P.Q., Nakashima, H., Takagi, T., Nemoto, T., Vereijken, J.M., Bak, H.G., Beintema, J.J., Volbeda, A., Gaykema, W.P., Hol, W.G. 1985. The structure of arthropod hemocyanins. Science 229, 519-524.

Lorenzini, D.M., da Silva, P.I., Soares, M.B., Arruda, P., Setubal, J., Daffre, S. 2006. Discovery of immune-related genes expressed in hemocytes of the tarantula spider Acanthoscurria gomesiana. Dev. Comp. Imm. 30, 545-556.

Lowry, O.H., Rosenbrough, N.J., Farr, A.L., Randall, R. 1951. Protein measurement with the Folin phenol reagent. J. Biol. Chem. 193, 265-275.

Lubzens, E., Ravid, T., Khayat, M., Daube, N., Tietz, A. 1997. Isolation and characterization of the high-density lipoproteins from the hemolymph and ovary of the penaeid shrimp Penaeus semisulcatus (de Haan): apoproteins and lipids. J. Exp. Zool. 278, 339-348.

Maaroufi, H. and Lamy, N. 1993. The quaternary structure of Scorpio maurus hemocyanin: Comparison with Androctonus australis hemocyanin. Comp. Biochem. Physiol. 104 B, 215-227.

Machado, E.A., Atella, G.C., Gondim, K.C., de Souza, W., Masuda, H. 1996. Characterization and immunocytochemical localization of lipophorin binding sites in the oocytes of Rhodnius prolixus. Arch. Insect Biochem. Physiol. 31, 185-196.

Markl, J. 1980. Hemocyanins in spiders, XI. The quaternary structure of Cupiennius hemocyanin. J. Comp. Physiol. 140 B, 199-207.

Markl, J. 1986. Evolution and function of structurally diverse subunits in the respiratory protein hemocyanin from arthropods. Biol. Bull. 171, 901145.

Markl, J., Schmidt, R., Czichos-Tiedt, S., Linzen, B. 1976. Haemocyanins in spiders, III. Chemical and physical properties of the properties in Dugesiella and Cupiennius blood. Physiol. Chem. 357, 1713-1725.

Maya-Monteiro, C.M., Daffre, S., Logullo, C., Lara, F.A., Alves, E.W., Capurro, M.L., Zingali, R., Almeida, I.C., Oliveira, P.L. 2000. HeLp, a heme lipoprotein from the hemolymph of the cattle tick, Boophilus microplus. J. Biol. Chem. 275, 36584-36589.

Mazzini, M., Burrini, A., Giorgi, F. 1989. The secretory pathway of vitellogenin in the fat body of the stick insect Bacillus rossius: an ultrastructural and immunocytochemical study. Tissue and Cell 21, 609-624. 
McCormick, S.J., Polis, G.A. 1990. Prey, predators, and parasites. In: Polis, G.A. (ed.), The Biology of Scorpions, Stanford University Press, Stanford, CA 294-320.

Merril, C. 1990. Gel staining techniques. In: Deutscher, H. (ed.), Method. Enzimol., Vol. 183. pp. 477-487.

Molinari, A.M., Minervino, E. 2006. Características generales e importancia de las arañas como agentes depredadores de insectos plaga.

Mongin, E.L., Holt, R.A., Birney, E., Collins, F.H. 2004.The Anopheles gambiae genome: an update. Trends. Parasitol. 20 (2), 49-52.

Morrison, W.R., Smith, L.M. 1992. Preparation of fatty acid methyl esters and dimethylacetals from lipid with boron fluoride-methanol. J. Lipid Res. 5, 600-608.

Mukai, S.T., Hoque, T., Morishita, F., Saleuddin, A.S. 2004. Cloning and characterization of a candidate nutritive glycoprotein from the albumen gland of the freshwater snail, Helisoma duryi (Mollusca: Pulmonata). Invert. Biol. 123, 83-92.

Nickerson, K.W., Van Holde, K.E. 1971. A comparison of molluscan and arthropod hemocyanin-I. Circular dichroism and absorption spectra. Comp. Biochem. Physiol. 39 B, 855-872.

Numata, K., Reagan, M.R., Goldstain, R.H., Rosenblatt, M., Kaplan, D.L. 2011. Spider silk-based gene carriers for tumor cell-specific delivery. Bioconjug. Chem .

O'Connor, J.D., Gilbert, L.I. 1968. Aspects of lipid metabolism in crustaceans. Am. Zool. 8, 529-539.

Osir, E.O., Anderson, D.R., Grimes, W.J., Law, J.H. 1986. Studies on the carbohydrate moiety of vitellogenin from the tobacco hornworm Manduca sexta. Insect Biochem. 16, 471-478.

Pattnaik, N.M., Mundall, E.C., Trambusti, B.G., Law, J.H., Kezdy, F.J. 1979. Isolation and characterization of a larval lipoprotein from the hemolymph of Manduca sexta. Comp. Biochem. Physiol. 63 B, 469-476.

Paul, R., Pirow, R. 1998. The physiological significance of respiratory proteins in invertebrates. Zoology 100, 319-327.

Pereira, M.S., Silva, P.I., Miranda, M.T.M., Almeida, I.C., Naoki, H., Konno, K., Daffre, S. 2007. Structural and biological characterization of one antibacterial acylpolyamine isolated from the hemocytes of the spider Acanthocurria gomesiana. Biochem. Biophy. Res. Co. 352, 953-959. 
Platnick, N. I. 2011. The world spider catalog, version 12.0. American Museum of Natural History, online at http://research.amnh.org/iz/spiders/ catalog. DOI: 10.5531/db.iz.0001.

Pollero, R.J. 1987. Transport of cholesterol in the hemolyumph of the mollusc Diplodon

Pollero, R.J., Heras, H. 1989. Inter-organ hemolymphatic transport of free fatty acids, triacylglycerols and phospholipids in the freshwater bivalve, Diplodon delodontus. Comp. Biochem. Physiol. 93 A, 673-676.

Pollero, R.J., Huca, G., Brenner, R.R. 1985. Role of hemocytes and plasma on lipid transport in the freshwater mollusc Diplodon delodontus. Comp. Biochem. and Physiol. 82 A, 339-343.

Pourié, G., Trabalon, M. 2003. The role of 20-hydroxyecdysone on the control of spider vitellogenesis. Gen. Comp. Endoc. 131, 250-257.

Punzo, F. 1983. Hemolymph chemistry of the spiders, Heteropoda venatoria (Sparassidae), Pisaurina mira (Pisauridae) and Amaurobius bennetti (Amaurobiidae). Comp. Biochem. Physiol. 75 A, 647-652.

Purcell, J.P., Quinn, T.M., Kunkel, J.K., and Nordin, J.H. 1988. Correlation of yolk phosphatase expression with the programmed proteolysis of vitellin in Blatella germanica during embryonic development. Arch. Insect Biochem. 8, 237-251.

Raikhel, A.S., Dhadialla, T.S. 1992. Accumulation of yolk proteins in insect oocytes. Annu. Rev. Entomol. 37, 217-251.

Rainer, J., Brouwer, M. 1993. Hemocyanin synthesis in the blue crab Callinectes sapidus. Comp. Biochem. Physiol. 104 B, 69-73.

Rappa, E., vernon, G.M., Hamilton, M., Witkus, R. 1992. Hemocyanin in Oniscus asellus (Isopoda). Comp. Biochem. Physiol. 103 B, 855-858.

Ravid, T., Tietz, A., Khayat, M., Boehm, E., Michelis, R., Lubzens, E. 1999. Lipid accumulation in the ovaries of a marine shrimp Penaeus semisulcatus (de Haan). J: Exp. Biol: 202 (13), 1819-1829.

Rimoldi, O.J., Soulages, J.L., Gonzalez, S.M., Peluffo, R.O., Brenner, R.R. 1989. Purification and properties of the very high density lipoprotein from the hemolymph of adult Triatoma infestans. J. Lipid Res. 30, 857864.

Roe, J.H. 1955. The determinación of sugar in blood and spinal fluid with anthrone reagent. J. Biol. Chem. 212, 335-343. 
Roeding, F., Borner, J., Kube, M., Klages, S., Reinhardt, R., Burmester, T. 2009. A 454 sequencing approach for large scale phylogenomic analysis of the common emperor scorpion (Pandinus imperator). Mol. Phylogenet. Evol. 53, 826-834.

Rosell, R., Coons, L. 1991. Purification and partial characterization of vitellin from the eggs of the hard tick, Dermacentor variabilis. Insect Biochem. $21,871-885$.

Rosell, R., Coons, L.B. 1992. The role of the fat body, midgut and ovary in vitellogenin production and vitellogenesis in the female tick, Dermacentor variabilis. Int. J. Parasitol. 22, 341-349.

Rupert, E.E., Barnes, R.D. 1996. Zoología de los invertebrados. McGraw-Hill interamericana. México.

Ryan, R.O., Van Der Horst, D.J. 2000. Lipid transport biochemistry and its role in energy production. Annu. Rev. Entomol. 45, 233-260.

Sahni, V., Blackledge, T.A., Dhinojwala, A. 2010. Viscoelastic solids explain spider web stickiness. Nature comm. 1 (2), 1-4.

Salerno, A.P., Dansa-Petretski, M., Silva-Neto, M.A., Coelho, H.S., Masuda, H. 2002. Rhodnius prolixus vitellin is composed of three different populations: comparison with vitellogenin. Insect Biochem. Molec. Biol. 32, 709-717.

Sanchez, D., Ganfornina, M.D., Gutierrez, G., Bastiani, M.J. 1998. Molecular characterization and phylogenetic relationships of a protein with potential oxygen-binding capabilities in the grasshopper embryo. A hemocyanin in insects? Mol. Biol. Evol. 15, 415-426.

Sappington, T.W., Oishi, K., and Raikhel, A.S. 2002. Structural characteristics of insect vitellogenins. In: Adiyodi, K.G. and Adiyodi, R.G. (eds.), Reproductive Biology of invertebrates. Progress in vitellogenesis, Vol. 1. Science Publishers, Inc., Enfield, NH, pp. 69-102.

Sappington, T.W., Raikhel, A.S. 1998. Molecular characteristics of insect vitellogenins and vitellogenin receptors. Insect Biochem. Molec. Biol. 28, 277-300.

Sato, Y., Yamashita, O. 1991. Synthesis and secretion of egg-specific protein from follicle cells of the silkworm Bombyx mori. Insect Biochem. 21, 233-238.

Schacht, K., Scheibel, T. 2011. Controlled hydrogel formation of a recombinant spider silk protein. Biomacromolecules 12 (7), 2488-2495. 
Schaerefer, M. 1976. An analysis of diapause and resistance in the egg stage of Floronia bucculenta (Araneida:Linyphiidae). Oecologia 25, 155.

Schartau, W., Leidescher, T. 1983. Composition of the hemolimph of the tarantula Eurypelma californicum. J. Com. Physiol 152, 73-77.

Schenk, S., Gras, H., Marksteiner, D., Patasic, L., Prommnitz, B., Hoeger, U., 2009. The Pandinus imperator haemolymph lipoprotein, an unusual phosphatidylserine carrying lipoprotein. Insect Biochem. Mol. Biol. 39, 735-744.

Schriefer, M.E. 1991.Vitellogenesis in Hyalomma dromedarii (Acari: Ixodidae): A model for analysis of endocrine regulation in ixodid ticks. Old Dominion University.

Scott, L.B. and Lennarz, W.J. 1989. Structure of a major yolk glycoprotein an its processing pathway by limited proteolysis are conserved in echinods. Dev. Biol. 132, 91-102.

Seixas, A., Leal, A.T., Nascimemto-Silva, M.C.L., Masuda, A., Termignoni, C., da Silva Vaz, I. 2008. Vaccine potential of a tick vitellin-degrading enzyme (VTDCE). Vet. Immunol. Immunop. 124 (3-4), 332-340.

Seixas, A., Oliveira, P.L., Termignoni, C., Logullo, C., Masuda, A., da Silva Vaz, I. 2011. Rhipicephalus (Boophilus) microplus embryo proteins as target for tick vaccine. Vet. Immunol. Immunop. In press.

Shanbaky, N.M., Main, A.J., El-Said, A., Helmy, N. 1990. Vitellogenic and non vitellogenic proteins in haemolimph, ovaries, and eggs of Argas (Persicargas) arboreus. Exp. Parasitol. 27, 986-992.

Shapiro, J.P., Law, J.H., Wells, M.A. 1988. Lipid transport in insects. Annu. Rev. Entomol. 33, 297-318.

Sharrock, W.J. 1983. Yolk proteins in Caenorhabditis elegans. Dev.Biol. 96, 182188.

Shultz, J.W., Pinto-da-Rocha, R. 2007. Morphology and functional anatomy. In: Pinto-da-Rocha, R., Machado, G., and Giribet, G. (eds.), Harvestmen: the biology of Opiliones, Harvard University Press, London, UK, pp. 14-61.

Silva, P.I., Daffre, S., Bulet, P. 2000. Isolation and characterization of gomesin, an 18-Residue cysteine-rich defense peptide from the spider Acanthoscurria gomesiana hemocytes with sequence similarities to horseshoe crab antimicrobial peptides of the tachyplesin family. J. Biol. Chem. 275 (43), 33464-33470. 
Snigirevskaya, E.S. and Raikhel, A.S. 2005. Receptor-mediated endocytosis of yolk proteins in insect oocytes. In: Raikhel, A.S. and Sappington, T.W. (eds.), Progress in Vitellogenesis. Part B, Science, Enfield, USAPlymouth UK, pp. 199-228.

Snigirevskaya, E.S., Sappington, T.W., Raikhel, A.S. 1997. Internalization and recycling of vitellogenin receptor in the mosquito oocyte. Cell and Tissue Res. 290, 175-183.

Sobotnik, J., Weyda, F., Hanus, R., Cvacka, J., Nebesarova, J. 2006. Fat body of Prorhinotermes simplex (Isoptera: Rhinotermitidae): Ultrastructure, inter-caste differences and lipid composition. Micron 37, 648-656.

Soulages, J.L., Brenner, R.R. 1991. Study on the composition-structure relationship of lipophorins. J. Lipid Res. 32, 407-415.

Soulages, J.L., Rimoldi, O.J., Peluffo, O.R., Brenner, R.R. 1988. Transport and utilization of free fatty acids in Triatoma infestans. Biochem. Biophys. Res. Commun. 157, 465-471.

Soulages, J.L., Wells, M.A. 1994a. Effect of diacylglycerol content on some physicochemical properties of the insect lipoprotein, lipophorin. Correlation with the binding of apolipophorin-III. Biochemistry 33, 2356-2362.

Soulages, J.L., Wells, M.A. 1994b. Lipophorin: the structure of an insect lipoprotein and its role in lipid transport in insects. Adv. Protein Chem. 45, 371-415.

Stratakis, E., Fragkiadakis, G., Tentes, I. 1993. Purification and properties of the fatty acid-binding VHDL from the hemolymph of the spider Eurypelma californicum. J. Exp. Zool. 267, 483-492.

Takahashi, S. 1987. Studies on the phosphorylation of ovarian proteins from the silkworm Bombyx mori . Insect Biochem. 17, 141-152.

Tatchell, R.J. 1971. Electrophoretic studies on the proteins of the haemolimph, saliva and eggs of the cattle tick, Dermacentor variabilis. Insect Biochem. 1, 47-55.

Telfer, W.H., Keim, P.S., Law, J.H. 1983. Arylphorin, a new protein from Hyalophora cecropia: comparisons with caliphorin and manducin. Insect Biochemestry 13, 601-613.

Tellam, R.L., Kemp, D., Riding, G., Briscoe, S., Smith, D., Sharp, P., Irving, D., Willadsen, P. 2002. Reduced oviposition of Boophilus microplus feeding on sheep vaccinated with vitellin. Vet. Parasitol. 103 (1-2), 141-156. 
Terpstra, H.A., Woodward, C.J., Sanchez-Muniz, F.J. 1981. Improved techniques for the separation of serum lipoproteins by density gradient ultracentrifugation: visualization by prestaining and rapid separation of serum lipoproteins from small volumes of serum. Anal. Biochem. 111, 149-157.

Terwilliger, N.B. 1998. Functional adaptations of oxygen-transport proteins. J. Exp. Biol. 201, 1085-1098.

Tirumalai, R., Subramoniam, T. 2001. Carbohydrate components of lipovitellin of the sand crab Enerita asiatica. Mol. Rep. Develop. 58, 54-62.

Toumadje, A., Alcorn, S.W., Johnson, W.C. 1992. Extending CD spectra of proteins to $168 \mathrm{~nm}$ improves the analysis for secondary structures. Anal. Biochem. 200, 321-331.

Tsuchida, K. and Wells, M.A. 1988. Digestion, absorption, transport and storage of fat during the larval stadium of Manduca sexta. Changes in the role of lipophorin in the delivery of dietary lipid to the fat body. Insect Biochem. 18, 263-268.

Tsuchida, K., Wells, M.A. 1990. Isolation and characterization of lipoprotein receptor from the fat body of an insect, Manduca sexta. J. Biol. Chem. 265, 5761-5767.

Tufail, M., Raikhel, A.S., Takeda, M. 2005. Biosynthesis and processing of insect vitellogenins. In: Raikhel, A.S. and Sappington, T.W. (eds.), Progress in vitellogenesis. Reproductive Biology of Invertebrates, Science, Enfield, USA-Plymouth, UK, pp. 1-32.

Tufail, M., Takeda, M. 2008. Molecular characteristics of insect vitellogenins. J. Insect Physiol. 54, 1447-1458.

Van Bruggen, E.F.J. 1980. Hemocyanin: the mystery of blue blood. Trends in Biol. Sci. 7, 185-188.

Van Holde, K.E.,Miller, K.I. 1982. Hemocyanins. Quart.Rev.Biophys 15, 1-129.

Voit, R., Feldmaier-Fuchs, G., Schweikardt, T., Decker, H., Burmester, T. 2000. Complete sequence of the 24-mer hemocyanin of the tarantula Eurypelma californicum. Structure and intramolecular evolution of the subunits. J Biol Chem. 275, 39339-39344.

Walker, A., Ando, S., Smith, G.D., Lee, R.F. 2006. The utilization of lipovitellin during blue crab (Callinectes sapidus) embryogenesis. Comp Biochem. Physiol. 143 B, 201-208. 
Wallace, R.A., Walker, S.L., Hauschka, P.V. 1967. Crustacean lipovitellin: isolation and characterization of the major high-density lipoprotein from eggs of decapods. Biochemistry 6, 1582-1590.

Waxman, L. 1975. the structure of Arthropod and Mollusc hemocyanins. J. Biol. Chem. 250, 3796-3806.

Wolfgang, E., Rudiger, H., Heinz, D. 2004. Structure-based calculation of multidonor multi-aceptor fluorescence resonance energy transfer in the 4x6-mer tarantula hemocyanin. Europ. Bioph. J. 33, 386-395.

Yeh, M.S., Huang, C.J., Leu, J.H., Lee, Y.C., Tsai, I.H. 1999. Molecular cloning and characterization of a hemolymph clottable protein from tiger shrimp. Eur J Biochem 266, 624-633.

Yepiz-Plascencia, G., Vargas-Albores, F., Higuera-Ciapara, I. 2000. Penaeid shrimp hemolymph lipoproteins. Aquaculture 191, 177-189.

Zagalsky, P.F., Cheesman, D.F., Ceccaldi, H.J. 1967. Studies on carotenoidcontaining lipoproteins isolated from the eggs and ovaries of certain marine invertebrates. Comp. Biochem. Physiol. 22 B, 851-871.

Zatta, P. 1981. Protein-lipid interactions in Carcinus maenas (Crustacea) hemocyanin. Comp. Biochem. Physiol. 69 B, 731-735.

Ziegler, R. 1997. Lipid synthesis by ovaries and fat body of Aedes aegypti (Diptera: Culicidae). Europ. J. Entomol. 94, 385-391.

Ziegler, R., Ibrahim, M.M., 2001. Formation of lipid reserves in fat body and eggs of the yellow fever mosquito, Aedes aegypti. J. Insect Physiol. 47, 623-627. 